\title{
Manufacturing, Evaluation and Field Implementation of Recycled GFRP-Composite Railroad Ties
}

\author{
Venugopal R. Chada \\ West Virginia University
}

Follow this and additional works at: https://researchrepository.wvu.edu/etd

\section{Recommended Citation}

Chada, Venugopal R., "Manufacturing, Evaluation and Field Implementation of Recycled GFRP-Composite Railroad Ties" (2012). Graduate Theses, Dissertations, and Problem Reports. 3358.

https://researchrepository.wvu.edu/etd/3358

This Thesis is protected by copyright and/or related rights. It has been brought to you by the The Research Repository @ WVU with permission from the rights-holder(s). You are free to use this Thesis in any way that is permitted by the copyright and related rights legislation that applies to your use. For other uses you must obtain permission from the rights-holder(s) directly, unless additional rights are indicated by a Creative Commons license in the record and/ or on the work itself. This Thesis has been accepted for inclusion in WVU Graduate Theses, Dissertations, and Problem Reports collection by an authorized administrator of The Research Repository @ WVU. For more information, please contact researchrepository@mail.wvu.edu. 


\title{
Manufacturing, Evaluation and Field Implementation of Recycled GFRP-Composite Railroad Ties
}

\author{
Venugopal R. Chada \\ Thesis submitted to the \\ College of Engineering and Mineral Resources \\ at West Virginia University \\ in partial fulfillment of the requirements \\ for the degree of \\ Master of Science \\ in \\ Civil and Environmental Engineering \\ P.V.Vijay, Ph.D, P.E., Chair \\ Hota.V.S. GangaRao, Ph.D, P.E., Co-Chair \\ Udaya B. Halabe, Ph.D, P.E.
}

Department of Civil and Environmental Engineering

Morgantown, West Virginia

2011

KEYWORDS: Glass Fiber, ABS, Recycled Composite Ties, Composite parts, Wood ties, Spike, Compression Molding. 


\title{
ABSTRACT \\ Manufacturing, Evaluation and Field Implementation of Recycled GFRP-Composite Railroad Ties
}

\author{
Venugopal R. Chada
}

Wood railroad crossties resistance to current higher axle loads, speeds and frequency, along with the durability under harsh environments has proven to be inadequate. Additionally, defects such as decay, holes, splits, checks etc may further impair the strength and durability characteristics of the wood crossties. In this project, recycled polymer and discarded wood were used to increase the performance characteristics of the RR tie including resistance to higher axle loads, minimization of defects, and better performance under harsh environmental conditions. The objective of this study is to enhance and assess the strength characteristics of the timber crossties by using the glass fiber reinforced polymer (GFRP) composite shell. This research involved two different techniques for manufacturing the recycled composite ties, followed by laboratory testing of wood ties and GFRP recycled composite shell with wood core ties (thermoplastic) in WVU-CFC. The previous research program at WVU-CFC consisted of strengthening and evaluating the wood crossties by wrapping only the 12 inches wide steel plate embedment location using glass fiber fabrics saturated with resorcinol formaldehyde resin (thermoset).

In this research, over 200 recycled composite components were manufactured in the CFC laboratory that were used to mold 24 full-scale recycled composite ties with wood as a core material and GFRP composite as a shell material. The GFRP composite shell was manufactured using glass fabric reinforcement and Acrylonitrile Butadiene Styrene (ABS) resin. Two different fiber configurations were used in the manufacturing process-I (composite ties manufactured using twelve composite parts). Recycled composite ties produced under manufacturing process-I were tested under three point bending to evaluate the flexural rigidity. Test results of recycled composite ties from manufacturing process-I having fabric configuration-I were compared with those having fabric configuration-II. Further, recycled composite tie from manufacturing process-II (composite ties manufactured using two composite parts) along with wood crossties were tested under three point bending to evaluate the flexural rigidity, modulus of rupture, and static bending strength. Recycled composite ties showed higher static bending strength by approximately sixty percent than wood ties. Recycled composite ties also showed higher spike insertion and pullout strengths than the wood ties.

In order to study the dynamic response, a full-scale recycled composite tie produced through manufacturing process-II was embedded in gravel ballast and tested under flexural fatigue. The measured maximum deflection and applied bending moment values were compared with the theoretical values based on the classical beams on elastic foundation theory. The theoretical values were found to correlate well with the experimental values (within 10\%). The research also included field testing of seven recycled composite ties on the South Branch Valley Railroad (SBVR) in Moorefield, WV. After three months of service, three ties with low fiber/fabric content showed localized horizontal cracking or some transverse cracks and the remaining four ties showed good field performance. Additional ties manufactured under this project are planned to be field-tested at TTCI, Pueblo, Colorado, test facilities. Conclusions and recommendations from this research work are summarized at the end of this report. 


\section{ACKNOWLEDGMENT}

I am gratefully for the enthusiastic supervision of Dr. Hota GangaRao, a great teacher and an advisor who was abundantly helpful and offered priceless assistance, support and guidance to accomplish this research project. I wish to thank Dr. P.V.Vijay for his suggestions, advises and encouragement in advancement of this work and reviewing of this thesis. I would also like to thank Dr. Udaya B. Halabe for serving as a committee member of this thesis.

I wish to thank Mr. Muhammad Asif, Mr. Aneesh Reddy, Mr. Mike McDevitt, Mr. Siddalingesh Kalligudd, Mr. Amir Hosssein Houshmandyar, Mr. David Dittenber, Mr. Praveen Kumar Reddy and Mr. Vardhan Kumar Perisetty for their assistance in the laboratory testing. I thank Mr. Mark Skidmore, Mr. Daniel Stanislavsky and Mr. Srinivas Majjiga for their assistance in the Field Implementation. I would like to express my special thanks to Mr. Jerry Nestor and Mr. Paul for his cooperation and support in the laboratory.

I gratefully acknowledge the financial support provided by Federal Railway Administration through the Constructed Facilities Center at West Virginia University.

I would like to dedicate this thesis to my family members and friends for the love, support and encouragement provided by them. 


\section{TABLE OF CONTENTS}

ABSTRACT ............................................................................................................................. II

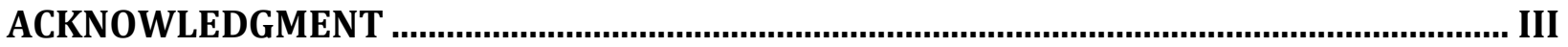

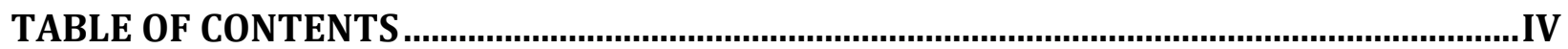

LIST OF TABLES........................................................................................................XIII

LIST OF FIGURES .................................................................................................................XV

1. INTRODUCTION AND BACKGROUND ........................................................................ 1

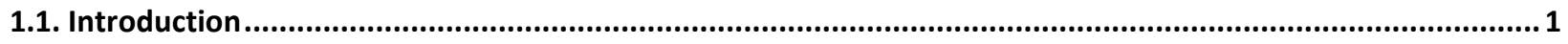

1.2. Previous Research on Recycled Composite Tie ...................................................................................

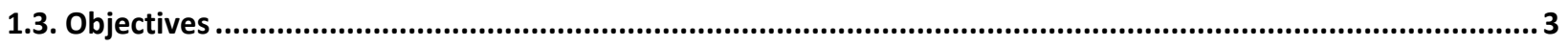

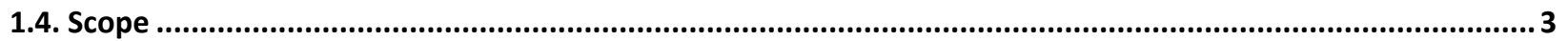

2. LITERATURE REVIEW ......................................................................................... 5

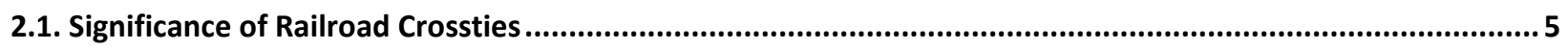

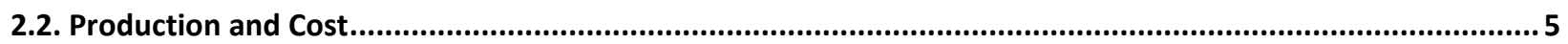

2.3. Companies Producing Composite Ties..............................................................................................6 
2.3.1. Tietek Composite Ties (Tietek website, January 6, 2011) .............................................................

2.3.2. IntegriCo Composite Ties (IntegriCo website, January 6, 2011) .......................................................

2.3.3. Dynamic Composite Ties (Dynamic website, January 6, 2011) ............................................................

2.3.4. PRT Composite Ties (PRT's website, January 6, 2011) ...................................................................

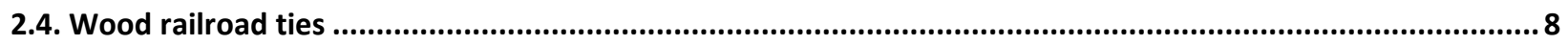

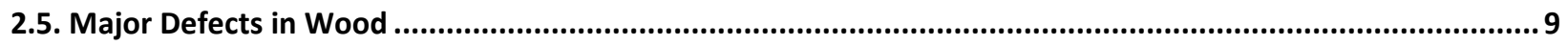

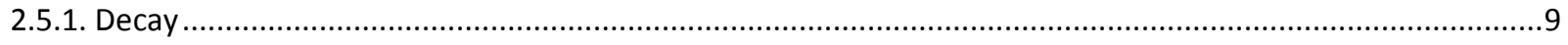

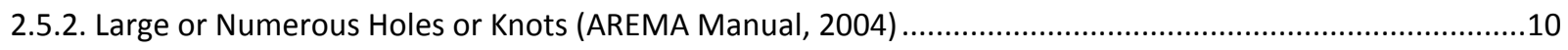

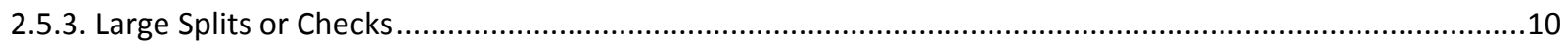

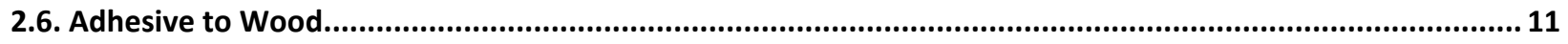

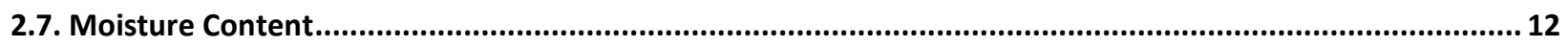

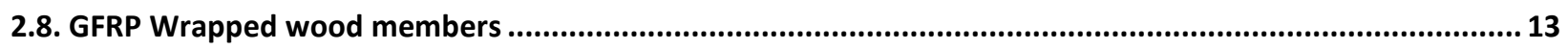

3. MANUFACTURING OF FULLSCALE RECYCLED COMPOSITE TIE .................................15

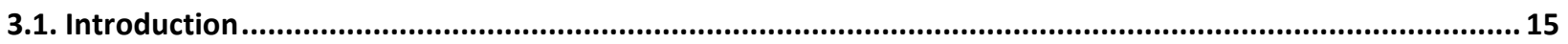

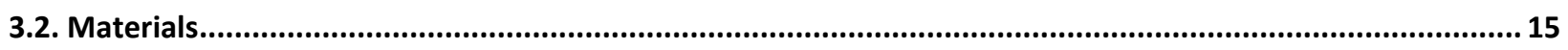

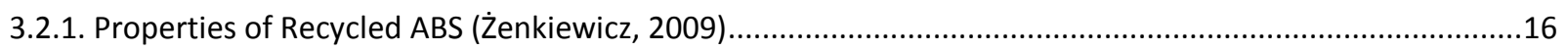

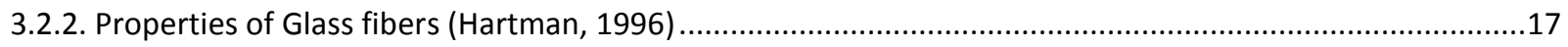

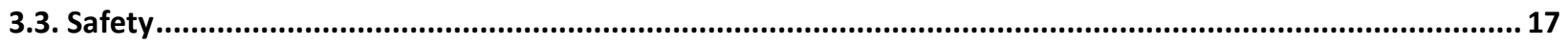

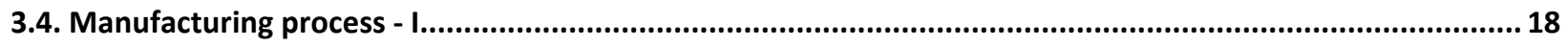

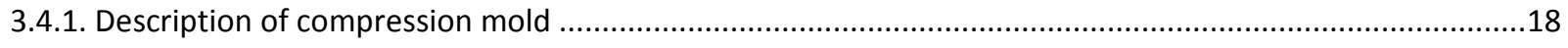

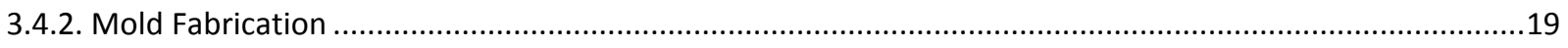




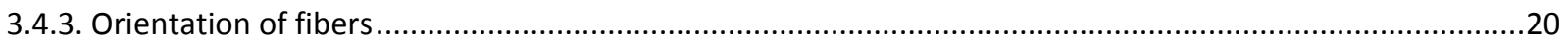

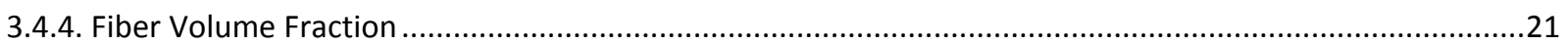

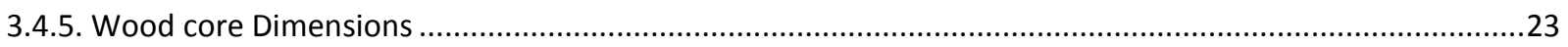

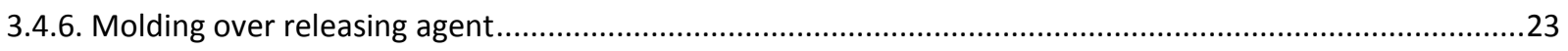

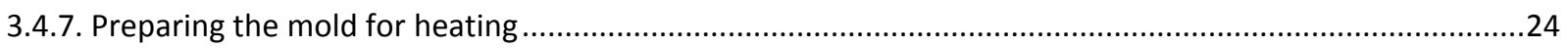

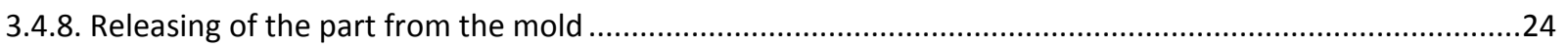

3.4.9. Preparing the mold for the next composite part ...................................................................................25

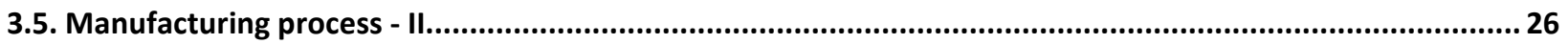

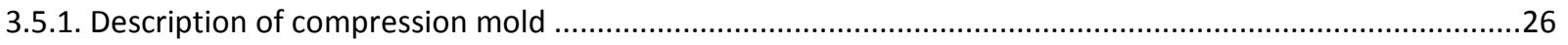

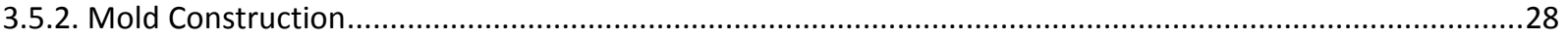

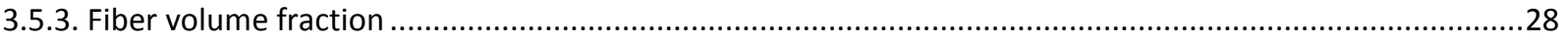

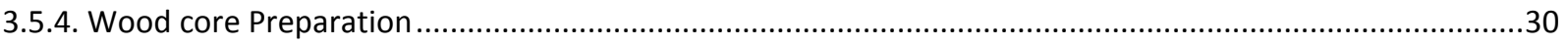

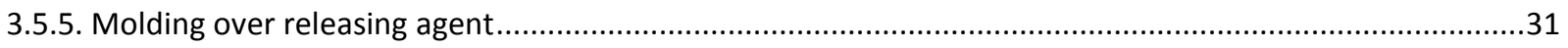

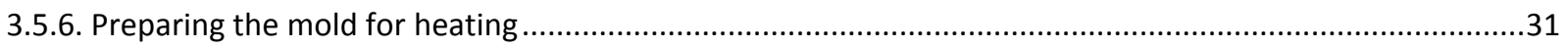

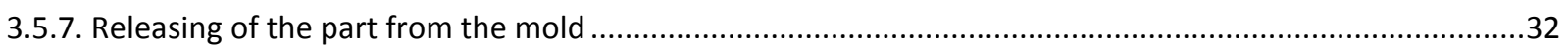

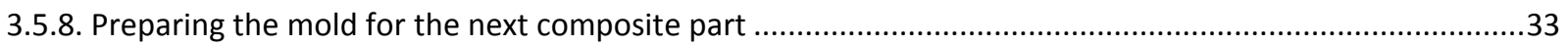

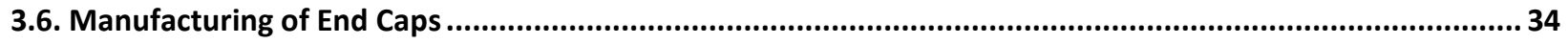

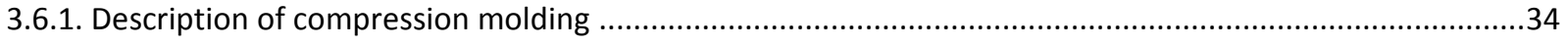

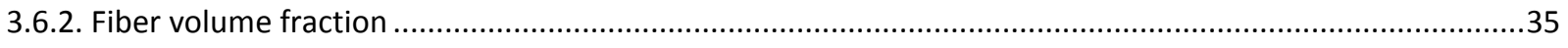

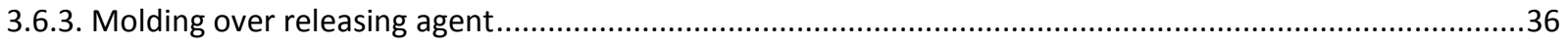

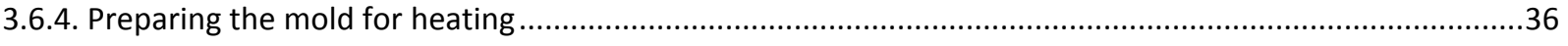

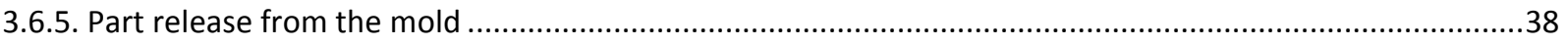

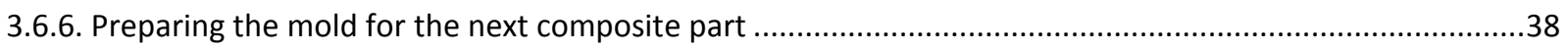

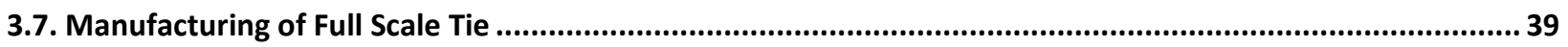

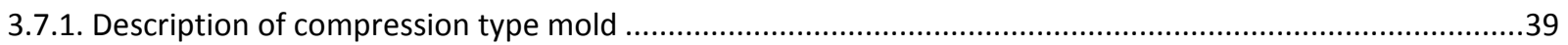




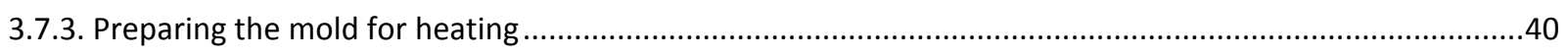

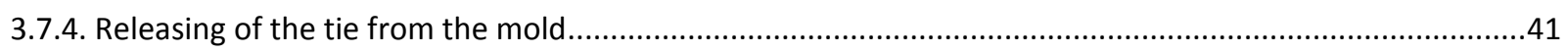

3.7.5. Preparing the mold for the next composite tie ..........................................................................

4. THREE POINT BENDING TESTS \& COMPARISON OF FLEXURAL RIGIDITIES............44

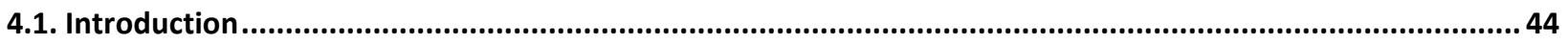

4.2. Objective.

4.3. Scope 44

4.4. Test Description

4.5. Instrumentation 
5.3. Scope

5.4. Test Description

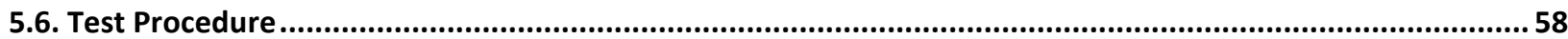

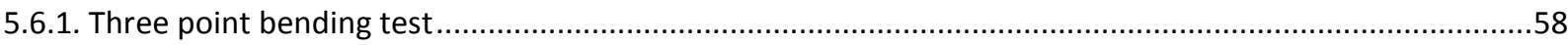

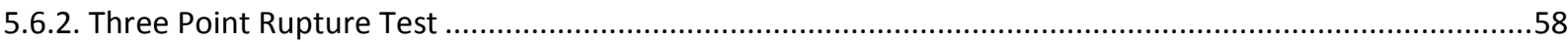

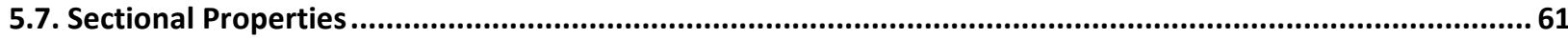

5.7.1. Calculations of Transformed Moment of Inertia ( $\left.I_{\text {transformed }}\right)$ for Recycled Composite Tie.........................61

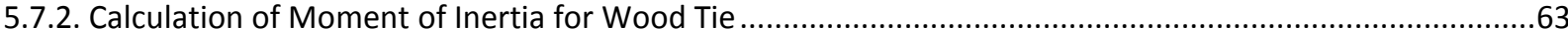

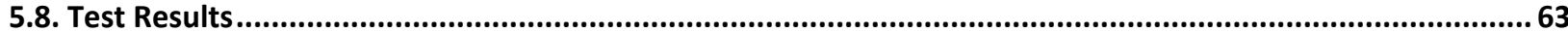

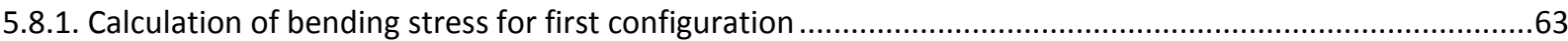

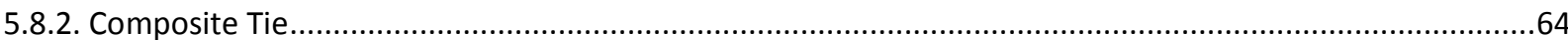

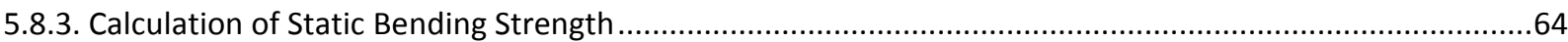

5.8.4. Comparison of Three Point Bending Results of Recycled Composite Tie and a Wood Tie ........................67

5.8.5. Comparison of Static bending Strength Results of Recycled Composite Tie and a Wood Tie ...................67

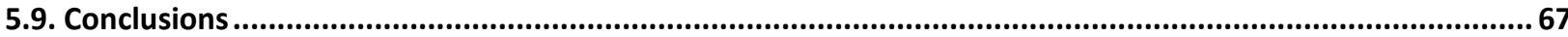




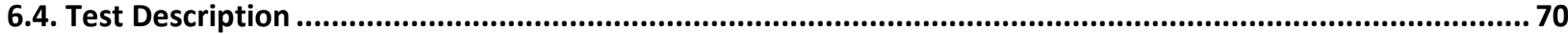

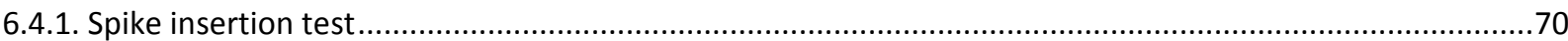

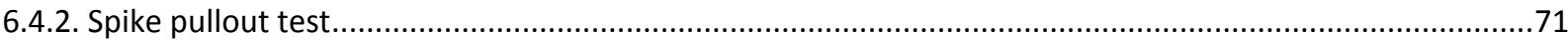

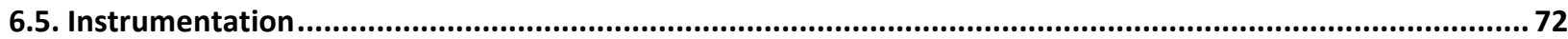

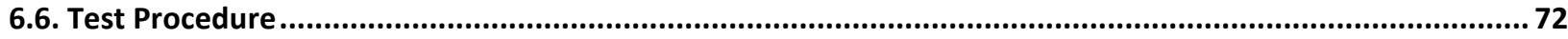

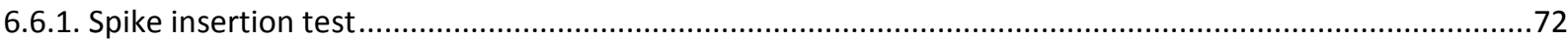

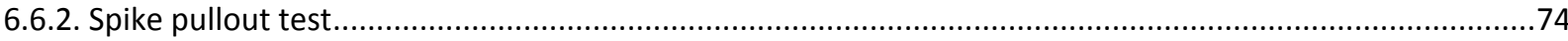

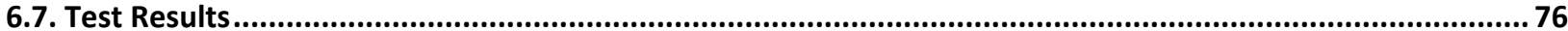

6.7.1. Comparison of Spike Insertion Results on Composite and Wood Tie ...............................................78

6.7.2. Comparison of Spike Pullout Test Results on Composite and Wood Tie ..............................................78

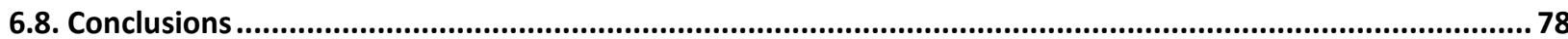

7. FATIGUE TESTING ON A RECYCLED COMPOSITE TIE ............................................. 79

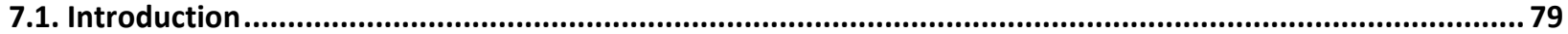

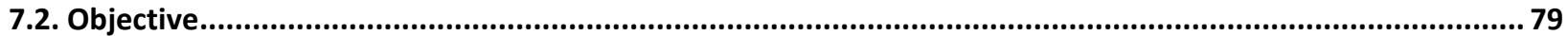

7.3. Scope 
7.5. Loading Calculations .

7.6. Test Description

7.7. Instrumentation.

7.8. Test Procedure

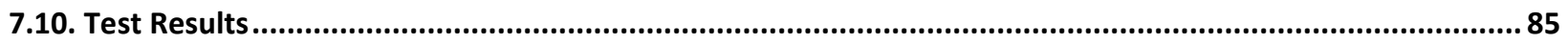

7.10.1. Comparison of Experimental and Theoretical Deflections using Elastic Foundation Theory....................86

7.10.2. Comparison of Experimental and Theoretical Bending Moments using Elastic Foundation Theory ..........87

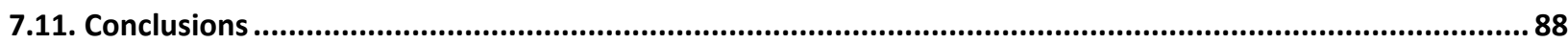

8. FIELD INSTALLATION AND TESTING .......................................................................... 90

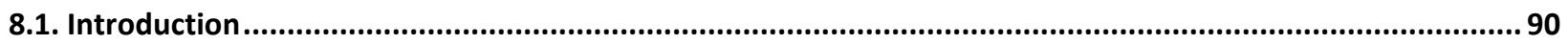

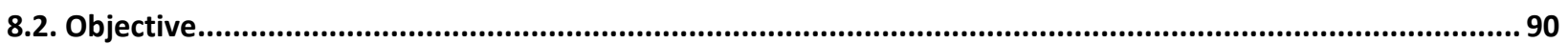

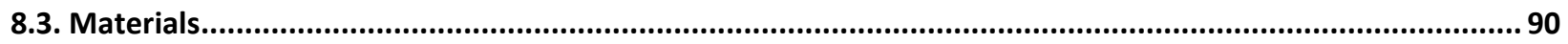

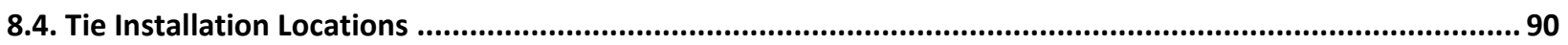

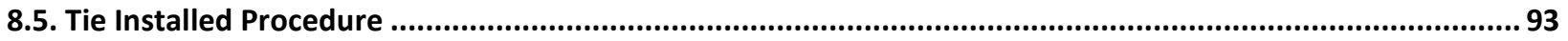

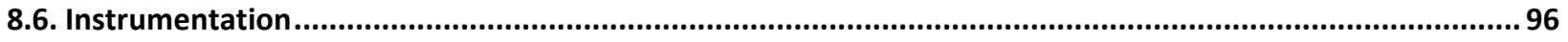

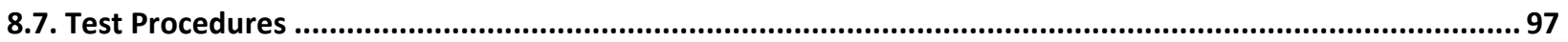




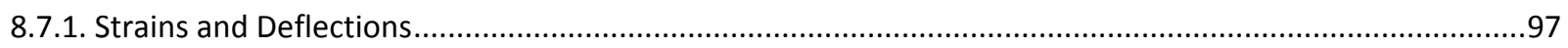

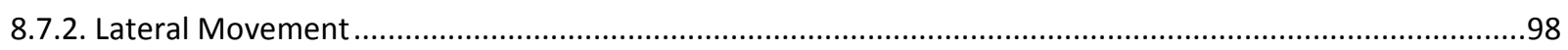

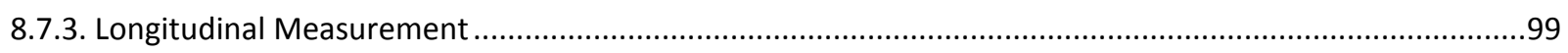

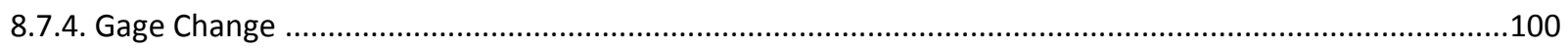

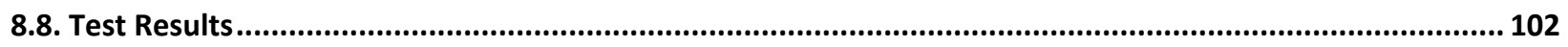

8.8.1. Comparisons of the Test Results at Sharp Curve and Gentle Curve of the Track.................................105

8.8.2. Comparisons of the Test Results at Gentle Curve of the Track and Straight Track................................105

8.8.3. Comparisons of the Test Results at Sharp Curve of the Track and Straight Track .................................106

8.8.4. Comparison of the Maximum Strains in First and Second Configuration of Fabric Layers .......................106

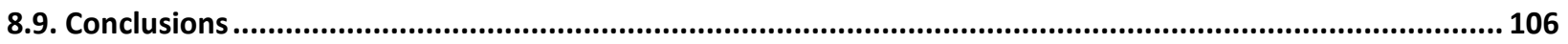

9. CONCLUSIONS AND RECOMMANDATIONS ........................................................ 108

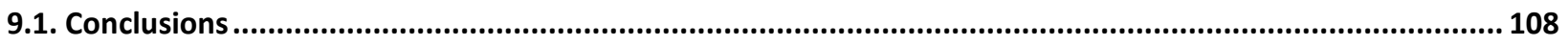

9.1.1. Chapter 4 (Manufacturing process-I: Comparison of flexural rigidities) ...........................................108

9.1.2. Chapter 5 (Manufacturing process-II: Modulus of rupture and flexural rigidities) ..............................109

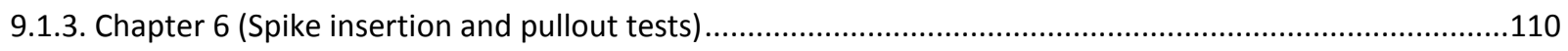

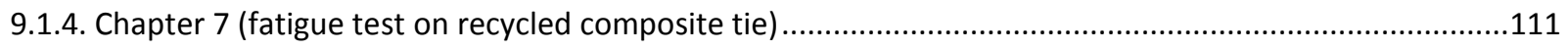

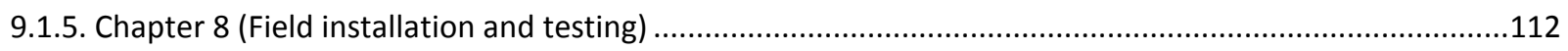

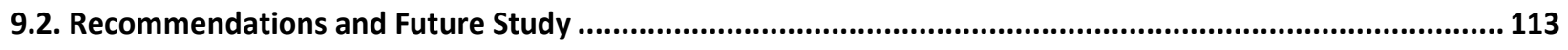

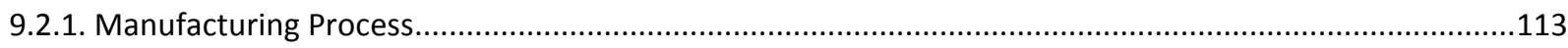

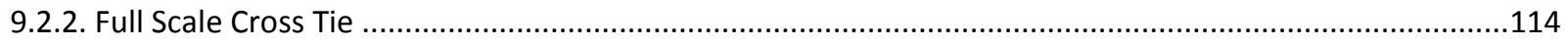

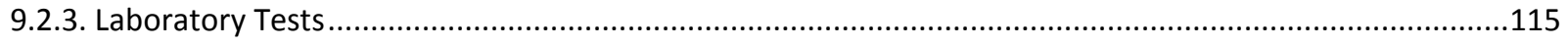

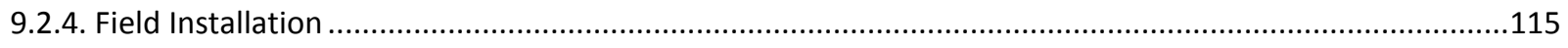




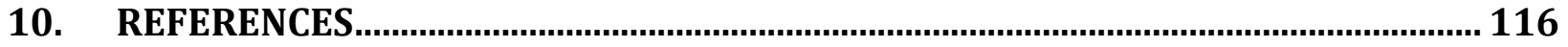

APPENDIX-A

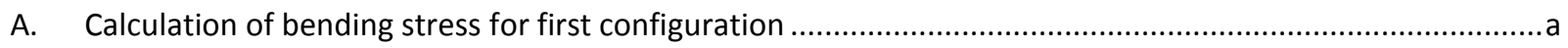

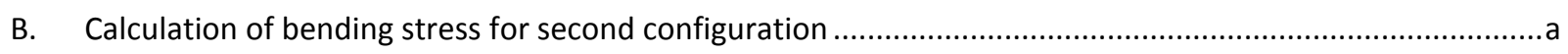

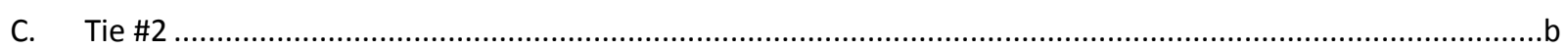

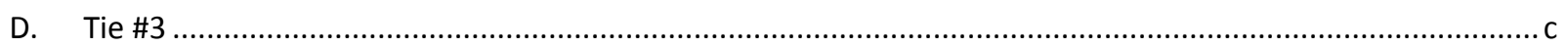

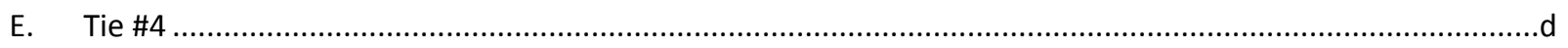

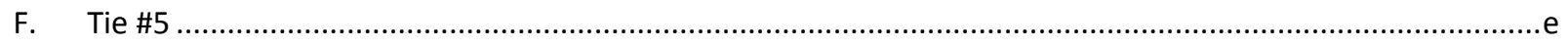

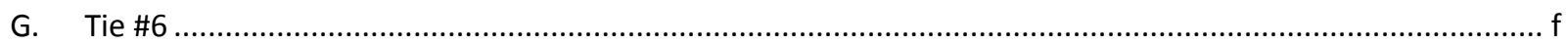

APPENDIX-B

A. Calculation of bending stress for first configuration ............................................................................

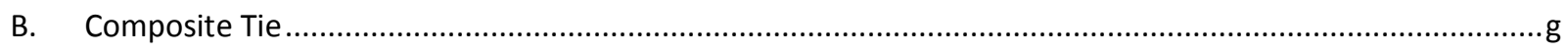

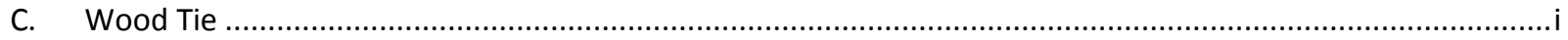

APPENDIX-C 


\section{LIST OF TABLES}

Table 2-1: Composite Tie Specifications of Different Companies............................................................ 8

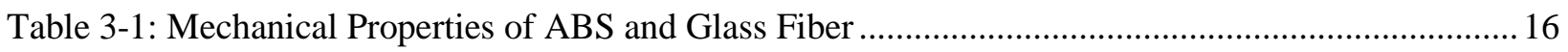

Table 3-2: Fiber/Fabric Configurations (Manufacturing process-I) ...................................................... 21

Table 3-3: Physical Properties of Composite Parts on all Sides............................................................ 23

Table 3-4: Physical Properties of Composite Parts on all Sides ............................................................ 30

Table 3-5: Physical Properties of End Cap …................................................................................. 36

Table 4-1: Description of specimen and fabric configuration ............................................................. 45

Table 4-2: Recycled Composite Tie Dimensions............................................................................... 47

Table 4-3: Transformed Moment of Inertia for different fiber/fabric configurations ................................ 50

Table 4-4: Flexural Rigidity Results for all composite tie with wood core ............................................. 52

Table 5-1: Description of specimen and fabric configuration ............................................................... 56

Table 5-2: Recycled Composite Tie Dimensions.................................................................................. 61

Table 5-3: Transformed Moment of Inertia for different fiber/fabric configurations ................................ 62

Table 5-4: Details of Test Results on Recycled Composite Tie and Wood Tie........................................ 65

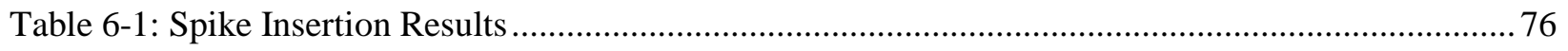

Table 6-2: Spike Pullout Results.................................................................................................... 76

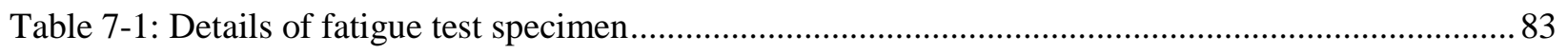

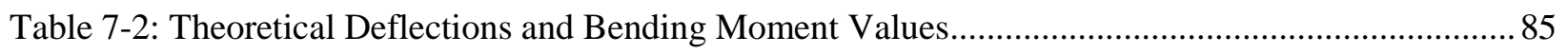

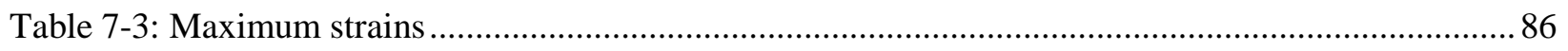

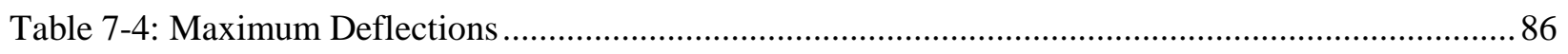

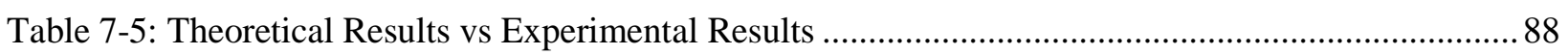

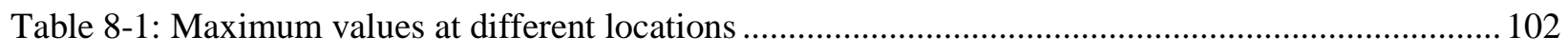

Table 8-2: The maximum values of strains in first and second configuration ties ................................. 102 


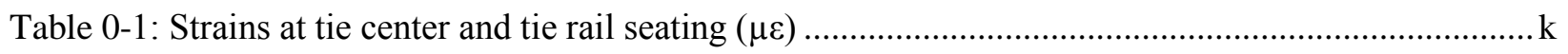

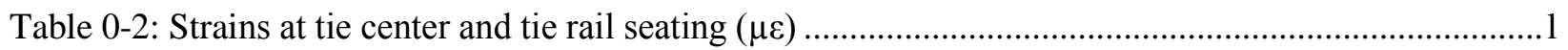

Table 0-3: Deflections on recycled composite tie at different locations (inch) .......................................

Table 0-4: Lateral movement of the tie at different locations (inch) .......................................................m

Table 0-5: Longitudinal movement of the tie at different locations (inch) ...............................................m

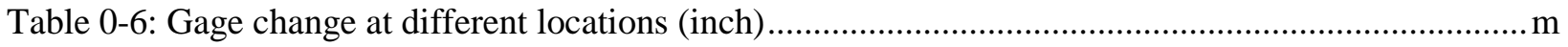




\section{LIST OF FIGURES}

Figure 3-1: Mold used to prepare composite parts........................................................................... 18

Figure 3-2: Mold used to prepare top and bottom composite parts of wood tie ...................................... 19

Figure 3-3: Mold used to prepare side composite parts of wood tie ...................................................... 20

Figure 3-4: Releasing of composite part along with aluminum plunger from the bottom mold................ 25

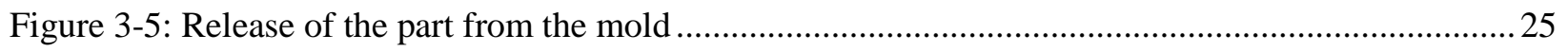

Figure 3-6: released composite parts from the aluminum plunger ….................................................. 26

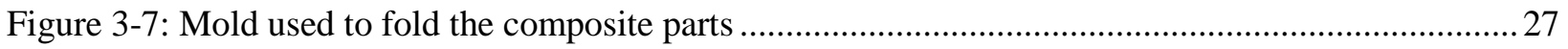

Figure 3-8: Top mold used to heat and apply the load on the composite part ......................................... 27

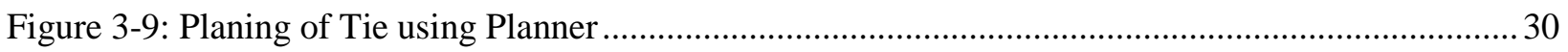

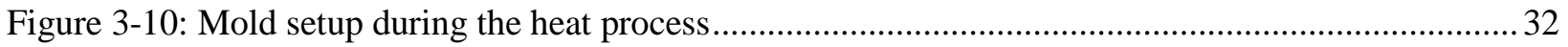

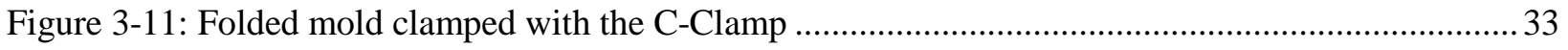

Figure 3-12: Required tools including male and female mold............................................................ 34

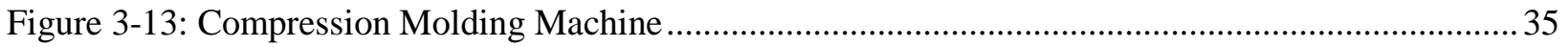

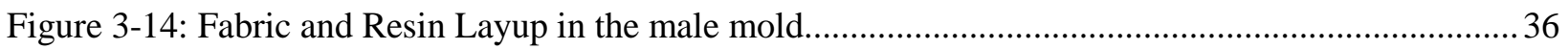

Figure 3-15: Inserting female mold in the male mold...................................................................... 37

Figure 3-16: Compressing the mold in Compression Molding Machine................................................ 37

Figure 3-17: Releasing the part from the Aluminum plunger ............................................................ 38

Figure 3-18: Required tools including top and bottom mold............................................................ 39

Figure 3-19: Wood core encapsulated with composite parts ............................................................ 40

Figure 3-20: Full Scale mold setup during the heat process ............................................................. 41

Figure 3-21: Releasing the tie from the mold …............................................................................... 42

Figure 3-22: Manufactured Recycled GFRP-Composite tie ............................................................... 43

Figure 4-1: Cad Drawings of Three Point Bending Test ................................................................. 45 


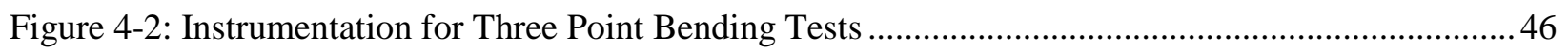

Figure 4-3: Three Point Bending Test Setup ................................................................................... 47

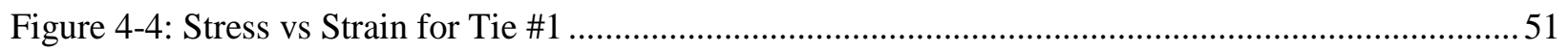

Figure 4-5: Bar Graph Showing the Flexural Rigidities for all Ties..................................................... 52

Figure 5-1: Three Point Bending Test on Recycled Composite Tie ....................................................... 57

Figure 5-2: Three Point Bending Test on Wood Tie......................................................................... 57

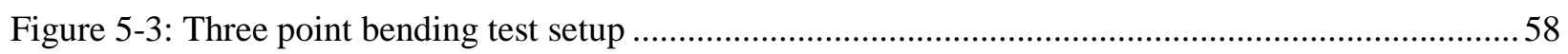

Figure 5-4: Recycled Composite Tie Failure with Three Point Bending Test.......................................... 59

Figure 5-5: Flexural Crack on the Side of the Recycled Composite Tie ................................................. 59

Figure 5-6: Flexural Crack at the Bottom of the Recycled Composite Tie.............................................. 60

Figure 5-7: Wood Tie Failure with Three Point Bending Test ............................................................ 60

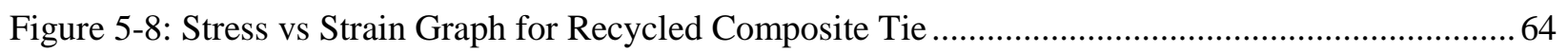

Figure 5-9: Bar Graph showing the 3 point bending results for composite and wood tie.......................... 66

Figure 5-10: Bar Graph showing the static bending strength results of composite tie and wood tie........... 66

Figure 6-1: Cad Drawing of Spike Insertion Test Setup....................................................................... 71

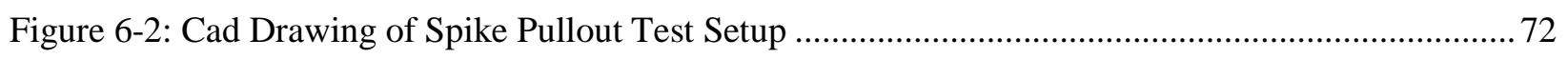

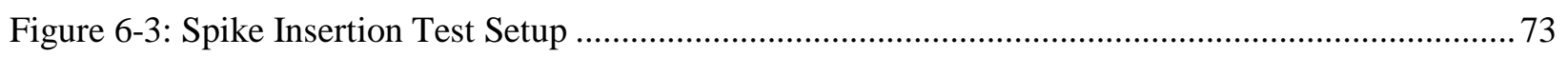

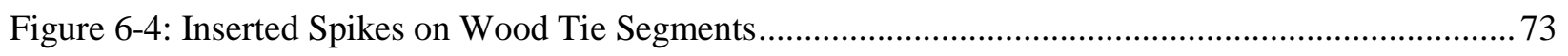

Figure 6-5: Inserted Spikes on Recycled Composite Tie along the length ........................................... 74

Figure 6-6: Spike Pullout Test on Recycled Composite Tie................................................................... 75

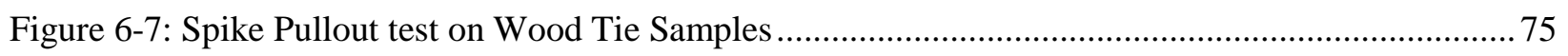

Figure 6-8: Bar Graph showing the spike insertion results on Composite and Wood Tie......................... 77

Figure 6-9: Bar Graph showing the spike pullout results on Composite and Wood Tie .......................... 77

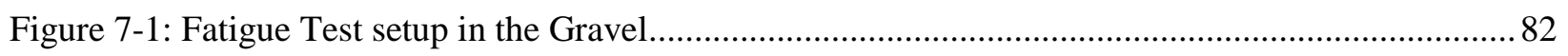

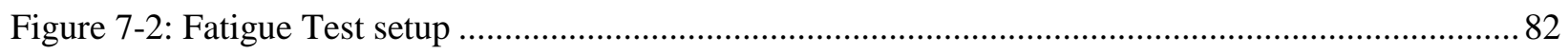


Figure 7-3: The embedded recycled composite tie

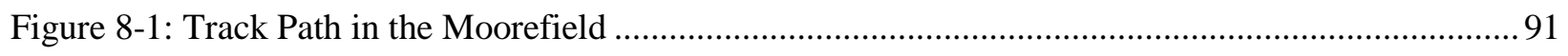

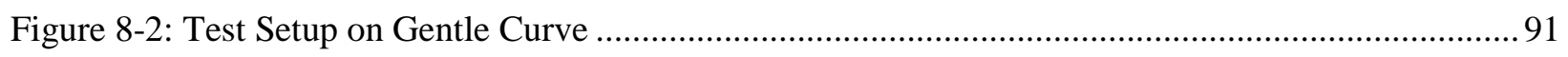

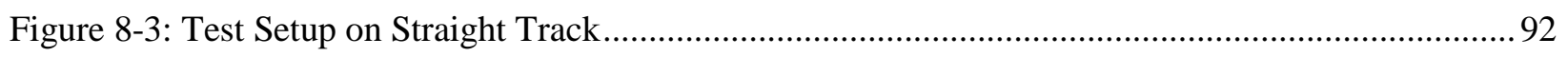

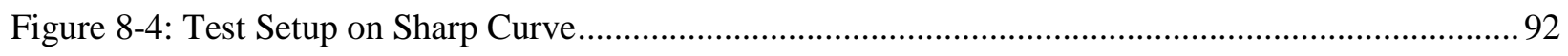

Figure 8-5: Composite ties were ready for replacing the deteriorated wooden ties on SBVR track ..........93

Figure 8-6: Composite tie being pushed into the space of removed wood tie ....................................... 94

Figure 8-7: Composite tie being nudged into the space of removed wood tie......................................... 94

Figure 8-8: Spikes were driven after the composite ties were installed................................................ 95

Figure 8-9: Recycled Composite Ties after installation....................................................................... 95

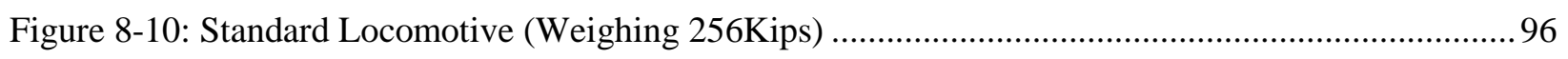

Figure 8-11: Installed Strain Gages on the Recycled Composite Tie .................................................97

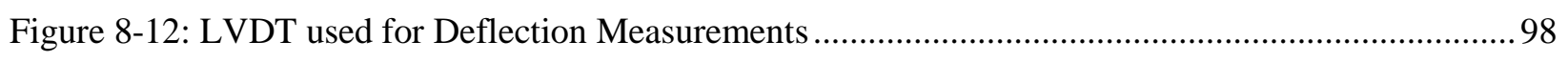

Figure 8-13: LVDT used for horizontal movement along the track direction (between ties).....................99

Figure 8-14: LVDT used for horizontal movement along the tie (perpendicular to tie).......................... 100

Figure 8-15: LVDT being used to measure change in the distance between rails .................................. 101

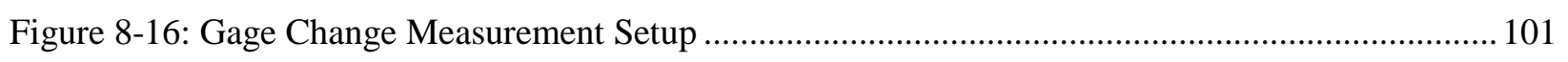

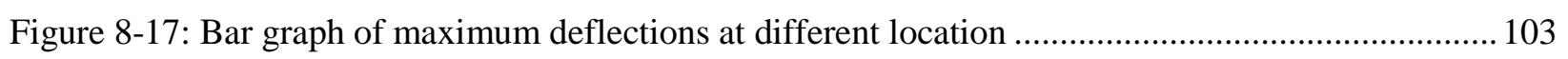

Figure 8-18: Bar graph of maximum lateral movement at different locations....................................... 103

Figure 8-19: Bar graph of maximum longitudinal movements at different locations.............................. 104

Figure 8-20: Bar graph of maximum gage change at different locations............................................. 104

Figure 8-21: Bar graph of maximum strains in first and second configuration ties................................ 105 


\section{INTRODUCTION AND BACKGROUND}

\subsection{Introduction}

Conventional wood ties have been in use in the American railroad industry since mid to late eighteen hundreds. In the last quarter century, the railroad industry has brought some changes in the loading environment, with an increasing importance in heavy axle trains. This change has in turn increased the stress concentration on all components of the track system. The vertical loading system is more severe than lateral loading. In particular, ability of the traditional wood tie to hold gauge and to maintain the track stability has proven to be inadequate due to high axle loads, speed and frequency. The heavy axle loading system also affects the gage widening, tie splitting and spike pullout performance of wood ties. According to TTCI RR08-32, to increase RR ties service life with limited gage widening, the railroad ties have to be strengthened to resist the heavy axle loading. The failure mechanism at certain track locations tends to be more closely associated with ties.

With the use of higher tonnage axles and higher speeds, the damages caused by the tie plate, spike and ballast to the wood ties are more severe. However, there are several defects that may impair their strength and durability of wood cross ties, such as decay, holes or knots, splits, checks, barks, seam, slope of grains, wane and shakes.

The durability and service life of the wood have been enhanced by using wood preservatives. The average life of untreated wood tie is approximately five and half years and the treated wood tie is enhanced in excess of thirty years (Wood Handbook, 1999). As of 1999, there is an annual replacement of 12.5 to 16 million ties approximately (Zarembski, 2000). Although the improvements for maintenance on ties were made using larger tie plates and better fastener system (i.e. cut spikes), bending and pullout strength of wood ties were not enhanced. Larger tie plates and cut spikes were used to reduce the plate cutting and spike killing. To develop the durability and service life of cross ties, materials such as 
concrete, steel and composites have been used as alternate materials by the railroad industries. Therefore, a suitable high strengthened tie is required to achieve proper track system performance in the railroad industry (Zarembski, 2000).

A comprehensive study conducted on the performance of the GFRP wrapped wood members has been growing rapidly in recent years (Karbhari, 2005). GFRP wrapping of ties is true composite structure having desired mechanical properties with exceptional physical characteristics. GFRP composite wrapped to wood tie has excellent strength to weight characteristics, longer life cycle under severe climate conditions (harsh environment), better vibration and noise absorption levels, better resistance to fungi and also better maintenance.

\subsection{Previous Research on Recycled Composite Tie}

The previous research program involved the strengthening and evaluating of wood crossties by wrapping only in the region that hold steel plates using glass fiber reinforced with resorcinol formaldehyde adhesives (Laosiriphong, 2000).

1. Test and evaluate five primer/resin combinations were screened to determine the wood-adhesive interface strength and durability.

2. Manufacture half-scale GFRC-wood crossties with wraps in regions that hold steel plates, using adhesives selected and conduct performance studies under static load testing after accelerated aging.

3. Manufacture full-scale GFRC-wood crossties with wraps only in the region holding steel plates and using predetermined adhesive to resist fatigue loading.

4. Field monitor of GFRC wood ties performance for durability. (Laosiriphong, 2000).

In this research recycled thermoplastic composites were used for strengthening the RR ties in lieu of the thermoset resins used in the previous work. 


\subsection{Objectives}

The main objectives of this research are:

1. Design and manufacture inexpensive metal mold with heaters for manufacturing the full scale recycled composite ties.

2. Manufacture full-scale Recycled Composite Tie by fusing twelve composite parts in first phase and two composite parts in second phase, through the use of compression molding.

3. Evaluate flexural rigidity parameter of full scale GFRP composite tie, under three point bending tests.

4. Evaluate modulus of rupture and static bending strength of recycled composite tie and general wood tie under three point bending.

5. Evaluate spike insertion and spike pullout strength by performing spike insertion and pullout tests on recycled composite tie and wood tie.

6. Compare maximum strains under static loading after specific number of fatigue cycles and determine the degradation in strength and stiffness as a function of fatigue stress level and number of cycles. Compare the experimental results with theoretical results for moments and deflections.

7. Field implement and Monitor the strength and durability performance of the recycled composite ties installed on straight, gentle and sharp curved tracks under the locomotive loads at SBVR, Moorefield, WV.

\subsection{Scope}

This research aims to find the static bending strength, spike insertion and pullout strength, maximum bending moments after two million cycles and the performance of the GFRP composite ties in the field. The work carried out through this research and its scopes are further elaborated in chapters 2 to 8 . Chapter 2 emphasizes the significance of railroad ties, cost related issues on timber ties, composite tie 
specifications of different manufacturing companies, failure types in timber ties and their causes of failure with respect to adhesives to wood, and moisture content. Information from technical papers and journal articles were reviewed from a range of literature in print. In addition, internet and AREMA manual has provided good bit of information for this thesis report. Chapter 3 discusses about the two different techniques and methodologies used to manufacture Recycled Composite Ties which include manufacturing of full-scale ties using twelve composite parts and manufacturing the full-scale ties using two composite parts. In Chapter 4, flexural rigidity results of the three point bending tests on full-scale ties that are manufactured using twelve composite parts have been compared. In Chapter 5, flexural rigidity results under three and four point bending on both the wood and recycled composite ties made of two composite parts were compared. It also provided with the comparison of static bending strength results of general wood tie and recycled composite tie. In Chapter 6, strength results of spike insertion and spike pullout data on both the wood and recycled composite tie have been presented. In Chapter 7, moment and deflection results obtained by running two million fatigue cycles on the full-scale Recycled Composite Tie (manufactured using two composite parts) have been compared with the theory. Chapter 8 discusses the field implementation and testing of seven recycled composite ties made of twelve composite parts (as given in Chapter 3). Comparison of strains, deflections, lateral movement of ties, longitudinal movement of ties and gage change results were presented in the same chapter. Finally, Chapter 9 presents the conclusions and recommendations for the future study. 


\section{LITERATURE REVIEW}

\subsection{Significance of Railroad Crossties}

The railroad ties play a significant role in a railroad track structure. They are normally laid transverse to the rails on top of crushed stone ballast. They were used as a foundation for the rail in the track structure. The function of cross ties is to transfer the axle wheel loads to the ballast, to hold rails to the correct gage and to reduce ballast abrasion. As wood is the only material which is abundantly available and renewable, it has served as a cross tie for American railroad industry since mid-eighteen hundreds. Durability and service life of wood have been enhanced using wood preservatives. They are normally treated with creosote or other preservatives (Wood Handbook, 1999).

The in-service performance of wood ties is uncertain. With the use of higher tonnage and high speed trains, damages caused by the tie plate, spike and ballast to the wood ties are more severe. The degradation in mechanical properties of wood has been mainly due to plate cutting, ballast abrasion, spike killing, splitting and checking or cracking (AREMA Manual, 2004). In addition, as wood is a cellulosic material, it can be adversely affected by decay fungi, insects and marine borers in harsh environments.

\subsection{Production and Cost}

There is a clear relationship between annual railroad tie installations, railroad purchasing practices and wood crossties industry's production and inventories (Zarembski, 2000). The tie installation is mainly dependent on the railroad operating system and annual tonnage from yearto-year. The wood tie production has several long term aspects. When trees reach their "size maturity" for cutting ties, they are normally air-dried for an average of 6-10 months before 
treating and installing them in track. The data from the foregoing sections is used to predict the distinct cyclic nature of the wood crossties. The data includes the past 40 years of class I railroad ties installation, annual traffic density and tonnage as reported by the Association of American Railroads.

Different tie installation procedures were used due to changes in cross-tie prices and maintenance requirements. Such variation is attributed to shrinking number of track miles and increasing level of tonnage (Annual MGT respectively). Table 2-1 shows the results in large scale fluctuations in ties installed in 1960, 1980 and 1999, from a normalized low of just under 11 million ties to a normalized high of almost 23 million ties.

The forecast for annual tie requirements fluctuates from 12.5 million to over 16 million, a variation of almost $30 \%$. The mean of these annual forecasts is 14.45 million ties. In order to calculate the future tie costs, the cost of each green tie and the treated tie from 1994 to 1999 are shown in the Table 2-2. There is almost 2.5 percent increase in the cost of the treated tie every year (Zarembski, 2000).

As reported by Daniels (2008), the maintenance cost improvements contributed by ties was 22\% of the total costs in 1970 and 34\% in 2000. Because of use of larger tie plates in 2000, there is a reduction in plate cutting and spike killing.

To improve durability and service life of cross ties, materials such as concrete, steel and composites have been used as alternate materials by the railroad industries.

\subsection{Companies Producing Composite Ties}

Wood ties are abundantly used in United States of America. While Wood ties dominate North America or railroad industry, concrete is widely used in other parts of the world. Due to problems such as increase in 
the cost, decrease in the production, tendency to decay, composite ties offer the advantage of being able to replace Wood ties. Composite ties last longer than the classic Wood ties and are impervious to decay Wood material (. A number of companies are selling composite ties manufactured from recycled plastic resins and recycled rubbers.

\subsubsection{Tietek Composite Ties (Tietek website, January 6, 2011)}

Tietek manufacturing process delivers composite ties made of plastic, rubber from used tires, waste fiberglass and various mineral fibers. Tietek composites are $85 \%$ recycled materials. The estimated lifespan is over 40 years. These ties are rectangular in shape with indentation on all sides.

\subsubsection{IntegriCo Composite Ties (IntegriCo website, January 6, 2011)}

IntegriCo manufacturing process delivers composite ties made of mixed plastic waste with mineral additives. These ties made largely from recycled materials. Spikes are driven without predrilling on these ties. These ties have an estimated life of 35 years with high load. Indentations are provided on three sides of the tie to increase the ballast retention and increase in track stability.

\subsubsection{Dynamic Composite Ties (Dynamic website, January 6, 2011)}

These ties are manufactured from the recycled high density polyethylene, recycled rubber, steel and concrete. While they are made largely from steel, recycled composite material is used as a composite inserts at the rail seat area and as a composite cover. These ties are perfectly rectangular in shape and expected life span is over 60 years.

\subsubsection{PRT Composite Ties (PRT's website, January 6, 2011)}

These ties are also called as ForcePro composite ties. These ties are manufactured with I-beam design in partial length of the cross-section of the crossties and made from plastics and molded metal parts and cavities. It is designed for over 50 years of life. Indentations are provided on three sides of the composite tie. 
Table 2-1: Composite Tie Specifications of Different Companies

\begin{tabular}{|c|c|c|c|c|}
\hline $\begin{array}{c}\text { Material and strength } \\
\text { properties }\end{array}$ & $\begin{array}{c}\text { IntegriCo } \\
\text { Composite Tie }\end{array}$ & $\begin{array}{c}\text { Tietek Composite } \\
\text { Tie }\end{array}$ & $\begin{array}{c}\text { Dynamic } \\
\text { Composite Tie }\end{array}$ & $\begin{array}{c}\text { PRT's Composite } \\
\text { Tie }\end{array}$ \\
\hline Length (in) & 102 & 102 & 102 & 102 \\
\hline Width (in) & 9 & 9 & 9 & 9 \\
\hline Depth (in) & 7 & 7 & 7 & 7 \\
\hline Moment of Inertia (in $\left.{ }^{4}\right)$ & 257.25 & 257.25 & 257.25 & 257.25 \\
\hline Weight (lbs) & 270 & 275 & 320 & 230 \\
\hline $\begin{array}{l}\text { Modulus of Elasticity } \\
\left(1.0 \times 10^{6} \mathrm{Psi}\right)\end{array}$ & 1.24 & $>1.18$ & 1.25 & 1.431 \\
\hline $\begin{array}{l}\text { Spike Insertion Strength } \\
\text { (lbs) }\end{array}$ & 7100 & 4000 & 8200 & 5907 \\
\hline $\begin{array}{l}\text { Spike Pullout Strength } \\
\text { (lbs) }\end{array}$ & 3500 & 2200 & 4500 & 2560 \\
\hline $\begin{array}{c}\text { Modulus of Rupture } \\
\text { (Psi) }\end{array}$ & 2700 & 2000 & 2600 & 3356 \\
\hline $\begin{array}{l}\text { Static Bending Strength } \\
\text { (in-Kips) }\end{array}$ & 198 & 147 & 191 & 247 \\
\hline Flexural Rigidity (Psi) & 319 & 303 & 321 & 368 \\
\hline
\end{tabular}

The composite ties that have been manufactured by various companies have similar dimensions.

Table 2-1 shows the specifications of composite ties of each company in United States. The modulus of elasticity and static bending strength of PRT's composite ties have been 12\% to 17\% higher compared to all other companies. The spike insertion and pullout strength results have been $13 \%$ to $51 \%$ higher compared to all other companies.

\subsection{Wood railroad ties}

Wood ties are the most abundant type used in United States. They have been serving American railroad industry since mid-eighteen hundreds. As of 2008, the approximate market share in United States for wood ties was 91.5\%, whereas approximate combined market share for concrete, steel and composite ties was 8.5\% (Wikipedia, 2008). As timber crop is cut and 
harvested on rotational basis, timber ties are relatively inexpensive, lightweight, easy to manufacture, install, maintain, repair and replace. However, there are several defects that might impair the strength and durability of cross ties, such as decay, knots, splits, checks, barks, seam, slope of grains, wane and shakes.

\subsection{Major Defects in Wood}

\subsubsection{Decay}

To protect the wood from the attack of these organisms, chemical preservatives are used which enhances the service life of the wood along with the degree of weather ability. The degree of protection is dependent upon the type of preservative, proper penetration and retention of the chemical preservatives. When properly treated with creosote, the deterioration due to fungi, termites and marine borers is essentially eliminated. Historically, wood tie is being treated with the creosote solution (Tie Guide, 2005).

The first treatment process used a water-borne solution of the inorganic salt Mercuric Chloride, Copper Sulphate and Zinc Chloride as the Wood preservative. In the second half of the nineteenth century, it was determined that these preservatives leached out of wood ties when placed in the exterior exposure conditions like "free running water". The first full cell creosote treatment plant built at Somerset, Massachusetts in 1865, was used for boiling under vacuum, removing free water from the wood and then allowing the creosote to be impregnated into the wood. Some other materials such as coal tar, water-gas and petroleum were mixed with creosote to reduce the overall cost of the mixtures without significantly reducing the effectiveness. 
The hardwood timbers, such as oaks, hickories and maples have a cellular structure which is positioned end to end, commonly known as vessels. The mechanical support is provided by fibers that surround the vessel.

The softwood timbers, such as Douglas-fir, pines, hemlock and true firs have elongated cells called fibers which serve as mechanical support and to conduct the sap.

The difference in the penetration of the preservative in both hardwoods and softwoods is the amount of heartwood and sapwood. Sapwood transmits fluids and nutrients between the roots and leaves of the tree and the heartwood pores are blocked with various pith like growths called tyloses and no longer transmits fluids of the tree and it is dark in color than the sapwood. Tyloses are commonly found in white oaks and are difficult to penetrate with liquids, whereas liquids can easily penetrate through red oak. Therefore untreated white oak will last provide a service life of about twelve years (Tie Guide, 2005).

\subsubsection{Large or Numerous Holes or Knots (AREMA Manual, 2004)}

A large hole is one having more than $1 / 2$ in. diameter and 3 in. deep within, or more than one-fourth the width of the surface on which it appears and 3 in. deep outside, or the numerous holes in sections of the tie between 20 in. and 40 in. from its middle.

A knot is considered to be large if the average diameter is more than one-third of the width of the surface on which it appears within the rail bearing areas.

\subsubsection{Large Splits or Checks}

A check or crack in a fully seasoned and/or treated tie is defined as the one having depth greater than onefourth the thickness and the length longer than half that of the tie. 
In an unseasoned crosstie, a large split is defined as the split having 4 in. length and/or width more than $1 / 8$ in., whereas in a seasoned crosstie it is the split having width more than $1 / 4 \mathrm{in}$. and/or the length longer than the width of the face across.

\subsection{Adhesive to Wood}

Adhesive bonding of wood is an essential factor in efficient utilization of timber resources. ASTM defines it as a substance capable of holding materials together by surface attachment. Adhesion is a state at which two surfaces are held together by interfacial forces, which may be valence forces or mechanical bonding (interlocking action). Valence forces are forces of attractions produced by interaction of atoms and molecules that exists at the surfaces of the adherent and adhesive. In mechanical bonding the surfaces are held together by an adhesive that has penetrated through the porous surface and anchored itself during solidification to produce excellent, strong and durable bonds. Effective interlocking takes place when adhesives penetrate beyond the surface of damaged fibers into sound wood. Furthermore, hydrogen bonding forces are most significant in the interfacial attraction of adhesive polymers for both the hemicelluloses and cellulosic materials (Vick.C.B, 1999).

Organic polymers such as thermoplastics generally are not as strong as wood but when these thermoplastic adhesives contain fiber reinforced materials, such as glass fibers, which can effectively transfer and distribute stresses, then increase in strength and stiffness of the material is noted surpassing the mechanical properties of wood. Effective transfer of stress from one component (wood core) to another (composite shell) depends upon the strength of the adhesive-bonding joint. The effective bond between the thermoplastic and wood is as a strong structural composite. The surface of plastic materials is nonpolar, hydrophobic and has certainly low energy. Adhesions to plastic surfaces occur usually by intermolecular attraction of forces or hydrogen bonding. Furthermore, it provides some mechanical interlocking by chemical etching. 
Thermoplastics are long chain polymers that soften, flow on heating and harden again on cooling. Pressure is normally applied to enhance wetting by forcing liquid adhesives to flow over the surfaces, replace air blockages and penetrate to sound wood. On increasing the viscosity of the liquid adhesive, it solidifies to the point where the bond effectively resists shear and tensile forces tending to separate the surfaces. The solid form may occur either by loss of solvent from the adhesives through evaporation or through diffusion into the wood or even cooling of molten adhesive on a cooling surface.

The surface of wood should be smooth, flat, free of burnishes, oils, dirt and other debris. When wood is subjected to high temperatures during processing, extractives diffuse to the wood surface where they concentrate and physically block adhesive contact with wood and deteriorate physical conditions. Physical deterioration and chemical contamination interfere upon essential wetting, flow, contamination, cure and resulting cohesive strength of the adhesives (Vick.C.B, 1999).

\subsection{Moisture Content}

Wood has strong molecular attraction to water primarily through hydrogen bonding, oven drying removes the free water from the wood cellulose and roughly 30\% remains bound within the cell walls. If wood regains the moisture after it has been dried below the fiber saturation point, at wood will swell and shrink, as a result stresses will develop, potentially leading to rupture of adhesive bond.

Adhesives bond is satisfactory at moisture content levels ranging from $6 \%$ to $14 \%$. Any value above or below this range has to be formulated for specialized processing. When wood becomes so dry i.e. below $3 \%$ to $5 \%$ moisture content, then it temporarily resists wetting by the adhesives and rupture may develop in the bonded joint. When wood contains excess amount of moisture, it absorbs less water and adhesive, which leads to excessive adhesive squeeze-out when pressure is applied. Furthermore, high vapor pressure builds internally at high temperature and on sudden release of internal pressure actually separates laminates along the bond lines (Vick.C.B, 1999). 


\subsection{GFRP Wrapped wood members}

The performance of the GFRP wrapped wood members have been growing rapidly in recent years. GFRP wrapping of wood members is a true composite structure having desired mechanical properties with exceptional physical characteristics. In the past, the Constructed Facilities Center at West Virginia University (CFC-WVU) has focused on developing techniques to rehabilitate and upgrade deteriorated regular timber ties and bridge beams using FRP composites. The work includes rehabilitation of timber ties and bridge beams through sprayed layup through Sprayed Glass Fiber Reinforced Polymer and Vacuum Assisted Resin Injection Process of defective pile caps on bridges owned by SBVR.

In the previous study on Railroad crossties, GFRP composites were wrapped to wood tie only in the region that holds steel plates. Phenolic resorcinol formaldehyde was selected as a compatible adhesive between the wood and the glass fabric. Shear strength based on ASTM D905 of shear block specimen test was utilized to choose the compatible adhesive. To evaluate the stiffness and durability of the wrapped samples under natural environmental conditions that were simulated by six cycles of aging, half scale wooden ties (3 in x 4 in x 42 in) wrapped at midspan over a length of 20 in were subjected to three point bending test. Based on the test results and specimen size it was concluded that the stiffness and durability of the wrapped specimen was $13 \%$ - $44 \%$ higher in flexural rigidity and $9 \%-18 \%$ in shear modulus. The results for aged samples imply that the flexural rigidity was reduced by $10 \%$ - 30\% for wrapped specimens and $17 \%$ - 20\% for nonwrapped specimen. To study the performance of the GFRP full scale ties, fatigue tests were conducted on GFRP wrapped at the rail seat zones and non-wrapped specimens. The results revealed that after 2 million cycles the bending degradation was 5\% for wrapped specimen and 25\% for non-wrapped specimen. After evaluating the performance of GFRP wrapped wood ties 
in the laboratory, the GFRP full scale ties were manufactured and installed in the field. The test results conclude that the bending stresses of wrapped crossties were very high at midspan when compared to those at other points in the same crossties because there was no wraps at the midspan regions. The tests also imply that the spike pullout force at wrapped crossties was $30 \%$ $70 \%$ more than that of non-wrapped ties.

The wood tie materials have excellent strength to weight characteristics, longer life cycle in severe climate conditions, decreases the vibration and noise due to absorption, provides fungus resistant, and also reduces the maintenance of the timber structures. GFRP composite resists the deterioration of the timber structure in harsh environments. The solutions for the damages caused in the timber structures are rehabilitation and repairs by using GFRP material. 


\section{MANUFACTURING OF FULLSCALE RECYCLED COMPOSITE TIE}

\subsection{Introduction}

Fiber reinforced plastic parts are manufactured using recycled acrylonitrile-butadiene styrene (ABS) as the matrix and a unidirectional glass fiber rovings along with continuous strand mat (CSM) as the reinforcement. These composite parts of varying shell thicknesses up to one half of an inch were compression molded in WVU-CFC Laboratories. Recycled ABS polymer compatible glass reinforcement selection was based on considerations such as fabric configuration, fiber volume fraction, void reduction, strength/stiffness, and cost-effective availability. In the laying up process, a layer of resin is laid-up while the layers of fiberglass are applied on it and subsequent layers are laid up by following the combined configuration.

For encapsulating the wood tie with the recycled GFRP composite parts, two different molding procedures were used. The first procedure was to encapsulate it with twelve composite parts and then followed by different procedure to encapsulate it with two composite parts. Red oak wood having a moisture content of $18 \%$ to $30 \%$ was planned to achieve the required dimensions and used as a core material. Following the initial study, the recycled GFRP Composite ties were manufactured at WVU-CFC Laboratory in the full scale compression mold by encapsulating composite parts over the wood core materials (section 3.7). The Manufacturing parameters such as temperature, flow issues, and pressure requirements were maintained same for all specimens.

\subsection{Materials}

The materials used for manufacturing recycled GFRP composite tie include recycled ABS, glass fibers and red oak wood. Typical properties of those materials are provided in Table 3-1 (Matbase website, 2010) 
Table 3-1: Mechanical Properties of ABS and Glass Fiber

\begin{tabular}{|c|c|c|}
\hline Mechanical Properties & ABS & Glass Fiber \\
\hline Young's Modulus (Psi) & $0.32-0.42 \times 10^{6}$ & $10.6 \times 10^{6}$ \\
\hline Tensile Strength (Psi) & $0.58-0.61 \times 10^{4}$ & $0.27-0.37 \times 10^{6}$ \\
\hline Elongation & $5-25 \%$ & $0-3.2 \%$ \\
\hline Specific Gravity (lbs/in $\left.{ }^{3}\right)$ & 0.0375 & 0.0917 \\
\hline
\end{tabular}

\subsubsection{Properties of Recycled ABS (Żenkiewicz, 2009)}

1. ABS combines the strength and rigidity of the acrylonitrile and styrene polymers with the toughness of the polybutadiene rubber.

2. The most important mechanical properties of ABS are impact resistance and toughness.

3. Stability under loads is excellent with limited loads.

4. ABS has useful characteristics within a temperature range of $-40^{0} \mathrm{~F}$ to $180^{\circ} \mathrm{F}$.

5. Molding at high temperature improves gloss and heat resistance of the product.

6. Fiber (usually glass fibers) and additives can be mixed with the resin pellets to make the final product strong and raise the operating range to as high as $100^{\circ} \mathrm{F}$.

7. The aging characteristics of the polymers are largely influenced by the polybutadiene content, and it is normal to include antioxidants in the composition.

8. Water, non-organic salts, acids and basics have less influence on ABS.

9. ABS can be processed by standard mechanical tools which are being used for machining of metals and wood. The cutting speed need to be high and the cutting tools has to be sharp.

10. Cooling is recommended to avoid melting of materials.

11. An attractive property of ABS is its processing temperature of around $200^{\circ} \mathrm{F}$ which allows for compounding with wood particulates without thermally degrading the wood (Hashim.S, 2006). 


\subsubsection{Properties of Glass fibers (Hartman, 1996)}

1. Glass fibers have high ratio of surface area to weight.

2. Glass fibers are very strong in tension but have no strength against compression.

3. The freshest and thinnest fibers are the strongest because the thinner fibers are more ductile. The more the surface is scratched, the less the resulting tenacity.

4. Humidity is an important factor in the tensile strength. Moisture is easily absorbed and can worsen microscopic cracks and surface defects, and lessen tenacity.

5. Strength usually depends on the amount of humidity in the atmosphere for the fiberglass to gel or set properly.

6. Do not attempt to work with fiberglass in a cold environment as the setting process could take a very long time.

\subsection{Safety}

1. It is recommended to work with fiberglass and resin in an open environment or where there is a flow of fresh air. One has to ensure wearing some form of mask to protect against contacting small glass fibers.

2. One should be very careful when carving or sanding fiberglass.

3. It is essential to wear protective gloves and eye protection at all times. 


\subsection{Manufacturing process - I}

\subsubsection{Description of compression mold}

Two different steel molds were used to yield two different parts which are significantly different from one to another. It is true that fabricating a component out of both kinds of parts or only one kind was easier to seal for achieving good surface characteristics. The outer mold used was made of steel. The aluminum plunger was used to compress the component and bring it to the required shape. The size of the finished top and bottom composite parts were 41in x 8.75in x 7in. and finished side composite parts were 41in $\mathrm{x}$ 6.375in x 6.75in. Each part has tendency to release easily. Every part has smooth outer and inner surfaces. The extra portions were trimmed during the assembling of composite parts to the full scale wood tie. This procedure was more time consuming. The desired end result of this mold has finished shape which will encapsulate the wood tie.

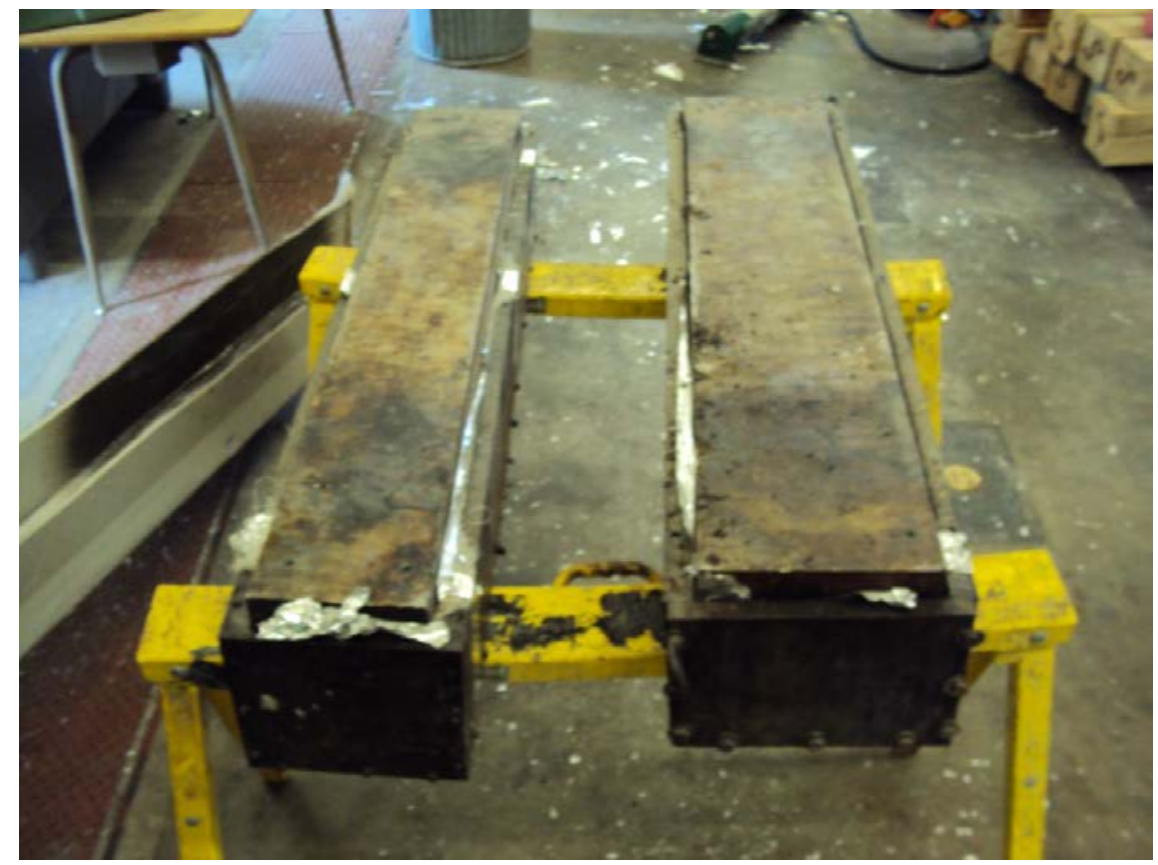

Figure 3-1: Mold used to prepare composite parts 


\subsubsection{Mold Fabrication}

The mold was manufactured to get the required shape of the finished part. In order to build the mold, careful consideration should be given to such fasteners physical properties of mold, time and cost of construction and material availability are enabled. Before selecting the material for mold, the factors such as length of the production run and the desired quality of the finished product were considered, including the material use. The materials used were steel and aluminum. The steel plates were bought from the manufacturing company and were cut to the required dimensions. The outer dimensions of the steel mold for manufacturing top and bottom composite parts were 42.5in x 10.5in x 7 in. and for manufacturing, side composite parts were 42in x 8in x 6.75in. The inner dimensions vary with length because there were angle plates at the ends on bottom and side plates (Figure 3-2). To get proper overlapping of the composite parts, angle plates were added to ends of sides and bottom of the inner surface. The angle plates of 6.5 in $x$ 4in $x$ 0.21in were cut at an angle of $6^{0}$. The solid aluminum plunger was also added with angle plate on one side of it. The width on one end of the aluminum plunger for manufacturing top and bottom composite parts was 8.25in and the other end was 8.75in. This mold has 8 parting planes as needed for complete separation. All parting planes are connected using 1in screws (Figure 3-2).

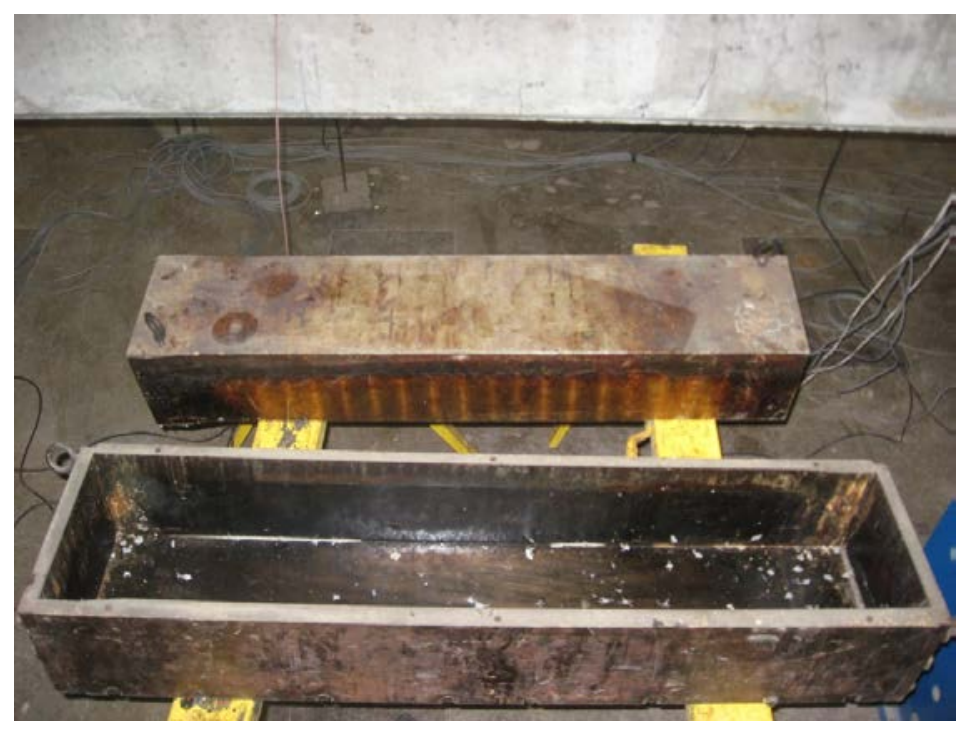

Figure 3-2: Mold used to prepare top and bottom composite parts of wood tie 
The width on one end of the aluminum plunger for manufacturing top and bottom composite parts was 6.375in and the other end was 5.875in. The dimensions vary with the length (Figure 3-3) because there are angle plates at the ends on side and bottom plates.

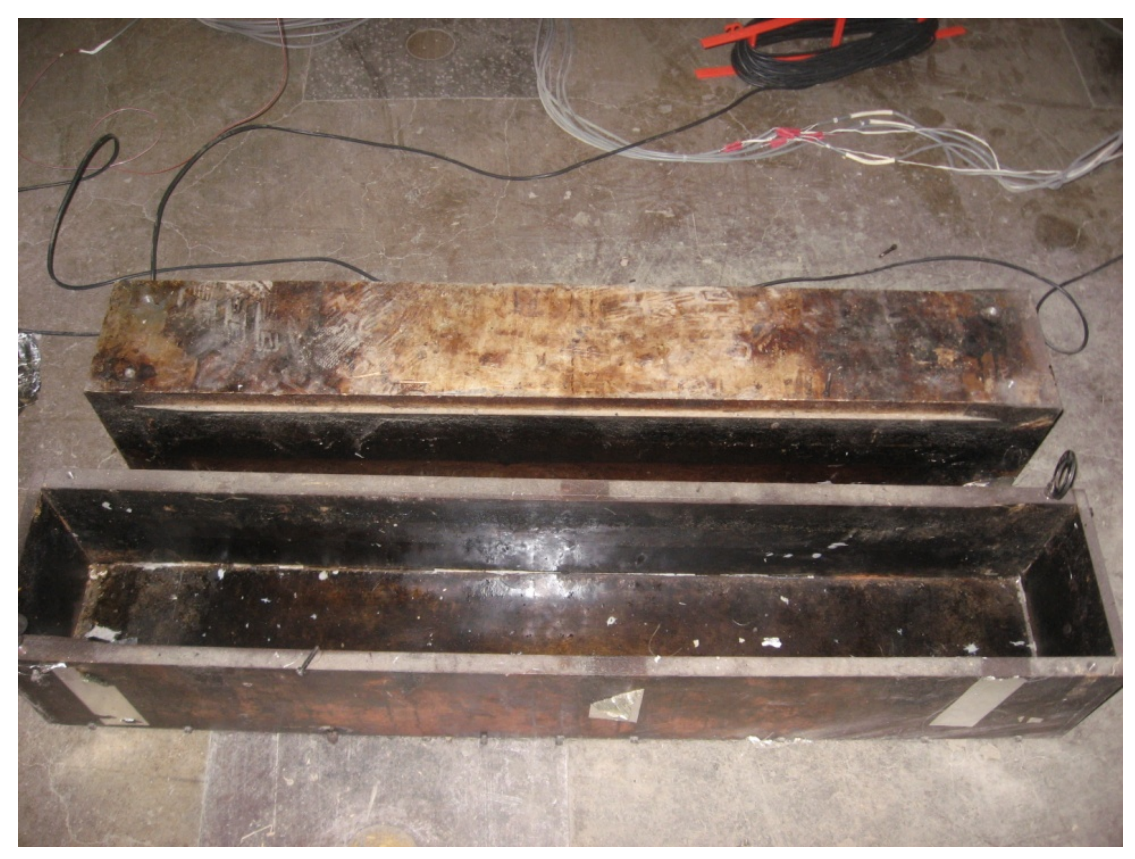

Figure 3-3: Mold used to prepare side composite parts of wood tie

\subsubsection{Orientation of fibers}

Six ties were made using the manufacturing process-I, ties such as Tie1, Tie2, Tie3 and Tie4 have seven layers of continuous mat fibers and eight layers of unidirectional fibers oriented in $0^{\circ}$ and $90^{\circ}$ angles. It was described as First Configuration.

Tie5 and Tie6 have five layers of continuous mat fibers and eleven layers of unidirectional fibers oriented in $0^{0}, 90^{\circ},+45^{0}$ and $-45^{0}$ angles (Table3-2). This was described as the Second Configuration. The end caps for each and every tie have five layers of continuous mat fibers. 
Table 3-2: Fiber/Fabric Configurations (Manufacturing process-I)

\begin{tabular}{|c|c|c|c|}
\hline \multirow{2}{*}{$\begin{array}{c}\text { Fiber/Fabric } \\
\text { Configuration }\end{array}$} & $\begin{array}{c}\text { Ties } \\
\text { 1, 2, 3 and 4 } \\
\text { (First Configuration) }\end{array}$ & $\begin{array}{c}\text { 5 and 6 } \\
\text { (Second Configuration) }\end{array}$ & \\
\cline { 2 - 4 } & 8 Layers & 11 Layers & NA \\
\hline $0^{0} / 90^{0}$ & NA & 4 Layers & NA \\
\hline$-45^{0} / 45^{0}$ & 7 Layers & 5 Layers & 5 Layers \\
\hline CSM & 15 layers & 20 Layers & 5 Layers \\
\hline Total &
\end{tabular}

\subsubsection{Fiber Volume Fraction}

\section{A. First configuration}

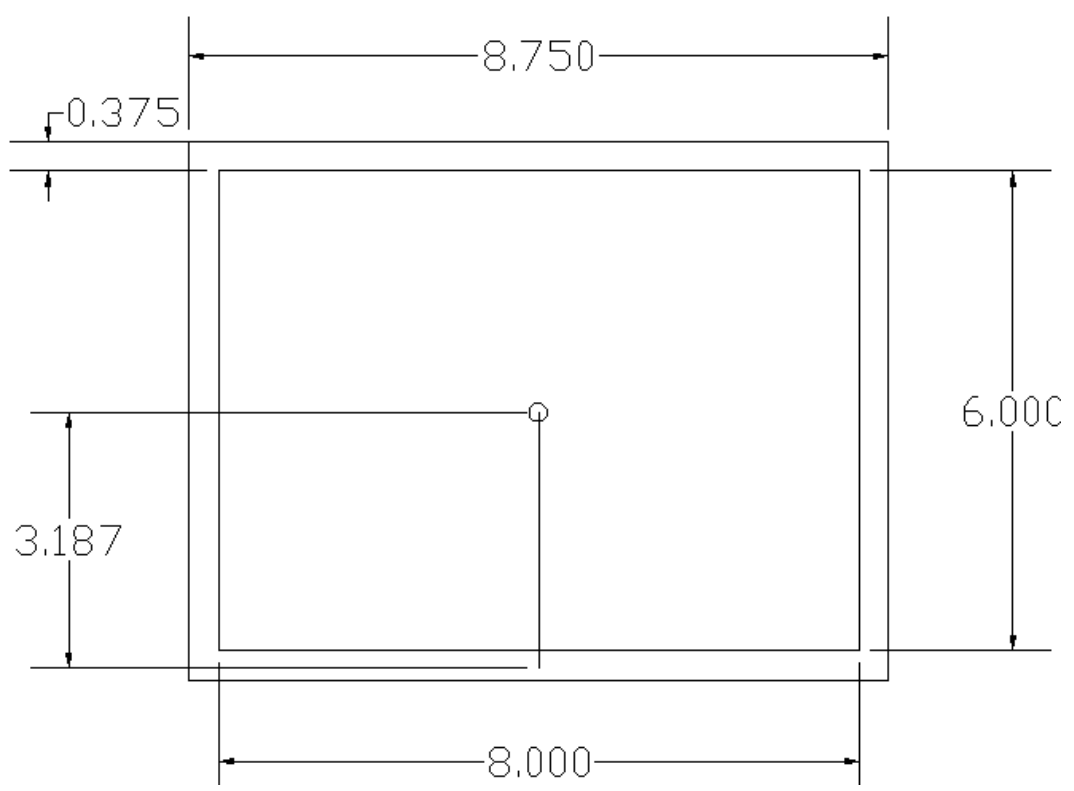

8 Unidirectional rovings $=7.4 \mathrm{oz} / \mathrm{sq}$ yd

7 Continuous strand mat $=9 \mathrm{oz} / \mathrm{sq}$ yd

Total Density of Glass Fibers $=122.2 \mathrm{oz} / \mathrm{sq}$ yd

Thickness of composite part $=3 / 8 \times 36 \times 36=486$ in $^{3}$

Glass fiber specific gravity $=2.54 \mathrm{gm} / \mathrm{cc}=0.0917 \mathrm{lbs} / \mathrm{in}^{3}$ 
Fiber volume $=122 / 16 \times 1 / 0.0917=83.23 \mathrm{in}^{3}$

Fiber volume fraction $=$ fiber volume/total volume $=83.09 / 486=0.17=17 \%$

Resin volume $=486-83.09=402.91$ in $^{3}$

Resin specific gravity $=1.04 \mathrm{gm} / \mathrm{cc}=0.037572 \mathrm{lbs} / \mathrm{in}^{3}$

Weight of resin $=0.037572 \times 402.91=15.13 \mathrm{lbs} / \mathrm{sq} \mathrm{yd}$

\section{B. Second configuration}

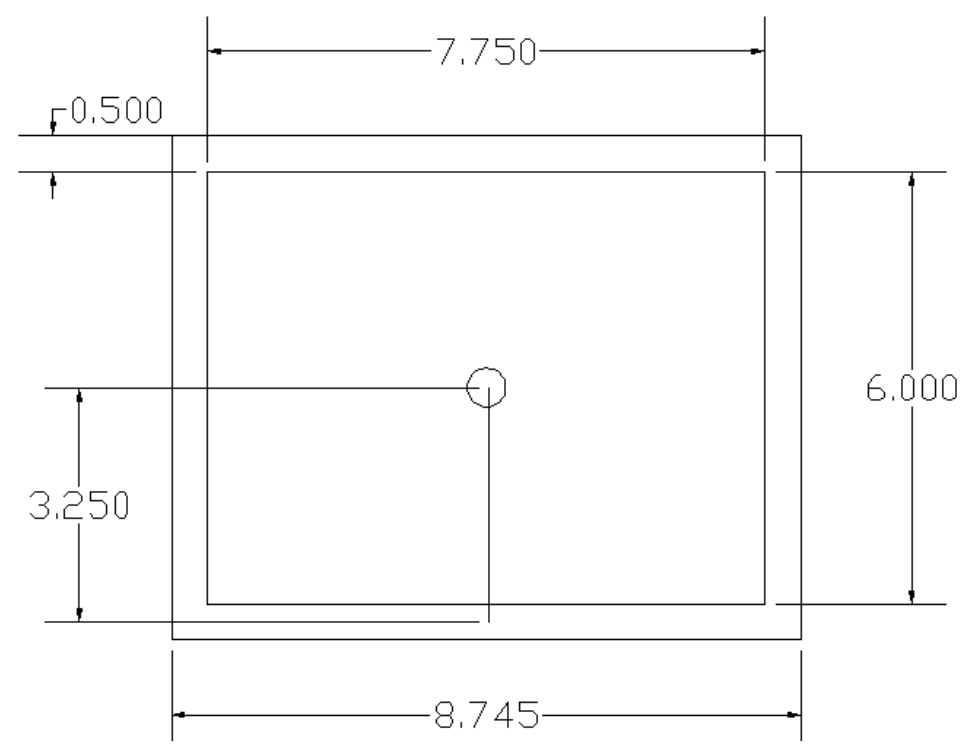

15 Unidirectional rovings $=7.4 \mathrm{oz} / \mathrm{sq}$ yd

4 Continuous strand mat $=9 \mathrm{oz} / \mathrm{sq}$ yd

Total Density of Glass Fibers $=147$ oz/sq yd

Thickness of composite part $=1 / 2 \times 36 \times 36=648 \mathrm{in}^{3}$

Glass fiber specific gravity $=2.54 \mathrm{gm} / \mathrm{cc}=0.091763 \mathrm{lb} / \mathrm{in}^{3}$

Fiber volume $=117.4 / 16 \times 1 / 0.091763=100.122 \mathrm{in}^{3}$ 
Fiber volume fraction $=$ fiber volume/total volume $=100.122 / 648=0.15=15 \%$

Resin volume $=648-100.122=547.8$ in $^{3}$

Resin specific gravity $=1.04 \mathrm{gm} / \mathrm{cc}=0.037 \mathrm{lbs} / \mathrm{in}^{3}$

Weight of resin $=0.037 \times 547.8=20.58 \mathrm{lbs} / \mathrm{sq}$ yd

Table 3-3: Physical Properties of Composite Parts on all Sides

\begin{tabular}{|c|c|c|c|c|c|}
\hline $\begin{array}{c}\text { Fiber/Fabric } \\
\text { Configuration }\end{array}$ & $\begin{array}{c}\text { Thickness of } \\
\text { shell (inch) }\end{array}$ & Roving's & CSM & $\begin{array}{c}\text { Weight of } \\
\text { Resin (lbs/yd } \mathbf{2} \text { ) }\end{array}$ & $\begin{array}{c}\text { Fiber volume } \\
\text { Fraction }\end{array}$ \\
\hline First Configuration & 0.375 & 8 Layers & 7 Layers & 15.13 & $17 \%$ \\
\hline Second Configuration & 0.5 & 15 Layers & 4 Layers & 20.58 & $15 \%$ \\
\hline
\end{tabular}

\subsubsection{Wood core Dimensions}

The initial dimensions of the wood core were 6.5in x 7.5in $x$ 102in. The wood was planned to the required dimensions to make the composite parts fit to it. The size of the wood core used was 6in $\mathrm{x}$ 7in $\mathrm{x}$ 102in.

\subsubsection{Molding over releasing agent}

A releasing agent was applied to the mold. This was the most important step, because if the release agent fails to perform its function, the mold can't be removed without damaging the mold and the part. The releasing agent can either be a parting wax or polyvinyl alcohol or oil. The releasing agent was used to avoid air gaps between the mold and the composite part.

The inner smooth surface of the mold was sprayed with oil before placing the aluminum foil. Then the aluminum foil was carefully positioned in the mold by spraying it with demolding agent, which helps to release the part when it was hardened. The demolding agent used was Tech-lube 25 from Technick products. The aluminum plunger was also sprayed with oil to put aluminum foil and demolding agent was sprayed on it. 


\subsubsection{Preparing the mold for heating}

After the releasing agent was sprayed and dried over the aluminum foil, the fabric and resin were laid up in the mold. The aluminum plunger was placed carefully using the crane without spoiling the foils. Once the mold was ready for heating, the bottom mold along with aluminum plunger was placed carefully between the heaters. Load was applied using manual hydraulic jack to close the mold. Once the heaters were turned in to reach $400^{\circ} \mathrm{F}$, then they were checked using the temperature gun to make sure that all the heaters are working properly. After the heaters were checked, the mold was covered with insulation to prevent heat loss. Once these steps were completed, the mold was carefully watched at every half an hour intervals and the load was increased when the resin started to melt. Initially, the mold was heated for one hour without loading and then load was applied at a rate of 7 kips per hour. The molten resin started flowing into the fabric layers when the mold was being compressed. Excess resin flows out, voids are reduced and the part emerges smooth on both sides. The heating process was carried for 4 hours.

\subsubsection{Releasing of the part from the mold}

Once the heating was processed for 4 hours, the heaters must be stopped. The mold was cooled for at least 4 hours. The insulation was removed carefully from the top and sides of the mold. The screws from one side of the mold were loosened and the release wedges were used to release the part from the mold. The wedges were inserted around the perimeter of the mold and gently tapped them into the place, progressing evenly around the edges. Slowly the part and the mold get separated. The composite part along with aluminum plunger was released. Then aluminum plunger was also released in the same manner. 


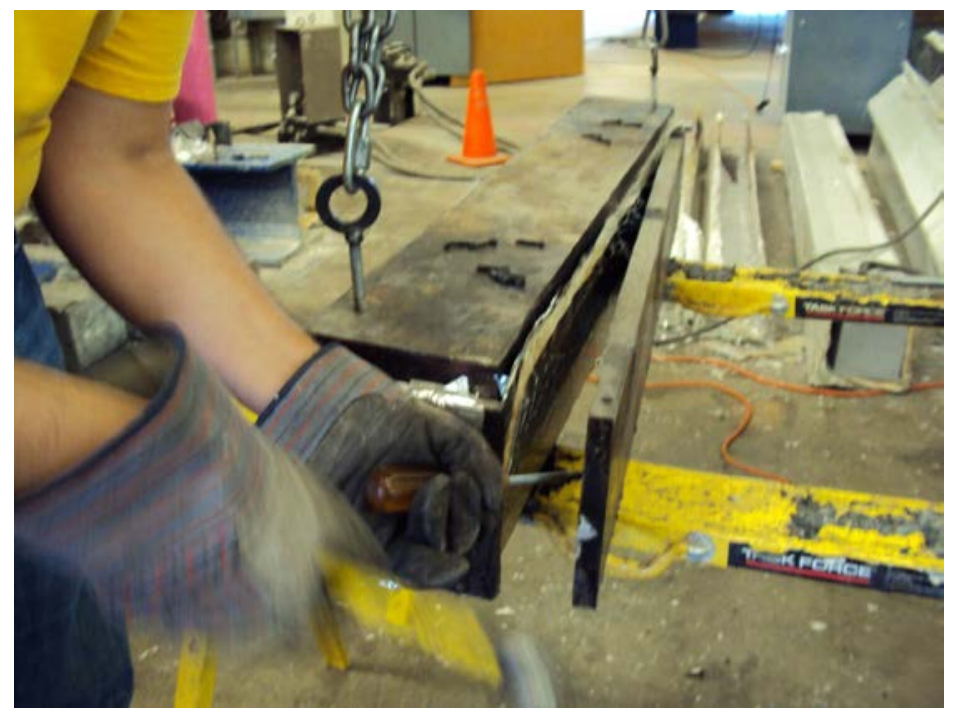

Figure 3-4: Releasing of composite part along with aluminum plunger from the bottom mold

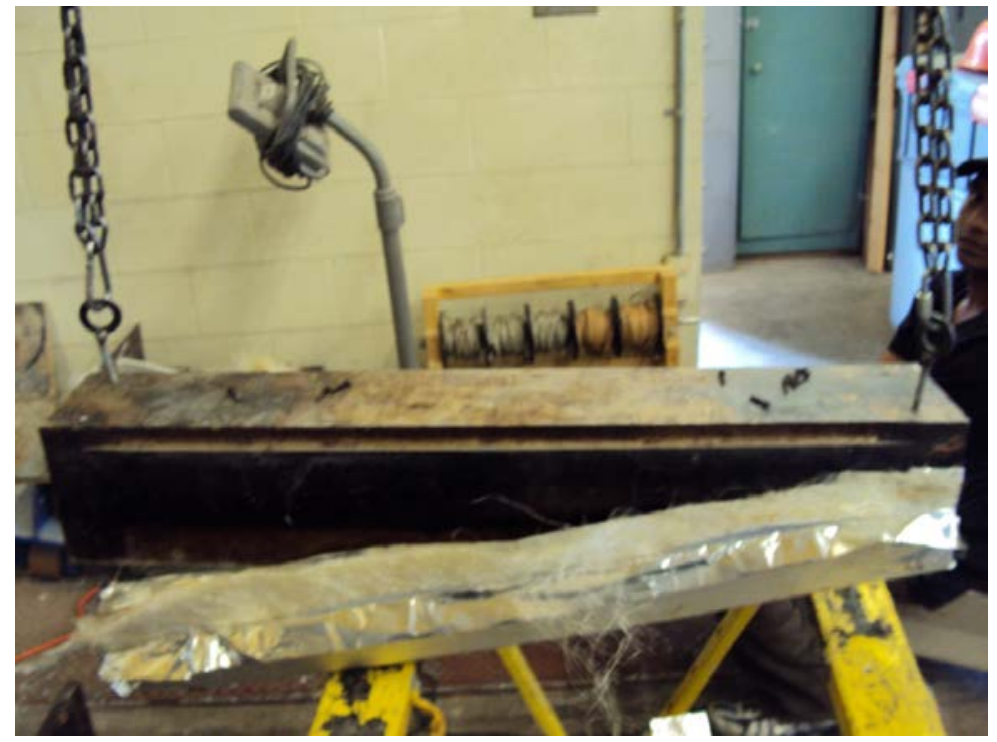

Figure 3-5: Release of the part from the mold

\subsubsection{Preparing the mold for the next composite part}

Once the composite part was separated from the mold, the surface was cleaned and looked for any serious defects. The problems would be typically, the mold releasing agent releases the texture behind which are easily removed by using a wedge, the broken screws would appear in the parting planes which are replaced with the new screws and the heaters wires would appear broken which are fixed using 
screwdriver. Any of these problems could give the awkward shape of the parts. These problems were solved before preparing the mold for the next composite part.

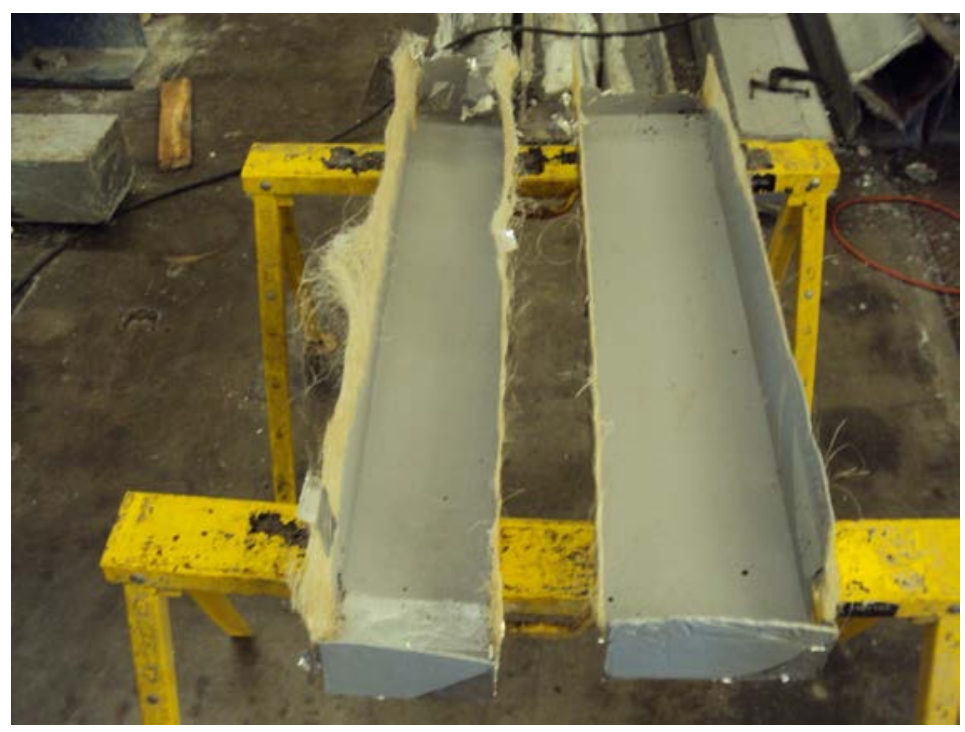

Figure 3-6: released composite parts from the aluminum plunger

\subsection{Manufacturing process - II}

\subsubsection{Description of compression mold}

This compression mold was developed to manufacture larger flat composite part which had to be soft and then folded to the required shape using the lifting mechanism. Two U-shape composite parts of different sizes were made out of this mold. It is true that fabricating a component out of these molds was easier for achieving good surface characteristics. The top plate having steel grid was used to compress the component and bring it to the required shape. Two I sections were put on the top plate as the hydraulic jack could not reach the mold which was placed on the floor. The size of the finished part is 102.5in x 9in x 8.75in. Each part has easy tendency to release. Every part has smooth outer and inner surfaces. This procedure is less time consuming and worth the extra effort. The desired end result of this mold has 
finished shape which will encapsulate the wood tie. The extra portions were trimmed during the assembling of composite parts to the full scale wood tie.

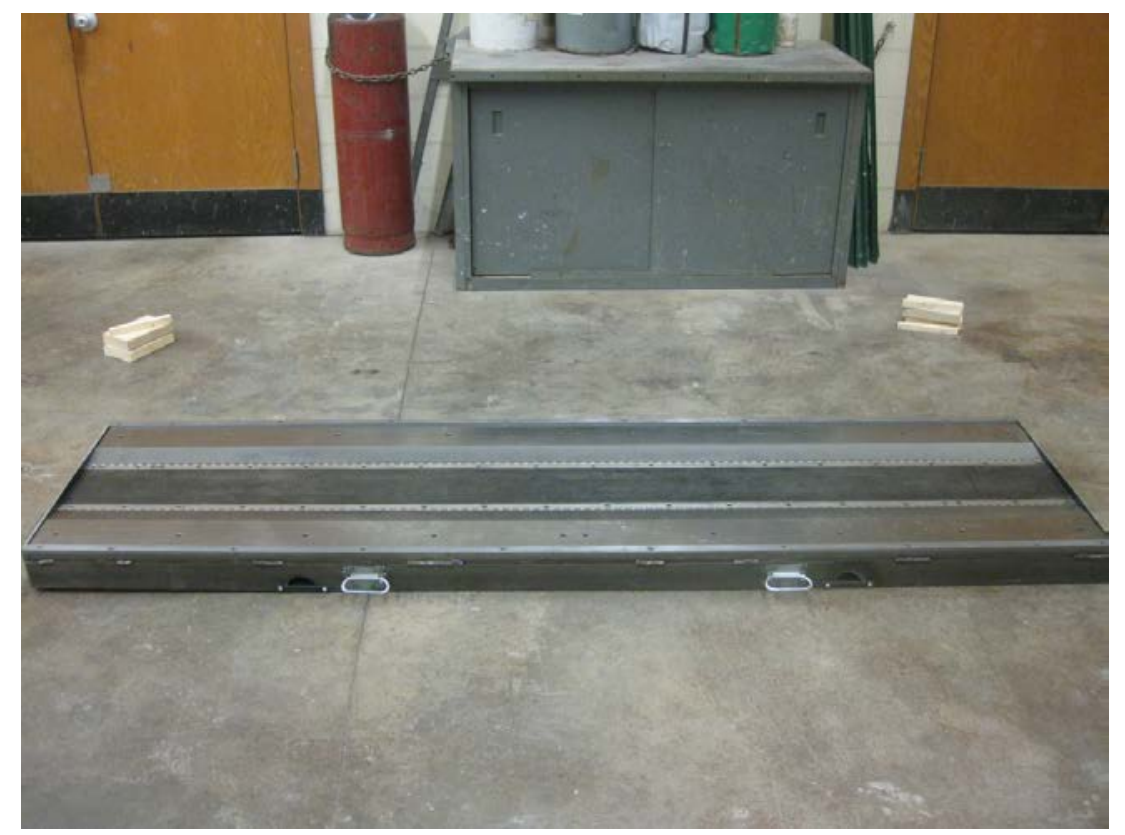

Figure 3-7: Mold used to fold the composite parts

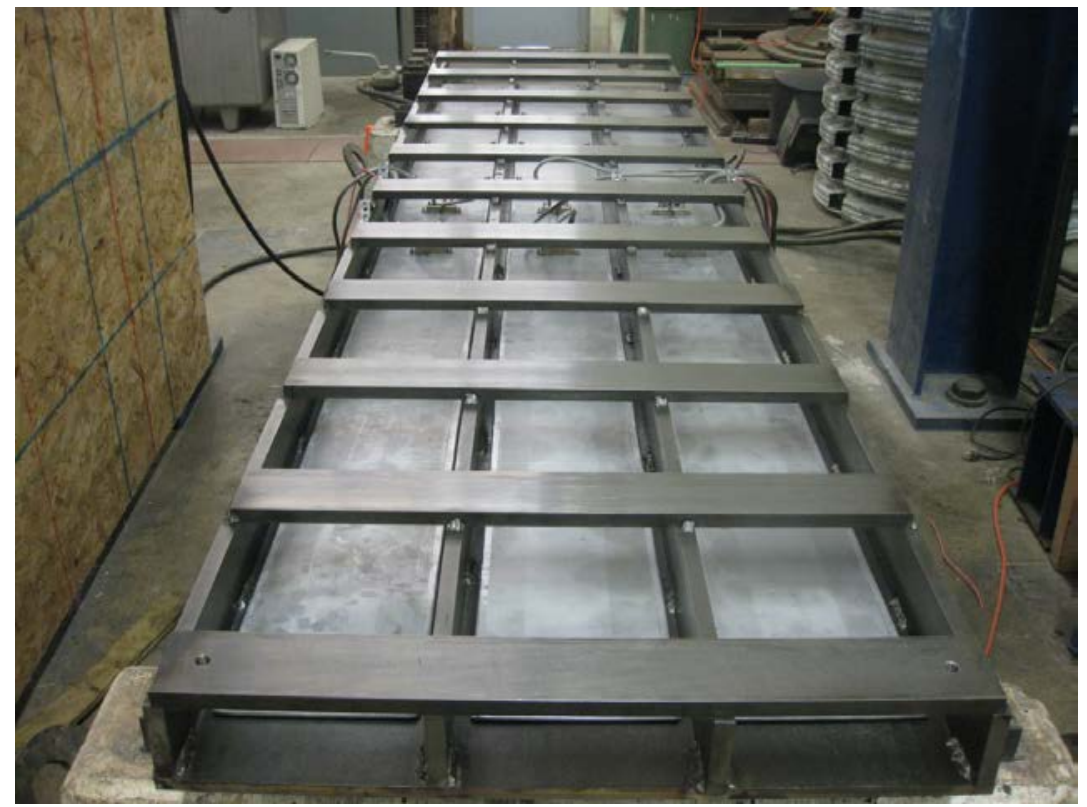

Figure 3-8: Top mold used to heat and apply the load on the composite part 


\subsubsection{Mold Construction}

The mold was manufactured to get the required shape of the finished part. In order to build the mold, careful consideration of factors such as the physical properties of mold, time and cost of construction and material availability are enabled. Before selecting the material for the mold, factors such as length of production run and desired quality of the finished product were considered, including material holding in use. The materials used were steel and aluminum. The steel plates were bought from the manufacturing company and were cut to the required dimensions. The outer dimensions of the male mold were $102.5 \mathrm{in} \mathrm{x}$ 27in $x$ 3.5in and the female mold were 105in x 26.25in x 4in. To get the finished shape of the composite part, the angle plates were added on the top surface of the male mold. The angle plates of 102.5in x 8.75in x 0.5 in were cut to an angle of $6^{0}$ at 5 in width. This mold has three parting planes as needed for complete separation. All parting planes are connected using 102in long hinge strip.

\subsubsection{Fiber volume fraction}

\section{First Configuration}

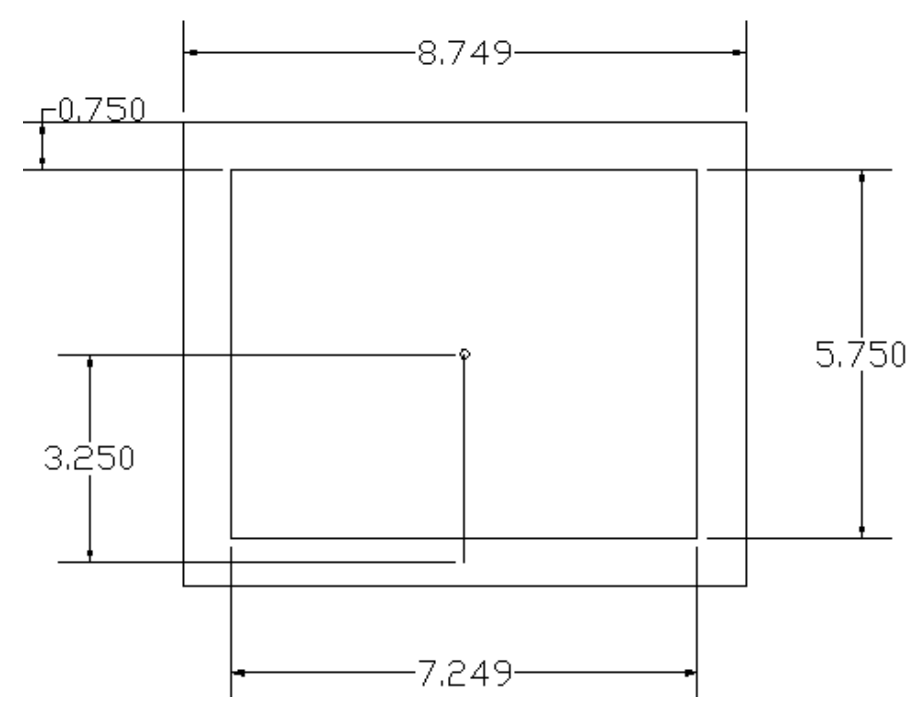

15 Unidirectional roving's $=7.4 \mathrm{oz} / \mathrm{sq}$ yd

4 Continuous strand mat $=9 \mathrm{oz} / \mathrm{sq}$ yd 
Total Density = 147 oz/sq yd

Thickness of composite part $=3 / 4 \times 36 \times 36=972 \mathrm{in}^{3}$

Glass fiber specific gravity $=2.54 \mathrm{gm} / \mathrm{cc}=0.0917 \mathrm{lb} / \mathrm{in}^{3}$

Fiber volume $=117.4 / 16 \times 1 / 0.091763=100.122 \mathrm{in}^{3}$

Fiber volume fraction $=$ fiber volume/total volume $=100.122 / 972=0.1030=10 \%$

Resin volume $=972-100.122=871.877$ in $^{3}$

Resin specific gravity $=1.04 \mathrm{gm} / \mathrm{cc}=0.037 \mathrm{lb} / \mathrm{in}^{3}$

Weight of resin $=0.037 \times 871.877=32.75 \mathrm{lbs} / \mathrm{sq}$ yd

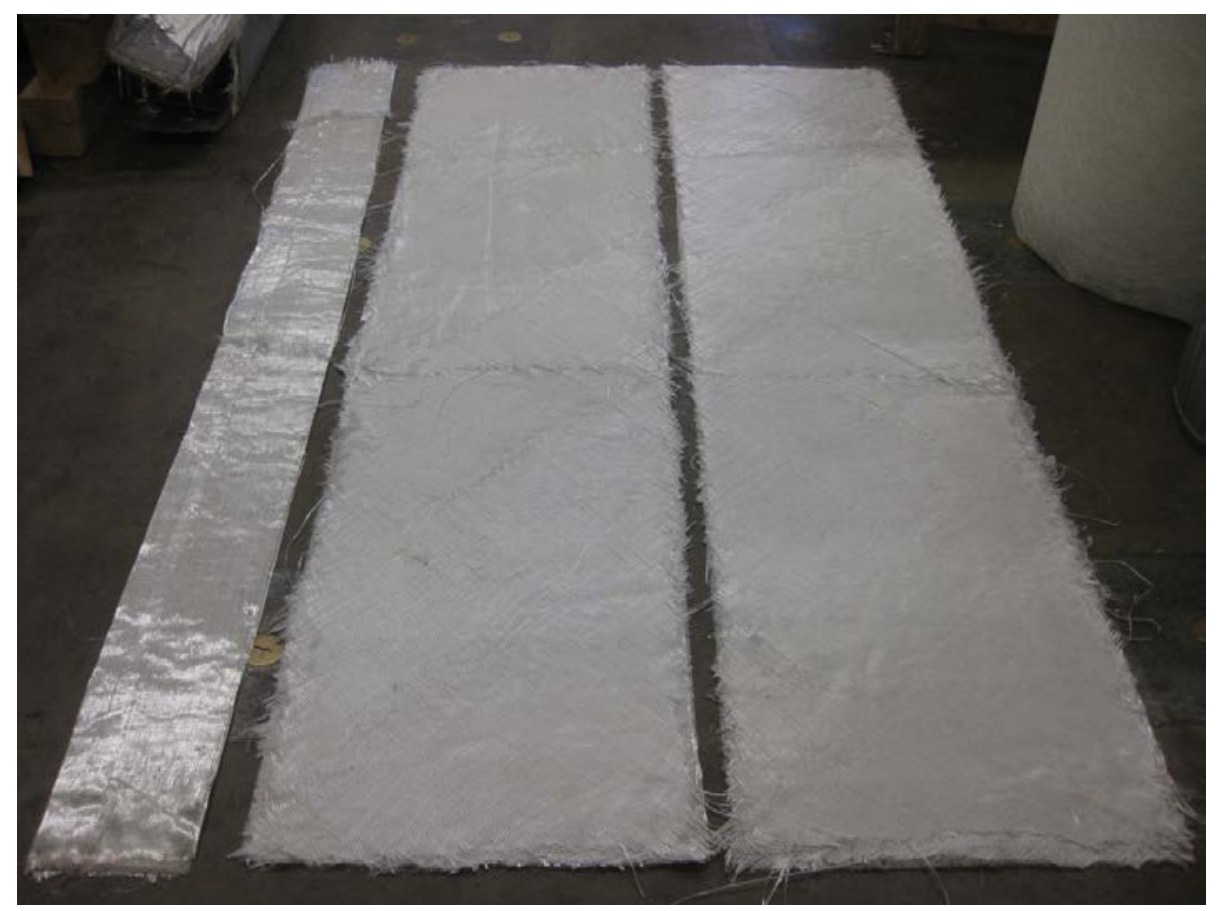

Figure 3-9: Fabric configuration used to manufacture composite parts 
Table 3-4: Physical Properties of Composite Parts on all Sides

\begin{tabular}{|c|c|c|c|c|c|}
\hline $\begin{array}{c}\text { Fiber/Fabric } \\
\text { Configuration }\end{array}$ & $\begin{array}{c}\text { Thickness of } \\
\text { shell (inch) }\end{array}$ & Rovings & CSM & $\begin{array}{c}\text { Weight of } \\
\text { Resin (lbs/yd } \mathbf{d}^{\mathbf{2}} \text { ) }\end{array}$ & $\begin{array}{c}\text { Fiber volume } \\
\text { Fraction }\end{array}$ \\
\hline First Configuration & 0.75 & 15 Layers & 4 Layers & 32.75 & $10 \%$ \\
\hline
\end{tabular}

\subsubsection{Wood core Preparation}

White oak wood was used as wood core for GFRC-wood ties. The dimension of each sample was 6.5in $\mathrm{x}$ 7.5in x 102in. Two wood cores of different dimensions were used to make two different composite parts. Wood core was planned to the required dimensions by using Wood Planner machine to make the composite parts fit to it. Wood core used to make inner composite part has the dimension of 6in x 6.5in $\mathrm{x}$ 102in and the wood used to make outer composite part has the dimension of 6in x 7in x 102in.

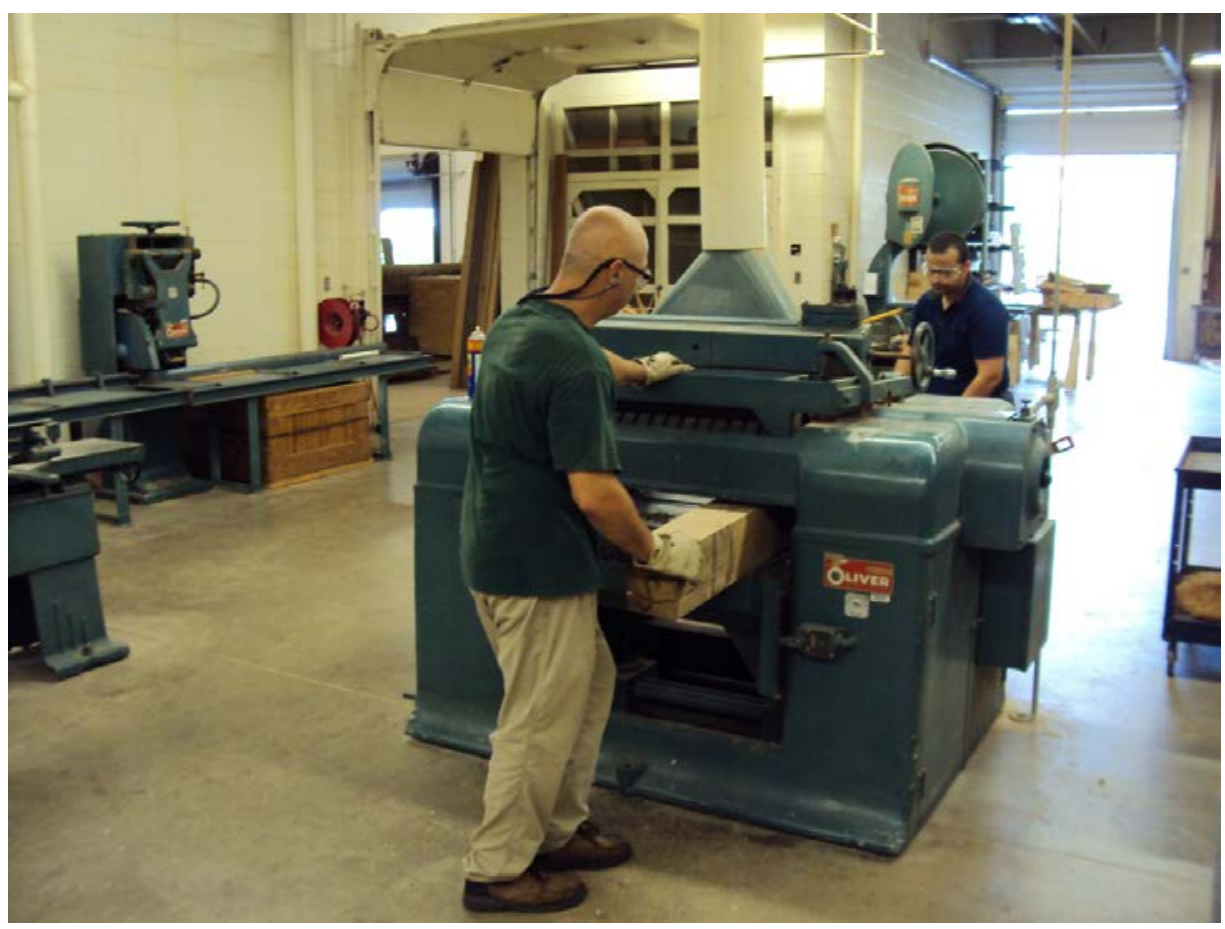

Figure 3-9: Planing of Tie using Planner 


\subsubsection{Molding over releasing agent}

A releasing agent was applied to the mold to release the composite part without any damage. Oil was used as a releasing agent. The releasing agent was used to avoid air gaps between the mold and the composite part.

On the 27 in $x$ 102.5in smooth surface of the mold, oil was sprayed to put aluminum foil on. Then the demolding agent was sprayed on aluminum foil which releases the part from the aluminum foil when it is hardened. The demolding agent used was Tech-lube 25 from Technick products. The top plate of 26in $\mathrm{x}$ 102.5in was also sprayed with oil to put aluminum foil and demolding agent was sprayed on it.

\subsubsection{Preparing the mold for heating}

The heaters were attached to the mold and the top plate. After the releasing agent was sprayed, the fabric and resin were laid up in the mold. The top plate is placed carefully using the crane without spoiling the foils. Then two I beams were placed on the top of the top plate as the hydraulic jack could not reach the mold which was placed on the floor. Once the mold was ready for heating, the complete set up was heated carefully by the heaters. The heating temperature maintained was $400^{\circ} \mathrm{F}$. The load was applied using hydraulic jack to close the mold. The heaters were checked using the temperature gun to make sure that all the heaters are working properly. After the heaters are checked, the mold was covered with insulation for not letting the heat to escape. Once these steps have been completed, the mold was carefully watched at thirty minutes intervals and the load was increased when the resin started to melt. Initially the mold was heated for one hour without loading and then load was applied at a rate of 7 kips per hour. The molten resin starts flowing in to the fabric layers when the mold was compressed. Excess resin flows out, reducing voids so that the part emerges smooth on both sides. The heating process was carefully monitored for 4 hours. 


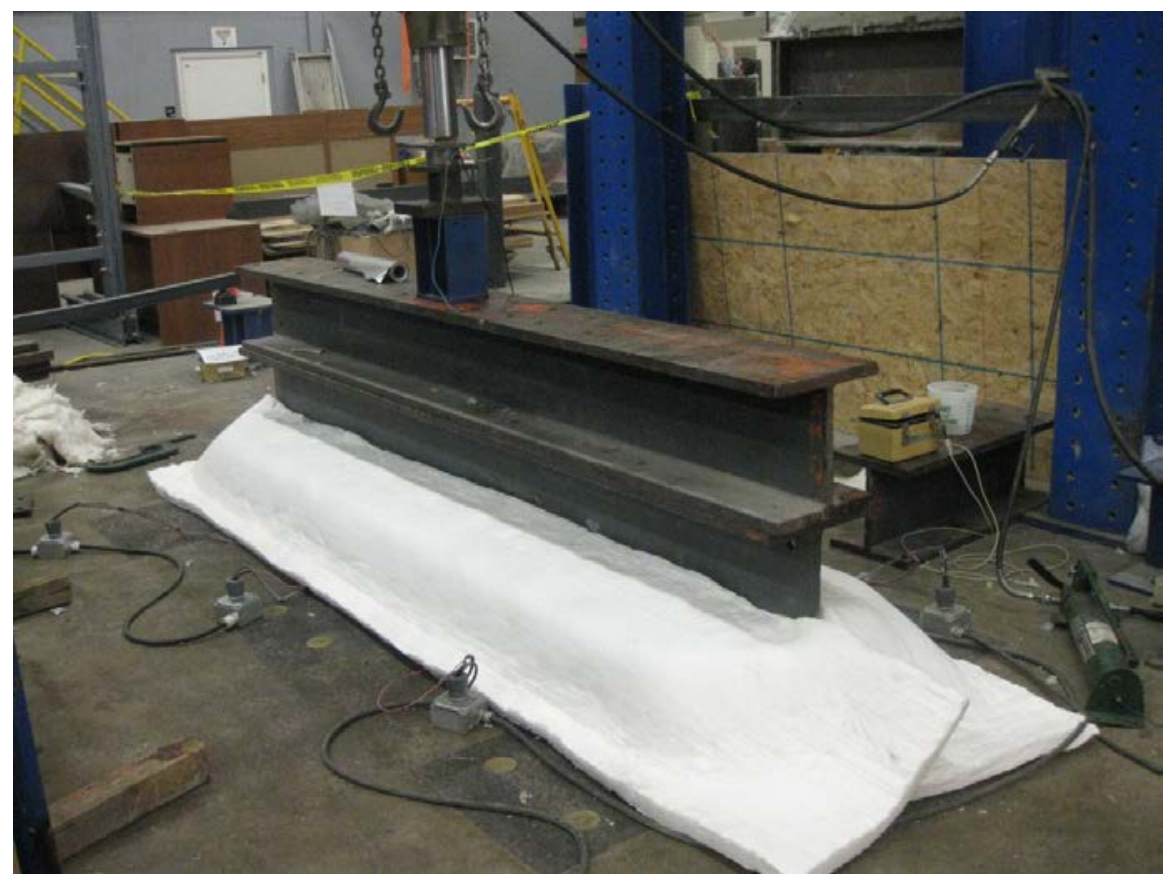

Figure 3-10: Mold setup during the heat process

\subsubsection{Releasing of the part from the mold}

After heating for 4 hours, it was stopped and the load was released slowly. The insulation was removed carefully from the top and sides of the mold. Before the mold gets cooled, the two I-beams were removed carefully using the crane. The screws from two ends of the mold were taken out and the release wedges were used to release the end plate from the mold. The top plate was lifted and placed carefully using the crane when the resin was soft. The wood core of required dimension was placed on the middle of the mold. Once these steps have been made, two divisions of the mold were lifted slowly and clamped with the C-clamps to acquire the required dimension of the composite part with the wood core inside it. The wedges were inserted around the perimeter of the middle part of the mold and gently tape them into the place, progressing evenly around the edges. Slowly the mold and the composite part with the wood core would separate out without interlocking. 


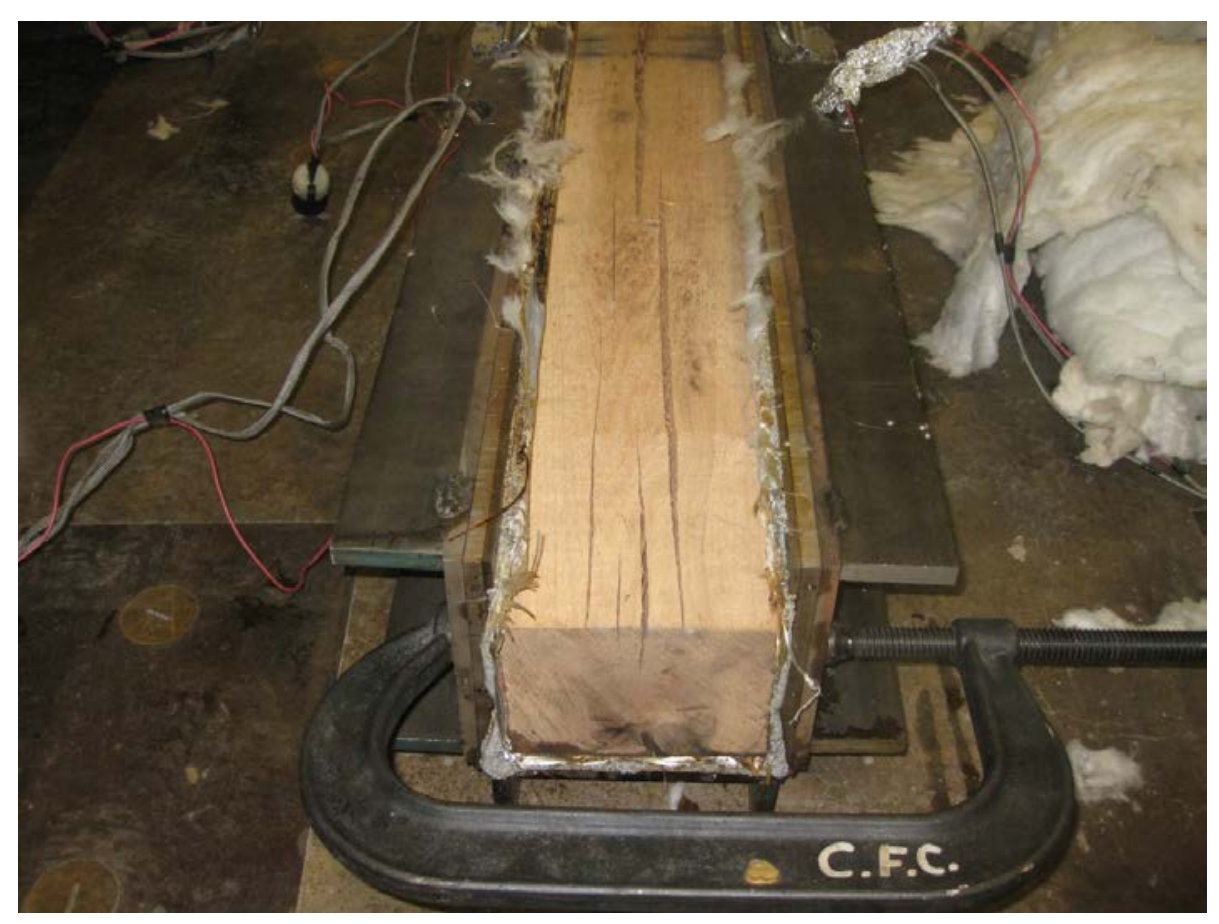

Figure 3-11: Folded mold clamped with the C-Clamp

\subsubsection{Preparing the mold for the next composite part}

Once the composite part was separated from the mold, the surface was cleaned and looked for serious defects. The wedges were inserted around the perimeter of the wood core and gently tape them into place, progressing evenly around the edges. Eventually the part and the wood core will separate. The problems would be typically, the mold releasing agent releases the texture behind which are easily removed by using a wedge, the broken screws would appear in the ends of the mold which are replaced with a new set of screws, and the heating wires would appear broken to be fixed for next production round. Any of these problems could give the awkward shape of the parts. These problems were overcome before preparing the mold for the next composite part. 


\subsection{Manufacturing of End Caps}

\subsubsection{Description of compression molding}

After encapsulating a wood tie with the side composite parts (Figure 3-21), it was also much necessary to encapsulate it on the ends. Two end composite parts of same dimensions were used to encapsulate each wood tie. Compression molding process was used to manufacture end composite parts. A steel mold was constructed and placed in the open heated mold cavity for manufacturing the required shape of the end composite parts. 5/8in thick steel plates were used to construct this mold with the inner dimensions of 6.75in x7.5in x3in for manufacturing. The dimensions were reduced to 6.5in $x 7$ x3in for second procedure of manufacturing. A solid aluminum material of 6.5in x7.25in x3in was used to compress the composite material in the steel mold for the first procedure of manufacturing. The dimensions were reduced to 6.25in x 6.75inx 3in for second procedure of manufacturing.

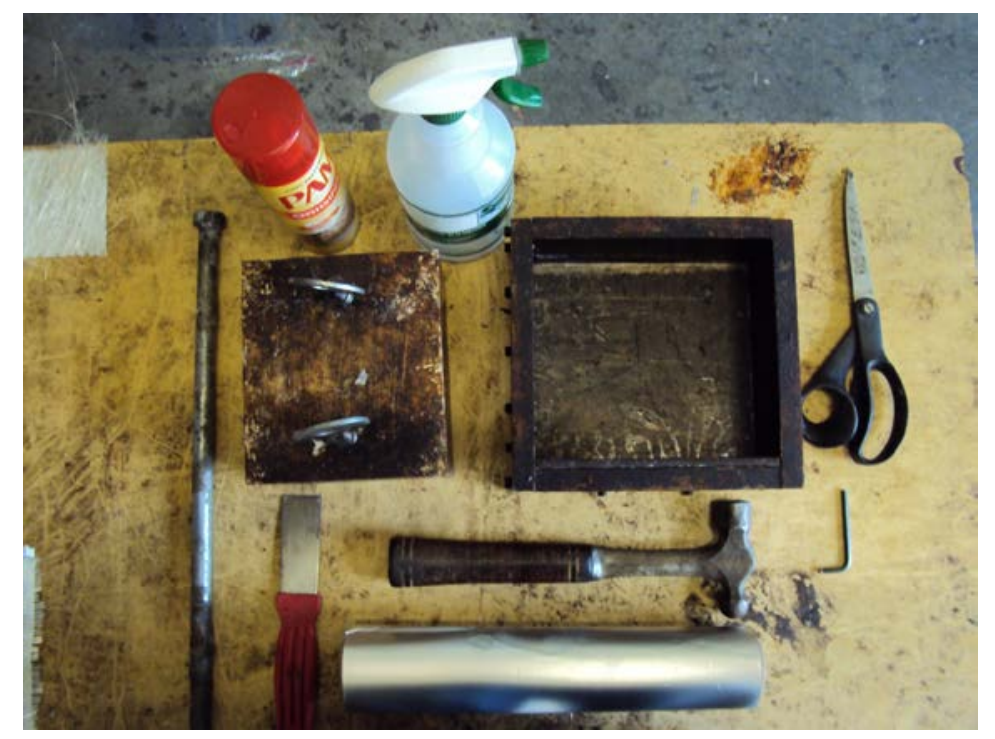

Figure 3-12: Required tools including male and female mold

The ABS thermoplastic was compression molded with continuous strand mat fibers to manufacture the glass fiber reinforced end composite part. The end product has easy tendency to release with the required shape of the part. 


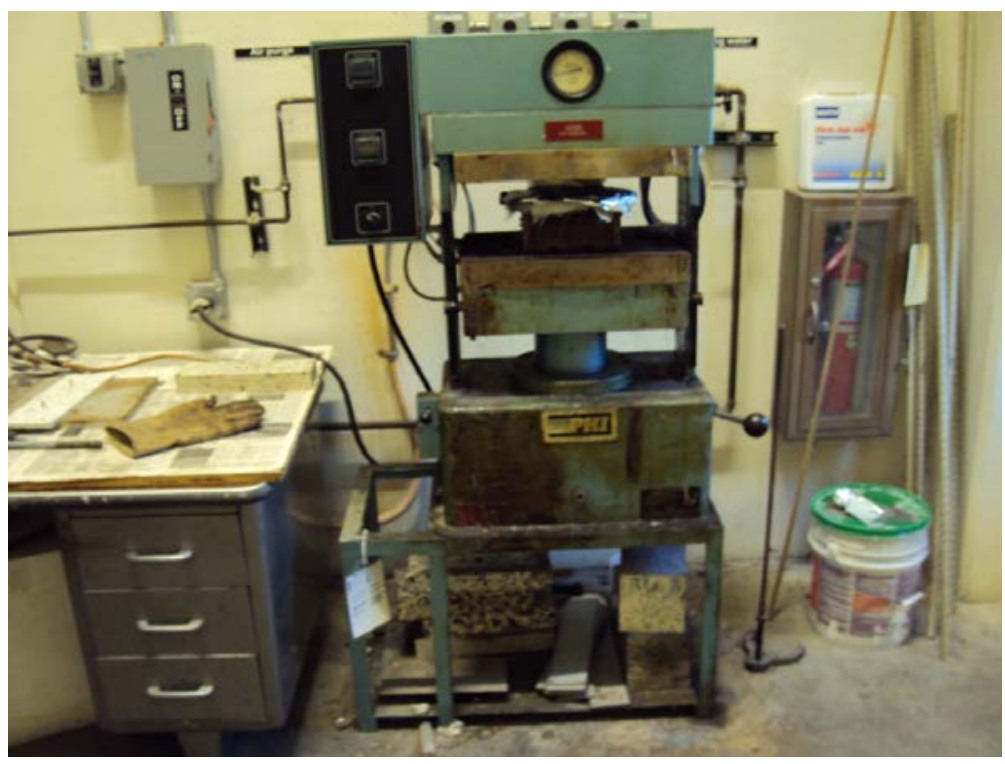

Figure 3-13: Compression Molding Machine

\subsubsection{Fiber volume fraction}

6 Continuous strand mat $=9 \mathrm{oz} / \mathrm{sq}$ yd

Total Density $=54$ oz/sq yd

Total volume of composite part $=1 / 4 * 36 * 36=324 \mathrm{in}^{3}$

Glass fiber specific gravity $=2.54 \mathrm{gm} / \mathrm{cc}=0.091763 \mathrm{lb} / \mathrm{in}^{3}$

Fiber volume $=54 / 16 * 1 / 0.091763=36.779$ in $^{3}$

Fiber volume fraction $=$ fiber volume/total volume $=36.779 / 324=0.11=11 \%$

Resin volume $=324-36.779=287.22 \mathrm{in}^{3}$

Resin specific gravity $=1.04 \mathrm{gm} / \mathrm{cc}=0.037572 \mathrm{lb} / \mathrm{in}^{3}$

Weight of resin $=0.037572 * 287.22=10.79 \mathrm{lbs} / \mathrm{sq}$ yd 
Table 3-5: Physical Properties of End Cap

\begin{tabular}{|c|c|c|c|c|c|}
\hline $\begin{array}{c}\text { Fiber/Fabric } \\
\text { Configuration }\end{array}$ & $\begin{array}{c}\text { Thickness of } \\
\text { shell (inch) }\end{array}$ & Rovings & CSM & $\begin{array}{c}\text { Weight of } \\
\text { Resin (lbs/yd } \mathbf{d}^{\mathbf{2}} \text { ) }\end{array}$ & $\begin{array}{c}\text { Fiber volume } \\
\text { Fraction }\end{array}$ \\
\hline First Configuration & 0.25 & NA & 5 Layers & 10.79 & $11 \%$ \\
\hline
\end{tabular}

\subsubsection{Molding over releasing agent}

Oil was sprayed to put aluminum foil on the 6.75in x7.5in x3in inner surface to release the part when it was hardened. Then the demolding agent was sprayed on aluminum foil which would release the part from the aluminum foil when it was hardened. The demolding agent used was Tech-lube 25 from Technick products. The aluminum plunger was also sprayed with oil to put aluminum foil and demolding agent was sprayed on it.

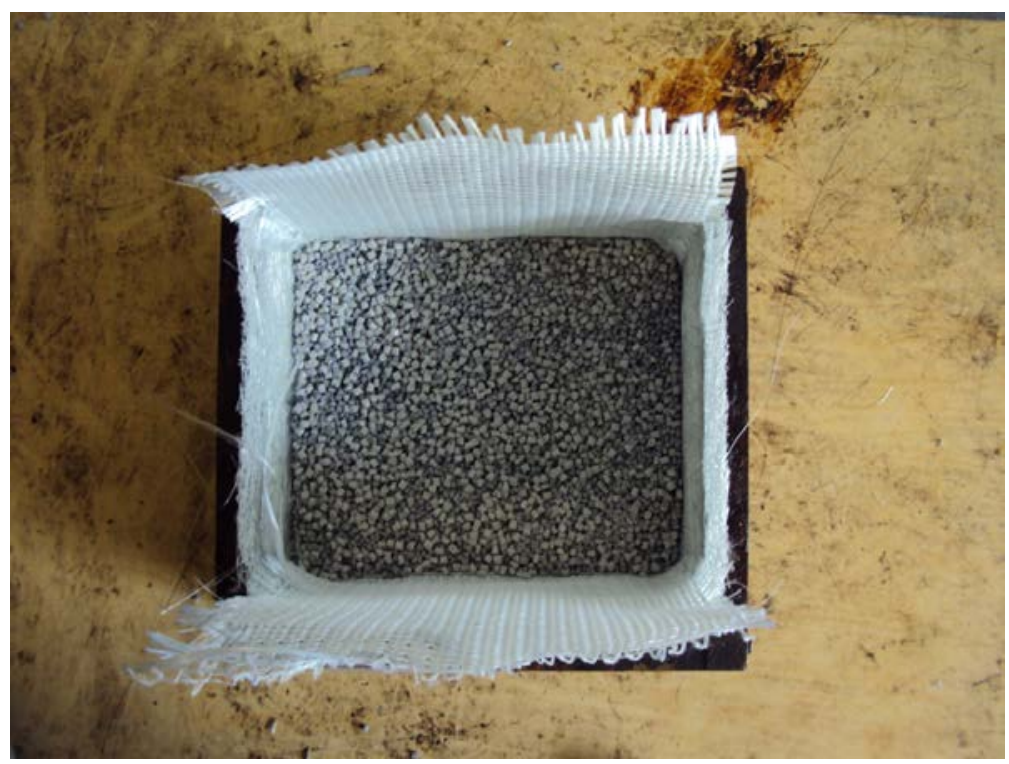

Figure 3-14: Fabric and Resin Layup in the male mold

\subsubsection{Preparing the mold for heating}

After the demolding agent was sprayed, the fabric and resin were laid up in the mold. The aluminum plunger was placed carefully using the two holding screws without spoiling the foils. Then the whole set was placed in open heated mold cavity. Once the mold was ready for heating, the compression molding machine was set at $300^{0} \mathrm{~F}$. It is preheated for 15 minutes with no force on it. Then the heating temperature 
was increased to $400^{\circ} \mathrm{F}$. Once these steps have been completed, load was applied with a plunger to force the excess resin to flow out of the mold, while heat and load were maintained until the molding material gets cured. By pressing the mold with the aluminum plunger, excess resin was flowed out, after retaining the composite part with perfect shape for the inner surface of the mold.

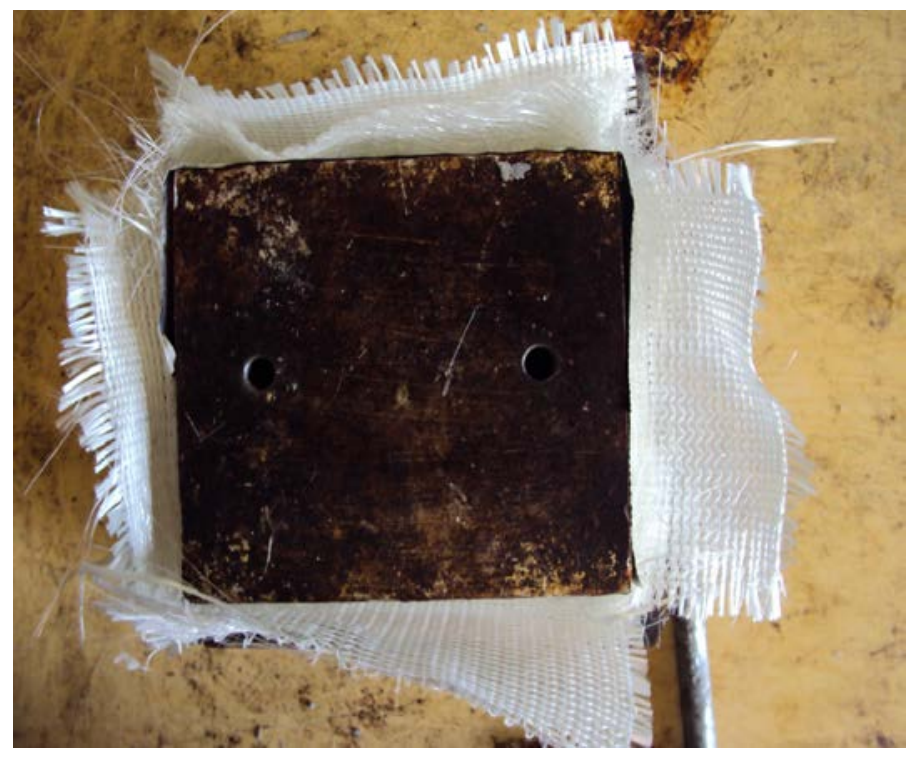

Figure 3-15: Inserting female mold in the male mold

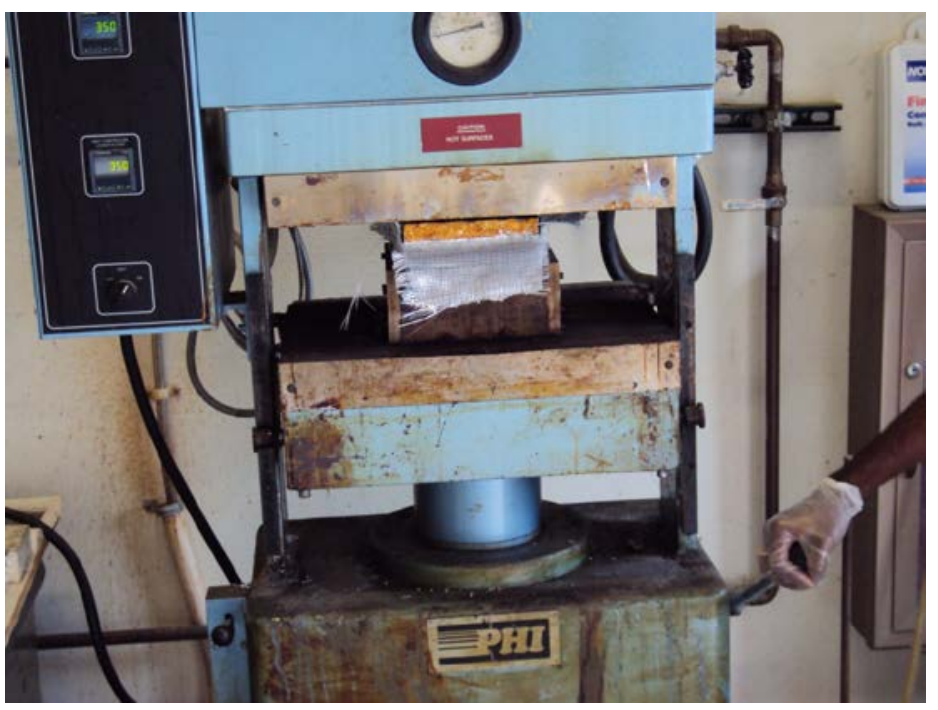

Figure 3-16: Compressing the mold in Compression Molding Machine 


\subsubsection{Part release from the mold}

Once the heating and pressure were processed for 50 minutes, the heating was stopped and the cooling water purge was turned on to cool the heating plates. The screws from one side of the mold were taken out and the release wedges were used to release the composite part along with aluminum plunger from the mold. Then the wedges were inserted around the perimeter of the composite part and gently tapped them into the place, progressing evenly around the edges. Slowly the aluminum plunger and the composite part got separated.

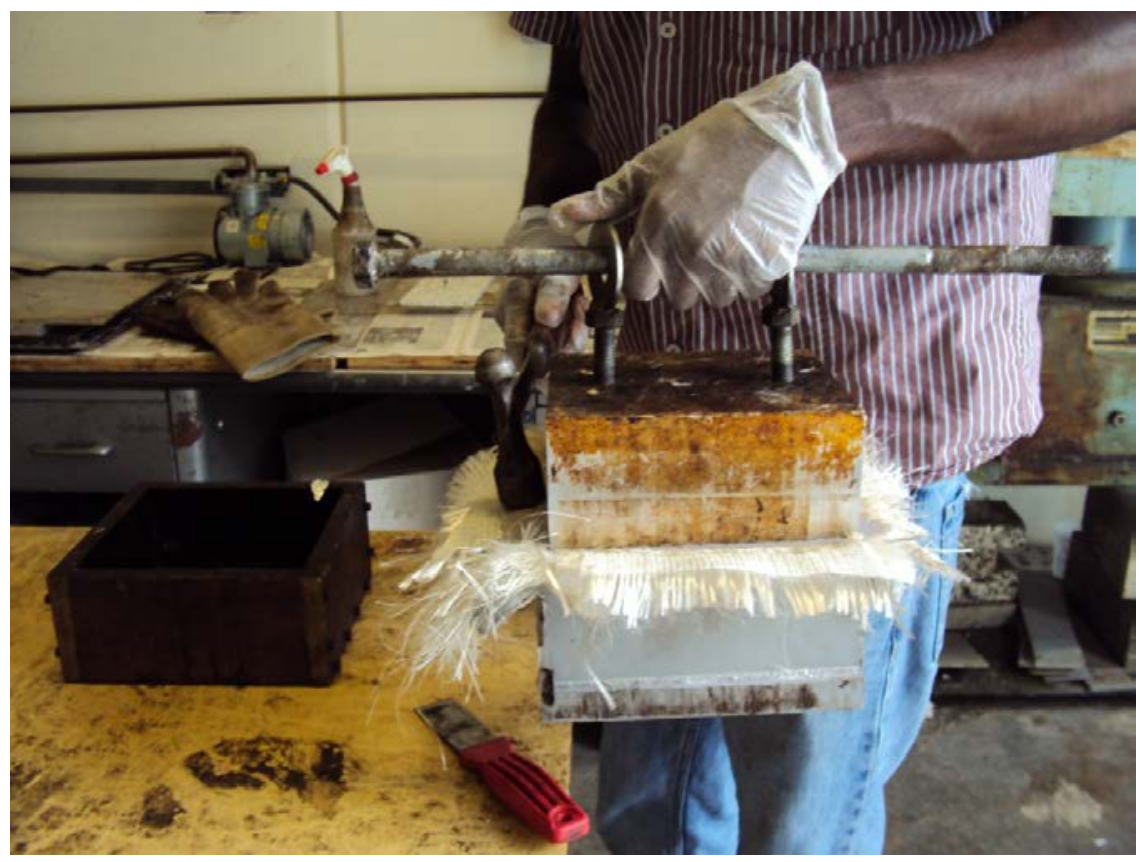

Figure 3-17: Releasing the part from the Aluminum plunger

\subsubsection{Preparing the mold for the next composite part}

Once the composite part was separated from the mold, the surface was cleaned and looked for any serious defects. Typically problems would be: mold releasing agent leaves the texture behind which are easily removed by using a wedge, broken screws would appear in the ends of the mold which are replaced with the new screws, and the heaters wires would appear broken which are fixed using screwdriver. Any of these problems could result in awkward shape of a part. These problems are taken care of before preparing the mold for the next composite part. 


\subsection{Manufacturing of Full Scale Tie}

\subsubsection{Description of compression type mold}

A full scale steel mold was constructed to manufacture full scale tie by encapsulating wood tie using composite parts. The encapsulated wood tie was placed in the compression molding press which molds the molten material into full scale GFRP-composite tie. Twelve composite parts were used to encapsulate the wood tie in manufacturing process-I and two composite parts were used to encapsulate a wood tie in manufacturing process-II. The steel mold has been designed to produce the end product with the dimensions of 7in x 9in x 102in. This mold has the tendency to produce smooth surface on all the sides of the end product. For this compression molding process, the better the heat and pressure is maintained, the proper bond between the wood and the FRP material would occur. The outer dimensions of the outside mold were 105.5in x 10in x 9.75in and the inside mold were 102in x 8.625in x 3.5in.

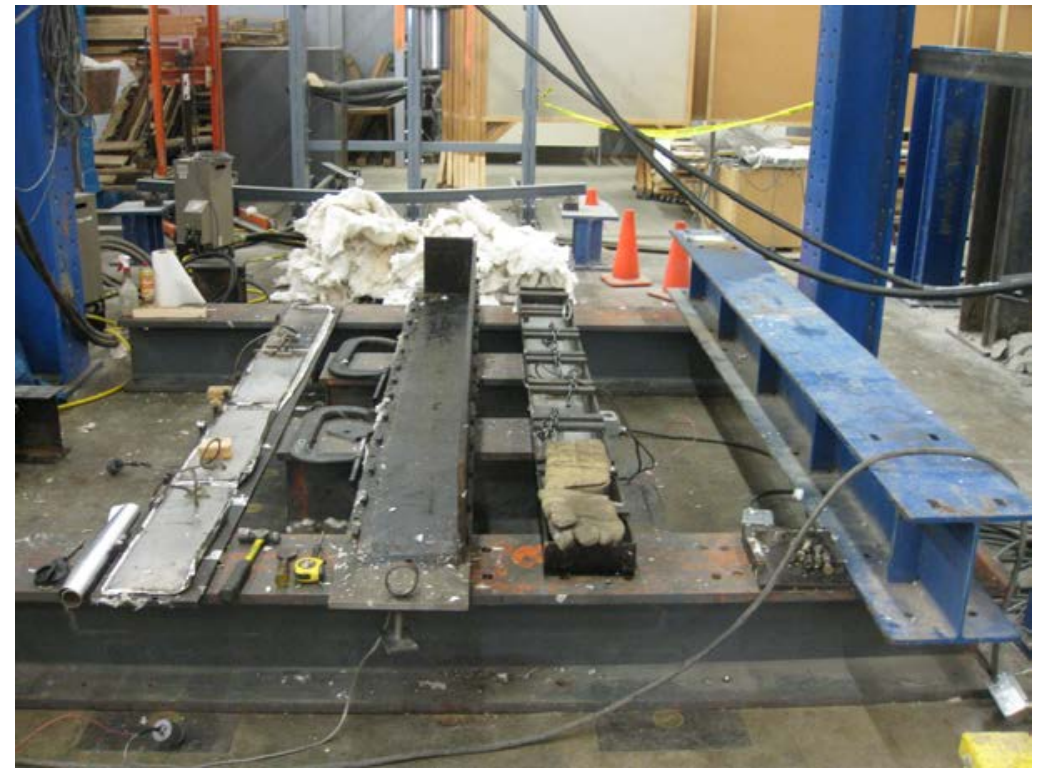

Figure 3-18: Required tools including top and bottom mold

\subsubsection{Molding over releasing agent}

One of the side plates was separated from the mold to put the encapsulated wood tie inside the mold. The side plate and the inner smooth surface of the mold were sprayed with oil to put aluminum foil. Then the 
aluminum foil was sprayed with demolding agent which releases the part when it gets hardened. The top plate was also sprayed with oil before placing aluminum foil and spraying demolding agent.

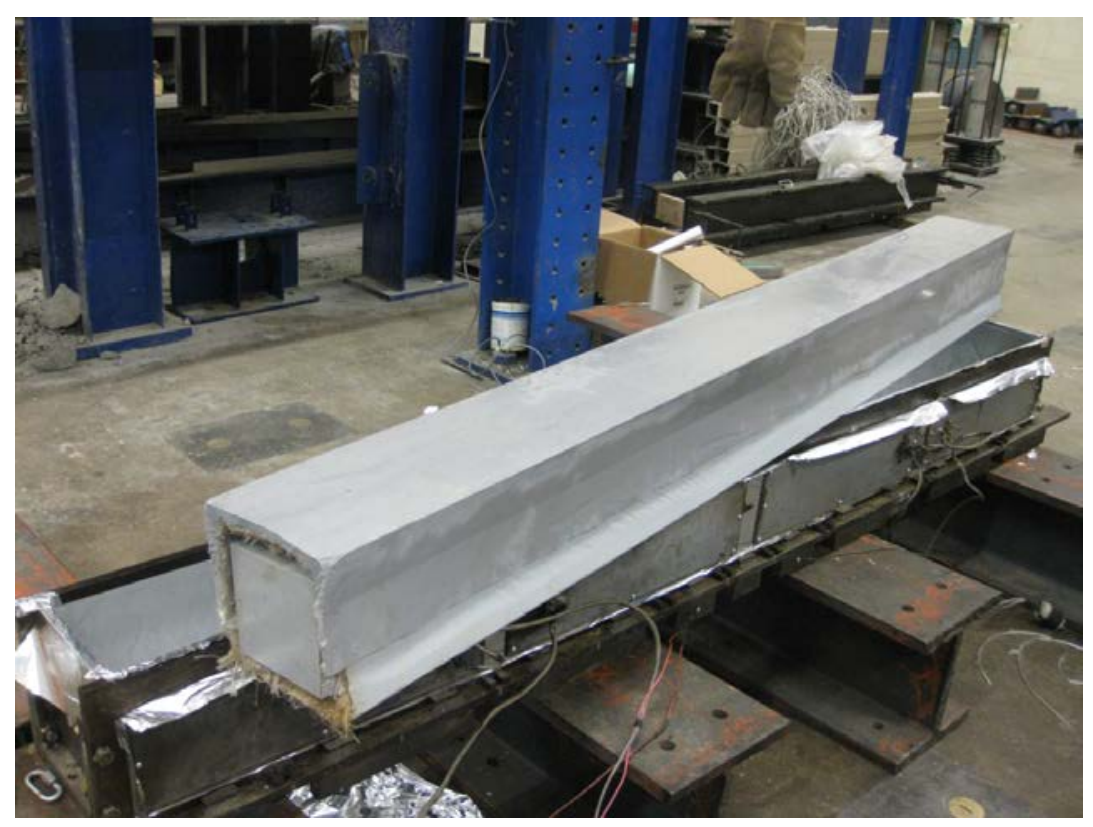

Figure 3-19: Wood core encapsulated with composite parts

\subsubsection{Preparing the mold for heating}

After the releasing agent was sprayed, the encapsulated wood tie was placed in the mold. The top plate was placed carefully on the top of the specimen without ruffling the foils. An I-beam was placed on the top of top plate as it distributes the load evenly along the length of the specimen. Once the mold was ready for heating, the thermoplastic (ABS) pellets were preheated for one hour. The heating temperature was maintained above the melting point of ABS. The load was applied using hydraulic jack to close the mold. After the heaters were turned on, the mold is covered with insulation for not letting the heat to escape. During the heating process, the heaters were checked using the temperature gun to make sure that all the heaters were working properly. Once these steps have been completed, the mold was carefully watched at every half an hour intervals and the load was increased when the resin started to melt. The heat and pressure were maintained until the molding material has cured. The molten resin starts flowing in to 
the fabric layers when the mold is compressed. Excess resin flows out, voids are reduced and the part emerges smooth on all sides. The heating process was carried for 4 hours.

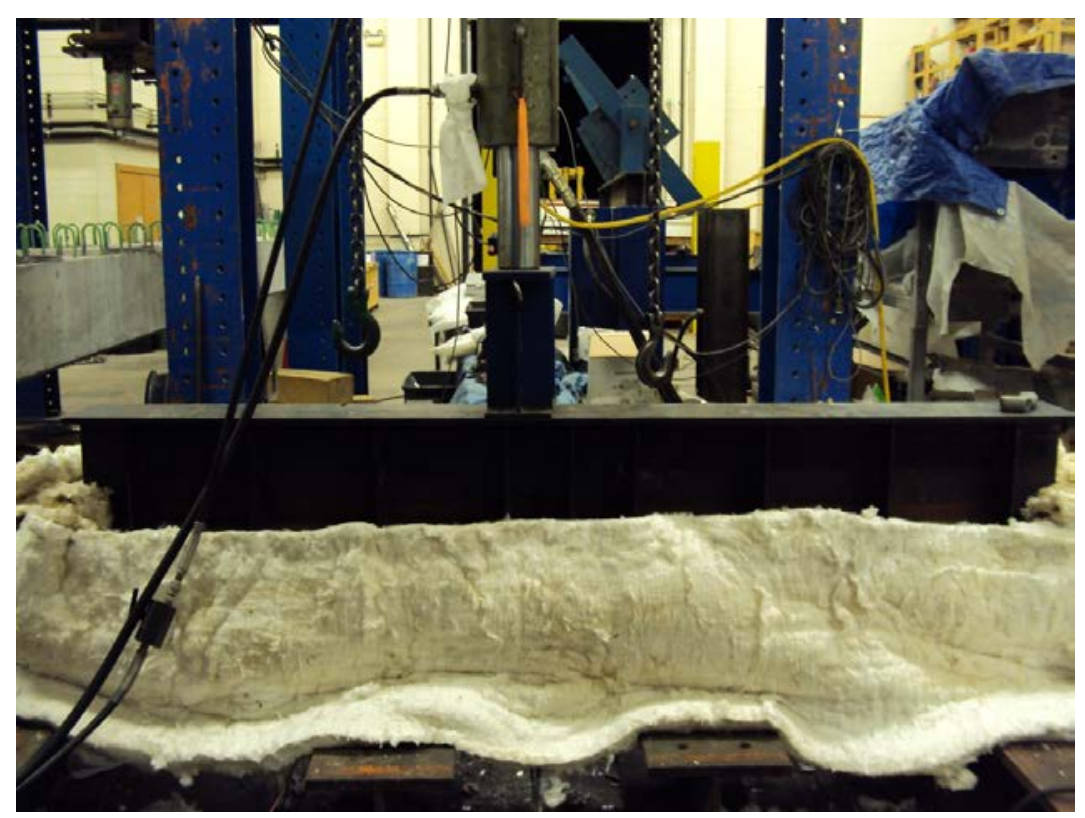

Figure 3-20: Full Scale mold setup during the heat process

\subsubsection{Releasing of the tie from the mold}

Once the heating is processed for 4 hours, the heating must be stopped. The mold was cooled for at least another 4 hours. The insulation was removed carefully from the top and sides of the mold. The screws from one side of the mold are loosened and one of the side plates was removed carefully using the crane. The wedges were inserted around the perimeter of the mold and were gently tapped them into the place, progressing evenly around the edges to release the tie from the mold. Slowly the part and the mold were separated. 


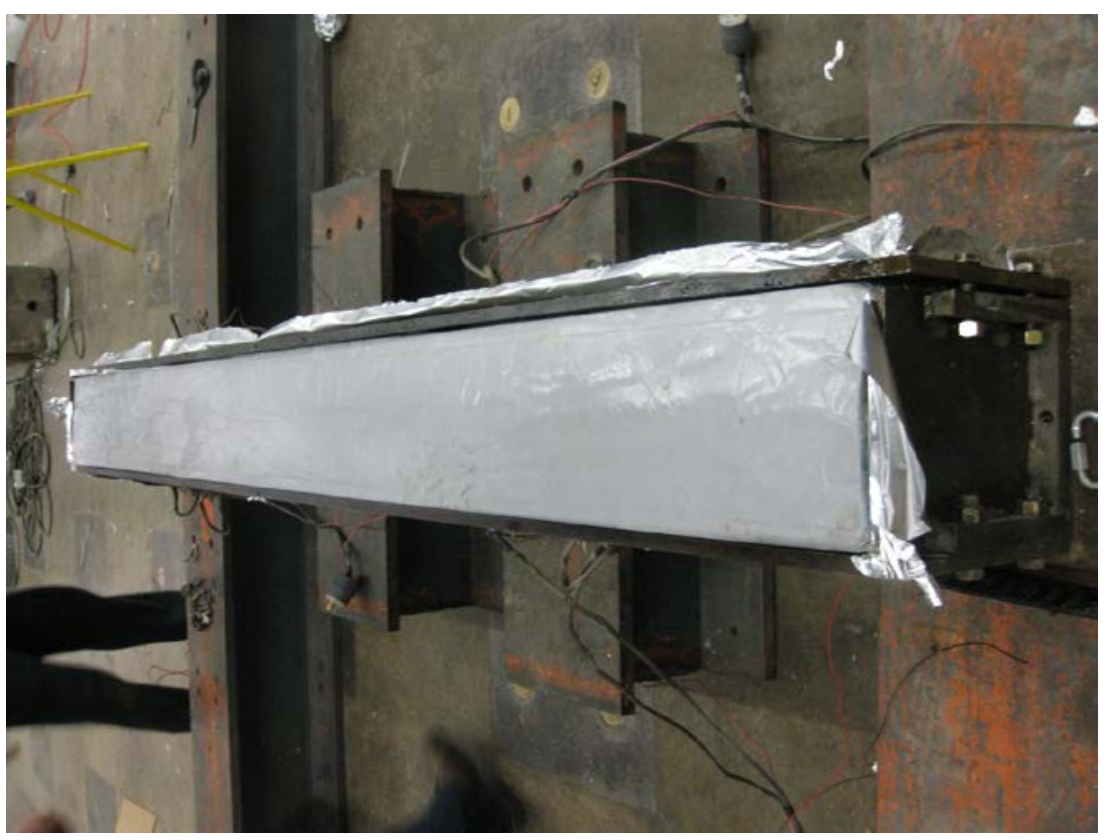

Figure 3-21: Releasing the tie from the mold

\subsubsection{Preparing the mold for the next composite tie}

Once the composite tie was separated from the mold, the surface was cleaned and evaluated for any serious defects. The problems would be typically, the mold releasing agent leaves the texture behind which can be easily removed using a wedge, the broken screws would appear in the parting planes which are replaced with the new screws and the heaters wires would appear broken which are fixed using screwdriver. Any of these problems could give the awkward shape of the parts. These problems are taken care of before preparing the mold for the next composite tie. 


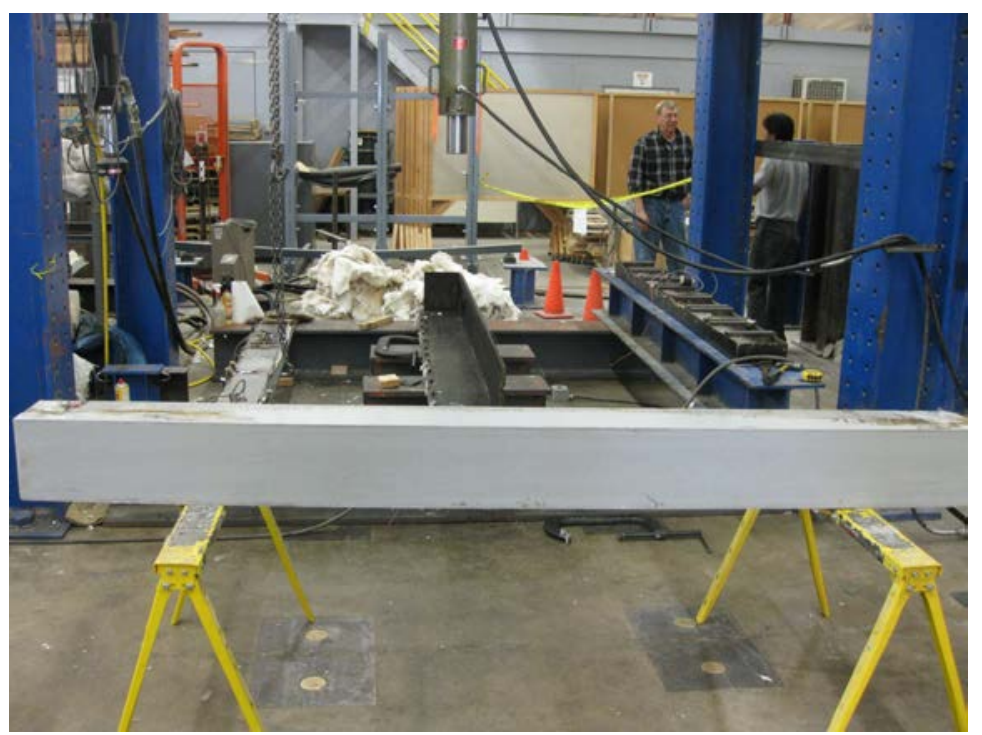

Figure 3-22: Manufactured Recycled GFRP-Composite tie

\subsection{Recycled GFRP-Composite tie}

These Composite ties are perfect rectangular shape with no indentations on any side of the part. Each tie weighed $225 \mathrm{lbs}$ which is less than all the other polymer composite ties that are being manufactured in the United States. In the manufacturing process-I, four ties were manufactured with first configuration and two ties were manufactured with second configuration. All these ties were tested under static three point bending with simply supported boundary conditions and were field implemented in South Branch Valley Railroad (SBVR-WV DOT), Moorefield, WV. Preliminary field test results of recycled GFRP composite ties were reported (Chapter 8).

In the manufacturing process-II, three ties were manufactured with first configuration. Two of these ties were tested under Static three point bending loads with simply supported boundary conditions. Fatigue test was conducted up to 2 million cycles using ballast support for the third tie. 


\section{THREE POINT BENDING TESTS \& COMPARISON OF FLEXURAL RIGIDITIES}

\subsection{Introduction}

Recycled Composite ties with two different fiber/fabric configurations (Table 3-3) were laboratory tested to determine the material and strength properties in this study. Tie stiffness depends on the fiber configuration and the wood core size. Fiber volume fraction of ties varied with the thickness of composite material on each side of the tie. The change in the fiber configuration (Table 3-3) was made to increase the strength properties of the Recycled ties. The size of the wood core changed with respect to the thickness of the composite material on each side of the tie. All the recycled composite ties which were tested had identical dimensions (9in x 8.5in x 102in). Measured wood moisture content in the wood of every recycled composite tie ranged from $12-18 \%$ on the outer surface and $30-40 \%$ in the inner surface. Three point bending tests were conducted to determine the flexural rigidity. The mechanical properties of a tie with one fiber configuration were used to compare with the other fiber configuration. The load was kept to a minimum to prevent any damage.

\subsection{Objective}

The objective was to test and evaluate the flexural rigidity of all full scale ties under three point bending test.

\subsection{Scope}

Three point bending tests were conducted on six full scale Recycled GFRP-Composite ties made from manufacturing process-I. All specimens were load tested to determine the properties such as flexural rigidity and shear modulus. These specimens were spanned at 90 in. Initially, the three point static bending test was conducted by applying a concentrated load of 2 kips at the mid span of the recycled composite tie. Strains and deflections at mid span were measured for each test case. 
Table 4-1: Description of specimen and fabric configuration

\begin{tabular}{|c|c|c|c|}
\hline $\begin{array}{c}\text { Recycled Composite } \\
\text { Ties }\end{array}$ & $\begin{array}{c}\text { Manufacturing } \\
\text { Process-I }\end{array}$ & $\begin{array}{c}\text { Fabric } \\
\text { Configuration }\end{array}$ & Number of Layers \\
\hline Tie \#1 & \multirow{3}{*}{$\begin{array}{l}\text { First configuration } \\
\text { (Table 3-2) }\end{array}$} & \multirow{3}{*}{$0^{0} / 90^{0}$} & \multirow{3}{*}{15} \\
\hline Tie \#2 & & & \\
\hline Tie \#4 & & & \\
\hline $\begin{array}{l}\text { Tie \#5 } \\
\text { Tie \#6 }\end{array}$ & $\begin{array}{c}\text { Second configuration } \\
\text { (Table 3-2) }\end{array}$ & $0^{0} / 90^{0} / \underline{+45^{0}}$ & 20 \\
\hline
\end{tabular}

\subsection{Test Description}

All testing equipment was provided by WVU-CFC. The concrete supports have a steel round stock fixed at the top to rest the specimen on it. The supports were spaced 90in apart with an overhang of 6in of the tie on each support. The hydraulic jack was connected to the hydraulic pump and was clamped to the steel frame. The hydraulic jack was spaced at a distance of 45in from both the supports. The load was applied to the center of this specimen.
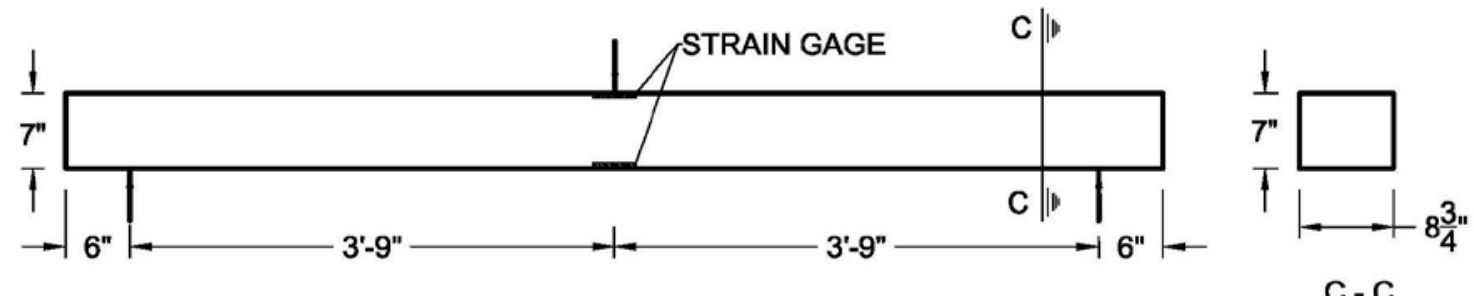

Figure 4-1: Cad Drawings of Three Point Bending Test 


\subsection{Instrumentation}

Load versus bottom strains and deflection at the center of the specimen were measured. The electrical strain gage was placed at the midspan of each specimen. This position was chosen to measure the maximum tensile strain. An LVDT was placed at the mid-span of a specimen to measure deflection. Load cell was placed on the specimen at the mid-span to measure the load. The strain smart software program was used to collect load versus strain and deflection using data acquisition system. Data was collected under static loading of 2 kips.

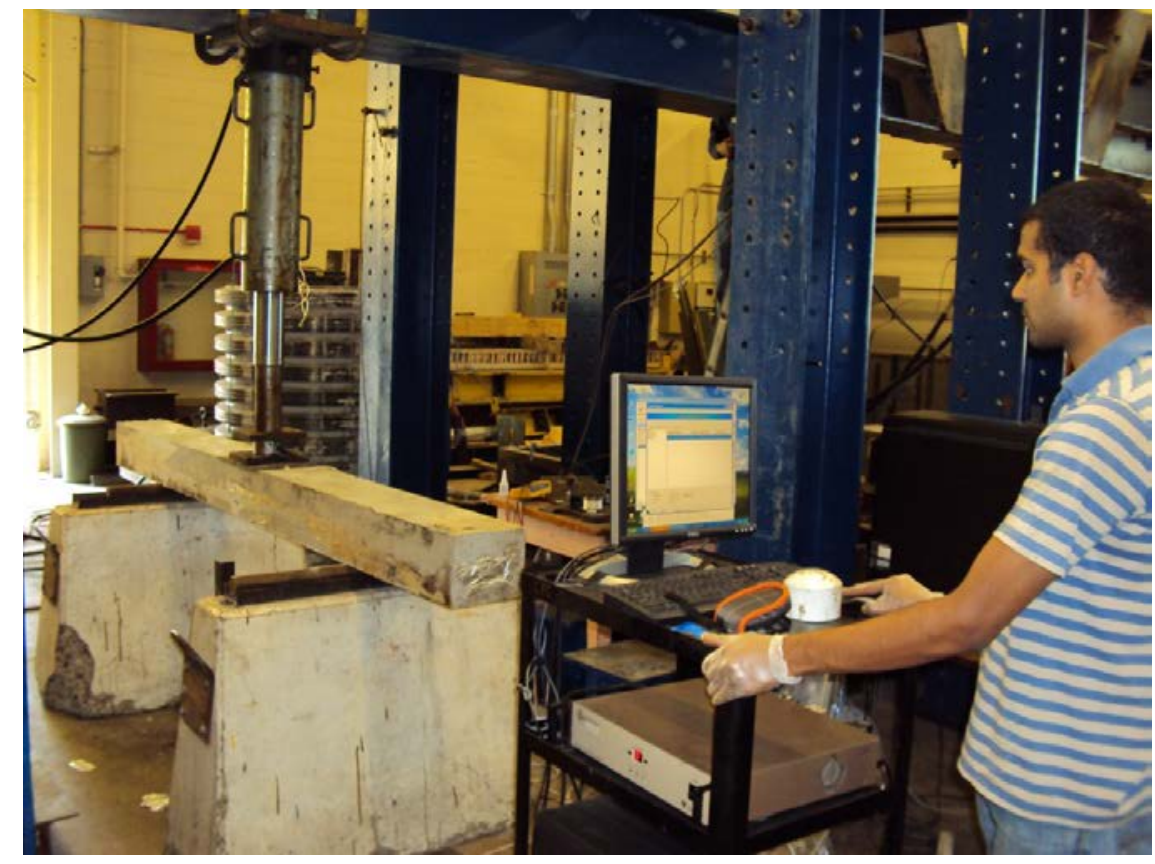

Figure 4-2: Instrumentation for Three Point Bending Tests

\subsection{Test Procedure}

The following test procedure was followed for all the test samples. First, the strain gage, load and LVDT were zeroed using the strain smart software of the Data Acquisition System. The sample was placed at a distance of 21 in from the end of the samples at the supports. It was then centered to the hydraulic jack by moving the sample on the supports. The load cell was kept on the top of the sample and the LVDT was 
arranged at the bottom of the mid span. The load cell was placed at the center of the recycled composite tie. Then a load of 2 kips was applied using the hydraulic jack. The load versus strain and deflection were collected. The procedure was repeated if any problems (such as collecting strain data, connections between strain gage and data acquisition system or between LVDT and data acquisition system) occur during the test.

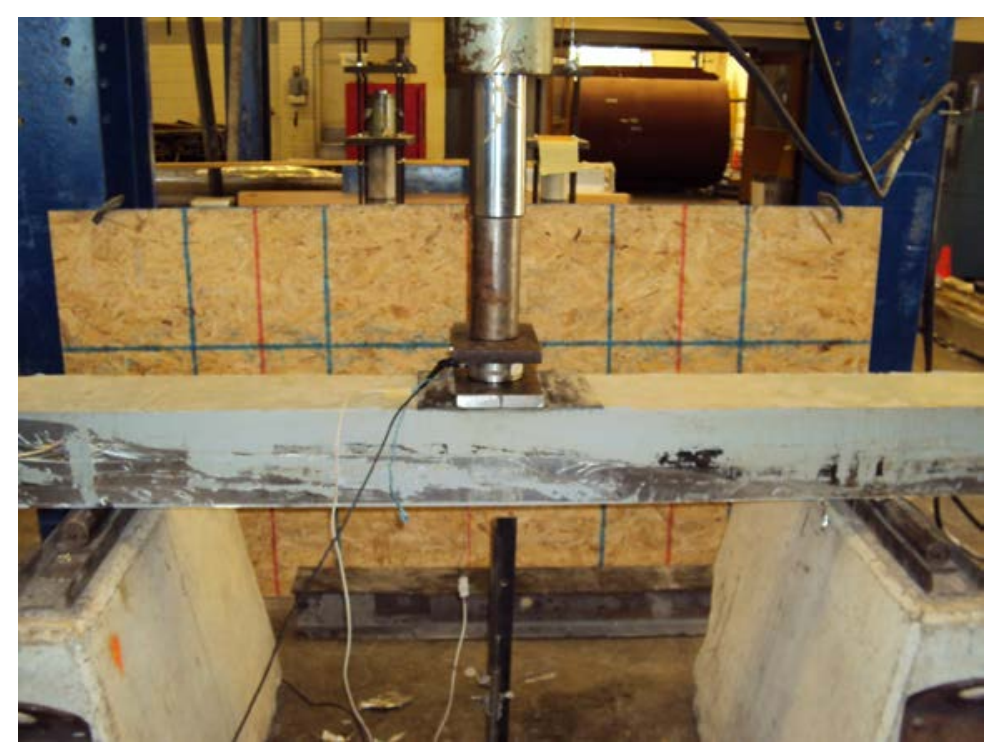

Figure 4-3: Three Point Bending Test Setup

\subsection{Sectional Properties}

The dimensions of the manufactured recycled composite ties are shown in Table 4-2. The transformed moments of inertia were calculated for first and second configurations recycled composite ties and are shown in Table 4-3.

Table 4-2: Recycled Composite Tie Dimensions

\begin{tabular}{|c|c|}
\hline Sample Dimensions & Recycled Composite Tie \\
\hline Length (in) & 102 \\
\hline Width (in) & 8.75 \\
\hline Depth (in) & 6.78 \\
\hline
\end{tabular}




\subsubsection{Calculations of Transformed Moment of Inertia ( $I_{\text {transformed }}$ )}

Elastic Modulus of Glass Fibers ( $\mathrm{E}_{\text {Glass Fibers }}$ ) from Table 3-1

$\mathrm{E}_{\text {Glass Fibers }}=10.6 \times 10^{6}$ Psi

Elastic Modulus of ABS ( $\left.\mathrm{E}_{\mathrm{ABS}}\right)$ from Table 3-1

$\mathrm{E}_{\mathrm{ABS}}=0.4 \times 10^{6} \mathrm{Psi}$

\section{First Configuration}

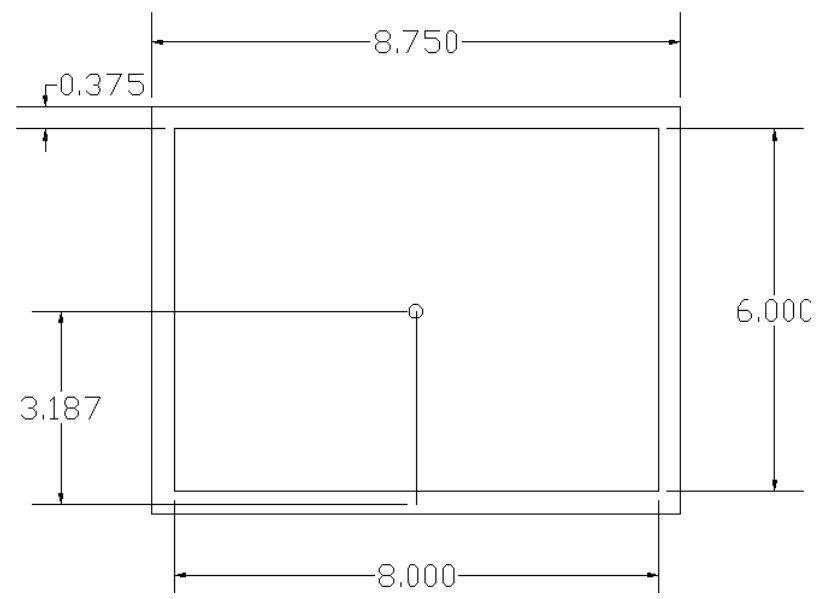

Fiber Volume Fraction for First Configuration $\left(\mathrm{V}_{\mathrm{f} 1}\right)$ from Table 3-2

$\mathrm{V}_{\mathrm{f} 1}=17 \%$

Elastic Modulus of the Composite ( $\left.\mathrm{E}_{\text {Composite }}\right)$

$\mathrm{E}_{\text {Composite }}=(0.17 \times 10.6+0.83 \times 0.4) \times 10^{6}=2.129 \times 10^{6} \mathrm{Psi}$

Elastic Modulus of the Wood Tie ( $\mathrm{E}_{\text {Wood }}$ ) from Table 5-3

$\mathrm{E}_{\text {Wood }}=1.29 \times 10^{6} \mathrm{Psi}$

Modular Ratio 
$\eta=\frac{E_{\text {composite }}}{E_{\text {wood }}}=1.65$

Depth of Neutral Axis from the center of the top flange of the Composite

$\mathrm{D}=\frac{h}{2}-\frac{t}{2}=\frac{6.75}{2}-\frac{0.375}{2}=3.1875$

Area of the crossection of the top and the bottom flange

$A_{f}=2(8.75 \times 0.375)=6.5625$

Transformed Moment of Inertia

$\mathrm{I}_{\text {transformed }}=\frac{b(h-2 t)^{3}}{12}+\eta A_{f} D^{2}=245$ in $^{4}$

\section{Second Configuration}

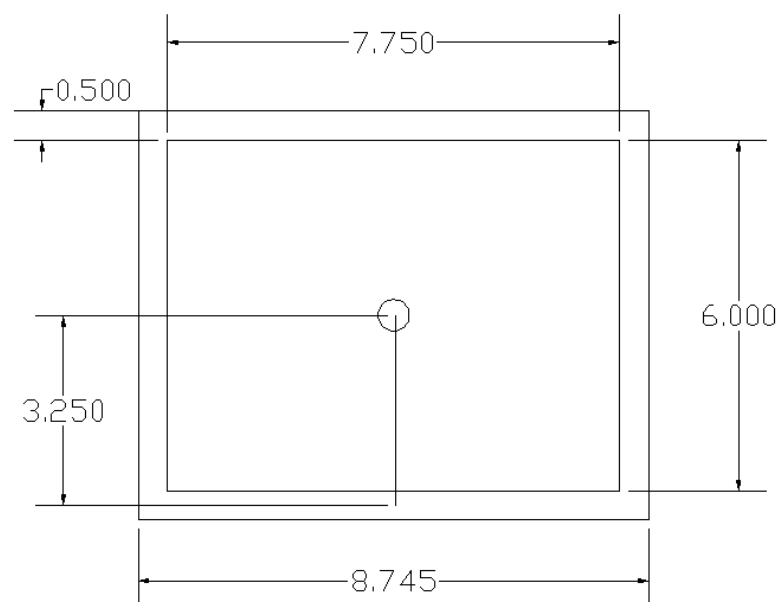

Fiber Volume Fraction for First Configuration $\left(\mathrm{V}_{\mathrm{f} 1}\right)$ from Table 3-2

$\mathrm{V}_{\mathrm{f1}}=15 \%$

Elastic Modulus of the Composite ( $\left.\mathrm{E}_{\text {Composite }}\right)$

$\mathrm{E}_{\text {Composite }}=(0.15 \times 10.6+0.85 \times 0.4) \times 10^{6}=1.96 \times 10^{6} \mathrm{Psi}$ 
Elastic Modulus of the Wood Tie ( $\mathrm{E}_{\mathrm{Wood}}$ ) from Table 5-3

$\mathrm{E}_{\text {Wood }}=1.29 \times 10^{6} \mathrm{Psi}$

Modular Ratio

$\eta=\frac{E_{\text {composite }}}{E_{\text {wood }}}=1.51$

Depth of Neutral Axis from the center of the top flange of the Composite

$\mathrm{D}=\frac{h}{2}-\frac{t}{2}=\frac{7}{2}-\frac{0.5}{2}=3.25$

Area of the Crossection of the top and the bottom flange

$A_{f}=2(8.75 \times 0.5)=8.75$

Transformed Moment of Inertia

$\mathrm{I}_{\text {transformed }}=\frac{b(h-2 t)^{3}}{12}+\eta A_{f} D^{2}=265.59 \mathrm{in}^{4}$

Table 4-3: Transformed Moment of Inertia for different fiber/fabric configurations

\begin{tabular}{|c|c|c|c|c|c|}
\hline $\begin{array}{l}\text { Fiber/Fabric } \\
\text { Configuration }\end{array}$ & $\begin{array}{c}\text { Fiber volume } \\
\text { Fraction }\end{array}$ & $\begin{array}{c}\mathrm{E}_{\text {Composite }} \\
\text { (Psi) }\end{array}$ & $\begin{array}{l}E_{\text {Wood }} \\
\text { (Psi) }\end{array}$ & 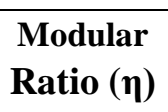 & $I_{\text {transformed }}\left(\mathrm{in}^{4}\right)$ \\
\hline First Configuration & $17 \%$ & $2.129 \times 10^{6}$ & $1.29 \times 10^{6}$ & 1.65 & 245 \\
\hline Second Configuration & $15 \%$ & $1.96 \times 10^{6}$ & $1.29 \times 10^{6}$ & 1.51 & 265.59 \\
\hline
\end{tabular}

\subsection{Test Results}

Flexural rigidity is a measure that describes a materials resistance to bending forces. Using three point bending test, stress versus strain graphs were plotted and flexural rigidities of recycled composite ties were calculated. Stiffness of the composite tie was evaluated using the strain data measured during the 
static testing. Calculation of flexural rigidity for Tie \#1 is shown below and rest of them are shown in the Appendix A.

\subsubsection{Calculation of bending stress for first configuration}

Note:

1. Span length $(\mathrm{L})=90$ in.

2. $\mathrm{I}_{\text {transformed }}=245 \mathrm{in}^{4}$ (Table 4-2)

3. Neutral Axis

$$
\mathrm{C}=\frac{\sum A_{i} y_{i}}{\sum A_{i}}=3.37 \text { in }
$$

4. Calculation of bending stress ( For three points bending )

Bending Stress $=\frac{M C}{I_{\text {transformed }}}=0.3094 \mathrm{P}$

Bending Moment $=\mathrm{M}=\frac{P L}{4}=22.5 \mathrm{P}$

\subsubsection{Tie \#1}

$\underline{\text { Calculation of flexural rigidity using } 3 \text { point bending test }}$

This specimen was done using first configuration.

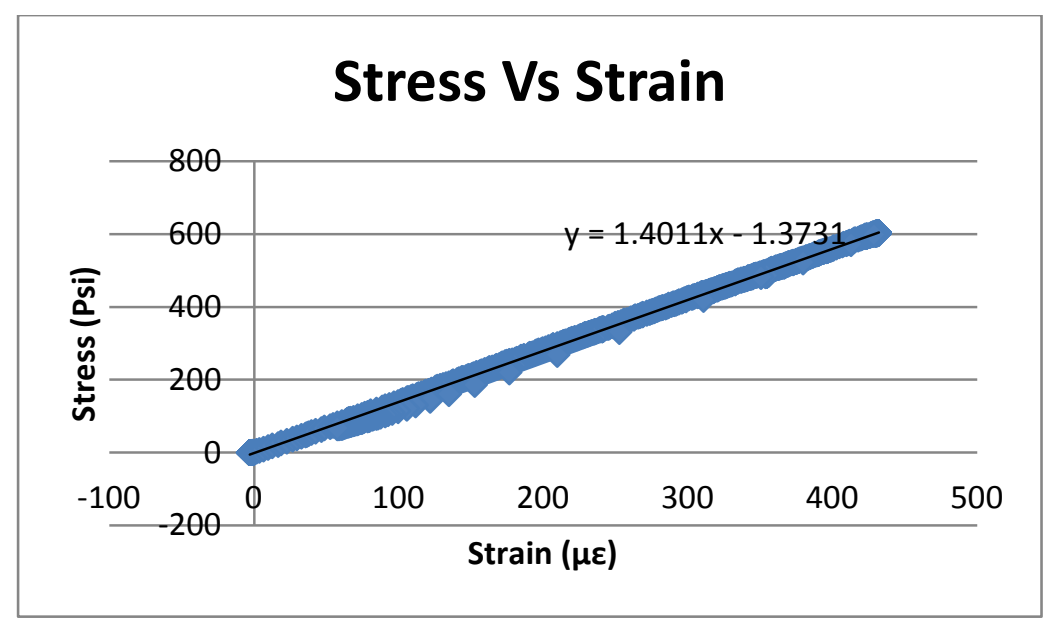

Figure 4-4: Stress vs Strain for Tie \#1 
Elastic modulus $=\mathrm{E}=1.4011 \times 10^{6} \mathrm{psi}$ (From the slope of the graph in Figure 4-4)

Moment of Inertia $=\mathrm{I}_{\text {transformed }}=245$ in $^{4}$

Flexural Rigidity $=\mathrm{EI}_{\text {transformed }}=1.4011 \times 10^{6} \times 245=343 \times 10^{6} \mathrm{lbs}_{-1 n^{2}}$

Table 4-4: Flexural Rigidity Results for all composite tie with wood core

\begin{tabular}{|c|c|c|c|c|c|c|c|}
\hline $\begin{array}{c}\text { Material and strength } \\
\text { properties }\end{array}$ & Tie\#1 & Tie\#2 & Tie\#3 & Tie\#4 & Tie\#5 & Tie\#6 & Average \\
\hline Dimensions & \multicolumn{4}{|c|}{ First Configuration } & \multicolumn{2}{|c|}{ Second Configuration } & \\
\hline Length (in) & 102 & 102 & 102 & 102 & 102 & 102 & 102 \\
\hline Width (in) & 8.75 & 8.75 & 8.75 & 8.75 & 8.75 & 8.75 & 8.75 \\
\hline Depth (in) & 6.78 & 6.78 & 6.78 & 6.78 & 7 & 7 & 6.89 \\
\hline $\begin{array}{l}\text { Moment of Inertia } \\
\left(\mathrm{I}_{\text {transformed }}\right) \\
\left(\text { in }^{4}\right)\end{array}$ & 245 & 245 & 245 & 245 & 265 & 265 & 252 \\
\hline $\begin{array}{l}\text { Modulus of Elasticity } \\
\text { (E) } \\
\left(1.0 \times 10^{6} \text { Psi }\right)\end{array}$ & 1.401 & 1.204 & 1.393 & 1.485 & 1.465 & 1.20 & 1.358 \\
\hline $\begin{array}{l}\text { Flexural Rigidity } \\
\left(\mathrm{EI}_{\text {transformed }}\right) \\
\left(1.0 \times 10^{6} \mathrm{lbs}_{-} \mathrm{in}^{2}\right)\end{array}$ & 343 & 294 & 341 & 363 & 389 & 318 & 341 \\
\hline
\end{tabular}

\section{Flexural Rigidity}

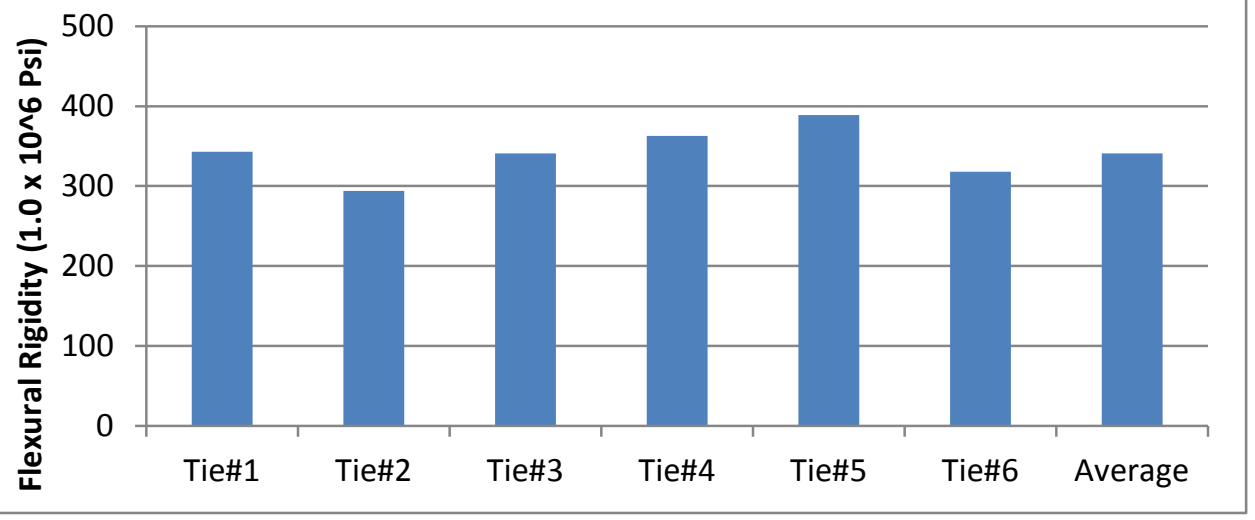

Figure 4-5: Bar Graph Showing the Flexural Rigidities for all Ties 


\subsubsection{Comparison of flexural rigidity between first configuration and second configuration}

The flexural rigidities of the second configuration composite ties were nearly similar to that of first configuration composite ties. The bending resistance of the second configuration fabric layers composite tie \#5 has higher value of all the other ties due to increase in the fabric layers and the orientations of fibers in all the directions.

\subsection{Conclusions}

1. With the increase in the number of glass fabric layers including $0 \%+45^{0} / 90^{0}$ configurations, the stiffness of the GFRP ties increased.

2. The flexural rigidities of recycled composite ties made of first configuration (15 layers of $0^{0} / 90^{0}$ ) and second configuration (20 layers of $0^{0} / 90^{\circ} / \pm 45^{0}$ ) were found to be nearly similar. The bending resistance of recycled composite tie \#5 with more number of fabrics along with the use of \pm 45 fabrics as compared to other ties resulted in higher flexural rigidity. (Table 4-4)

3. The average flexural rigidity of the recycled composite ties was compared with the oak ties from Railway Tie Association (Tie Guide, 2005). The composite shell system improved the flexural rigidity of recycled composite ties in a range of $15 \%$ to $20 \%$. (341Psi vs $272 \mathrm{Psi}$ )

4. The average flexural rigidity of the recycled composite ties was compared from our study with similar ties from IntegriCo and Tietek, the flexural rigidity of recycled composite ties was more than that of composite ties from IntergriCo and tietek by about a range of $6 \%$ to $11 \%$, respectively (comparison of Tables 2-1 and 4-4).

5. The average flexural rigidity of the recycled composite ties was compared from our study with the Dynamic and PRT's composite ties that are made of steel, concrete, recycled rubber and recycled polymers, the flexural rigidity of recycled composite ties was more than that of Dynamic composite ties by about 5\% and less than that of PRT's composite ties by about 7\%. 
To achieve better recycled composite ties, cost effectiveness and speed in manufacturing, less number of composite parts can be used to reduce the fabric overlapping. Moreover, symmetry of the fabric layers is most important because it reduces the thermal stresses in the composite structure. Testing and evaluation of the test results of the recycled composite ties with less number of fabric overlapping were described in the following chapter. 


\section{STATIC RUPTURE TEST FOR WOOD AND RECYCLED COMPOSITE TIE}

\subsection{Introduction}

Three point bending method was used to determine the tensile fracture strength and modulus of rupture in a recycled composite tie and white oak wood tie. Tensile fracture strength was required because these materials usually fail in tension under heavy axle loading. Recycled composite ties with various configurations were laboratory tested under bending to determine the strength properties. Mechanical behavior of the materials was characterized under the three point bending test. The tie was manufactured using manufacturing process-II. The size of the wood core changed as the thickness of the composite material changed (fiber volume fraction) on each side of the tie. The recycled composite tie which was tested has the same dimensions of 9 x 8.5 x 102in. The wood core of recycled composite tie tested has the moisture content range of $12 \%$ to $18 \%$ on the outer surface and $30 \%$ to $40 \%$ in the inner surface.

Three point bending test was conducted to determine the modulus of rupture. The mechanical properties of a GFRP composite tie were used to compare with the white oak wood tie.

\subsection{Objective}

The objective is to test and evaluate the modulus of rupture and static bending strength of recycled composite tie and wood tie under three point bending to establish their strength and stiffness.

\subsection{Scope}

Three point bending test was conducted at the WVU Structures laboratory on a Recycled Composite Tie and a wood tie in this study. Span length of these samples was 60 in. First the static three point bending test was conducted on recycled composite tie. The moisture content test was done on the wood tie before conducting the three point bending test. Strains and deflections at mid span of both the specimens were measured. 
Table 5-1: Description of specimen and fabric configuration

\begin{tabular}{|c|c|c|c|}
\hline $\begin{array}{c}\text { Recycled Composite } \\
\text { Ties }\end{array}$ & Manufacturing & Fabric & Number of Layers \\
\hline Tie \#1 & Frocess-II & Configuration & \\
\hline
\end{tabular}

\subsection{Test Description}

Oven drying of the test specimens was made in WVU Kiln Damper to reduce the moisture content to 20\% in the wood cellulose. The concrete supports have a steel round stock fixed at the top to rest the specimen on it. The supports were spaced at a distance of 21in from the ends. The hydraulic jack which was connected to the hydraulic pump was used to apply the load. It was clamped to the steel frame.

\subsection{Instrumentation}

Load versus strains, deflections at the center of the specimen were measured during testing. The electrical strain gage was centered at the middle of each specimen on the tension side. This position was chosen to measure the maximum strain levels. An LVDT was placed at the mid span of the specimen to measure deflection. Load cell was placed on the specimen at the mid span to measure the load. The strain smart software program was used to plot load versus strain and deflection. 


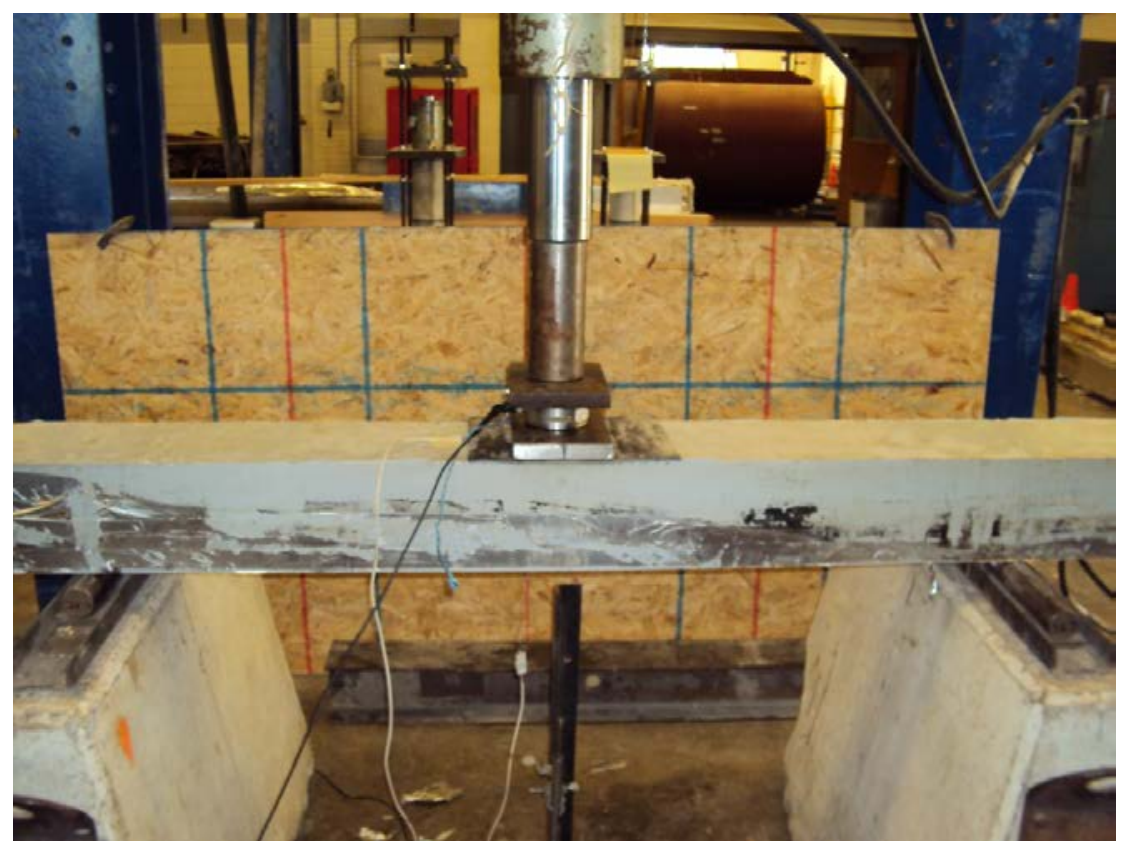

Figure 5-1: Three Point Bending Test on Recycled Composite Tie

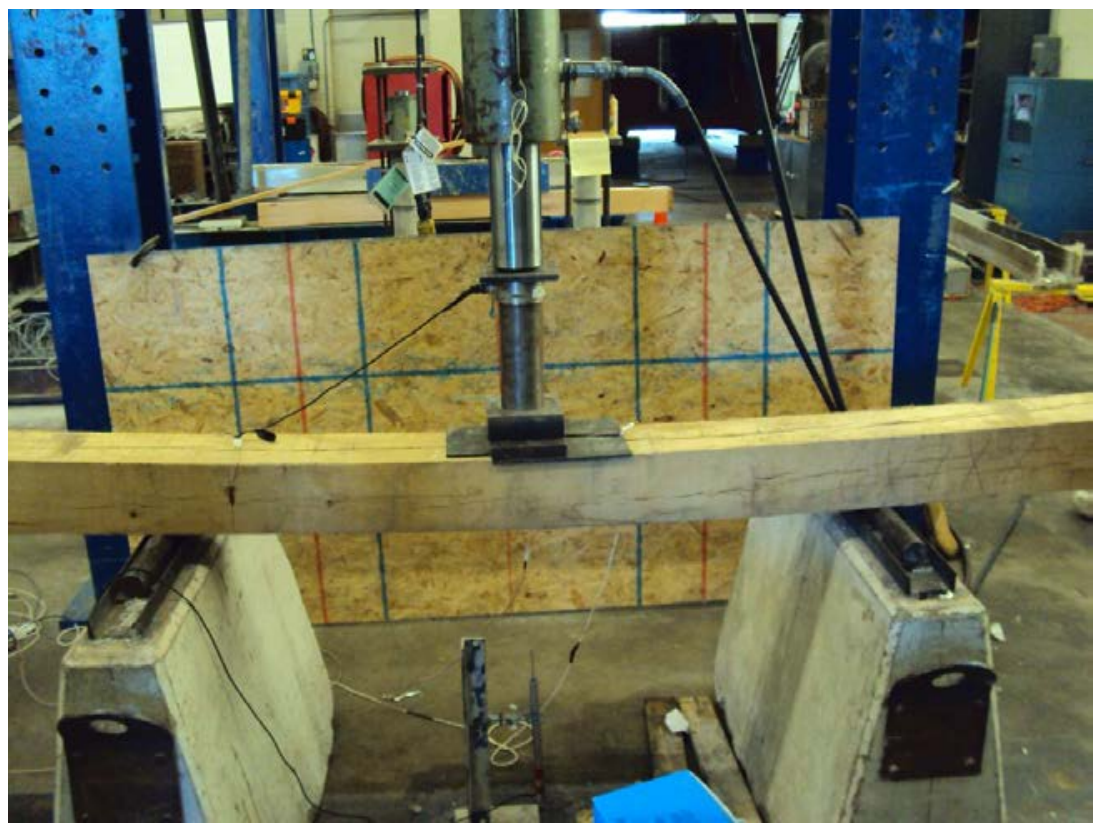

Figure 5-2: Three Point Bending Test on Wood Tie 


\subsection{Test Procedure}

The following test procedure was followed for all the test samples. First, the strain gage, load and LVDT were zeroed using the strain smart software of the data acquisition system. The sample was placed at a distance of 21 in from the end of the samples at the supports. It was then centered to the hydraulic jack by moving the sample on the supports. The load cell was kept on the top of the sample and the LVDT was arranged at the bottom of the mid span.

\subsubsection{Three point bending test}

The hydraulic jack was spaced at a distance of 30 inches from both the supports. The testing load was applied at the center of a test specimen. The load cell was placed in the center to measure the required force applied by the hydraulic jack. Then the load was applied by pumping the hydraulic jack for 2 kips. The strain, load and deflection data was collected in the strain smart software. The procedure was repeated if any of the instruments fail to work.
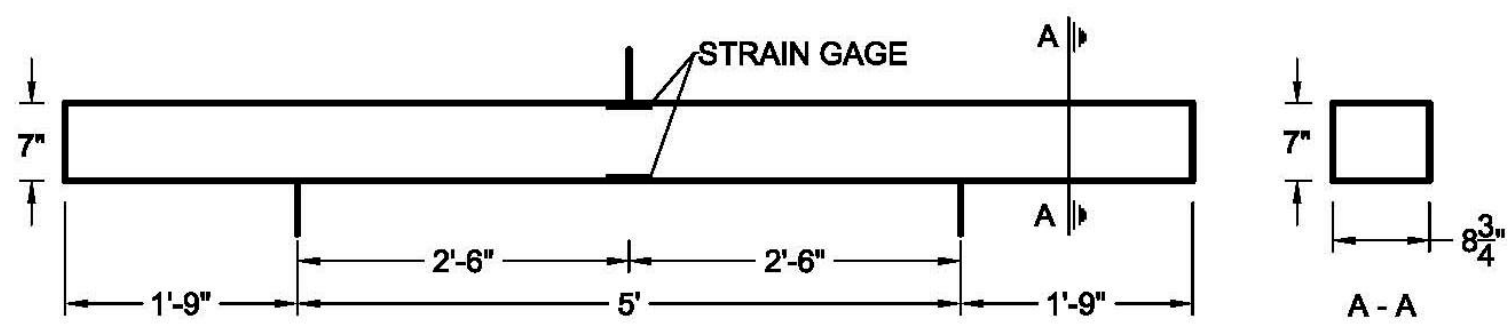

Figure 5-3: Three point bending test setup

\subsubsection{Three Point Rupture Test}

After both the above test has done for collecting the data to calculate modulus of elasticity, the tie was set

to three point rupture test. The same arrangement as for the three point bending test was made. Then the load was applied by the hydraulic jack until the tie gets ruptured completely and the load data drops 
down. The strain, load and deflection data was collected in the strain smart software. The procedure was repeated if any of the instruments fail to work.

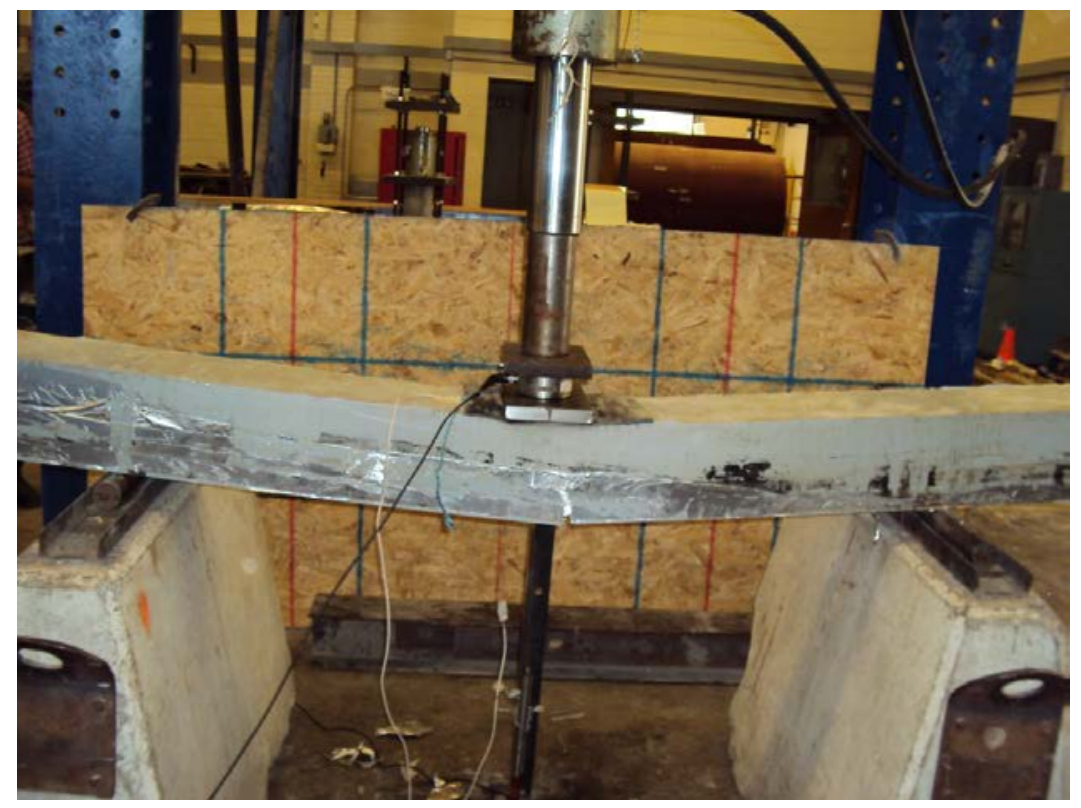

Figure 5-4: Recycled Composite Tie Failure with Three Point Bending Test

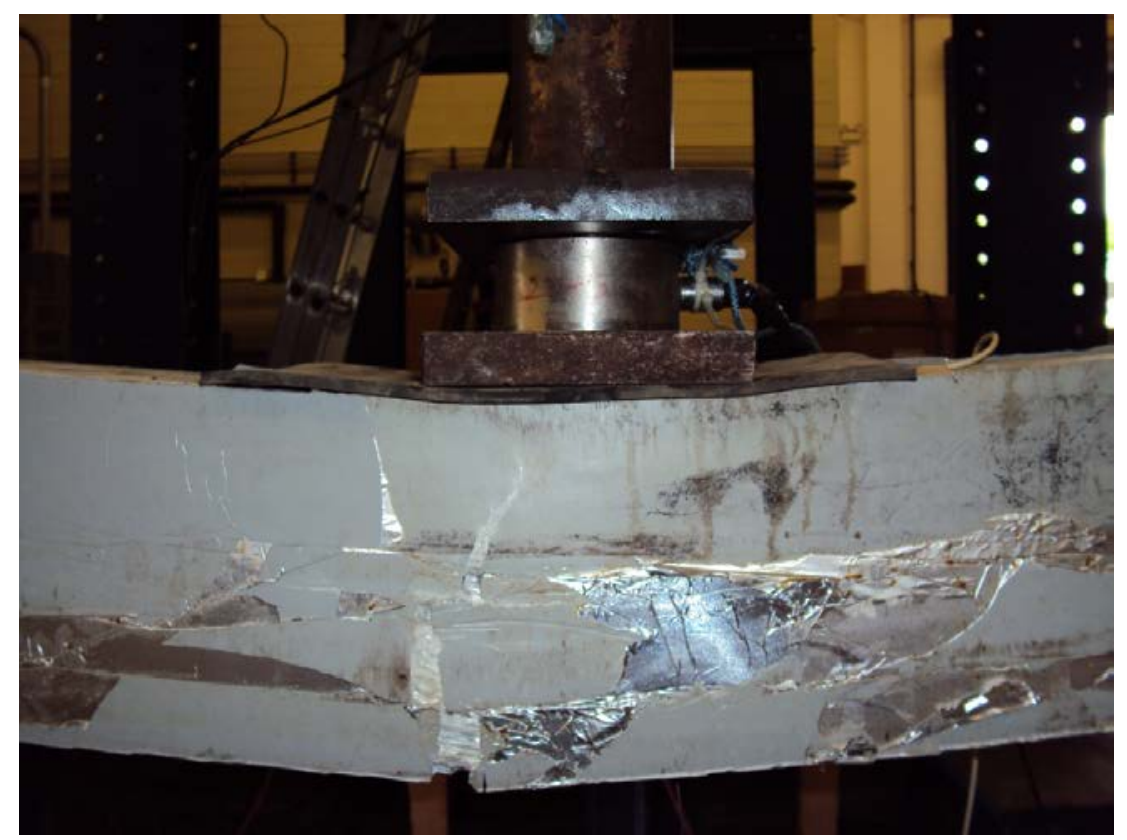

Figure 5-5: Flexural Crack on the Side of the Recycled Composite Tie 


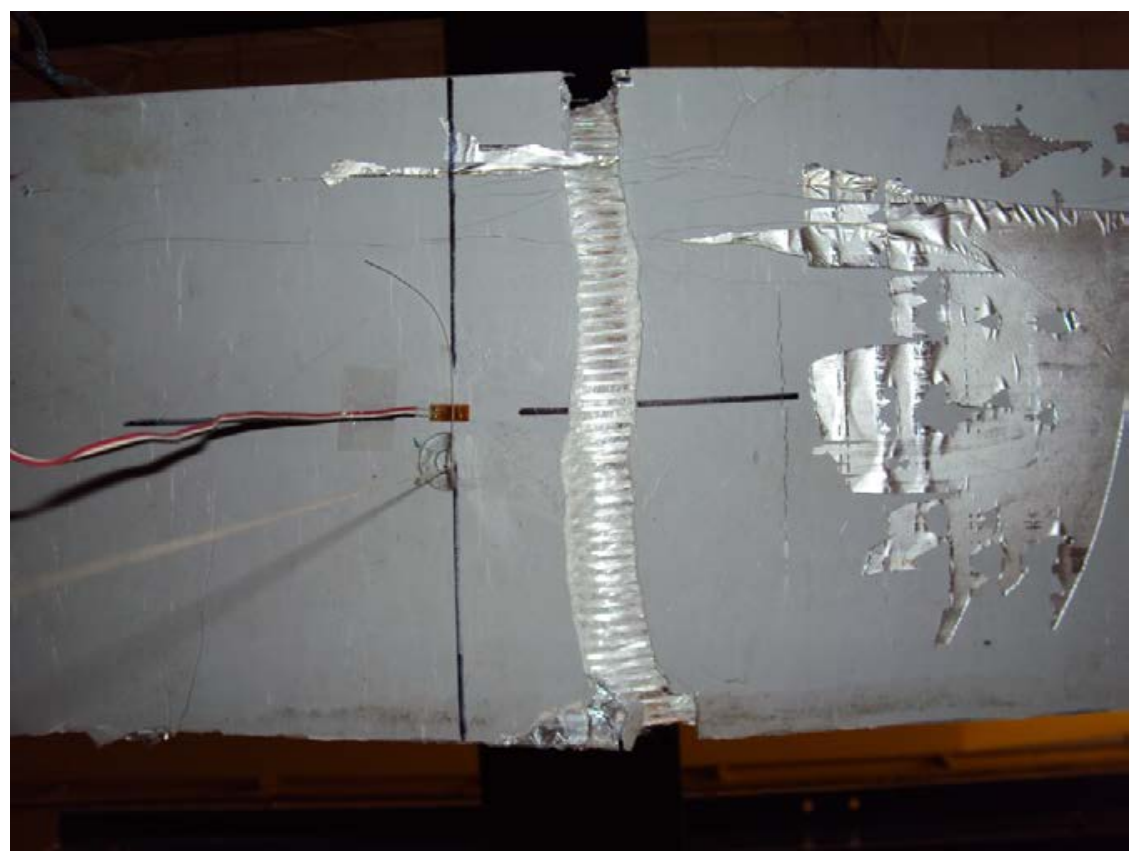

Figure 5-6: Flexural Crack at the Bottom of the Recycled Composite Tie

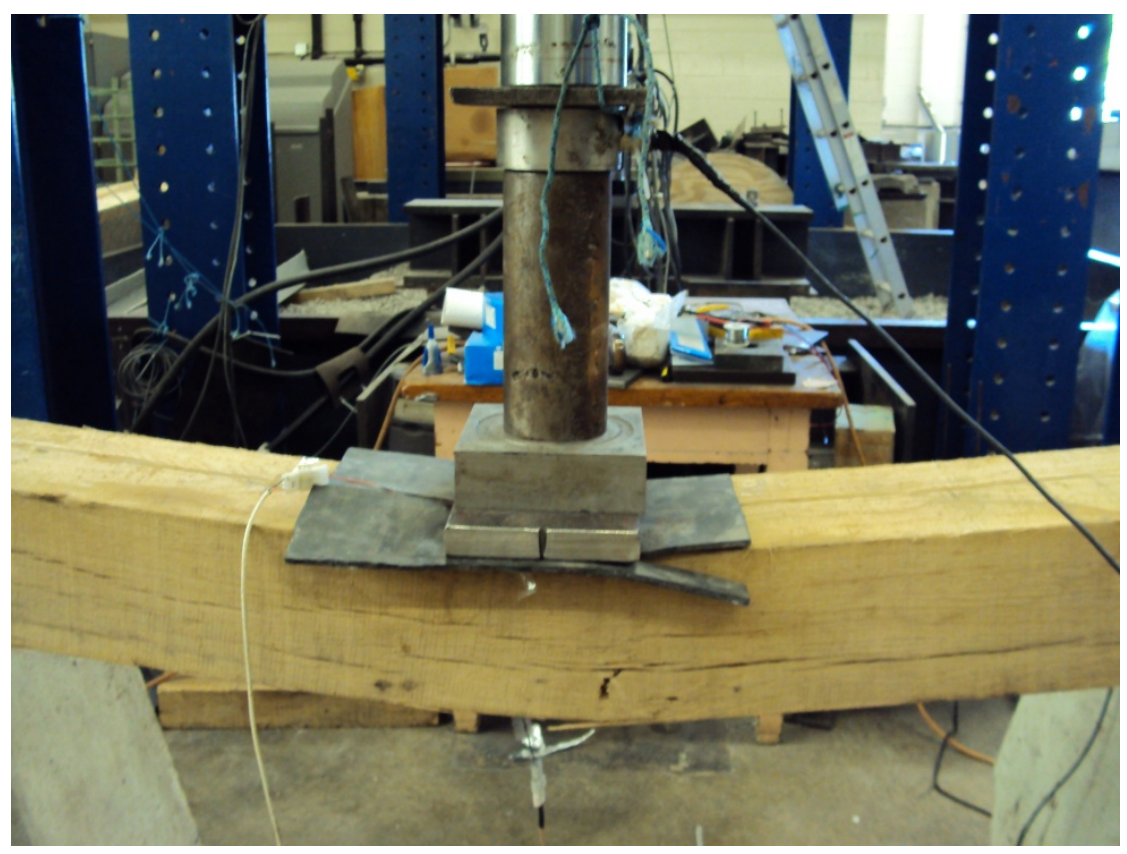

Figure 5-7: Wood Tie Failure with Three Point Bending Test 


\subsection{Sectional Properties}

After the manufacturing of recycled composite ties the dimensions were shown in Table 5-1. The transformed moment of inertia were calculated for first and second configuration recycled composite ties and shown in Table 5-2.

Table 5-2: Recycled Composite Tie Dimensions

\begin{tabular}{|c|c|c|}
\hline Sample Dimensions & Recycled Composite Tie & Wood Tie \\
\hline Length (in) & 102 & 102 \\
\hline Width (in) & 8.75 & 7.2 \\
\hline Depth (in) & 7 & 6 \\
\hline
\end{tabular}

\subsubsection{Calculations of Transformed Moment of Inertia ( $I_{\text {transformed }}$ ) for Recycled Composite Tie}

Elastic Modulus of Glass Fibers (Elass Fibers) from Table 3-1

$\mathrm{E}_{\text {Glass Fibers }}=10.6 \times 10^{6}$ Psi

Elastic Modulus of ABS ( $\left.\mathrm{E}_{\mathrm{ABS}}\right)$ from Table 3-1

$\mathrm{E}_{\mathrm{ABS}}=0.4 \times 10^{6} \mathrm{Psi}$

\section{First Configuration}

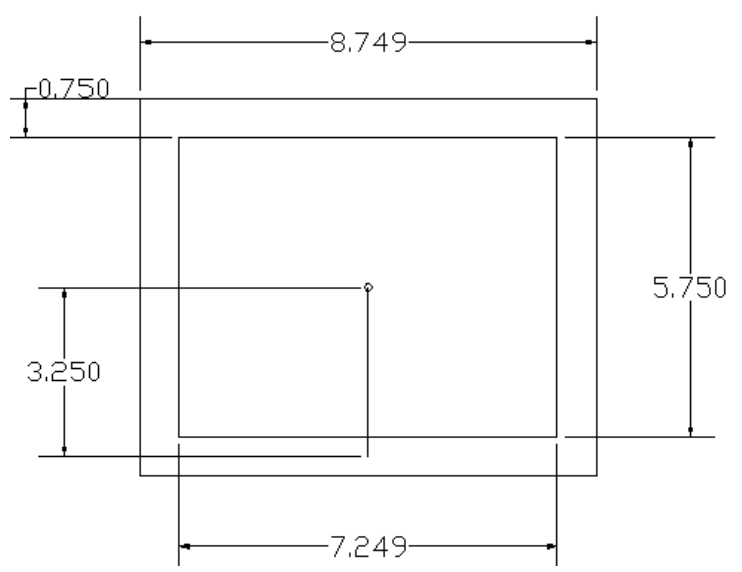


Fiber Volume Fraction for First Configuration $\left(\mathrm{V}_{\mathrm{f} 1}\right)$ from Table 3-4

$\mathrm{V}_{\mathrm{f} 1}=10 \%$

Elastic Modulus of the Composite ( $\left.\mathrm{E}_{\text {Composite }}\right)$

$E_{\text {Composite }}=(0.1 \times 10.6+0.9 \times 0.4) \times 10^{6}=1.44 \times 10^{6}$ Psi

Elastic Modulus of the Wood Tie ( $E_{\text {Wood }}$ ) from Table 5-3

$\mathrm{E}_{\text {Wood }}=1.29 \times 10^{6} \mathrm{Psi}$

Modular Ratio

$\eta=\frac{E_{\text {composite }}}{E_{\text {wood }}}=1.109$

Depth of Neutral Axis from the center of the top flange of the Composite

$\mathrm{d}=\frac{5.75}{2}+\frac{0.75}{2}=3.25$

Area of the Crossection of the top and the bottom flange

$A_{f}=2(7.5 \times 0.75)=13.125$

Transformed Moment of Inertia

$\mathrm{I}_{\text {transformed }}=\frac{b d^{3}}{12}+\eta A_{f} d^{2}=\frac{7.5 * 6^{3}}{12}+0.7238 * 13.125 * 3.25^{2}=268 \mathrm{in}^{4}$

Table 5-3: Transformed Moment of Inertia for different fiber/fabric configurations

\begin{tabular}{|c|c|c|c|c|c|}
\hline $\begin{array}{c}\text { Fiber/Fabric } \\
\text { Configuration }\end{array}$ & $\begin{array}{c}\text { Fiber volume } \\
\text { Fraction }\end{array}$ & $\begin{array}{c}\mathbf{E}_{\text {Composite }} \\
\mathbf{( P s i )}\end{array}$ & $\begin{array}{c}\mathbf{E}_{\text {Wood }} \\
(\mathbf{P s i})\end{array}$ & $\begin{array}{c}\text { Modular } \\
\text { Ratio ( } \boldsymbol{\eta})\end{array}$ & $\mathbf{I}_{\text {transformed }}$ (in $\left.^{\mathbf{4}}\right)$ \\
\hline First Configuration & $10 \%$ & $1.44 \times 10^{6}$ & $1.29 \times 10^{6}$ & 1.109 & 268 \\
\hline
\end{tabular}




\subsubsection{Calculation of Moment of Inertia for Wood Tie}

Moment of Inertia

$\mathrm{I}=\frac{b d^{3}}{12}=\frac{7.2 * 6.2^{3}}{12}=143 \mathrm{in}^{4}$

\subsection{Test Results}

From the stress vs. strain graph obtained by performing the three point bending test, the flexural rigidities of the recycled composite ties were calculated. Stiffness of the composite tie and wood tie was evaluated using the strain data measured during the static testing. Static bending strength for recycled composite tie and wood tie was calculated. Calculation of flexural rigidity of recycled composite tie is shown below and the rest of them are shown in the Appendix 'B'.

\subsubsection{Calculation of bending stress for first configuration}

Note:

1. Span length $(\mathrm{L})=60$ in.

2. $\mathrm{I}_{\text {transformed }}=268 \mathrm{in}^{4}$ (Table C- 13)

3. Neutral Axis

$$
\mathrm{C}=\frac{\sum A_{i} y_{i}}{\sum A_{i}}=3.75 \text { in }
$$

4. Calculation of bending stress ( For three points bending )

Bending Stress $=\frac{M C}{I_{\text {transformed }}}=0.20988 \mathrm{P}$

Bending Moment $=\mathrm{M}=\frac{P L}{4}=15 \mathrm{P}$ 


\subsubsection{Composite Tie}

Calculation of flexural rigidity using 3 point bending test

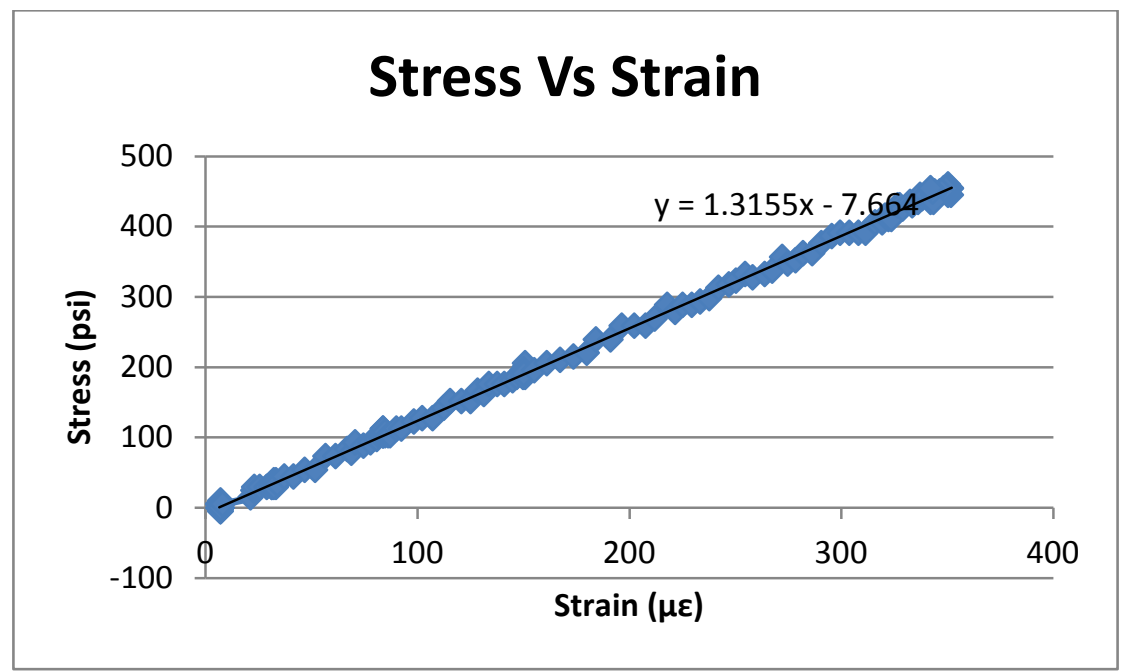

Figure 5-8: Stress vs Strain Graph for Recycled Composite Tie

Elastic modulus $=\mathrm{E}=1.3155 \times 10^{6} \mathrm{psi}$ (From the slope of the graph in Error! Reference source not found.)

Moment of Inertia $=\mathbf{I}_{\text {transformed }}=268 \mathrm{in}^{4}$

Flexural Rigidity $=$ EI $=1.3155 \times 10^{6} \times 268=352 \times 10^{6}$ lbs-in $^{2}$

\subsubsection{Calculation of Static Bending Strength}

Recycled Composite Tie

The maximum load to failure

$\mathrm{P}=45.66$ Kips

Static Bending Strength

$\mathrm{M}=\frac{P * L}{4}=\frac{45.66 * 60}{4}=660$ in-kips 
Modulus of Rupture

$\sigma=\frac{M * c}{I}=\frac{660 * 3.75}{268}=9244$ Psi

$\underline{\text { Wood Tie }}$

Maximum load to failure

$\mathrm{P}=26.86$ Kips

Static Bending Strength

$\mathrm{M}=\frac{P * L}{4}=\frac{26.86 * 60}{4}=403$ in-kips

Modulus of Rupture

$\sigma=\frac{M * C}{I}=\frac{403 * 3.1}{144}=8680$ Psi

Table 5-4: Details of Test Results on Recycled Composite Tie and Wood Tie

\begin{tabular}{|c|c|c|}
\hline $\begin{array}{c}\text { Material and strength } \\
\text { properties }\end{array}$ & $\begin{array}{c}\text { Recycled } \\
\text { Composite Tie }\end{array}$ & Wood Tie \\
\hline Length (in) & 102 & 101.75 \\
\hline Width (in) & 8.75 & 7.2 \\
\hline Depth (in) & 7 & 6.2 \\
\hline $\begin{array}{c}\text { Moment of Inertia } \\
\text { (in }{ }^{4} \text { ) }\end{array}$ & 1.316 & 1.29 \\
\hline $\begin{array}{c}\text { Modulus of Elasticity } \\
\left(1.0 \text { x 10 }{ }^{6} \text { Psi) }\right.\end{array}$ & 352 & 186 \\
\hline $\begin{array}{c}\text { Flexural Rigidity } \\
\left.\text { (1.0 x 10 }{ }^{6} \text { lbs-in }{ }^{2}\right)\end{array}$ & 9244 & 8680 \\
\hline $\begin{array}{c}\text { Modulus of Rupture } \\
\text { (Psi) }\end{array}$ & 660 & 403 \\
\hline $\begin{array}{c}\text { Static Bending Strength } \\
\text { (in-Kips) }\end{array}$ & & \\
\hline
\end{tabular}




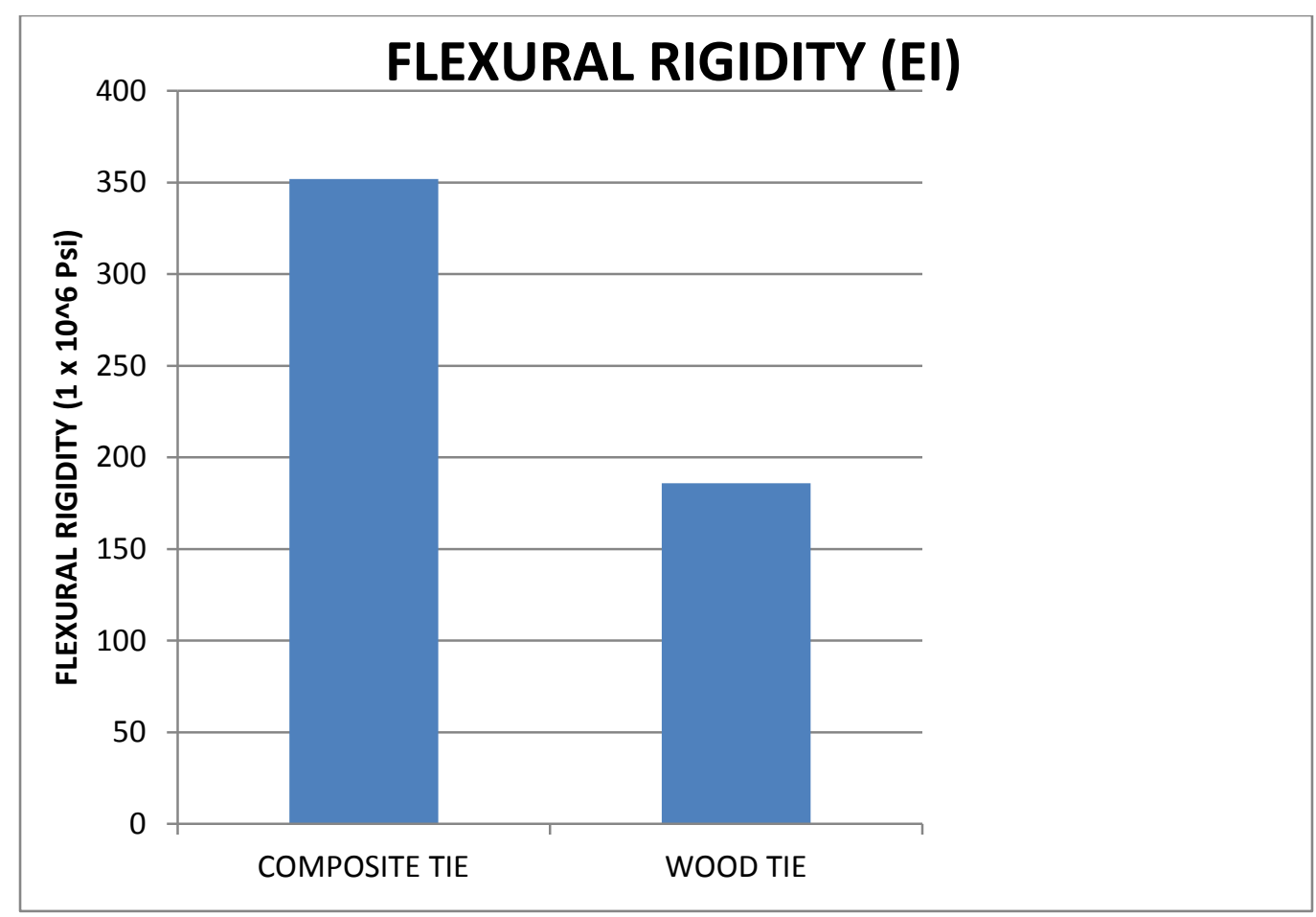

Figure 5-9: Bar Graph showing the 3 point bending results for composite and wood tie

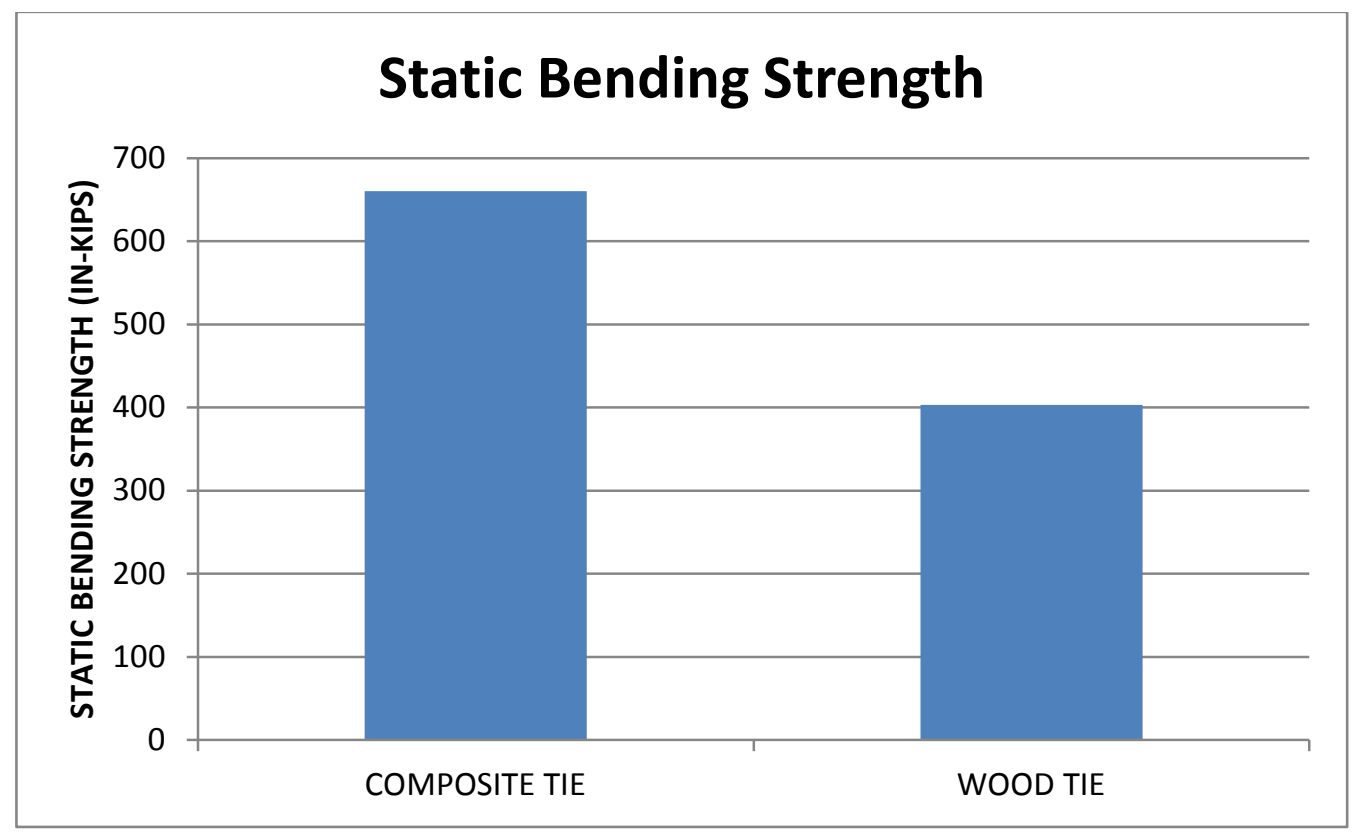

Figure 5-10: Bar Graph showing the static bending strength results of composite tie and wood tie 


\subsubsection{Comparison of Three Point Bending Results of Recycled Composite Tie and a Wood Tie}

In terms of flexural rigidity, the three point bending test results of composite tie were more than those of a wood tie by about 47 percent. Therefore, the bending resistance of the wood tie has increased by using the GFRP composite shell.

\subsubsection{Comparison of Static bending Strength Results of Recycled Composite Tie and a Wood Tie}

In terms of modulus of rupture, the composite tie is more than that of a wood tie by about 6 percent, respectively. The static bending strength of composite tie is more than that of a wood tie by about 38 percent. The maximum stress to failure of the composite tie was very high because after the failure of the wood material, the higher bending resistance was offered by the GFRP composite shell with the increase in the load.

\subsection{Conclusions}

1. The flexural rigidity of composite tie was $47 \%$ higher than that of a wood tie. (352 lbs-in ${ }^{2}$ vs 186 lbs-in ${ }^{2}$ ) (Table 5-4)

2. The flexural rigidity of Recycled Composite Tie \#5 that was manufactured using manufacturing process-I was more than that of Recycled Composite Tie manufactured using manufacturing process-II by about 11 percent because the fiber volume fraction of the composite part in the manufacturing process-II was lower than that of manufacturing process-I. (Note: It should be noted that the wood in this case has higher mechanical properties than the resin used in this study. Hence, reducing wood dimensions and increasing resin content by keeping the same number of GFRP fabrics will result in decreased flexural rigidity.) 
3. Modulus of Rupture of the composite tie was $6 \%$ higher than that of a wood tie. (9244Psi vs 8680Psi)

4. The static bending strength of composite tie was $38 \%$ higher than that of a wood tie. (660 in-Kips vs 403 in-Kips)

5. Following the initial failure of wood core, higher load resistances were carried by the GFRP composite shell.

6. Prior to the GFRP composite shell failure, failure of the wood core was noticed along with wood rupturing sound.

7. Good bond was between the wood core and the GFRP composite shell was found to be debonding between the wood core and the GFRP composite shell. (Note: This was observed from sliced from sliced tie sections after tie loading and failure)

8. The loading strength can be further increased by increasing the high matrix modulus, high fiber modulus and fiber/matrix interfacial strength.

9. To make the tie cost effective, the thickness of the laminate need to be reduced by increasing the fiber volume fraction and reducing the fiber buckling of GFRP composite shell. 


\section{SPIKE INSERTION AND PULLOUT TEST ON WOOD AND COMPOSITE TIE}

\subsection{Introduction}

The tie plate in a railroad is to hold the rail to the tie and the plate is held down with spikes. Two spikes are more efficient for holding the rail to the tie. The spikes have a tendency to become loose due to the heavy cyclic mechanical loading imparted by rail car axles. The spikes exert the resistance to up and down pull from cyclic mechanical loading (i.e. Fatigue). The objective of this chapter is to show test data where recycled composite tie resistance has been more than adequate to overcome stresses induced by cyclic environmental and mechanical loads.

\subsection{Objective}

The specific objective is to determine the force to be exerted on a spike to insert a spike in to wood and recycled composite tie, and also to find the resistance to spike pull force offered by the wood and recycled composite tie.

\subsection{Scope}

Spike insertion tests and spike pullout tests were conducted on a wood tie specimen as well as a recycled composite tie specimen. Three spikes were inserted and pulled out from these specimens one spike at a time to determine the insertion force and pull out force of each spike. First the spike insertion test was conducted one spike at a time by applying the load on the solid head of the conventional spike. The spikes were spaced at least 8 inches apart. Then the whole setup was changed to conduct the spike pullout test by applying the load to pull the spikes out from the specimens. Forces required for inserting and pulling out of a spike from the specimens were measured in each test, on an individual spike at a time and not as a group effect. 


\subsection{Test Description}

The testing equipment was developed at WVU-CFC (Figure 6-1). The four feet long tie segments were cut from both the wood and recycled composite full scale ties. The dimensions of the wood tie segments were 7x8x18 inch and recycled composite tie segments and 7x9x48 inch, respectively. These specimens were used to drive the spikes in it. The moisture content level in the wood specimen and the wood used in the GFRC-wood specimen was around 12\%. The fiber volume fraction in GFRC-wood specimen was 8\% (Table 3-4). Conventional spikes were used in this test. Conventional spikes have solid shaft and a solid head. It is essential to bore a hole of $3 / 8$ in diameter in the ties as per the specifications in AREMA Manual. Holes were bored/ drilled in these specimens with a drill bit of 3/8 inch diameter to a depth of 4inch.

\subsubsection{Spike insertion test}

The specimens were placed on the laboratory test floor to establish the magnitude of force needed to insert a spike. The hydraulic jack which was connected to the hydraulic pump was used to apply the load. It was clamped to the steel frame. It has a maximum load range of 100,000lbs (Figure 6-1).

The shape of the solid head of the conventional spike was made on one side of a steel plate to put the load cell on the other side of the plate. Load was applied on the solid head of the convention spike. The load cell was placed in the center of the steel plate and the hydraulic jack to measure the required force applied by the hydraulic jack to insert the spike (Figure 6-1). 


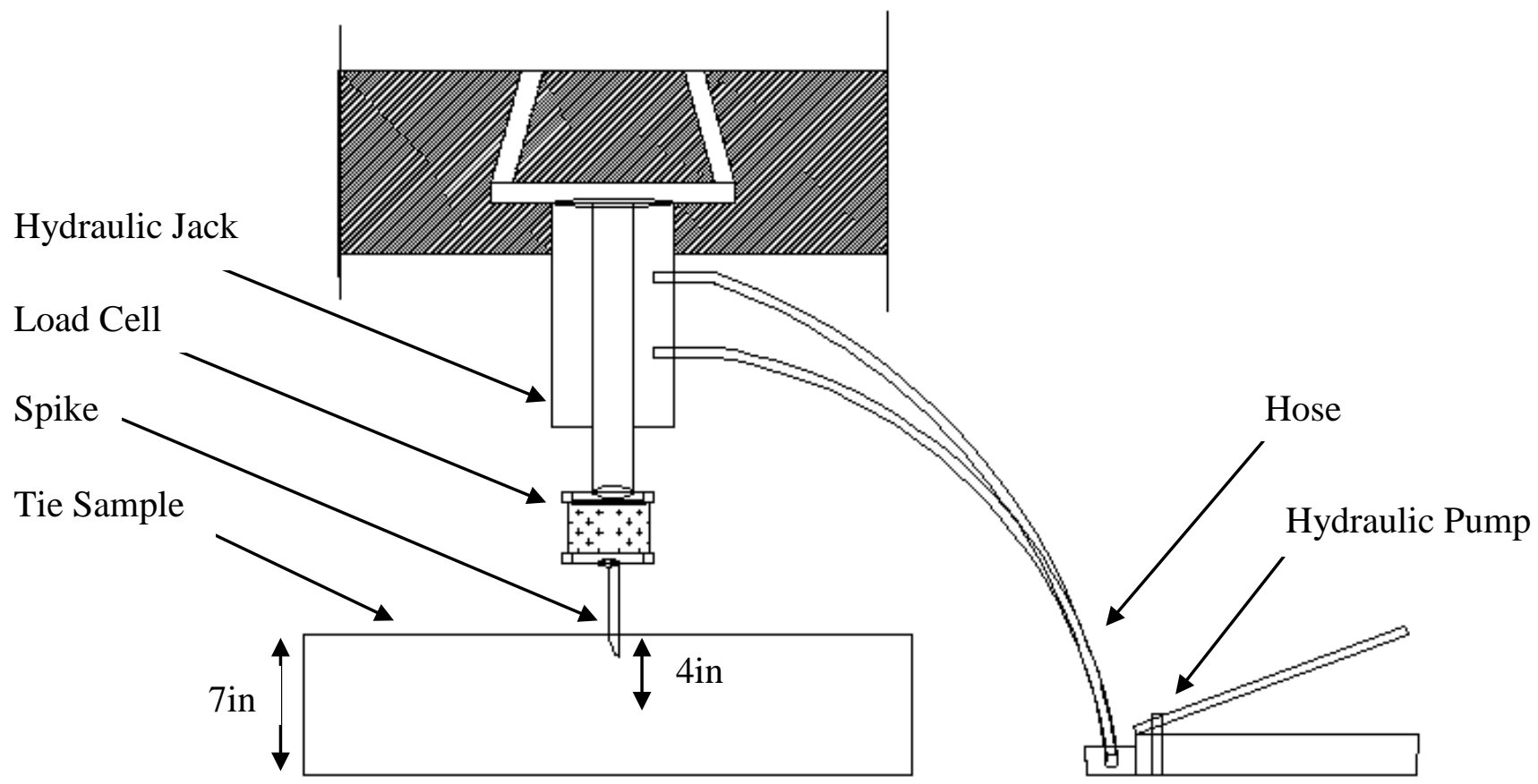

Figure 6-1: Cad Drawing of Spike Insertion Test Setup

\subsubsection{Spike pullout test}

The setup for spike pullout test was made by CFC-WVU. Two U-shape steel structures were used in this test. A small U-shape steel structure was used to hold the spike and another U-shape steel structure was used to put the hydraulic jack on the top of it. Both the U-shape steel structures have a hole in the top to run the steel rod from it. The steel rod has grooves to put screws on both sides of it. The load cell was placed in the middle of the hydraulic jack and the outer U-shape steel structure to measure the load applied by the hydraulic jack to pull the spike (Figure 6-2). 


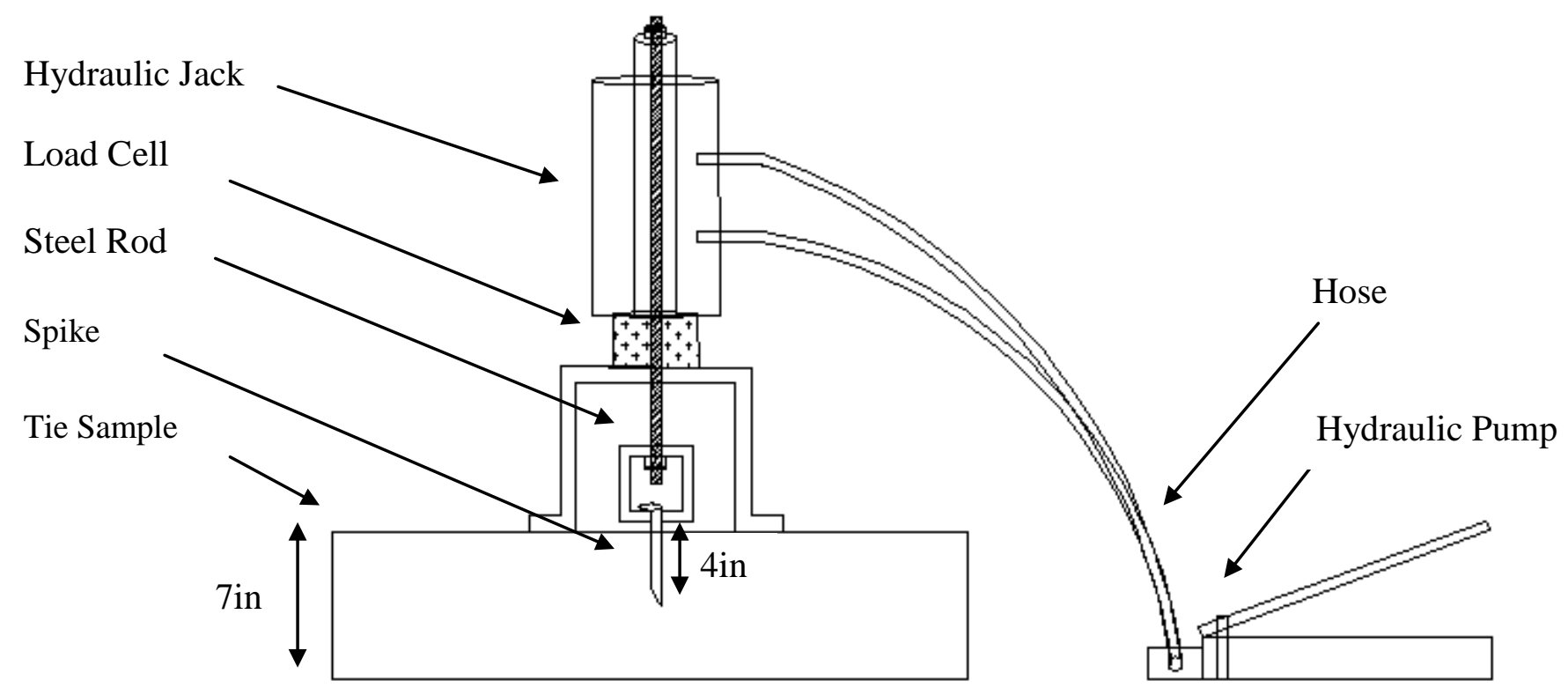

Figure 6-2: Cad Drawing of Spike Pullout Test Setup

\subsection{Instrumentation}

Load required for inserting or pulling out of the spike at three different places of a wooden tie were measured using a load cell. A load cell was placed at the middle of the hydraulic jack and the steel plate to measure the spike insertion load. The spike was inserted into a pre-drilled hole using a spike head shaped steel plate (Figure 6-2). The strain smart software program was used to collect the load data from the data acquisition system (Figure 6-6). Data was collected until the spike reaches 4in. depth in the specimen.

\subsection{Test Procedure}

\subsubsection{Spike insertion test}

A drilling machine with the drill bit of 3/8in diameter was used for boring of the tie for insertion of spikes. Three holes were made at a spacing of 7in with a depth of 3in. After drilling 3 holes, the tie was moved under the hydraulic jack; the spike was gently hit in the hole using a hammer. After the spike was barely inserted into the tie, the steel plate with the shape of the spike head was placed on it. At this point the load cell was arranged in between the hydraulic jack and the steel plate. Once these steps were 
completed, the load was applied on the spike by pumping the hydraulic jack to push the spike to a depth of 3in and the data was collected in the strain smart software program.

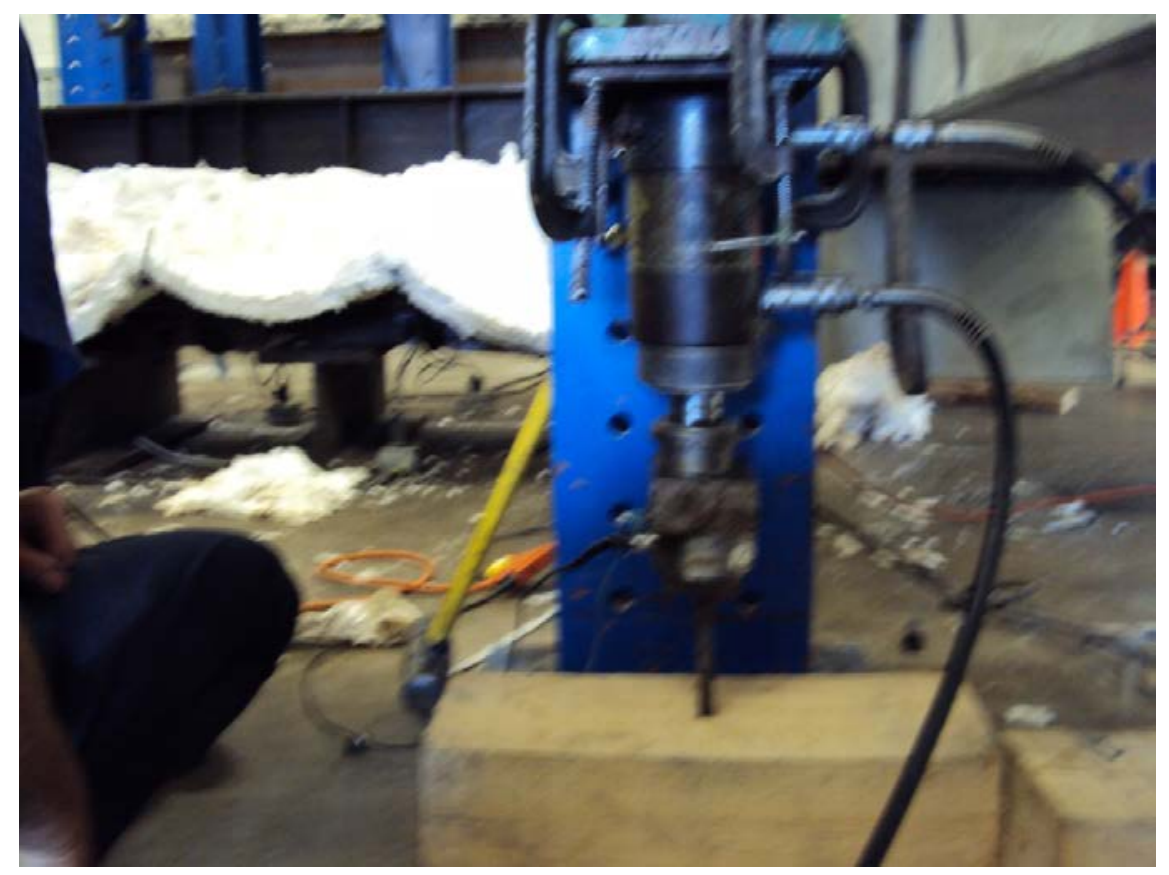

Figure 6-3: Spike Insertion Test Setup

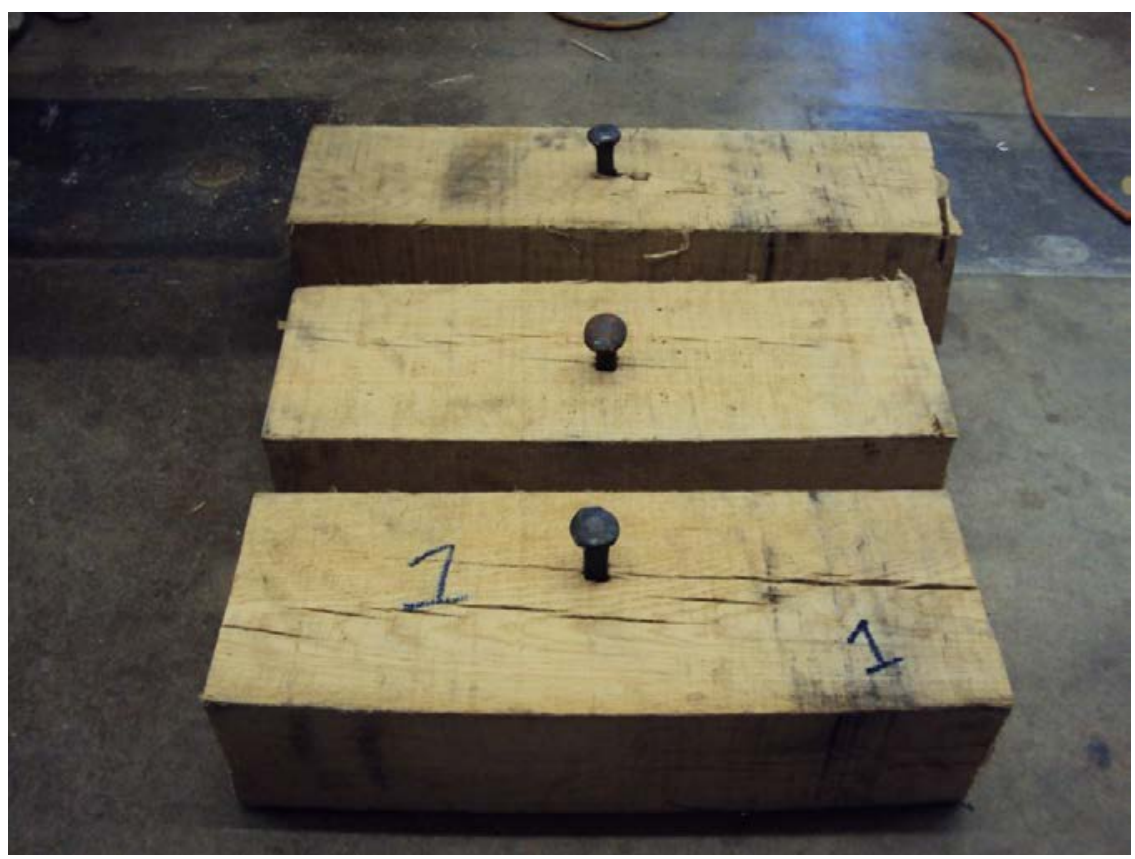

Figure 6-4: Inserted Spikes on Wood Tie Segments 


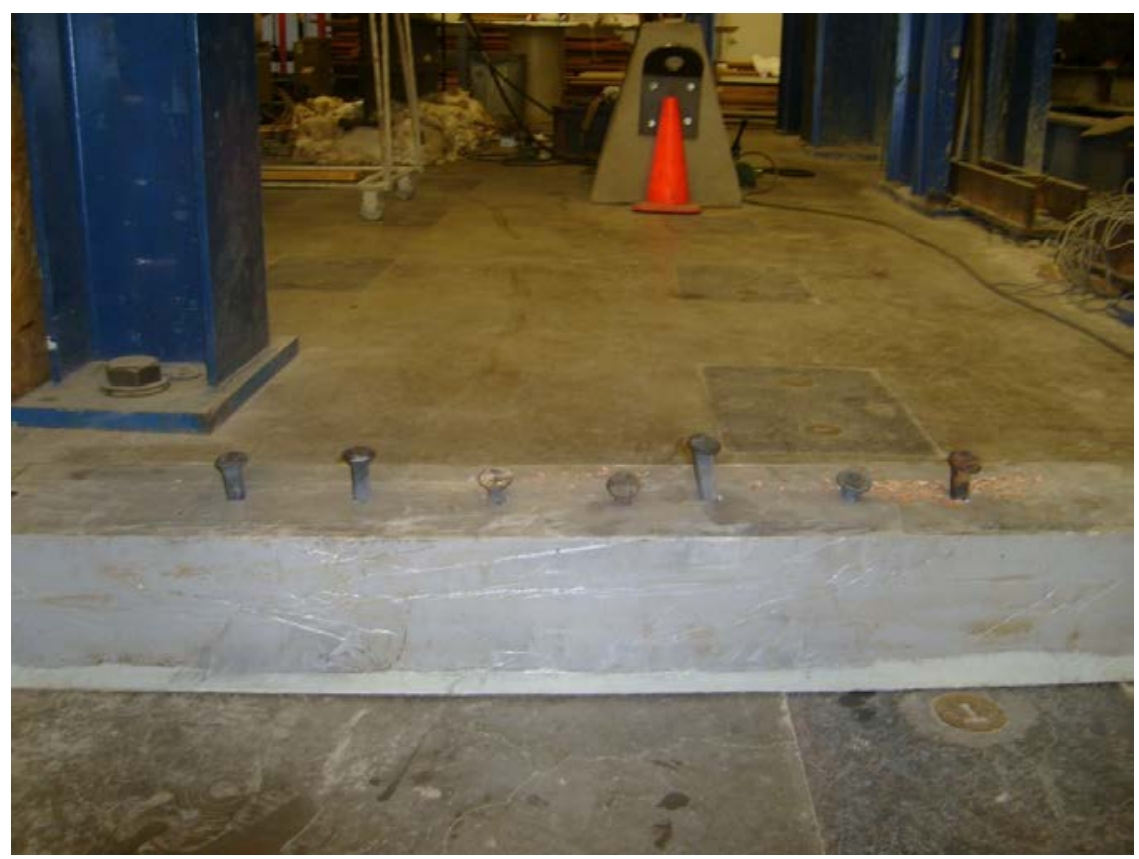

Figure 6-5: Inserted Spikes on Recycled Composite Tie along the length

\subsubsection{Spike pullout test}

After the spikes were inserted on the specimen, different set of arrangement was made to pullout the spikes. The small U-shape steel structure with the steel rod was used to hold the spike head. The outer Ushape steel structure, load cell and the hydraulic jack were placed from the top by passing the steel rod through the middle hole. At this point a bolt was screwed on top and bottom of the steel rod. Once these steps have been completed, the load was applied to pull the spike out from the specimen by pumping the hydraulic jack and the data was collected using the strain smart software program. 


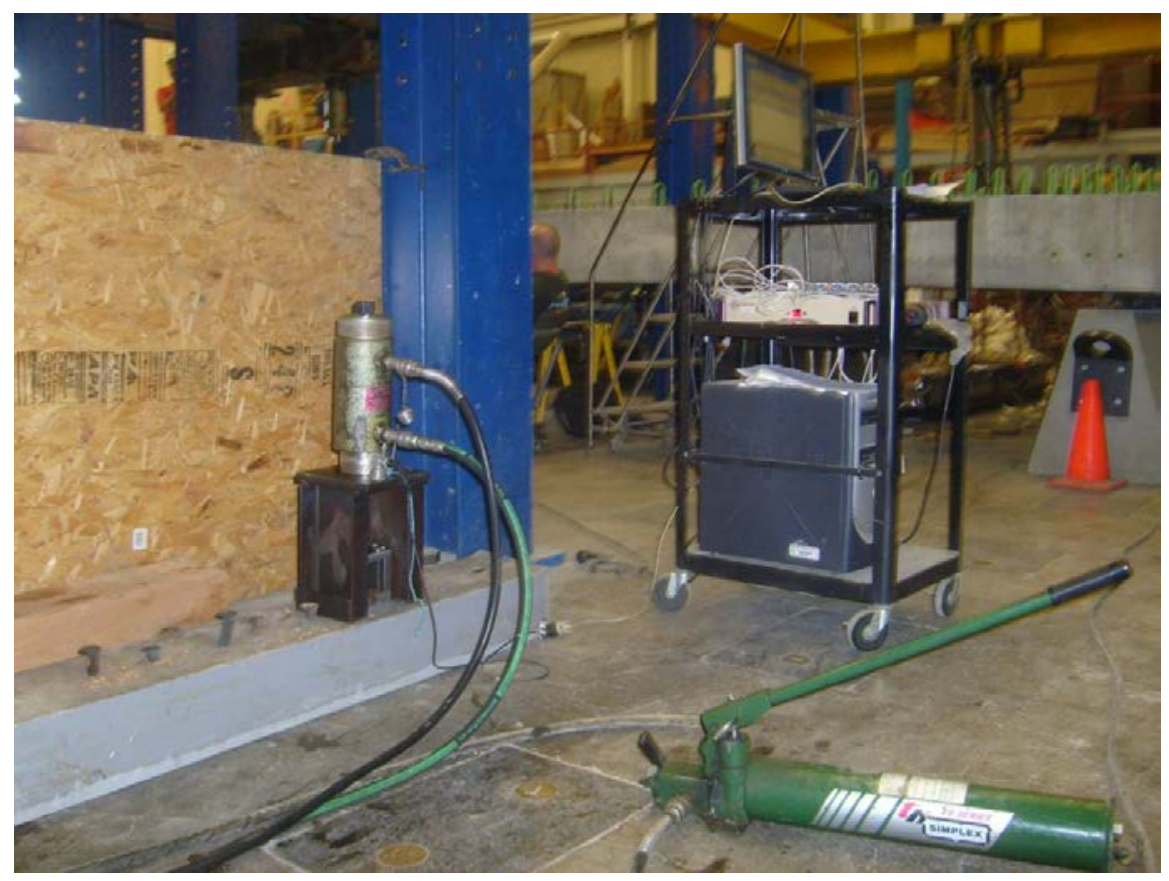

Figure 6-6: Spike Pullout Test on Recycled Composite Tie

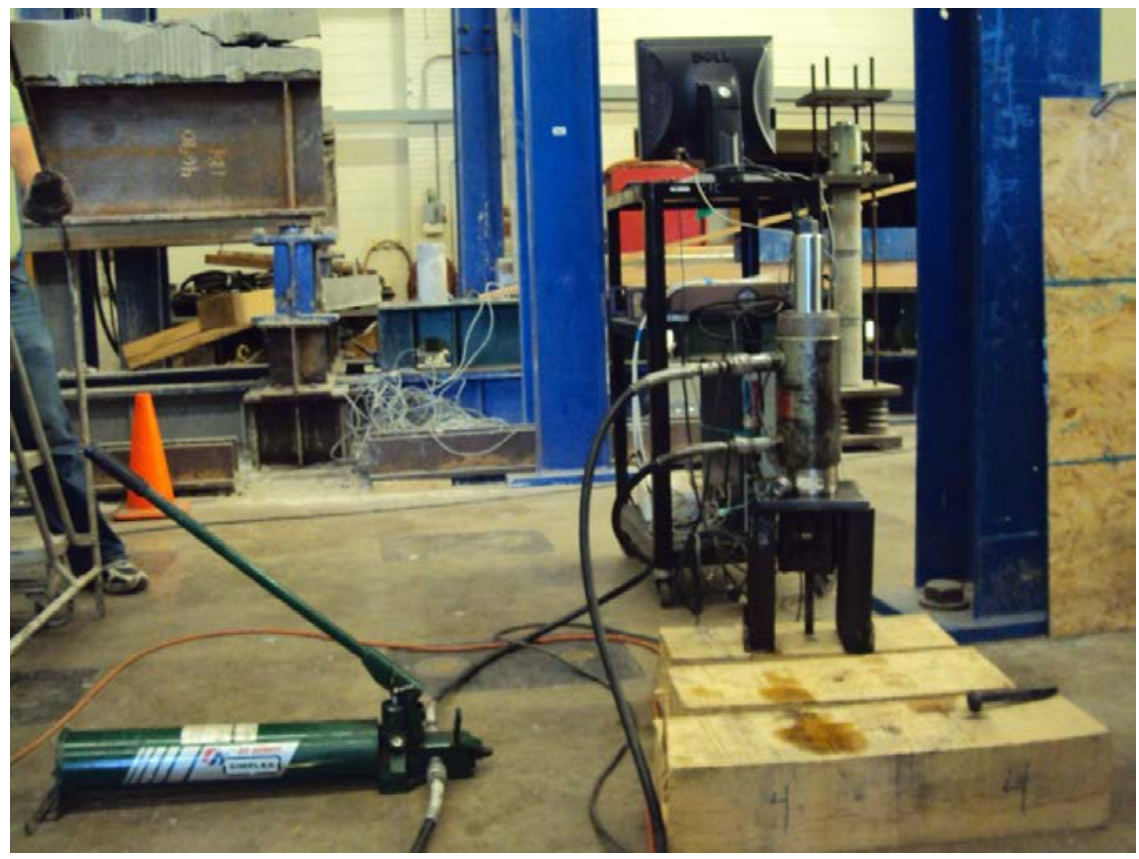

Figure 6-7: Spike Pullout test on Wood Tie Samples 


\subsection{Test Results}

The load data obtained by performing Spike Insertion Test and Spike Pullout test were tabulated in two separate tables. The average load of all the three spikes on Recycled Composite Tie and Wood Tie were also shown in the tables. The results for Spike Insertion and Pullout Test were plotted in the Bar Graphs.

Table 6-1: Spike Insertion Results

\begin{tabular}{|c|c|c|c|c|}
\hline \multirow{2}{*}{$\begin{array}{c}\text { Type of } \\
\text { Material }\end{array}$} & \multicolumn{4}{|c|}{ Spike Insertion Strength (lbs) } \\
\cline { 2 - 5 } & Spike 1 & Spike 2 & Spike 3 & Average \\
\hline Composite Tie & 14596 & 14340 & 15110 & 14682 \\
\hline Wood Tie & 12144 & 9902 & 10673 & 10906 \\
\hline
\end{tabular}

Table 6-2: Spike Pullout Results

\begin{tabular}{|c|c|c|c|c|}
\hline \multirow{2}{*}{ Type of Material } & \multicolumn{4}{|c|}{ Spike Pullout Strength (lbs) } \\
\cline { 2 - 5 } & Spike 1 & Spike 2 & Spike 3 & Average \\
\hline Composite Tie & 9248 & 5932 & 6703 & 7294 \\
\hline Wood Tie & 5792 & 8081 & 3924 & 5932 \\
\hline
\end{tabular}




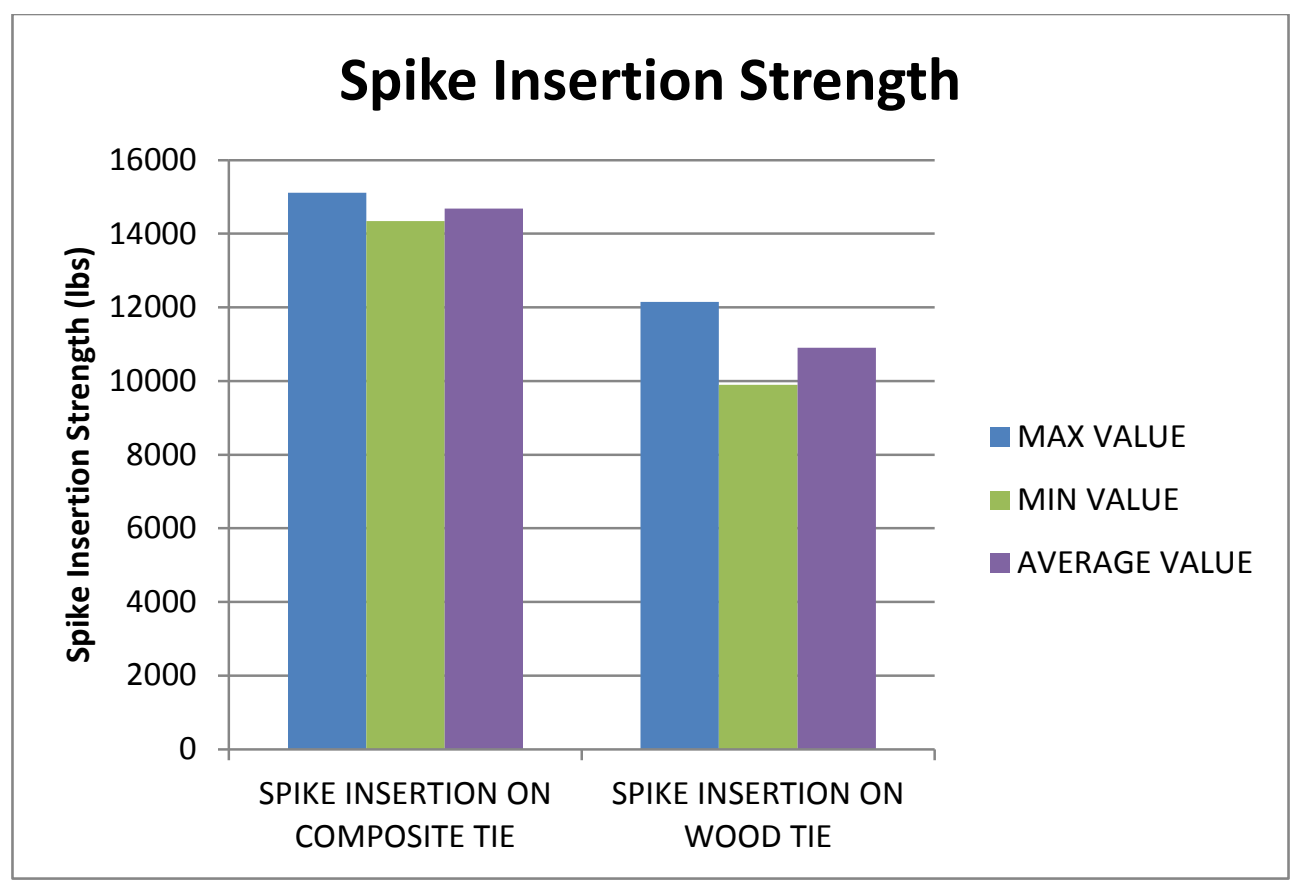

Figure 6-8: Bar Graph showing the spike insertion results on Composite and Wood Tie

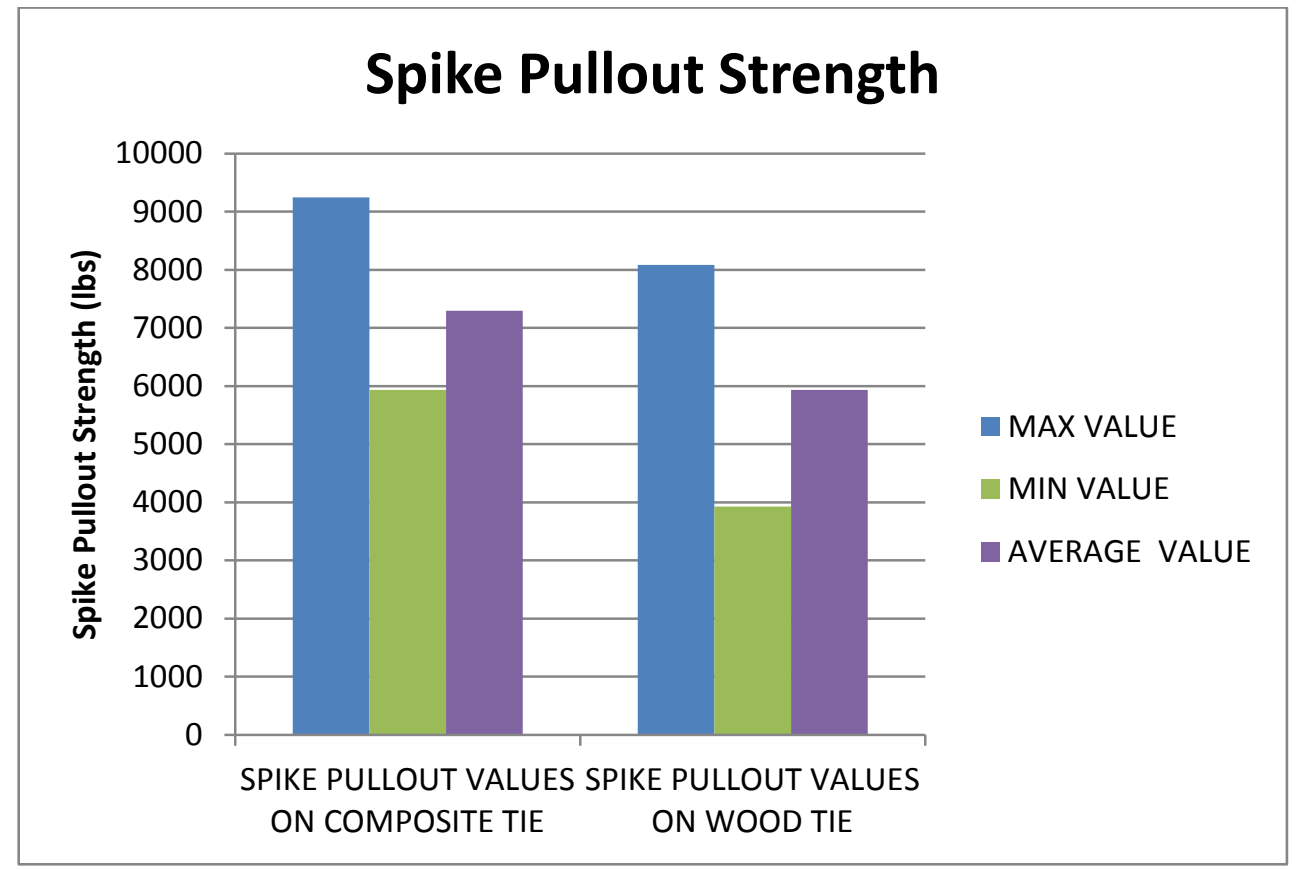

Figure 6-9: Bar Graph showing the spike pullout results on Composite and Wood Tie 


\subsubsection{Comparison of Spike Insertion Results on Composite and Wood Tie}

In this comparison, the spike insertion strength results on recycled composite ties were $26 \%$ higher than those of wood ties.

\subsubsection{Comparison of Spike Pullout Test Results on Composite and Wood Tie}

The pullout tests were performed on three spikes that were inserted in the recycled composite tie and wood Tie. In this comparison, the spike pullout strength results on recycled composite tie were 20 percent higher than the wood ties.

\subsection{Conclusions}

1. The strength to insert and pullout the spike was higher than wood tie in the recycled composite tie to prevent any movement of the rail with respect to the ties under mechanical loading.

2. The spike insertion strength results on recycled composite ties are $26 \%$ higher than wood ties because the additional load hindrance to insert the spike was offered by the composite shell. (14682psi vs 10906psi) (Table 6-1)

3. The spike pullout strength results on recycled composite tie were 20 percent higher in relation to wood ties because the additional load hindrance to pull the spike was offered by the composite shell. (7294psi vs 5932psi) (Table 6-2)

4. No splits or cracks were found after the spikes were inserted in the recycled composite ties.

5. Spikes in the recycled composite tie have more ability to attenuate dynamic impact loading and to resist uplift forces than wood ties.

6. Higher spike pullout strength in the recycled composite ties results in economical, operation and maintenance of the tie-track system, because the track system life depends mostly on spike performance. 


\section{FATIGUE TESTING ON A RECYCLED COMPOSITE TIE}

\subsection{Introduction}

The behavior of any material under fatigue loading varies from those under static loading. Some of the inservice materials undergo fatigue loadings with variable amplitudes. Fatigue testing was performed in the laboratory to predict the in-service life of recycled composite ties under constant amplitude fatigue loading. The application of load can be repeated several millions of times under constant amplitude loading conditions or under variable load conditions. Even in ductile materials, fatigue cycles cause brittle failures at various alternating stress levels. Crack initiation, crack growth and sudden failure are the three stages that occur generally in fatigue failures. Initiation of cracks may occur due to voids inside the material or surface flaws. These cracks propagate due to constant stress cycles and cause sudden failure in the material. These cracks mostly occur in the direction perpendicular to maximum tensile stress. Fatigue data were represented using a plot of constant amplitude stress levels (S) versus number of cycles to failures $(\mathrm{N})$. S-N curves are more significant in predicting the failure of metallic materials at various stress levels.

\subsection{Objective}

To determine the degradation in strength and stiffness of recycled composite ties under fatigue and comparing the experimental results with theoretical results for moment and deflections.

\subsection{Scope}

Flexural fatigue tests were performed on full scale recycled composite ties followed by intermediate static flexural test. Three point bending tests were conducted testing them under fatigue to establish static stiffness values of recycled composite ties and for calculating and deflection. Applied stresses were under flexural and shear. The tie embedded in a bin containing aggregate replicating ballast material was subjected to static load test at 0 cycles, 250,000 cycles and 500,000 cycles. 


\subsection{Tie Description}

Full scale recycled composite tie with approximate dimensions of 6.8in x 9in x 102in was embedded in ballast for fatigue testing. The ballast was compacted to $1 \mathrm{ft}$ depth in a composite bin. The recycled composite tie used was manufactured using the manufacturing process-II. This tie has GFRP shell and the core used was wood. The wood core (6.5in x 7in x 101in) had the moisture content of $12 \%$ on the surface. Two composite parts of various sizes were used to manufacture this tie. The fiber volume fraction of the tie was $10 \%$.

\subsection{Loading Calculations}

The test was carried out with the axle loads of 78000lbs (347KN). Minimum tie spacing of 19in was taken from the AREMA Manual, as reduction in the tie spacing reduces rail flexural stress; ballast compression stress, tie flexural stress and increases track modulus were observed. The load distribution factor for 19in spacing was taken from the figure 30-4-1 of AREMA Manual, as it is mainly dependent upon the tie and axle spacing, ballast and sub grade reaction, and rail rigidity. Impact factor for composite tie was assumed to be $130 \%$ because the wheel-to-rail load carried by the single tie varies from place to place. The approximate calculation of average ballast pressure was made as the tie-to-ballast pressure does not have uniform distribution. The average ballast pressure is equal to the total axle load modified by the impact factor and the load distribution factor divided by the bearing area of a tie. It can be calculated using:

Average ballast pressure $=(2 \mathrm{P})(1+\mathrm{IF} / 100)(\mathrm{DF} / 100) / \mathrm{A}$

Where $\mathrm{P}=$ Wheel load in pounds

$$
\begin{gathered}
\text { IF }=\text { Impact factor in percent } \\
\text { DF }=\text { Distribution factor in percent }
\end{gathered}
$$


A = Bearing area of cross tie in square inches

Average ballast pressure $=(2 \times 39000)(1+130 / 100)(43 / 100) /(102 \times 9)$

$$
=84.03 p s i
$$

AREMA Manual has recommended not exceeding 85psi for high quality and abrasion resistant ballast.

Average heavy axle load $=(2 \times \mathrm{P})(1+\mathrm{IF} / 100)(\mathrm{DF} / 100)$

$$
\begin{aligned}
& =(2 \times 39000)(1+130 / 100)(43 / 100) \\
& =77142 \mathrm{lbs}
\end{aligned}
$$

The maximum static load applied was $80,000 \mathrm{lbs}$. The fatigue load ranged from 77000 to $78000 \mathrm{lbs}$. The load was applied vertically with $90^{\circ}$ angles to the horizontal.

\subsection{Test Description}

Tie plates and rails were installed on the tie with five spikes on each side. 3/8in holes were made to drive the spikes in the tie. The I-beam was connected to the Computer controlled hydraulic system and set to rest on the rails. Strain and deflection data were collected to evaluate the degradation of strength after half a million cycles. Figure 7-1 shows the test setup for static and fatigue testing on a gravel bed.

\subsection{Instrumentation}

Three strain gages on the compression side and three on the tension side were installed on the recycled composite tie. One of the strain gage under a rail seat failed while installing the tie plate and rail. Static and fatigue loads were applied using computer controlled hydraulic system. Computer controlled hydraulic system which was capable of monitoring and controlling load-time and displacement-time cyclic patterns was used for conducting the fatigue testing. The strain smart software program was used to collect the strain data of the five strain gages by using data acquisition system. The data from computer controlled hydraulic system and data acquisition system can measure data as a function of time. 


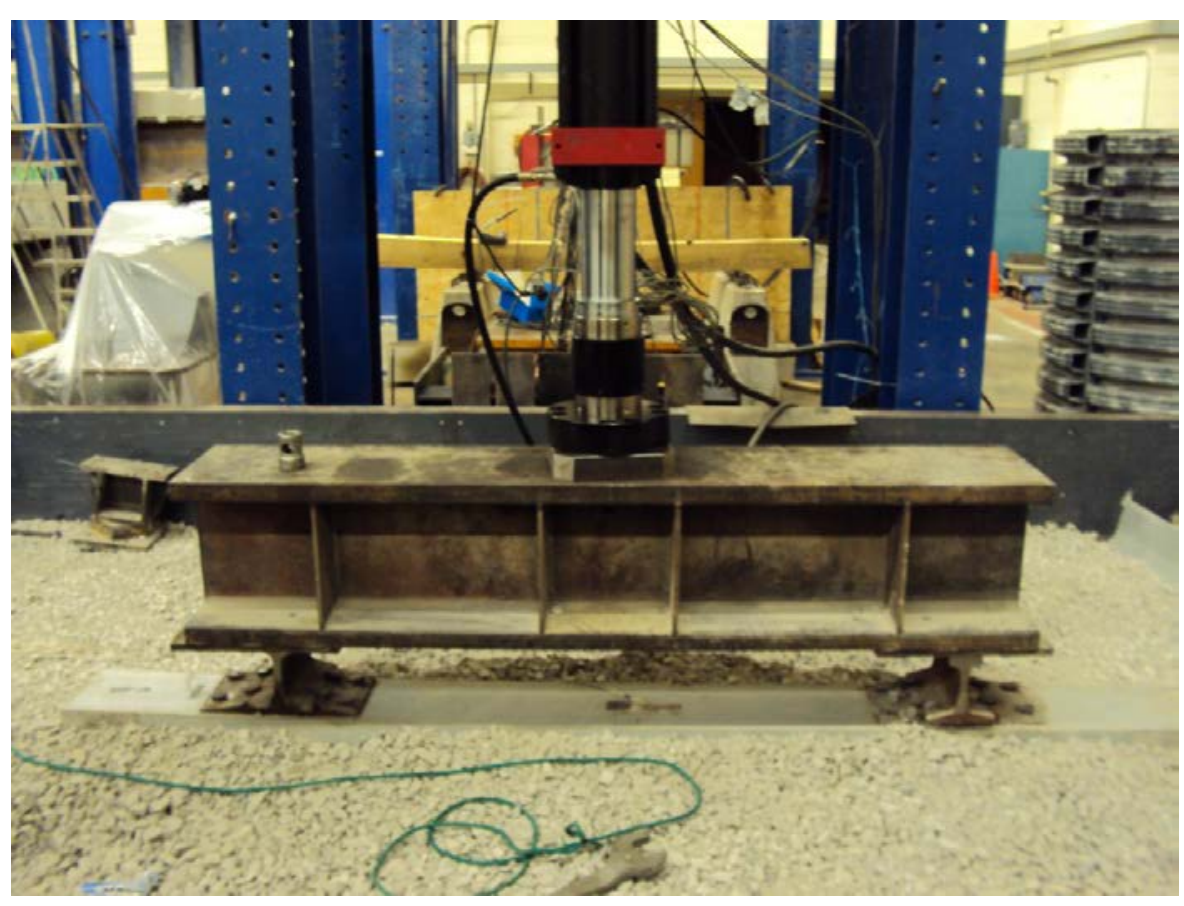

Figure 7-1: Fatigue Test setup in the Gravel

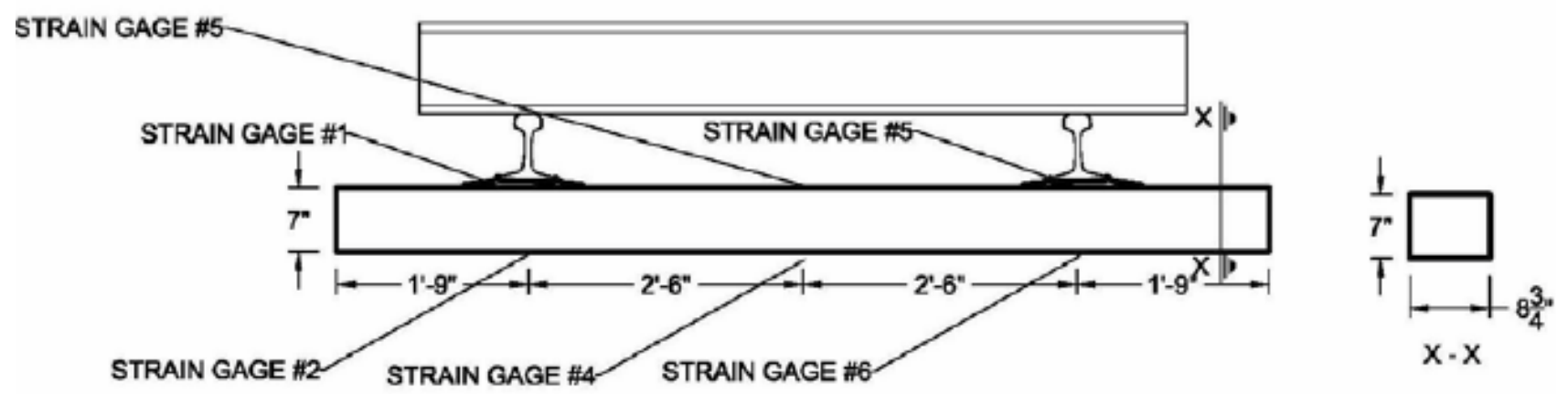

Figure 7-2: Fatigue Test setup 


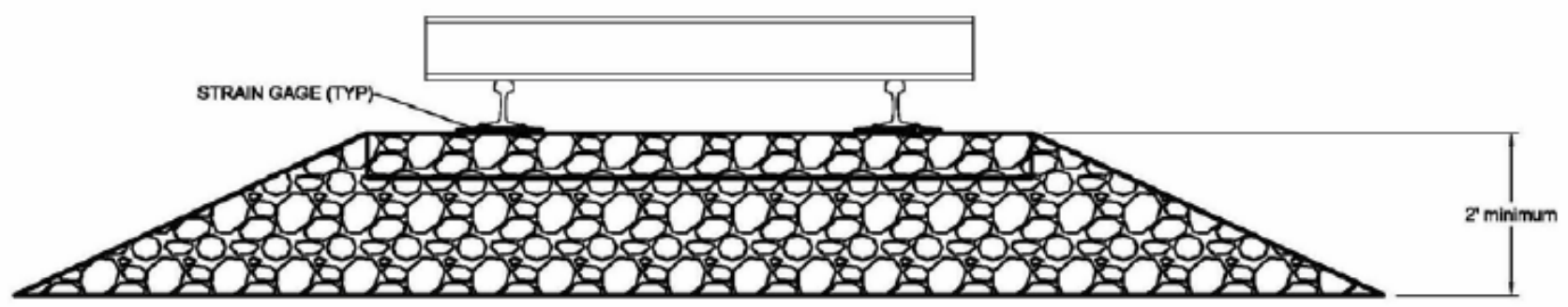

Figure 7-3: The embedded recycled composite tie

\subsection{Test Procedure}

The actuator was operated using the test star software program. The static test followed by the fatigue test was done after exerting five hundred thousand cycles of fatigue load.

The I-beam was connected to the Computer controlled hydraulic system and set to rest on the rails. The static and fatigue loads were applied with $0^{0}$ angles to the vertical on the tie embedded in the gravel. The maximum deflections were collected from the test star software program and the maximum strains were collected from the strain smart software program. The hydraulic jack was then released and set to run five hundred thousand cycles. The required set of maximum deflections and strains were collected from their respective software programs. The static test was repeated at intervals of every five hundred thousand cycles.

Table 7-1: Details of fatigue test specimen

\begin{tabular}{|c|c|}
\hline Specimen Manufactured Process & Manufacturing process-II \\
\hline Fatigue Load Range (Kips) & $8-78$ \\
\hline Static Load Range (Kips) & $0-80$ \\
\hline Total number of Fatigue Cycles & 2 Million \\
\hline Intervals at which static tests are conducted & 500,000 Cycles \\
\hline
\end{tabular}




\subsection{Theoretical Evaluation}

The theoretical values of bending moment and deflections were calculated using elastic foundation theory (Boresi, 2003). The rail road tie resting on the elastic foundation is not rigid. The analysis of beam bending on the elastic foundation is developed on the assumption that the reaction forces are proportional to the deflection and bending moment at any point (Boresi, 2003). The elastic foundation transmits normal loads to the base of the structure and the closed spaced linearly independent elastic spring with the constant (K) determines the vertical displacement characteristics of the foundation.

$\underline{\text { Theoretical Deflection and Bending Moment Analysis }}$

Modulus of foundation, $\mathrm{K}_{0}=250 \mathrm{lbs} / \mathrm{in}^{3}$

Spring constant, $\mathrm{K}=2187.5 \mathrm{lbs} / \mathrm{in}^{2}$

Moment of inertia, I = 268 in $^{4}$ (Table 5-4)

Modulus of elasticity, $\mathrm{E}=1.316$ × $10^{6}$ Psi (Table 5-4)

Length of the Recycled Composite Tie, $\mathrm{L}=102$ in

Span, $2 \mathrm{C}=60$ in

Applied single load, $\mathrm{P}=39$ Kips

Distance from the deflection point to the point of loading, $\mathrm{Z}_{1}$

From Euler - Bernoulli beam theory

From the fourth order ordinary differential equation, $v^{\mathrm{IV}}+4 \beta^{4} v=0$

$$
\text { Where, } \beta=\sqrt[4]{\frac{\mathrm{K}}{4 \mathrm{EI}}}=0.0353 \text { in }
$$

\section{Deflection at the center}

Distance from one of the point load to the center of the ties, $Z=30$ in

Deflection at the Center of the tie,

$$
v(\mathrm{z})=\frac{P \beta}{2 K} e^{-\beta Z}(\sin (\beta Z)+\cos (\beta Z))(2)=0.297 \text { in (Boresi, 2003) }
$$




\section{$\underline{\text { Deflection at the rail seat }}$}

Distance between the point loads, $\mathrm{Z}=60$ in

Deflection at the rail seat,

$$
v(\mathrm{z})=\frac{P \beta}{2 K}+\frac{P \beta}{2 K} e^{-\beta Z}(\sin (\beta Z)+\cos (\beta Z))=0.327 \text { in }
$$

Bending Moment at the center

Distance from one of the point load to the center of the ties, $\mathrm{Z}=30 \mathrm{in}$

Bending Moment at the center of the tie,

$$
M=\frac{\mathrm{P}}{4 \beta} \mathrm{e}^{-\beta \mathrm{Z}}(\cos (\beta \mathrm{Z})-\sin (\beta \mathrm{Z}))(2)=73162 \text { lbs-in }
$$

Bending Moment at the rail seat

Distance between the point loads, $\mathrm{Z}=60$ in

Bending Moment at the Rail Seat,

$$
M=\frac{P}{4 \beta}+\frac{\mathrm{P}}{4 \beta} \mathrm{e}^{-\beta \mathrm{Z}}(\cos (\beta \mathrm{Z})-\sin (\beta \mathrm{Z}))=230605 \text { lbs-in }
$$

Table 7-2: Theoretical Deflections and Bending Moment Values

\begin{tabular}{|c|c|c|}
\hline Distance from one point load & Deflection (v(z)) & Bending Moment (M) \\
\hline To the center of the tie, $Z=30$ in & 0.297 in & 73162 lbs-in \\
\hline To the other point load, $Z=60$ in & 0.327 in & 230605 lbs-in \\
\hline
\end{tabular}

\subsection{Test Results}

Results of the fatigue test in terms of strain values and deflections on the railroad tie at different locations are shown in Figure 7-2 and Figure 7-3 and different fatigue cycles. These results are further discussed in sections 7.10.1 and 7.10.2. 
Table 7-3: Maximum strains

\begin{tabular}{|c|c|c|c|c|c|}
\hline \multirow{2}{*}{ Strain gage \# } & \multicolumn{5}{|c|}{ Maximum Strains $(\boldsymbol{\mu} \boldsymbol{\varepsilon})$} \\
\cline { 2 - 6 } & $\begin{array}{c}1 \\
\text { cycles }\end{array}$ & $\begin{array}{c}500.000 \\
\text { cycles }\end{array}$ & $\begin{array}{c}1000000 \\
\text { cycles }\end{array}$ & $\begin{array}{c}1500000 \\
\text { cycles }\end{array}$ & $\begin{array}{c}2000000 \\
\text { cycles }\end{array}$ \\
\hline$\# 1$ & -1272 & -1530 & -1441 & -1778 & -2019 \\
\hline$\# 2$ & 2173 & 2515 & 2930 & Offscale & Offscale \\
\hline$\# 3$ & 608 & 514 & 560 & 547 & 850 \\
\hline$\# 4$ & -514 & 349 & 1402 & 1410 & 1707 \\
\hline$\# 5$ & Offscale & Offscale & Offscale & Offscale & Offscale \\
\hline$\# 6$ & 1308 & 999 & 1269 & 1609 & 1363 \\
\hline
\end{tabular}

Table 7-4: Maximum Deflections

\begin{tabular}{|c|c|c|c|c|c|}
\hline \multirow{2}{*}{ Location } & \multicolumn{5}{|c|}{ Maximum Deflections (inch) } \\
\cline { 2 - 6 } & $\begin{array}{c}1 \\
\text { cycles }\end{array}$ & $\begin{array}{c}500.000 \\
\text { cycles }\end{array}$ & $\begin{array}{c}1000000 \\
\text { cycles }\end{array}$ & $\begin{array}{c}1500000 \\
\text { cycles }\end{array}$ & $\begin{array}{c}2000000 \\
\text { cycles }\end{array}$ \\
\hline Center of tie & 0.29 & 0.23 & 0.24 & 0.245 & 0.248 \\
\hline
\end{tabular}

\subsubsection{Comparison of Experimental and Theoretical Deflections using Elastic Foundation Theory}

Maximum experimental deflection from Table 7-4 was used to compare with theory.

\section{$\underline{\text { Experimental Deflections }}$}

As the theory static data corresponds to only first cycle of loading, the experimental deflection at first cycle of loading from the maximum deflections Table 7-4 was considered.

$$
v(\mathrm{z})=0.29 \text { in }
$$

The theoretical deflection $(0.327$ ', Table $7-2)$ at the rail seat of the cross tie was compared with the experimental deflections. The theoretical deflection was 11 percent higher than the experimental 
deflection. There was a good correlation between the test results and theory. This could be adjusted upon the sub-grade modulus value.

\subsubsection{Comparison of Experimental and Theoretical Bending Moments using Elastic Foundation Theory}

The strain data from the Table 7-3 is used to calculate the experimental bending moment at center and rail seat of the Recycled Composite Tie.

\section{Experimental Bending Moment}

The formula based on bending in a beam from Beam Theory is given as,

$$
\begin{gathered}
\sigma=\frac{M C}{I} \\
M=\frac{\sigma I}{C}=\frac{E \varepsilon I}{C}
\end{gathered}
$$

In which,

$\mathrm{M}=$ Moment in the beam in inch-lbs (or inch-kips)

$\sigma=$ Bending stress in Psi (or Ksi)

I $=$ Moment of Inertia in inch` 4

$\mathrm{C}=$ Centroidal distance from the top extreme fiber of the tie in inch

$\mathrm{E}=$ Young's Modulus of the tie in Psi (or Ksi)

$\varepsilon=$ Maximum strain in $\mu \varepsilon$ 
On the top of a tie, maximum strain at the center was $608 \mu \varepsilon$ and at the rail seat was $1272 \mu \varepsilon$. On the bottom of a tie, maximum strain at the center was $514 \mu \varepsilon$ and at the rail seat was $2173 \mu \varepsilon$. The composite tie properties are taken from Table 5-4

Maximum bending moment at center of the tie, $\mathrm{M}_{\mathrm{tc}}$

$$
M=\frac{E \varepsilon I}{C}=\frac{1.36 * 608 * 227.75}{3.39}=61266 \text { lbs-in }
$$

Maximum bending moment at rail seat of the tie, $\mathrm{M}_{\mathrm{bc}}$

$$
M=\frac{E \varepsilon I}{C}=\frac{1.36 * 2173 * 227.75}{3.39}=218968 \text { lbs-in }
$$

\begin{tabular}{|c|c|c|c|c|}
\hline Location & $\begin{array}{l}\text { Theoretical } \\
\text { Deflection } \\
(v(z))\end{array}$ & $\begin{array}{l}\text { Experimental } \\
\text { Deflections } \\
(v(z))\end{array}$ & $\begin{array}{c}\text { Theoretical } \\
\text { Bending Moment } \\
\text { (M) }\end{array}$ & $\begin{array}{c}\text { Experimental } \\
\text { Bending Moment } \\
\text { (M) }\end{array}$ \\
\hline Center of tie & 0.297 in & N/A & 73162 lbs-in & 61266 lbs-in \\
\hline Rail Seat area & 0.327 in & 0.29 in & 230605 lbs-in & 218968 lbs-in \\
\hline
\end{tabular}

Table 7-5: Theoretical Results vs Experimental Results

After applying two million cycles, the experimental bending moment at the center of the cross tie was 16 percent lower than the theoretical bending moment and at the rail seat area was 5 percent lower than the theoretical bending moment. The above comparison shows that there was a good correlation between the experimental and the theoretical results.

\subsection{Conclusions}

1. No visible flexural and shear cracks were observed up to one million cycles but a shear crack under the rail seat was noted after two million cycles. 
2. No visible signs of tie plate compression and spike pullout after two million cycles were found. Use of composite laminate shell has resulted in better pullout and plate compression performance of the tie.

3. In composite laminate, the strain gage $(\# 2)$ at the bottom of the rail seat went offscale after one million cycles. It was due to the crack initiation of the composite laminate.

4. Theoretical deflection based on 'Beams on elastic foundations' of composite ties was 11 percent higher than the experimental deflection. (0.327in vs 0.29in)

5. Recycled composite ties carried 16 percent higher bending moment than the theoretical value at the center (73162lbs-in vs 61266lbs-in) and 5 percent lower bending moment than the theoretical value at the rail seat area. (230605lbs-in vs 218968lbs-in)

6. After one million cycles, the top and bottom maximum strains at the center of the tie were $560 \mu \varepsilon$ and $1402 \mu \varepsilon$, respectively. The increase in the top and bottom maximum strains after two million cycles was $34 \%$ and $17 \%$, which is attributed to the gradual stiffness reduction in the composite laminate at the center of the tie.

7. After one million cycles, top and bottom maximum strains at the rail seat were $-1441 \mu \varepsilon$ and $1269 \mu \varepsilon$, respectively. The increases in the top and bottom maximum strains after two million cycles were $28 \%$ and $6 \%$, respectively. It was due to gradual stiffness reduction in the composite laminate at the rail seat of the tie. 


\section{FIELD INSTALLATION AND TESTING}

\subsection{Introduction}

Recycled Composite Ties with two different fiber configurations (Table 3-3) that were manufactured using manufacturing process-I were field installed in Moorefield, WV at three different locations Figure 8-1. Old wooden ties were removed from the track at different locations and were replaced by the Recycled Composite Ties and respiked. Installation procedure was similar to those of wood ties. Three ties were installed on straight track, two ties on gentle curve and two ties on sharper curve. A locomotive was provided by SBVR-WVDOT for testing purpose. The test data was collected for static and dynamic loading by the locomotive on the installed ties. Four different test results were collected during the tests.

\subsection{Objective}

To monitor the performance of installed GFRP composite ties at different speeds of the locomotive in terms of their strength.

\subsection{Materials}

Full scale cross ties were made using manufacturing process-I with two different fiber configurations (Refer to chapter 2). Five GFRP composite ties consisting of unidirectional and mat fibers were considered as first configuration (No.1, No.2, No.3, No.4, No.7) and two Recycled Composite Ties consist of unidirectional, $90^{\circ}, \pm 45^{\circ}$ and continuous mat fibers which were considered as second configuration (No.5, No.6). The adhesive used was recycled ABS.

\subsection{Tie Installation Locations}

Seven ties were installed in the field at three different locations within a distance of half a mile of each other on straight and curving track locations. Tie No.1, No.5 and No.3 were installed on straight track (Figure 8-3). Tie No.4 and No.6 were installed on gentle curve $\left(<2^{0}\right.$ curve) (Figure 8-2). Tie No.2 and No.7 were installed on sharp curve (above $5^{0}$ ) (Figure 8-4). 


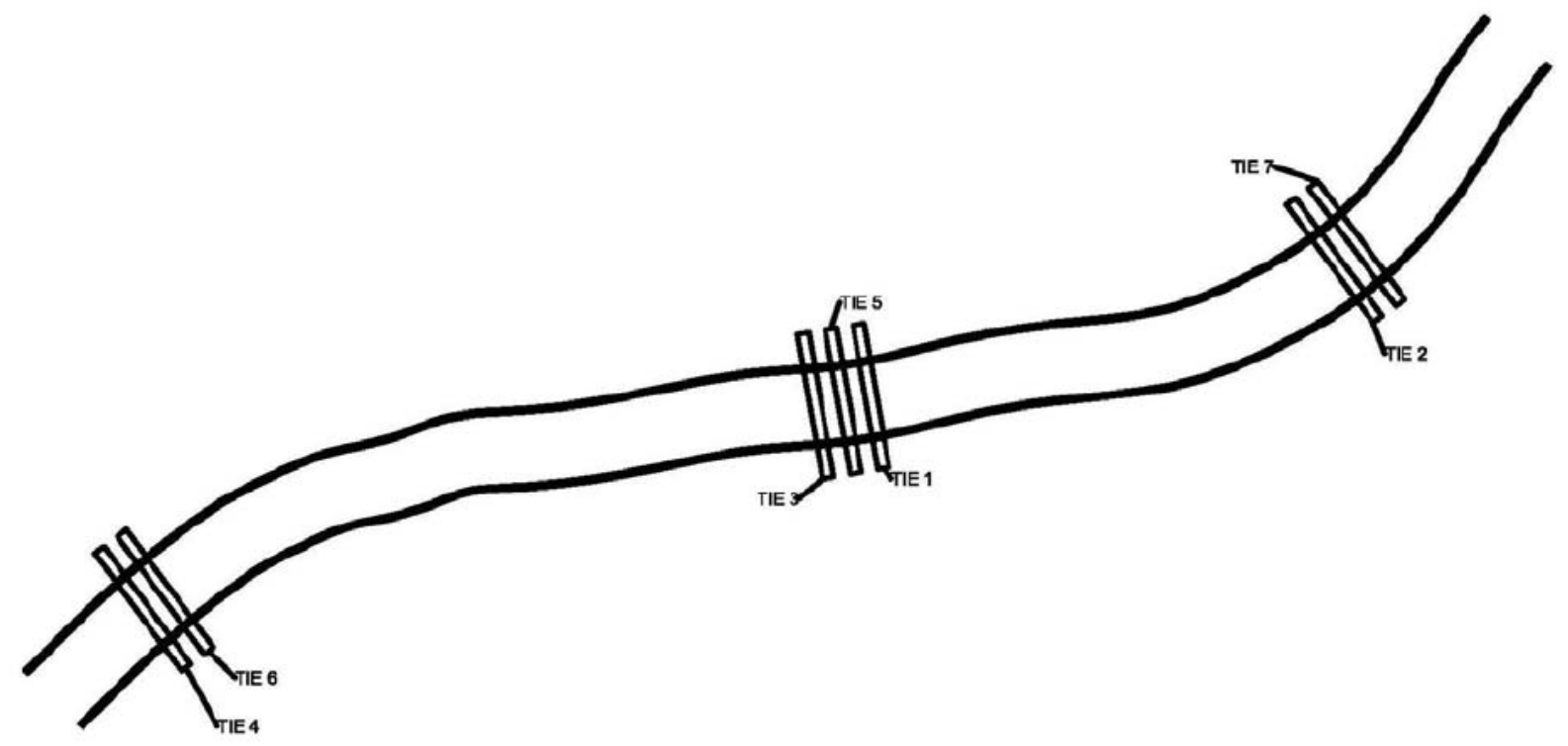

Figure 8-1: Track Path in the Moorefield

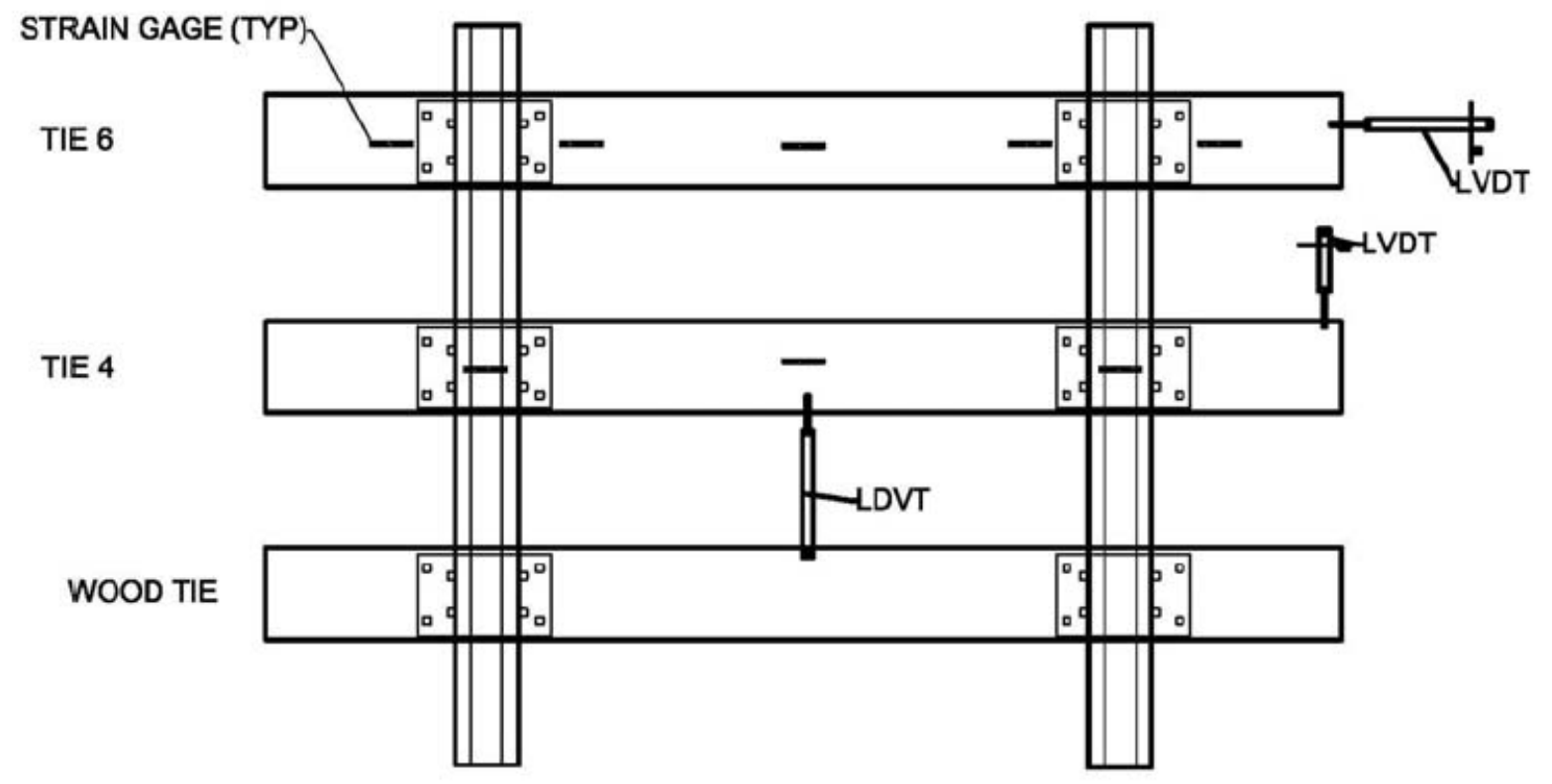

Figure 8-2: Test Setup on Gentle Curve 


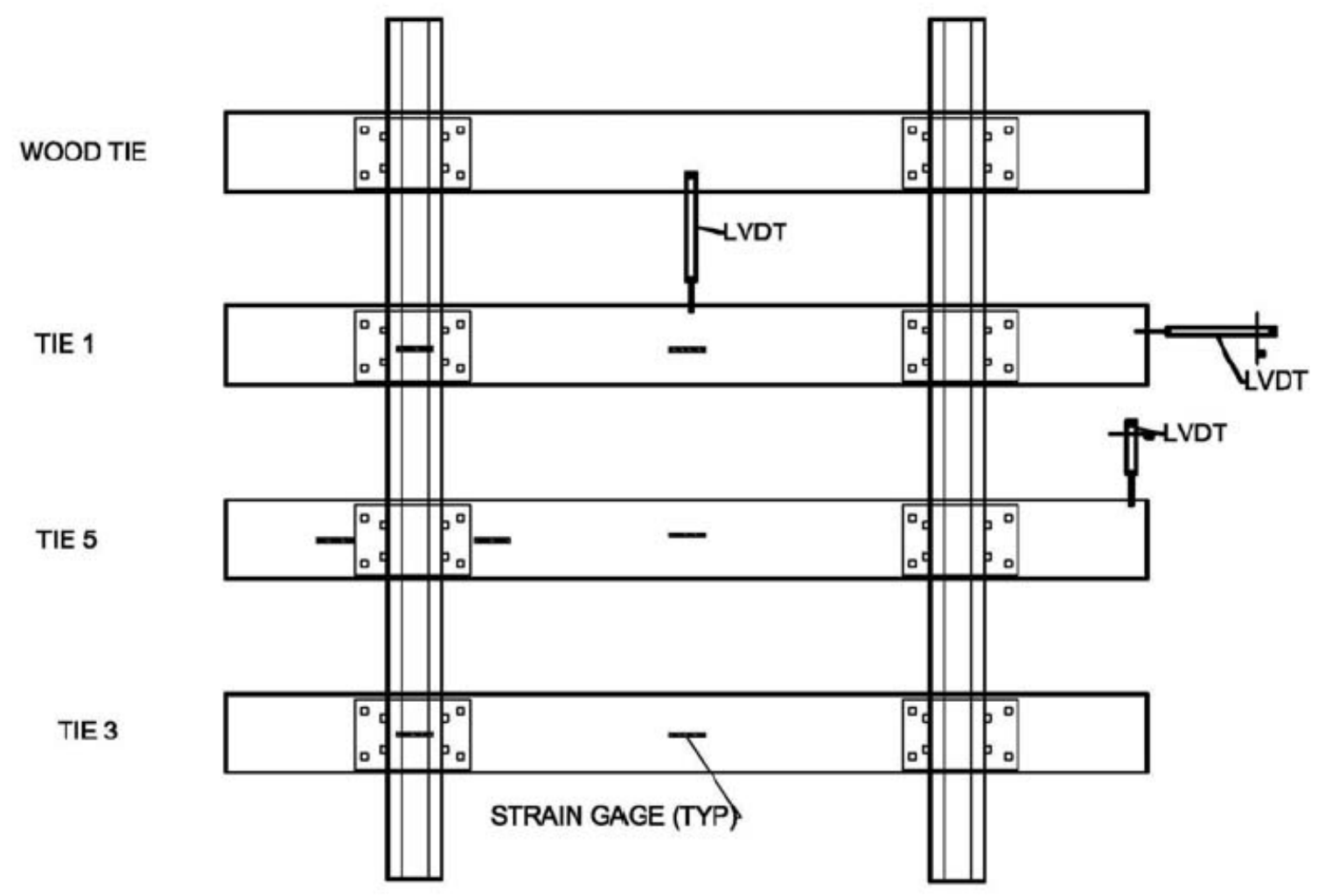

Figure 8-3: Test Setup on Straight Track

TIE 2

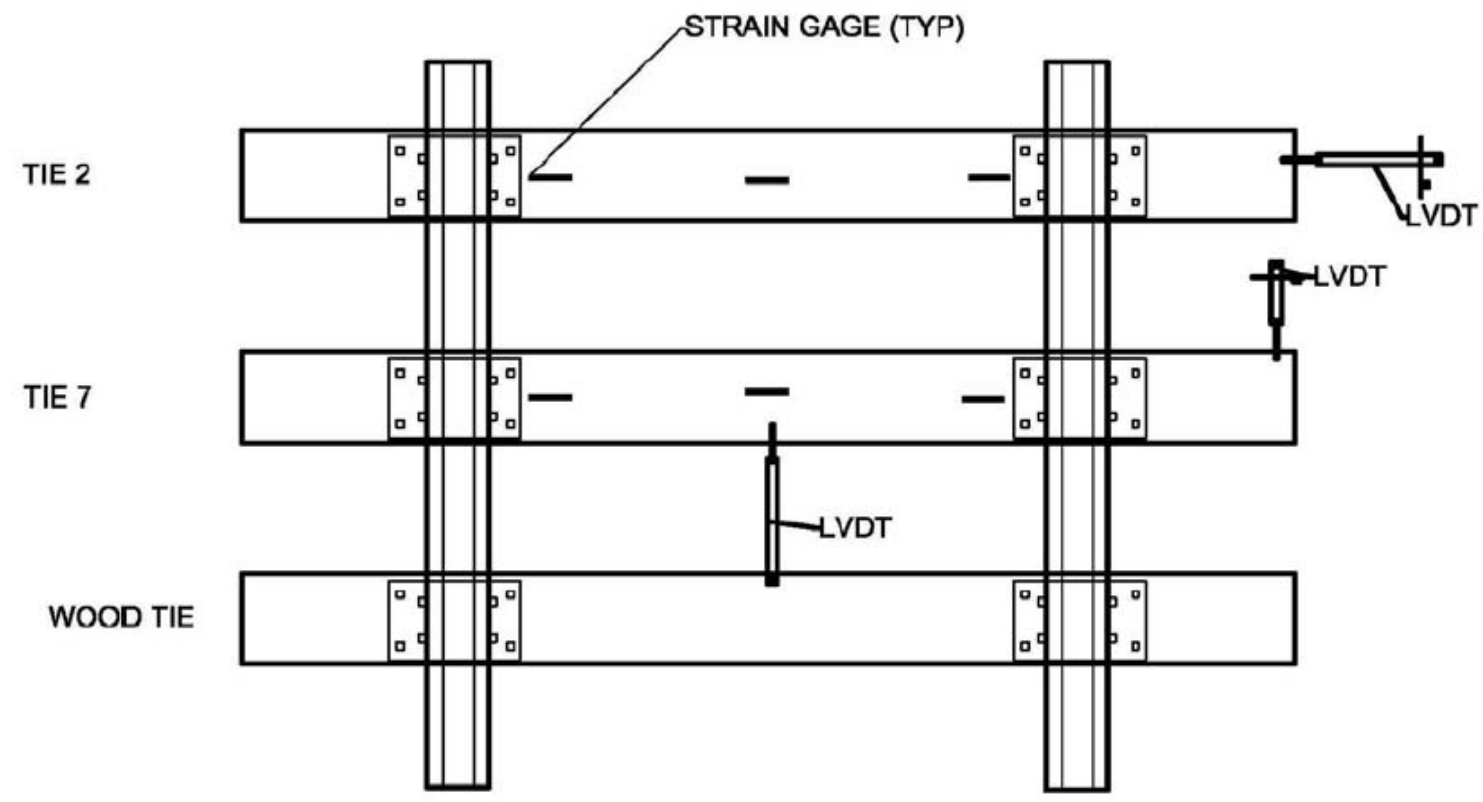

Figure 8-4: Test Setup on Sharp Curve 


\subsection{Tie Installed Procedure}

Some of the deteriorated wooden ties were selected to be replaced by the composite ties. Spikes were removed from the selected wooden ties. Once the spikes have been removed, the ties were taken off by lifting the rails using. The gravel bed was leveled at the place where the wooden ties have been removed and the space was cleared to install composite ties. The composite ties were installed very carefully. After that the spikes were driven in to the composite ties using the Spike Driving Machine.

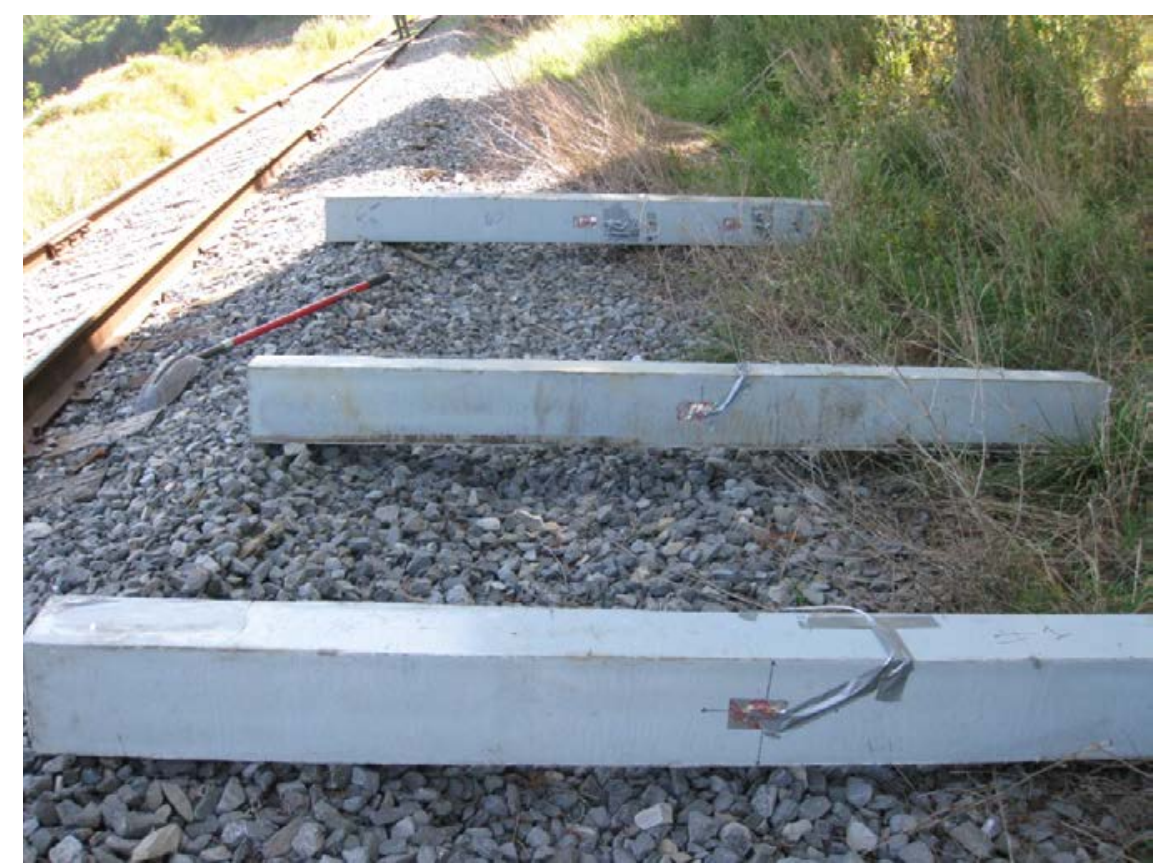

Figure 8-5: Composite ties were ready for replacing the deteriorated wooden ties on SBVR track 


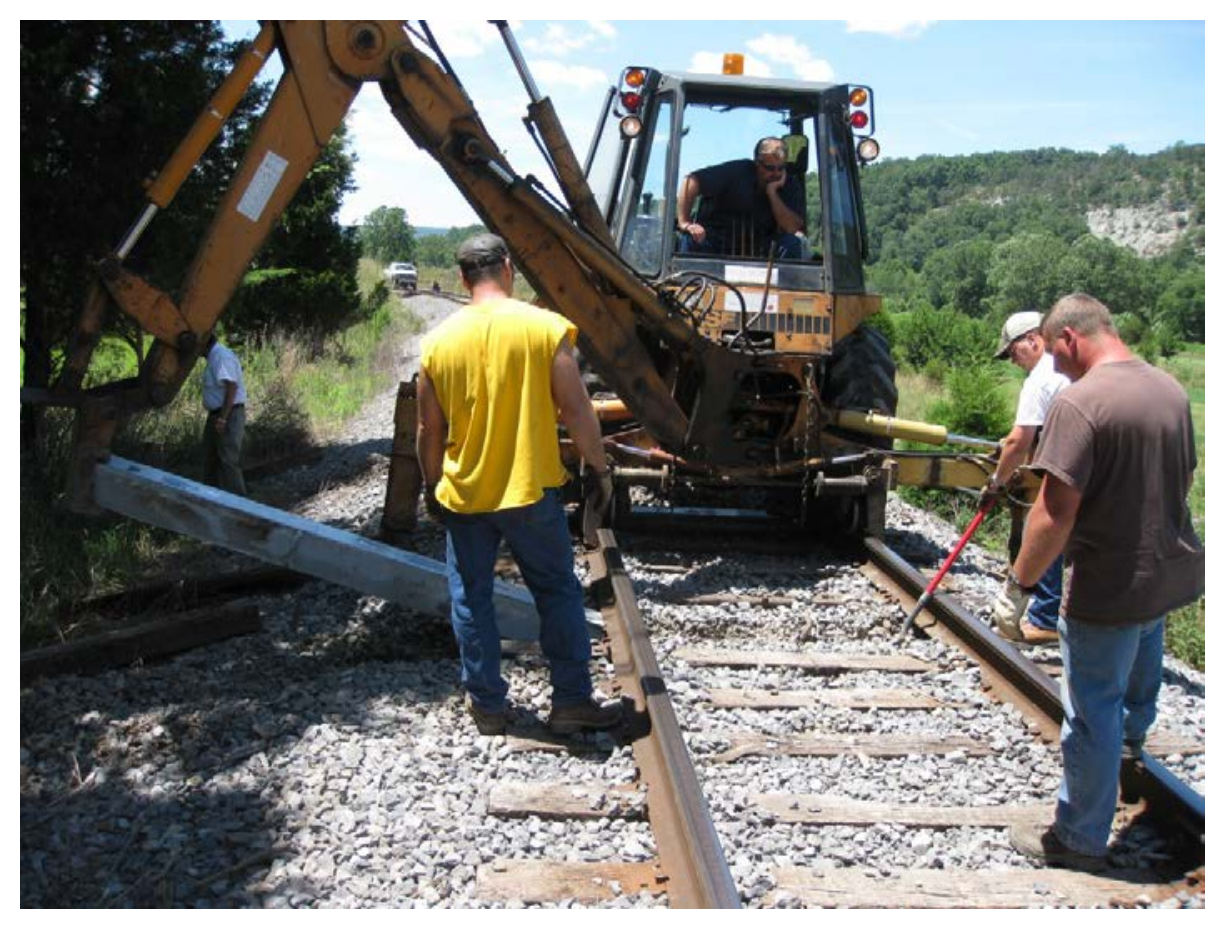

Figure 8-6: Composite tie being pushed into the space of removed wood tie

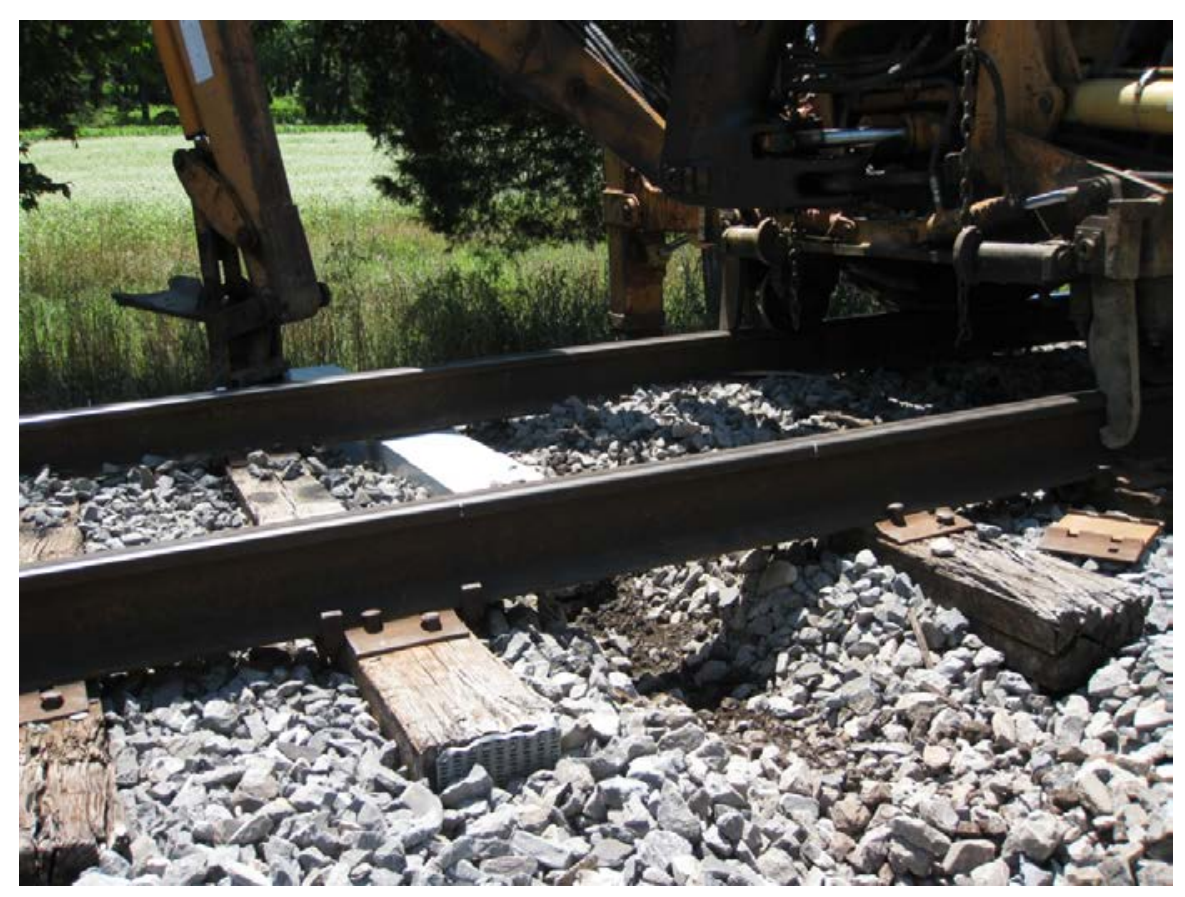

Figure 8-7: Composite tie being nudged into the space of removed wood tie 


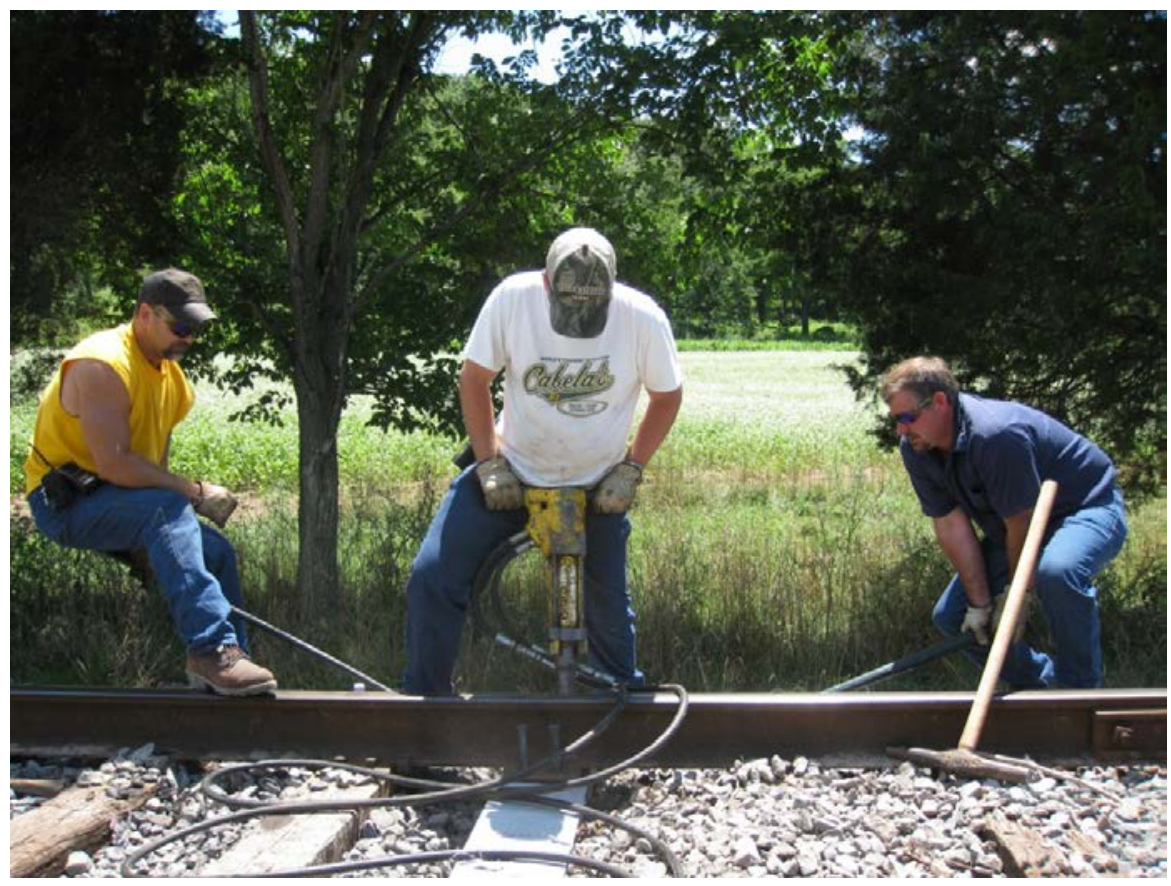

Figure 8-8: Spikes were driven after the composite ties were installed

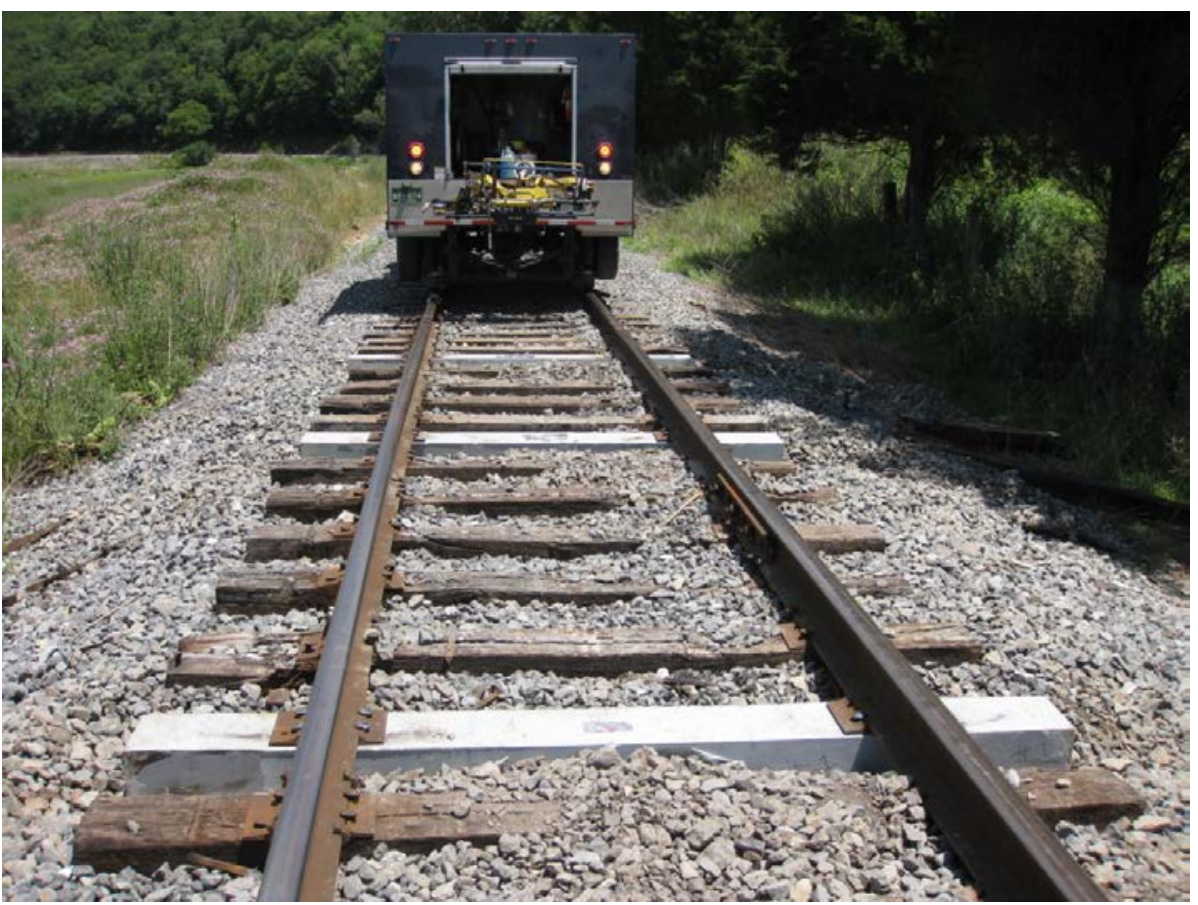

Figure 8-9: Recycled Composite Ties after installation 


\subsection{Instrumentation}

Some of the strain gages were mounted before the ties was installed in the field and some after. They were protected using the thick rubber pads to resist the harsh environmental conditions in the field. They were mounted at the center and near to the rail seat on top of the ties.

LVDT's were used to measure deflections, longitudinal movement, lateral movement and gage change.

The strain smart software program was used to collect the data from the data acquisition system.

Standard locomotive (weighing 256kips) was used to apply static and dynamic loading in the field.

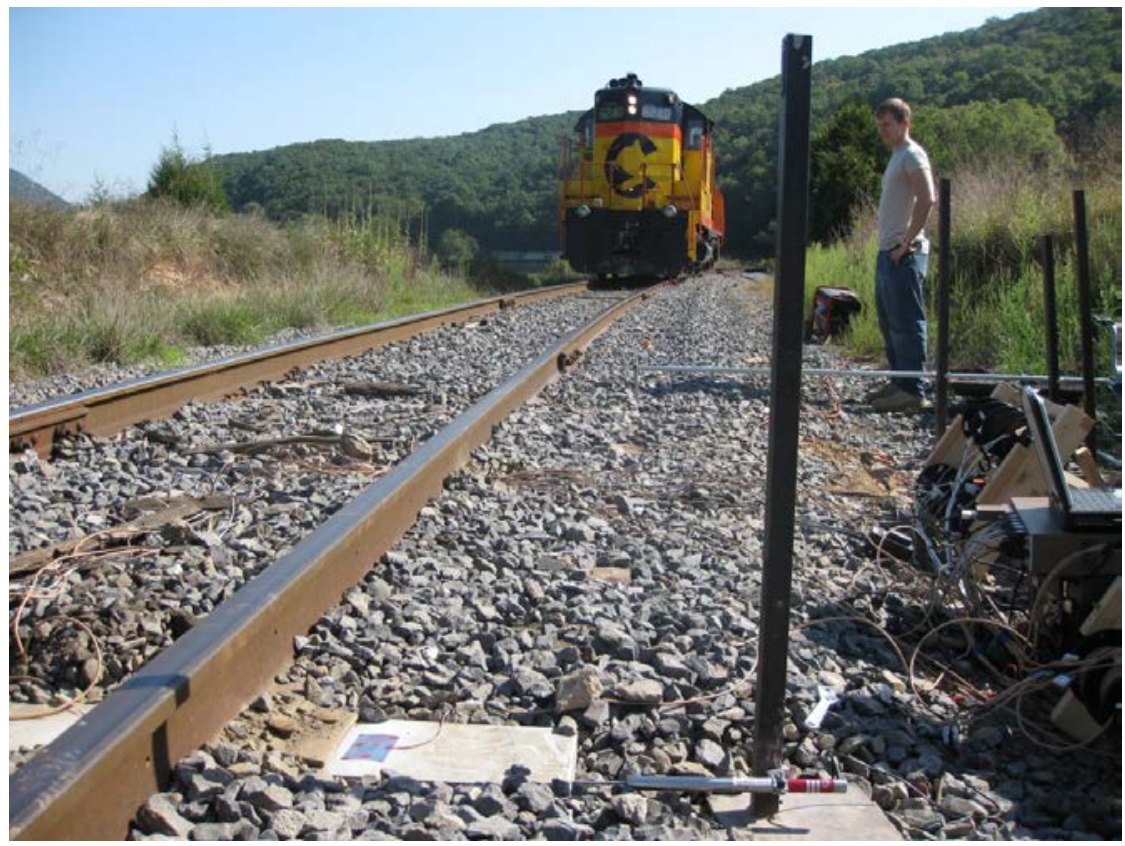

Figure 8-10: Standard Locomotive (Weighing 256Kips) 


\subsection{Test Procedures}

\subsubsection{Strains and Deflections}

Deflections were measured at three different locations on two old configuration ties and one new configuration tie. Strains were measured on seven Recycled Composite Ties and one wood tie. The locations of the LVDT's and strain gages were shown in cad drawings. Deflection and strain data were collected when the ties were subjected to static and dynamic loading by a locomotive.

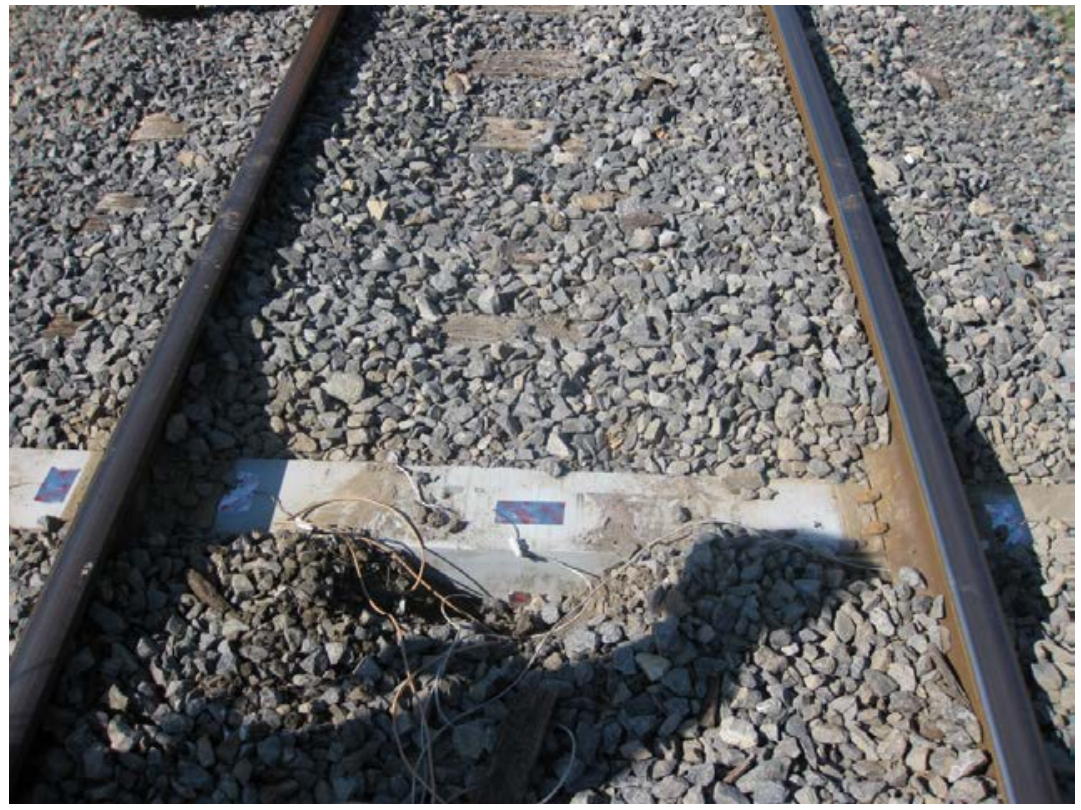

Figure 8-11: Installed Strain Gages on the Recycled Composite Tie 


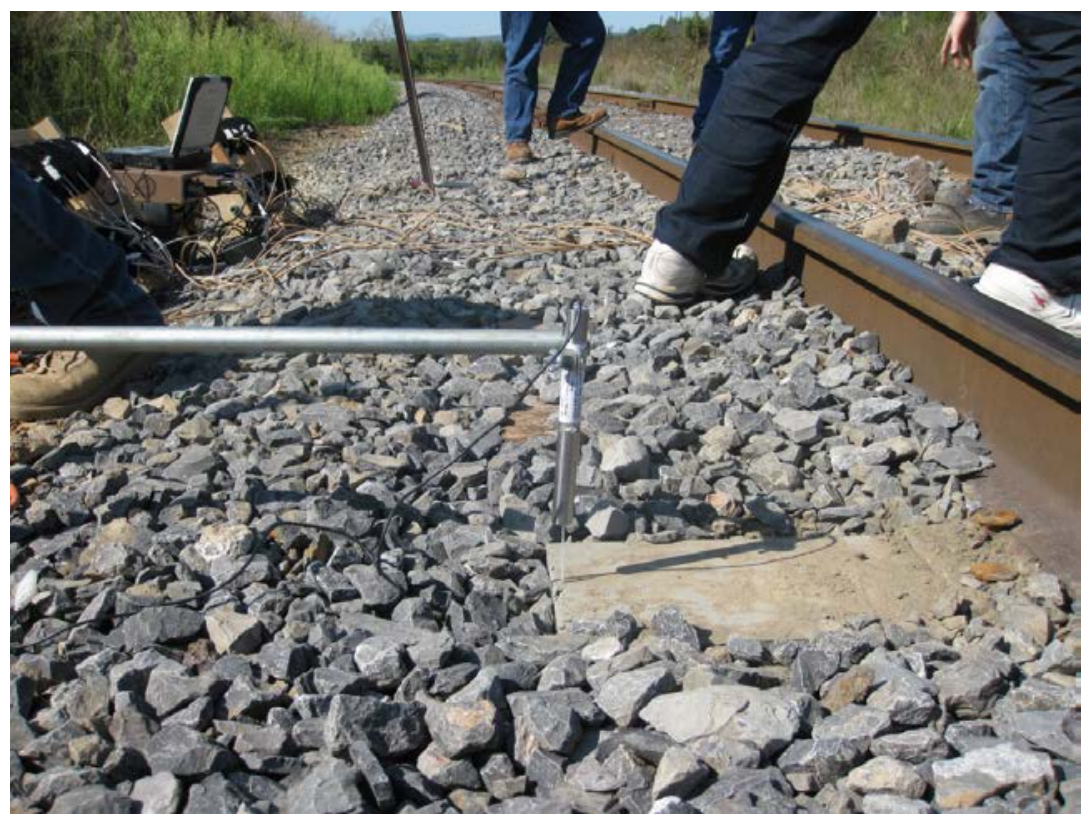

Figure 8-12: LVDT used for Deflection Measurements

\subsubsection{Lateral Movement}

Lateral movement is defined as change in the distance between two consecutive ties when the ties were subjected to moving loads. An LVDT was placed in between the two ties to measure the lateral movement. The location of the LVDT was shown in the Figure 8-13. At the beginning, the data was reset to zero and when the tie was subjected to dynamic loading the data was collected using the strain smart software program. 


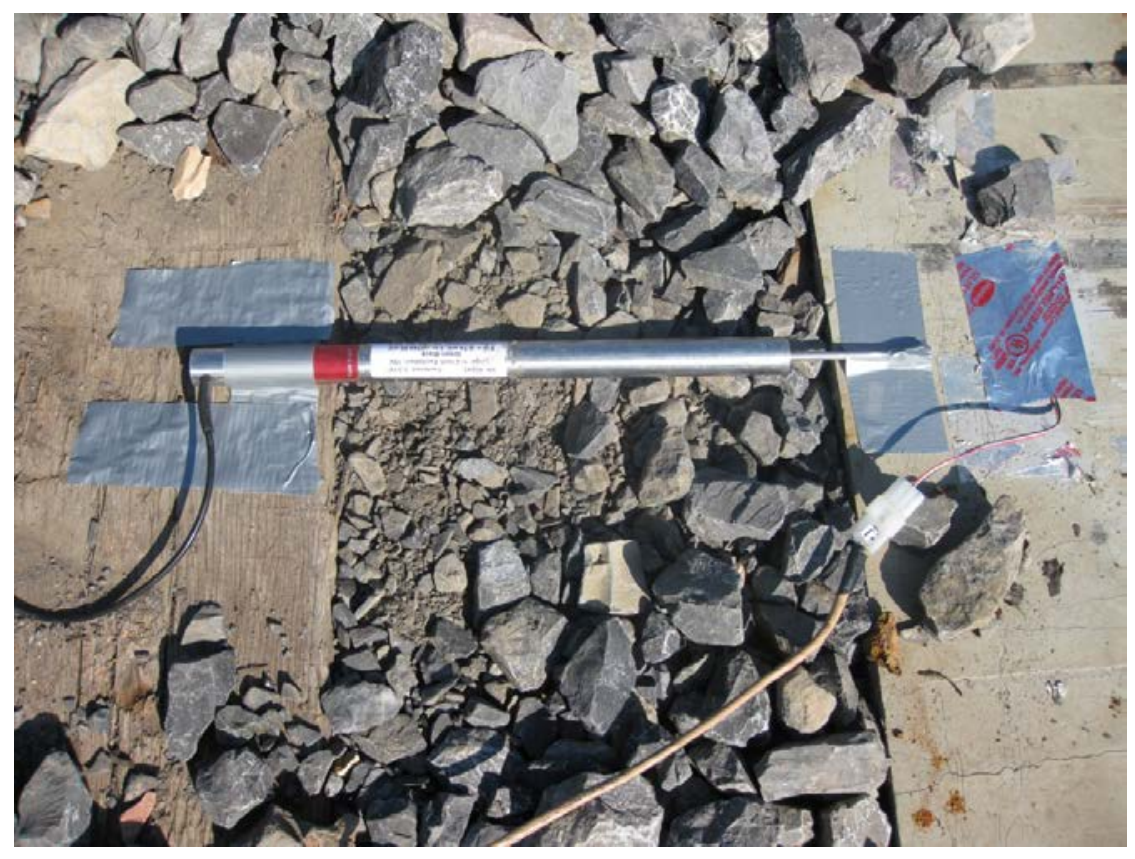

Figure 8-13: LVDT used for horizontal movement along the track direction (between ties)

\subsubsection{Longitudinal Measurement}

Longitudinal movement measurement is the longitudinal movement of an individual tie in the gravel when the tie was subjected to moving loads. An LVDT was placed at the end of the tie to measure the longitudinal movement. The location of LVDT was shown in Figure 8-14. The data has been collected when the tie was subjected to dynamic loading. 


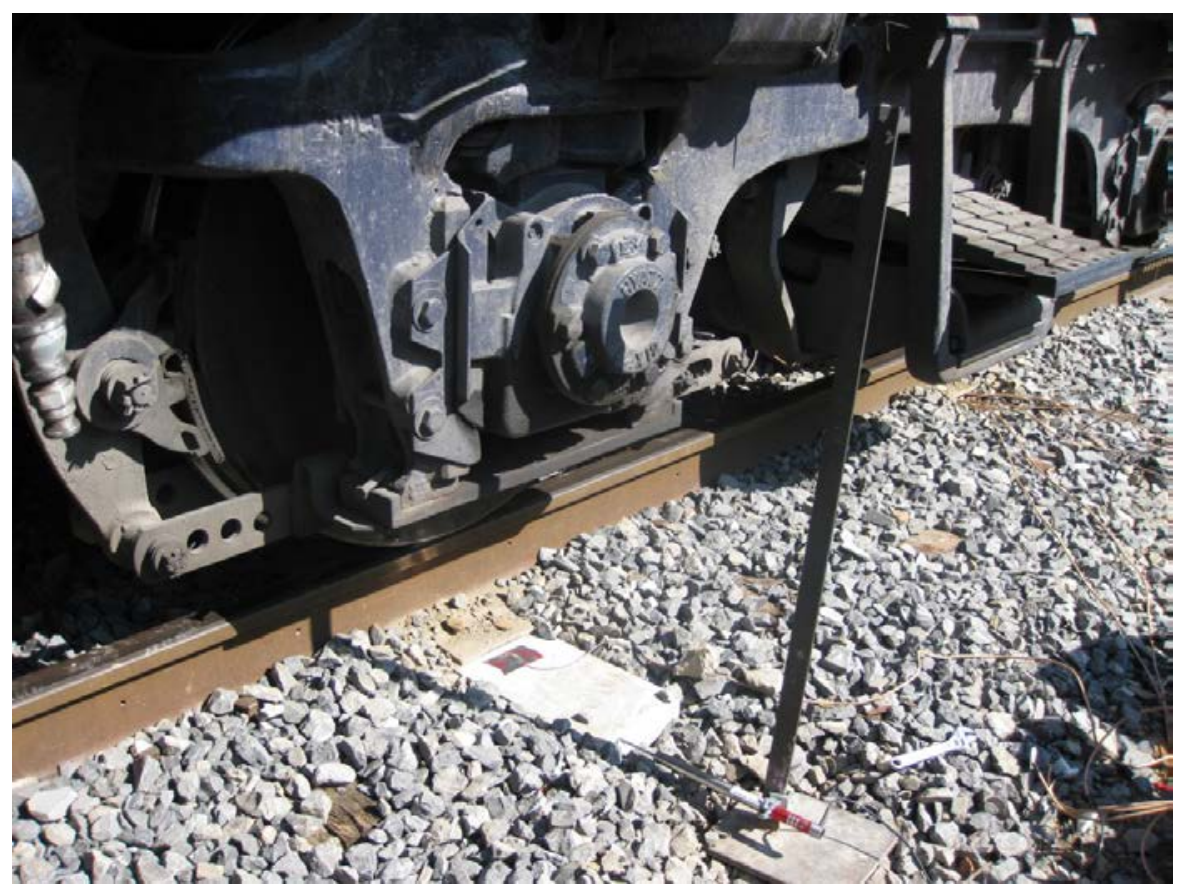

Figure 8-14: LVDT used for horizontal movement along the tie (perpendicular to tie)

\subsubsection{Gage Change}

Gage change measurement is the change in the distance between the rails when the rails were subjected to moving loads. An LVDT was placed in between the rails to measure the gage change. Figure 8-15 shows the location of the LVDT. The LVDT readings were collected when the rails were subjected to dynamic loading. 


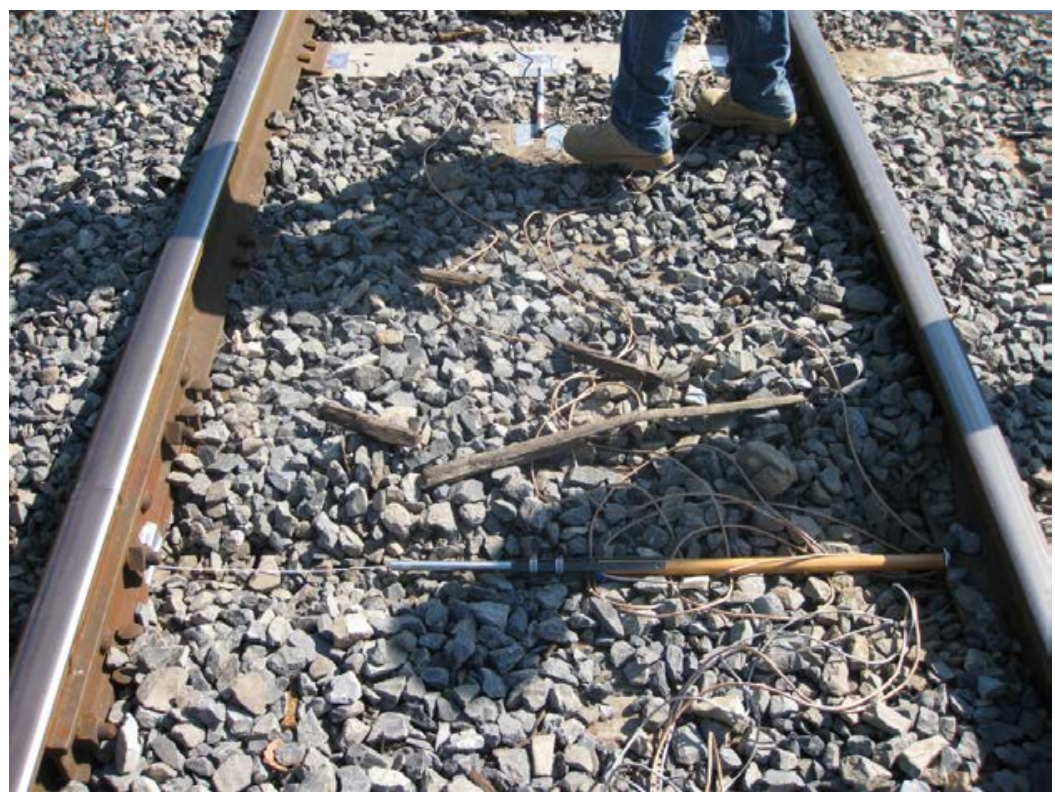

Figure 8-15: LVDT being used to measure change in the distance between rails

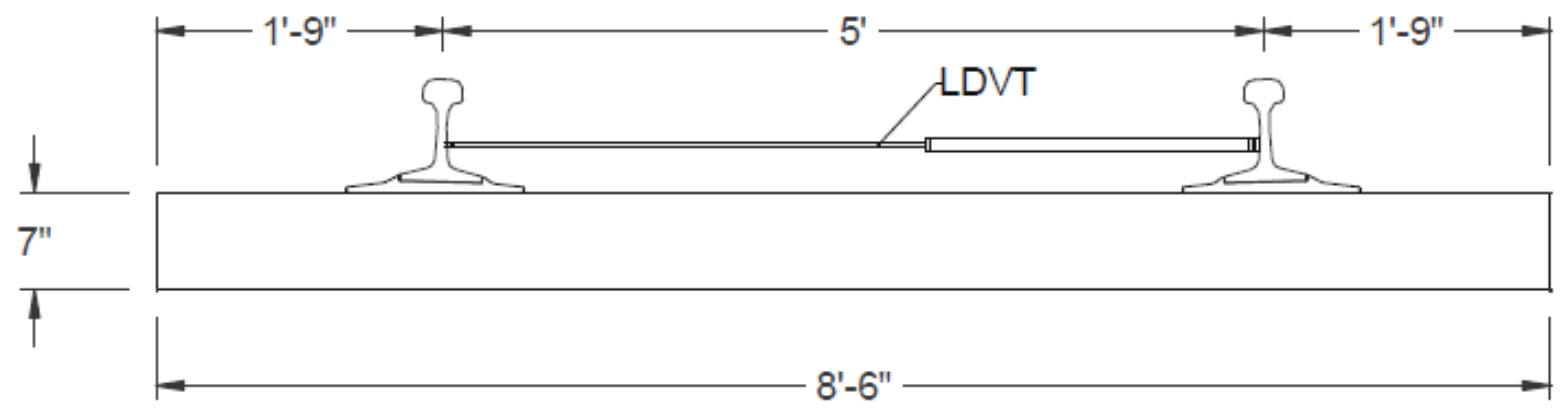

Figure 8-16: Gage Change Measurement Setup 


\subsection{Test Results}

Strains on the tie center and tie rail seating of first configuration and second configuration of the ties are presented in Table 8-1and Table 8-2 in Appendix 'C'. Deflections, longitudinal movement, lateral movement and the gage change at three different locations such as straight track, gentle curve and sharp curve are presented in Table 0-1,Table 0-2,Table 0-3 and Table 0-4 in appendix. The maximum values at three different locations were presented in Table 0-5 and Table 0-6. The results are graphically represented in Figure 8-17 through Figure 8-21. Comparisons of the test results at three different locations of the track and also between the first configurations and second configurations of the fabric layers were made. The different track locations were shown in Figure 8-1.

Table 8-1: Maximum values at different locations

\begin{tabular}{|c|c|c|c|c|c|}
\hline $\begin{array}{c}\text { Location of } \\
\text { ties }\end{array}$ & $\begin{array}{c}\text { Strains } \\
(\boldsymbol{\mu} \varepsilon)\end{array}$ & $\begin{array}{c}\text { Deflections } \\
\text { (in) }\end{array}$ & Movement (in) & Movement (in) & (in) \\
\hline Sharp curve & 1103 & 0.018 & 0.001 & 0.01 & 0.286 \\
\hline Gentle curve & 934 & 0.015 & 0.005 & 0.008 & 0.085 \\
\hline Straight Track & 497 & 0.045 & 0.022 & 0.006 & 0.343 \\
\hline
\end{tabular}

Table 8-2: The maximum values of strains in first and second configuration ties

\begin{tabular}{|c|c|c|}
\hline Location of ties & Strains in first configuration $(\boldsymbol{\mu} \boldsymbol{\varepsilon})$ & Strains in second configuration $(\boldsymbol{\mu} \varepsilon)$ \\
\hline Straight Track & 497 & 429 \\
\hline Gentle curve & 934 & 324 \\
\hline Sharp curve & 1103 & NA \\
\hline
\end{tabular}




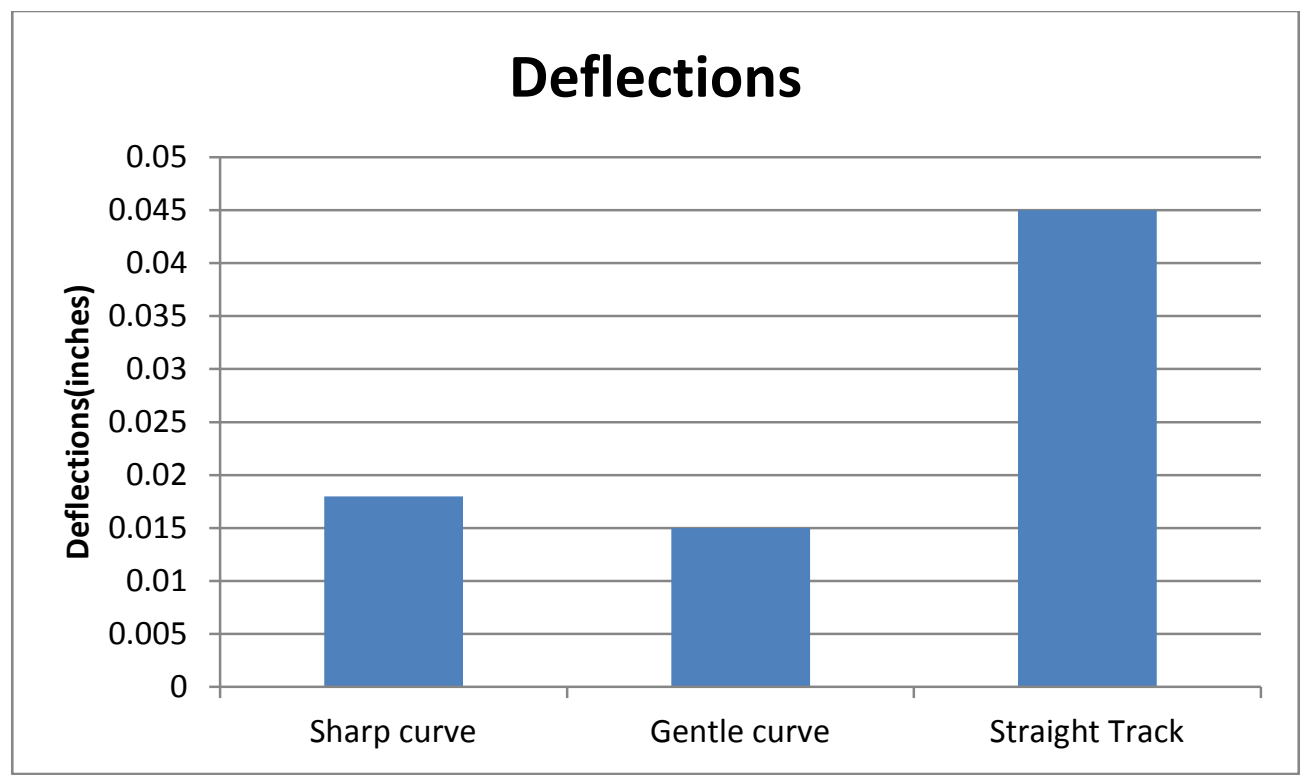

Figure 8-17: Bar graph of maximum deflections at different location

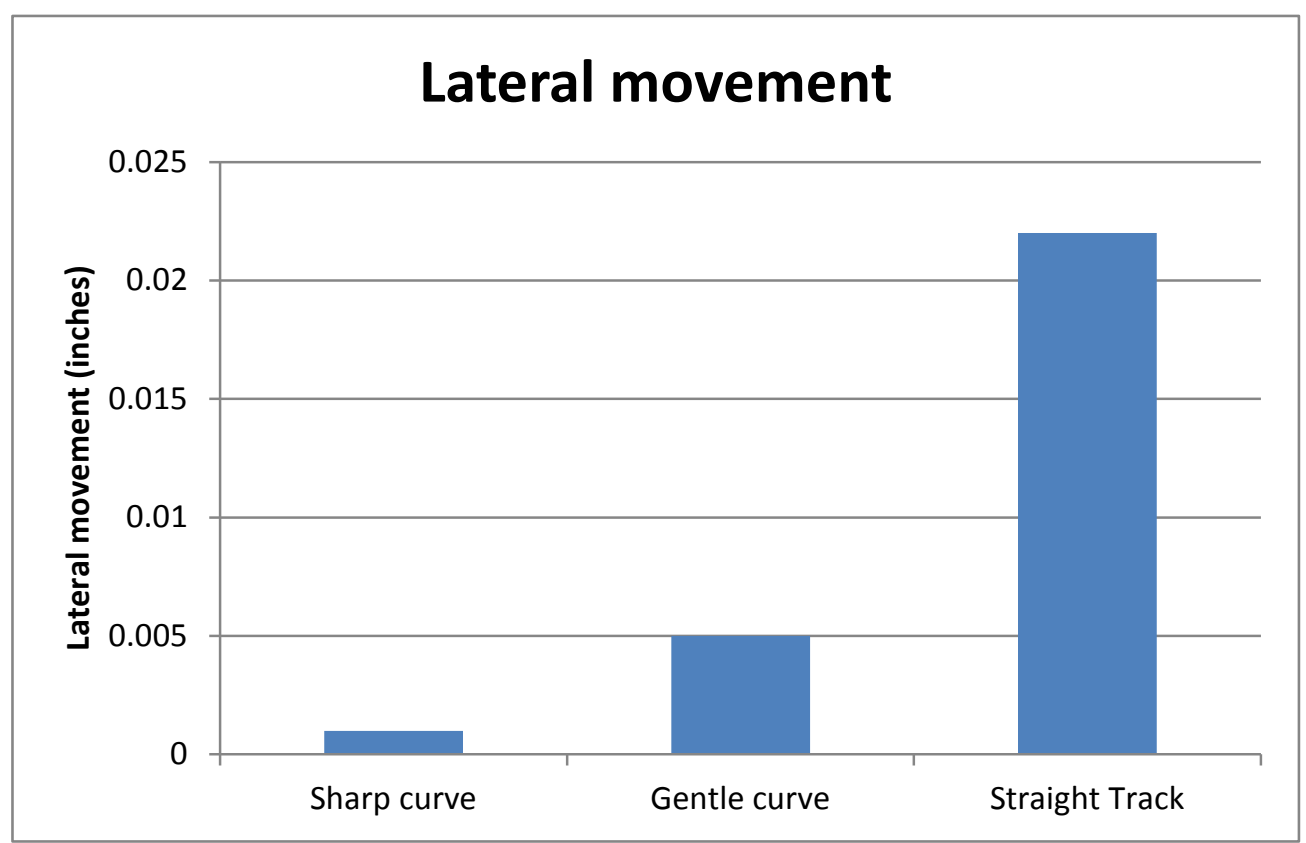

Figure 8-18: Bar graph of maximum lateral movement at different locations 


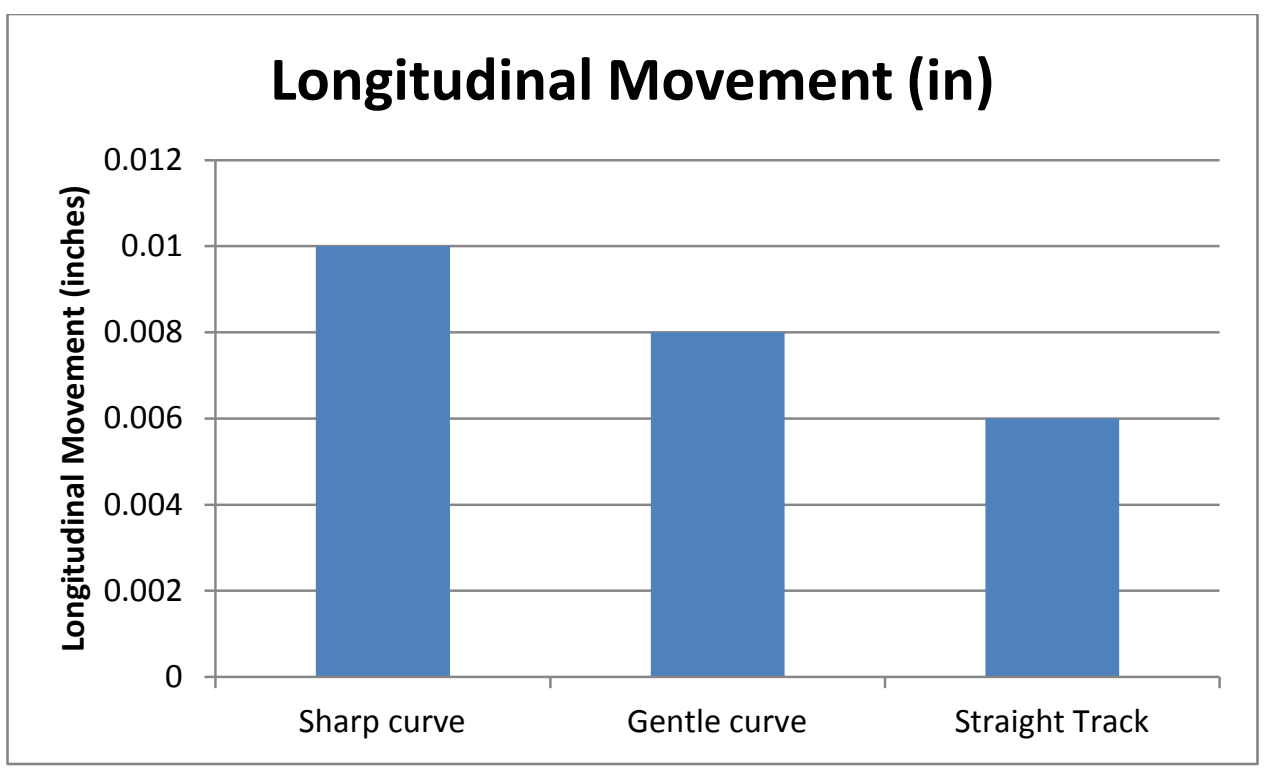

Figure 8-19: Bar graph of maximum longitudinal movements at different locations

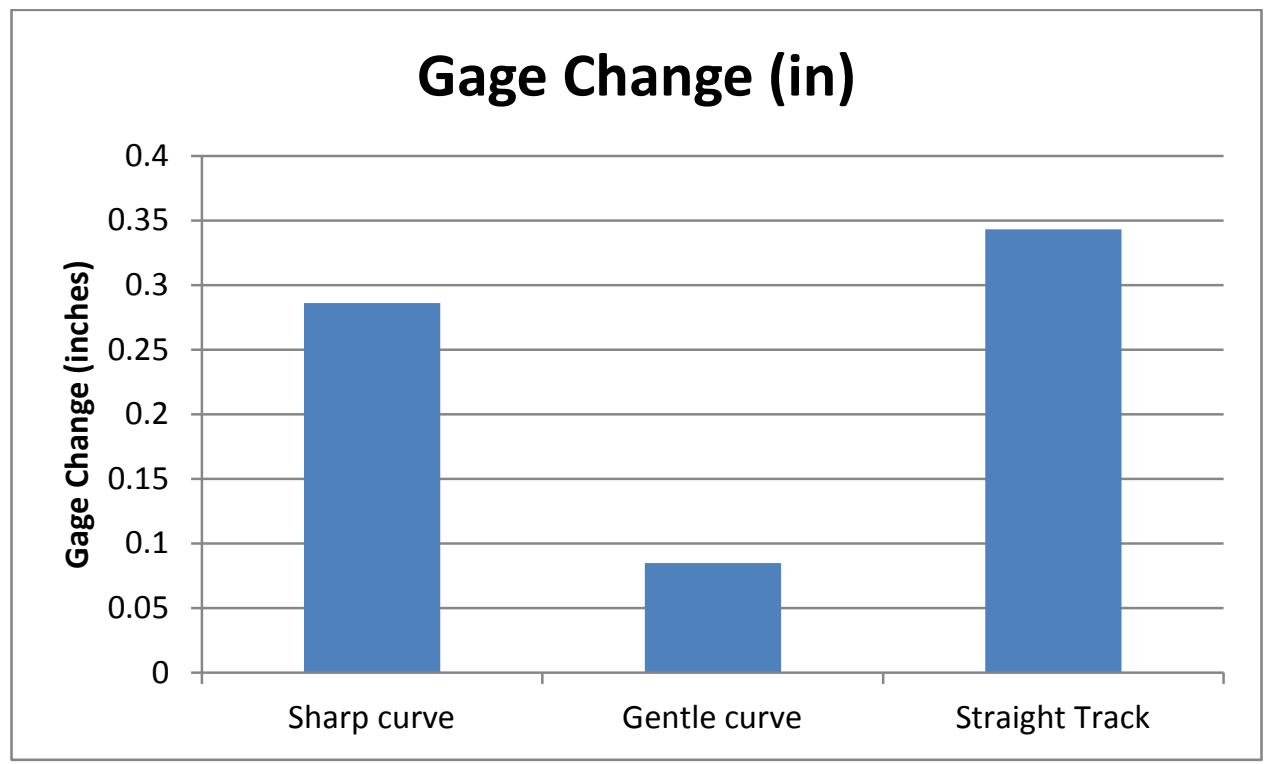

Figure 8-20: Bar graph of maximum gage change at different locations 


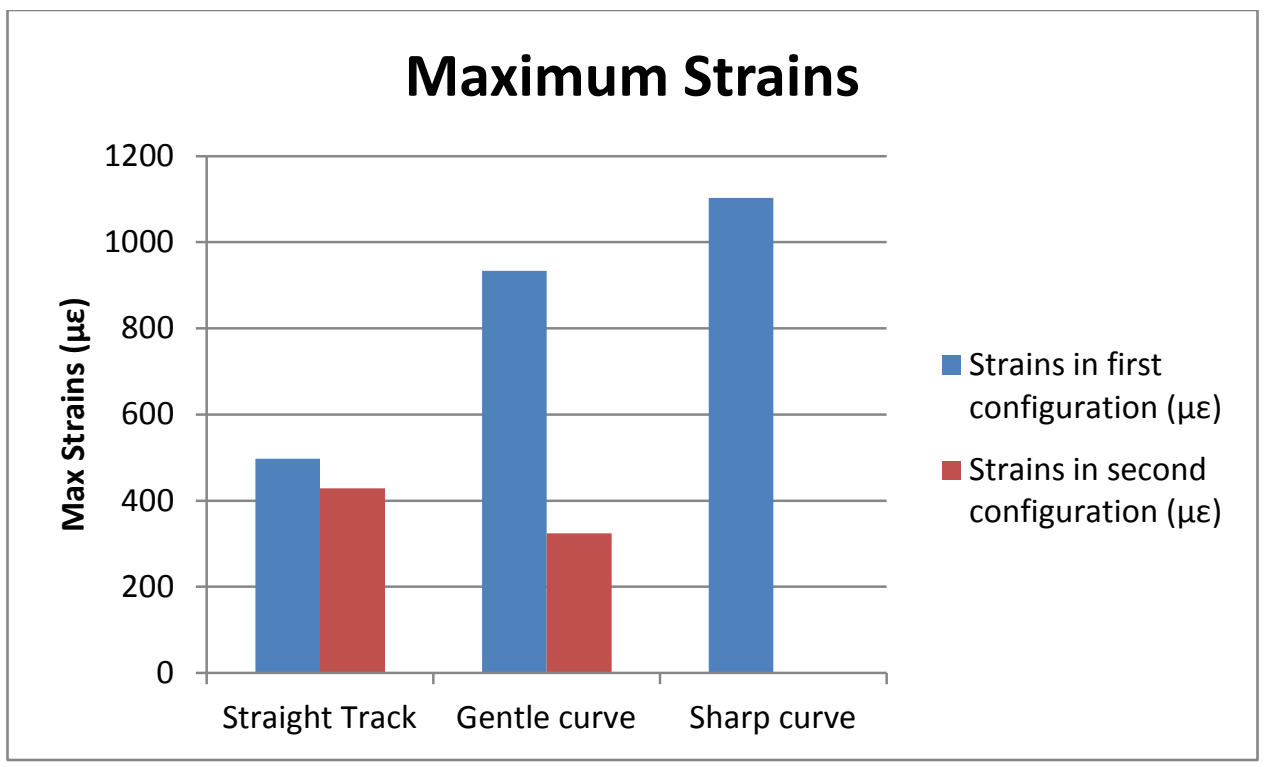

Figure 8-21: Bar graph of maximum strains in first and second configuration ties

\subsubsection{Comparisons of the Test Results at Sharp Curve and Gentle Curve of the Track}

The maximum strain, deflection, longitudinal movement and gage change values in the recycled composite ties at the sharp curve were 15, 16, 20 and 70 percent more than the recycled composite ties at the gentle curve because no proper settlement of ballast under the tie and no adequate fasteners strength in sharp curve than in gentle curve . However, the lateral movement value in the recycled composite tie at the sharp curve was 80 percent less than in the recycled composite tie at the gentle curve because the tie has adequate ballast on the sides at sharp curve than in gentle curve.

\subsubsection{Comparisons of the Test Results at Gentle Curve of the Track and Straight Track}

The maximum strain and longitudinal movement values in the recycled composite tie at the gentle curve were 47 and 25 percent more than the recycled composite tie at the straight track because no proper settlement of ballast at the bottom of the tie in the gentle curve then in straight track. However, the 
deflection, lateral movement and gage change values in the recycled composite tie at the gentle curve were 66, 77 and 75 percent less than the recycled composite tie at the straight track because the tie has adequate ballast on the sides and the fasteners have adequate strength at gentle curve than in straight track.

\subsubsection{Comparisons of the Test Results at Sharp Curve of the Track and Straight Track}

The maximum strain and longitudinal movement values in the recycled composite tie at the sharp curve were 55 and 40 percent more than the recycled composite tie at the straight track because no proper settlement of ballast at the bottom of the tie in the sharp curve than in straight track. However, the deflection, lateral movement and gage change values in the recycled composite tie at the sharp curve were 60, 95 and 16 percent less than the recycled composite tie at the straight track because the tie has adequate ballast on the sides and the fasteners have adequate strength at sharp curve than in straight track.

\subsubsection{Comparison of the Maximum Strains in First and Second Configuration of Fabric Layers}

The maximum strains in the composite tie made of second configuration fabric layer in the straight track and gentle curve were 14 and 65 percent less than the composite ties made of first configuration. It was due to the fiber reinforcement in all the directions to resist the stresses occurring in all the directions.

\subsection{Conclusions}

1. The strains on the top center of the tie increased with the increase in the tie track curvature. It was due to the centrifugal force acting away from the center of the rotation and affecting the inertia of the track. 
2. The strains were very high in the gentle and the sharp curve on first fabric configuration ties with 15 layers of $0^{0} / 90^{0}(1103 \mu \varepsilon$ and $934 \mu \varepsilon)$ respectively because the ties were not strengthened with lower number of fabric layers in those locations.

3. Three first configuration ties were found to have failed due to less fabric layers and inadequate strength in shear direction but the second configuration ties with 20 layers of fabric in $0 \% / 90^{0} / \pm$ $45^{0}$ have survived well for 6-8 months of service.

4. Deflections, lateral movement and gage change values were very high in straight track; they were 66, 77 and 75 percent respectively higher than in the composite ties at gentle curve and 60, 95 and 16 percent respectively higher than in the composite ties at sharp curve. (Table 0-5)

5. The longitudinal movement was much higher at the sharp curve (i.e. 0.01in) due to inadequate settlement of ballast on the sides and under the tie.

6. The gage change values corresponded to the vertical deflection readings, that depends upon the pullout strength and integrity of the fasteners was found to be higher.

7. Number of transverse cracks, longitudinal cracks and shear cracks were found to be in the first configuration ties than in the second configuration ties. Transverse cracks were mostly on the weak fiber overlapping regions due to use of more number of components (12 components) and more fiber overlapping. There were one or two longitudinal cracks noted in one of the composite ties.

8. There were few shear cracks in ties that were made of first fabric configuration (\#1, \#2, \#3 and \#4) because $+45^{0}$ angle laminas were not used in the laminate.

9. Some of the end caps had cracks due to less number of fabric layers in it and the weak overlapping with the fibers of the composite shell.

10. Field loading conditions including exposure to moisture, temperature variations and ultra violet radiations results in recycled composite tie strength, stiffness/cracking performance. 


\section{CONCLUSIONS AND RECOMMANDATIONS}

\subsection{Conclusions}

The conclusions of three point bending tests, spike insertion and pullout tests and fatigue tests related to laboratory evaluations including those of field installed ties are provided corresponding to different chapters of this report.

\subsubsection{Chapter 4 (Manufacturing process-I: Comparison of flexural rigidities)}

Static three point bending tests were conducted on simply supported recycled composite ties that were manufactured using manufacturing process-I. Four ties that were manufactured with first configuration and two ties that were manufactured with second configuration were used for testing in the laboratory.

1. The flexural rigidities of recycled composite ties made of first configuration (15 layers of $0^{0} / 90^{0}$ ) and second configuration (20 layers of $0 \% 190^{0} / 45^{0}$ ) were found to be nearly similar. The bending resistance of recycled composite tie \#5 with more number of fabrics along with the use of $+45^{0}$ fabrics as compared to other ties resulted in the highest flexural rigidity.

2. The average flexural rigidity of the recycled composite ties was compared with the oak ties from Railway Tie Association (Tie Guide, 2005). The composite shell system improved the flexural rigidity of recycled composite ties in a range of 20\% (341Psi vs 272Psi).

3. The average flexural rigidity of the recycled composite ties was compared from our study with similar ties from IntegriCo and Tietek, the flexural rigidity of recycled composite ties was more than that of composite ties from IntergriCo and tietek by about a range of $6 \%$ to $11 \%$, respectively.

4. The average flexural rigidity of the recycled composite ties was compared from our study with the Dynamic and PRT's composite ties that are made of steel, concrete, recycled rubber and 
recycled polymers, the flexural rigidity of recycled composite ties was more than that of Dynamic composite ties by about 5\% and less than that of PRT's composite ties by about 7\%.

\subsubsection{Chapter 5 (Manufacturing process-II: Modulus of rupture and flexural rigidities)}

Modulus of rupture and static bending strength parameters were evaluated under three point bending. These tests were performed on both recycled composite tie that was manufactured using manufacturing process-II and general wood tie.

1. The flexural rigidity of composite tie was more than that of a wood tie by about 47 percent (352Psi vs 186Psi).

2. The flexural rigidity of Recycled Composite Tie \#5 that was manufactured using manufacturing process-I was more than that of Recycled Composite Tie manufactured using manufacturing process-II by about 11 percent because the fiber volume fraction of the composite part in the manufacturing process-II was lower than that of manufacturing process-I. (Note: It should be noted that the wood has higher properties than the resin alone. Hence, reducing wood dimensions and increasing resin content by keeping the same number of GFRP fabrics will result in decreased flexural rigidity.)

3. Modulus of Rupture of the composite tie was more than that of a wood tie by about 6 percent (9244Psi vs 8640Psi).

4. The static bending strength of composite tie was more than that of a wood tie by about 38 percent (660 vs 403Psi).

5. Following the initial failure of wood core, higher load resistances were carried by the GFRP composite shell.

6. Prior to the GFRP composite shell failure, failure of the wood core was noticed along with wood rupturing sound. . 
7. Good bond was between the wood core and the GFRP composite shell was found to be debonding between the wood core and the GFRP composite shell (Note: This was observed from sliced from sliced tie sections after tie loading and failure).

8. The loading strength can be further increased by increasing the high matrix modulus, high fiber modulus and fiber/matrix interfacial strength.

9. To make the tie cost effective, the thickness of the laminate need to be reduced by increasing the fiber volume fraction and reducing the fiber buckling of GFRP composite shell.

\subsubsection{Chapter 6 (Spike insertion and pullout tests)}

Six spike insertion and pullout tests were conducted on recycled composite tie and wood tie to show the improved strength in recycled composite tie.

1. The strength to insert and pullout the spike was higher in the recycled composite tie to prevent any movement of the rail with respect to the ties under mechanical loading.

2. The spike insertion strength results on recycled composite ties were more than those of wood ties by about 26 percent which is attributed to the additional load resistance was offered by the composite shell (14682psi vs 10906psi).

3. The spike pullout strength results on recycled composite tie were 20 percent higher in relation to wood ties which is attributed to the additional load resistance offered by the composite shell (7294psi vs 5932psi).

4. Spikes in the recycled composite tie have more ability to attenuate dynamic impact loading and to resist uplift forces than in wood tie.

5. The track system life and maintenance are mostly based on the spike performance because the strength characteristics of the spike will degrade after long term traffic loading. Higher spike pullout strength in the recycled composite ties results in economical, operation and maintenance of the tie-track system. 
6. Following spike insertion, polyurethane can be used to seal any openings to prevent moisture entry due to openings under temperature changes.

\subsubsection{Chapter 7 (fatigue test on recycled composite tie)}

Fatigue test was conducted on a recycled composite tie that was manufactured using manufacturing process-II. Two million fatigue cycles were applied with the load of 78kips.

1. No visible flexural and shear cracks were observed up to one million cycles but a shear crack under the rail seat was noted after two million cycles.

2. No visible signs of tie plate compression and spike pullout after two million cycles were found. Use of composite laminate shell has resulted in better pullout and plate compression performance of the tie.

3. The theoretical deflection of composite ties was 11 percent higher than the experimental deflection (0.327in vs 0.29in).

4. Recycled composite ties carried 16 percent higher bending moment than the theoretical value at the center (73162lbs-in vs 61266lbs-in) and 5 percent lower bending moment than the theoretical value at the rail seat area (230605lbs-in vs 218968lbs-in).

5. After one million cycles, the top and bottom maximum strains at the center of the tie were $560 \mu \varepsilon$ and $1402 \mu \varepsilon$, respectively. The increase in the top and bottom maximum strains after two million cycles was $34 \%$ and $17 \%$. It was due to the gradual stiffness reduction in the composite laminate at the center of the tie.

6. After one million cycles, the top and bottom maximum strains at the rail seat of the tie was $1441 \mu \varepsilon$ and $1269 \mu \varepsilon$, respectively. The increase in the top and bottom maximum strains after two million cycles was $28 \%$ and $6 \%$. It was due to the gradual debonding in the composite laminate at the rail seat of the tie. 


\subsubsection{Chapter 8 (Field installation and testing)}

Seven recycled composite ties that were manufactured using manufacturing process-I were field installed in three different track locations. Tests were conducted with the locomotive weight of 265kips to collect the deflections, strains, lateral movement, longitudinal movement and gage change data after 6 months.

1. The strains on the top center of the tie increased with the increase in the tie track curvature. It was due to the centrifugal forces acting away from the center of the rotation and affecting the inertia of the track.

2. The strains were very high in the gentle and the sharp curve on first fabric configuration ties with 15 layers of $0^{0} / 90^{0}(1103 \mu \varepsilon$ and $934 \mu \varepsilon)$ respectively because the ties were not strengthened with lower number of fabric layers in those locations.

3. Three first configuration ties were found to have failed due to less fabric layers and inadequate

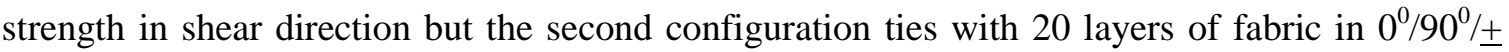
$45^{0}$ have survived well for 6-8 months of service.

4. Deflections, lateral movement and gage change values were very high in straight track; they were 66, 77 and 75 percent respectively higher than in the composite ties at gentle curve and 60, 95 and 16 percent respectively higher than in the composite ties at sharp curve.

5. The longitudinal movement was much higher at the sharp curve (i.e. 0.01in) due to inadequate settlement of ballast on the sides and under the tie.

6. The gage change corresponded to the vertical deflection readings, that depends upon the pullout strength and integrity of the fasteners was found to be higher.

7. Number of transverse cracks, longitudinal cracks and shear cracks were found to be in the first configuration ties than in the second configuration ties. Transverse cracks were mostly on the weak fiber overlapping regions due to use of more number of components (12 components) and more fiber overlapping. There were one or two longitudinal cracks noted in one of the composite ties. 
8. There were few shear cracks in ties that were made of first fabric configuration (\#1, \#2, \#3 and \#4) because $+45^{\circ}$ angle laminas were not used in the laminate.

9. Some of the end caps had cracks due to less number of fabric layers in it and the weak overlapping with the fibers of the composite shell.

10. Field loading conditions including exposure to moisture, temperature variations and ultra violet radiations influence recycled composite tie strength, stiffness/cracking performance.

\subsection{Recommendations and Future Study}

\subsubsection{Manufacturing Process}

1. Always work with fiberglass in an open environment or where there is a flow of fresh air. Wearing some form of mask is important to protect against the small glass fibers.

2. One should be particularly careful when sanding fiberglass during composite manufacturing.

3. It is essential to wear protective gloves and eye protection at all times.

4. To avoid using aluminum foil for the manufacturing of composite parts, use mold releasing agents such as surface cleaner, multishield, enviroshield and flex manufactured by Zywax.

5. The tie has to be placed properly inside the mold and the resin has to be uniform on all sides of the mold.

6. The heaters have to be checked before the heating process and after every one hour to make sure that all the heaters are working good and provide the same amount of heat on all sides.

7. To avoid loss of heat, the mold needs to be covered properly with the insulation on all sides.

8. Make sure all the bolts of the mold parts are fastened properly before applying the load.

9. The process has to be monitored continuously for load using the strain smart software.

10. The initial 10kips load has to be applied at least after one hour of heating and gradually increased by 5kips after every hour.

11. Ensure that all the heaters are turned off after the heating process. 


\subsubsection{Full Scale Cross Tie}

1. The voids and fiber buckling of the GFRP composite shell can be reduced by reducing the thickness of the laminate and by increasing the dimensions of the wood core.

2. The important design parameters to be considered for the composite laminate are thickness, orientation, stacking sequence and material properties.

3. As the composite tie is undergoing bending stresses, the fibers need to be stiff on top and bottom because the stresses are more at the top and bottom. CSM has to be provided in the middle because the stresses are less in the middle of the laminate.

4. The balanced symmetric laminate is recommended to be used because it reduces the shear stresses and thermal forces which induce warping of the final part.

5. To enhance mechanical properties of the GFRP composite shell, the higher density continuous fiber layers with less number of layers in a laminate can be provided because it increases the fiber wetting.

6. Additives need to be added to increase the flow of the thermoplastic resin because they are viscous than thermoset resins.

7. The fibers need to be placed in all the directions, because the coefficient of thermal expansion of the matrix is greater in the direction where the fibers are not oriented and lesser in the direction where the fibers are oriented.

8. Make sure the bond between the fibers and the matrix is good because it increases the fiber matrix interfacial strength and reduces the shear cracks.

9. The wrapping of wood ties result in avoiding the fracture below the tie surface, splitting of ties and decay of ties. 


\subsubsection{Laboratory Tests}

1. Before performing the three point bending and modulus of rupture test make sure the load cell and LVDT are calibrated.

2. Use 6in x 9in plate on the top of the tie at the point of loading and follow the AREMA Manual procedure for testing.

3. To get more accurate modulus of elasticity of the composite tie, the preliminary testing load for three point and four point bending test can be taken up to 4kips.

4. The strength of the spike pulling force can be further increased by filling the spike holes with polyurethane. Moreover, it also prevents the glass fibers in absorbing moisture.

\subsubsection{Field Installation}

1. Make sure all the ties are installed properly with ballast covered on all four sides and carefully observe the ballast compaction.

2. The strain gages need to be installed and protected at the top and bottom of the tie too because the strains are important to design the tie shell. The bottom strain gages of the tie need to be protected using the groove steel plates and the top strain gages should be protected using the thick layer of elastomeric pads because strain gages may get ruined due to the variation in temperature.

3. Use of the spring system LVDT instead of regular LVDT is recommended for measuring the deflection, lateral movement, longitudinal movement and gage change readings.

4. The ties installed in the sharp curve of the track need to be provided with more number of transverse fabric laminate to counter slightly higher stresses.

5. The strain gages need to be installed in the transverse and longitudinal directions on the top and along the depth of the tie to calculate the Poisson's effect 


\section{REFERENCES}

1. Laosiriphong.K, Gangarao.H, "Development and Evaluation of Glass Fiber Reinforced Composites/Wood Railroad Crossties” Master Thesis, West Virginia university, 2000.

2. Zipfel.M.G, "Development and Evaluation of a Composite-Reinforced Wood Railroad Crosstie" Master’s Thesis, Mechanical Engineering, West Virginia University, 1997.

3. Reza.S.A, Gangarao.H, "Rehabilitation of Timber Railroad Bridges Using Glass Fiber Reinforced Polymer Composites” Problem Report, West Virginia University, 2007.

4. Raghuram, P.A, Kenneth, H. Means, Vijay, P.V., "Manufacturing and Evaluation of Structural Products with Recycled Polymers” Master Thesis, West Virginia University, 2004.

5. Vick.C.B, “Adhesive Bonding of Wood Materials “Chapter 9, page: 1 to 12, 1999.

6. Zarembski.A.M, Gauntt.J.C, “Analysis of Wood Cross-tie Price Sensitivities” Zeta-Tech Associates, Inc., Railway Tie Association, 2000.

7. Webb.D.A, Zarembski.A.M, “The Tie Guide” Published by the Railway Tie Association, 2005.

8. The Railway Tie Association (RTA), "Material Properties of Wood Crossties” Published by the Railway Ties Association, Favetteville, GA.

9. Sirius.R, “Composite Crossties Test Cyclic Load” Letter Report P-09-003, Transportation Technology Center, Inc., IntegriCo Composites, LLC.

10. Poo.C, “Mechanical Properties with Eight IntegriCo Composite Crossties” University of Illinois, Urbana, IL, 2007.

11. Basto.J.R.M, “Mechanical Characterization of Aged Recycled Polymers and Applications" Master's Thesis, West Virginia University, 2002.

12. Bargo.J.E, “Mechanical Property Characterization of Recycled Thermoplastic” Master’s Thesis, West Virginia University, 2000. 
13. Rafael. J, David. D, Joe. L, Satya. S, “Major Finding of Wood Tie and Fastener Performance under Heavy Axle Loads” Published by the Railway Tie Association, 1999.

14. Zarembski.A, "Wood Tie-Fasteners Performance Specifications” Published by the Railway Tie Association.

15. Vijay. P.V., Gangarao. H, Aneesh. B, Muhammad. A.M.Q, Venugopal.C, "Development and Implementation of Recycled Thermoplastic RR Ties” Published in Transportation Research Board, 2010.

16. AREMA Manual for Railway Engineering, 2004.

17. Mechanical Edition 3701, Materials of Engineering Laboratory, Railway Age Gazette, Volume 56, LSU.

18. James. C. G., “Extending Tie Life Through Optimized Tie Replacement” Zeta-Tech Associates, Published by the Railway Tie Association, 2002.

19. Vijay. P.V, Gangarao. H, Aneesh. B, Muhammad. A.M.Q, "Manufacturing and Evaluation of Composites RR Ties” Published in Joint Rail Conference, Champaign, IL, 2008.

20. Conners.S, “Producing and Inspecting Railroad Crossties” UK Cooperative Extension Service, Department of Forestry, University of Kentucky, College of Engineering.

21. Daniels.L.E, “Tie Maintenance costs on Rail Transit Properties” Document 43, L. E. Daniels Transportation Engineering, Fair Oaks, CA, 2008.

22. TTCI, "Update of Heavy Axle Load Revenue Service Testing at Mega Sites in Revenue Service” RR08-32, FRA, U.S Department of Transportation, 2008.

23. Sharir, B. H, “Mechanical, Chemical and Flammable Properties of ABS/PVC Blends” University Technology Malaysia, 2006.

24. United States Department of Agriculture, “Wood Handbook” Wood as an Engineering Material, 1999.

25. Barbero.E.J, “Introduction to Composite Materials Design” Chapter 3, 4, 5 and 6. 
26. GangaRao.V.S, Vijay.P.V, “Reinforced Concrete Design with FRP Composites” 2006.

27. Żenkiewicz.M, Rytlewsk.P, "Some effects of multiple injection molding on selected properties of ABS”, 2009.

28. Boresi.A.P and Schmidt, R.J, "Advanced Mechanics of Materials," John Wiley \& Sons, New York, 2003.

29. Tietek Composite Crossties, Accessed January 6, 2011.

30. Dynamic Composites, Accessed January 6, 2011.

31. PRT Composite Ties, Accessed January 6, 2011. 


\section{APPENDIX-A}

\section{A. Calculation of bending stress for first configuration}

Note:

1. Span length $(\mathrm{L})=90 \mathrm{in}$.

2. $\mathrm{I}_{\text {transformed }}=245 \mathrm{in}^{4}$ (Table 4-2)

3. Neutral Axis

$$
\mathrm{C}=\frac{\sum A_{i} y_{i}}{\sum A_{i}}=3.37 \text { in }
$$

4. Calculation of bending stress ( For three points bending )

Bending Stress $=\frac{M C}{I_{\text {transformed }}}=0.3094 \mathrm{P}$

Bending Moment $=\mathrm{M}=\frac{P L}{4}=22.5 \mathrm{P}$

\section{B. Calculation of bending stress for second configuration}

Note:

1. Span length $(L)=90$ in.

2. $\mathrm{I}_{\text {transformed }}=265.59 \mathrm{in}^{4}$ (Table 4-2)

3. Neutral Axis

$$
\mathrm{C}=\frac{\sum A_{i} y_{i}}{\sum A_{i}}=3.5 \text { in }
$$

4. Calculation of bending stress ( For three points bending )

Bending Stress $=\frac{M C}{I_{\text {transformed }}}=0.2965 \mathrm{P}$

Bending Moment $=\mathrm{M}=\frac{\mathrm{PL}}{4}=22.5 \mathrm{P}$

From the data obtained by performing the test, bending stress vs strain graphs were plotted. 


\section{Tie \#2}

Calculation of flexural rigidity using 3 point bending test

This specimen was done using first configuration.

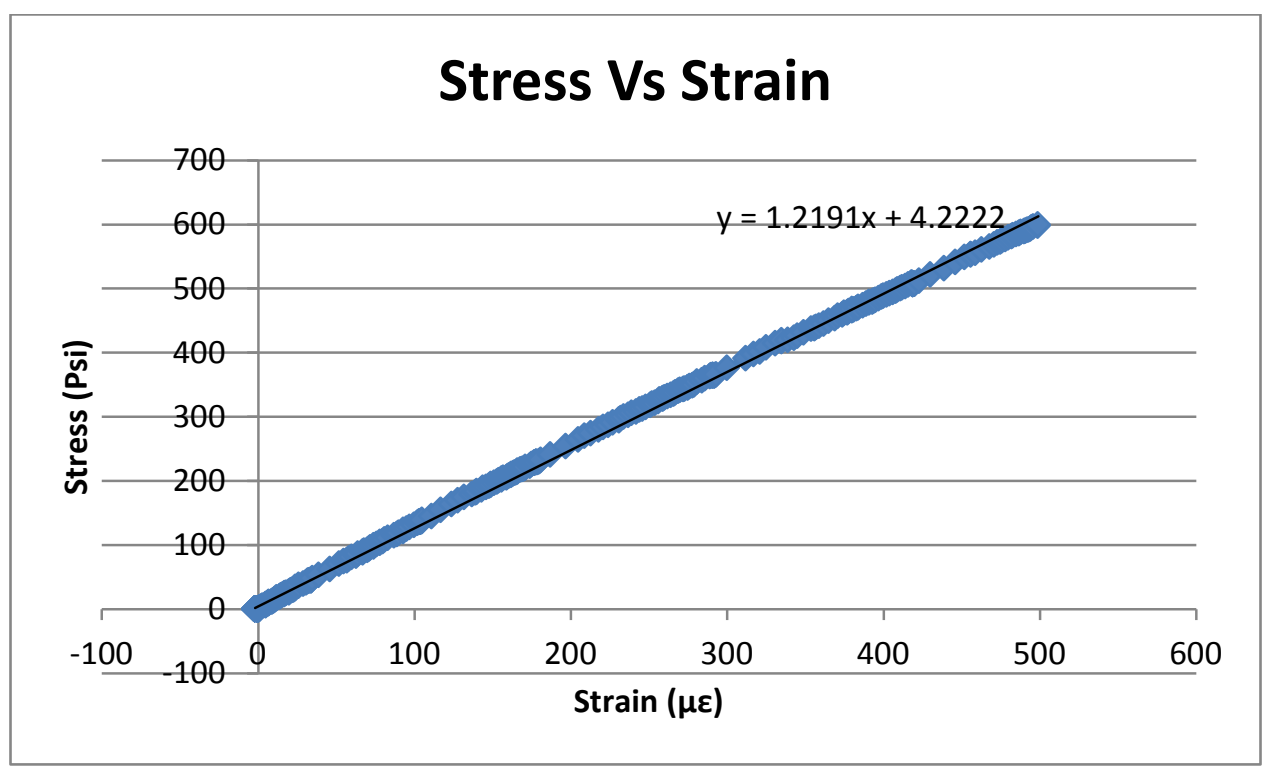

Figure A- 1: Stress vs Strain for Tie \#2

Elastic modulus $=\mathrm{E}=1.2191 \times 10^{6} \mathrm{psi}$ (From the slope of the graph in Figure A- 1)

Moment of Inertia $=\mathrm{I}_{\text {transformed }}=245 \mathrm{in}^{4}$

Flexural Rigidity $=\mathrm{EI}_{\text {transformed }}=1.2191 \times 10^{6}$ × $245=298 \times 10^{6} \mathrm{lbs}_{-1 n^{2}}$ 


\section{Tie \#3}

Calculation of flexural rigidity using 3 point bending test

This specimen was done using first configuration.

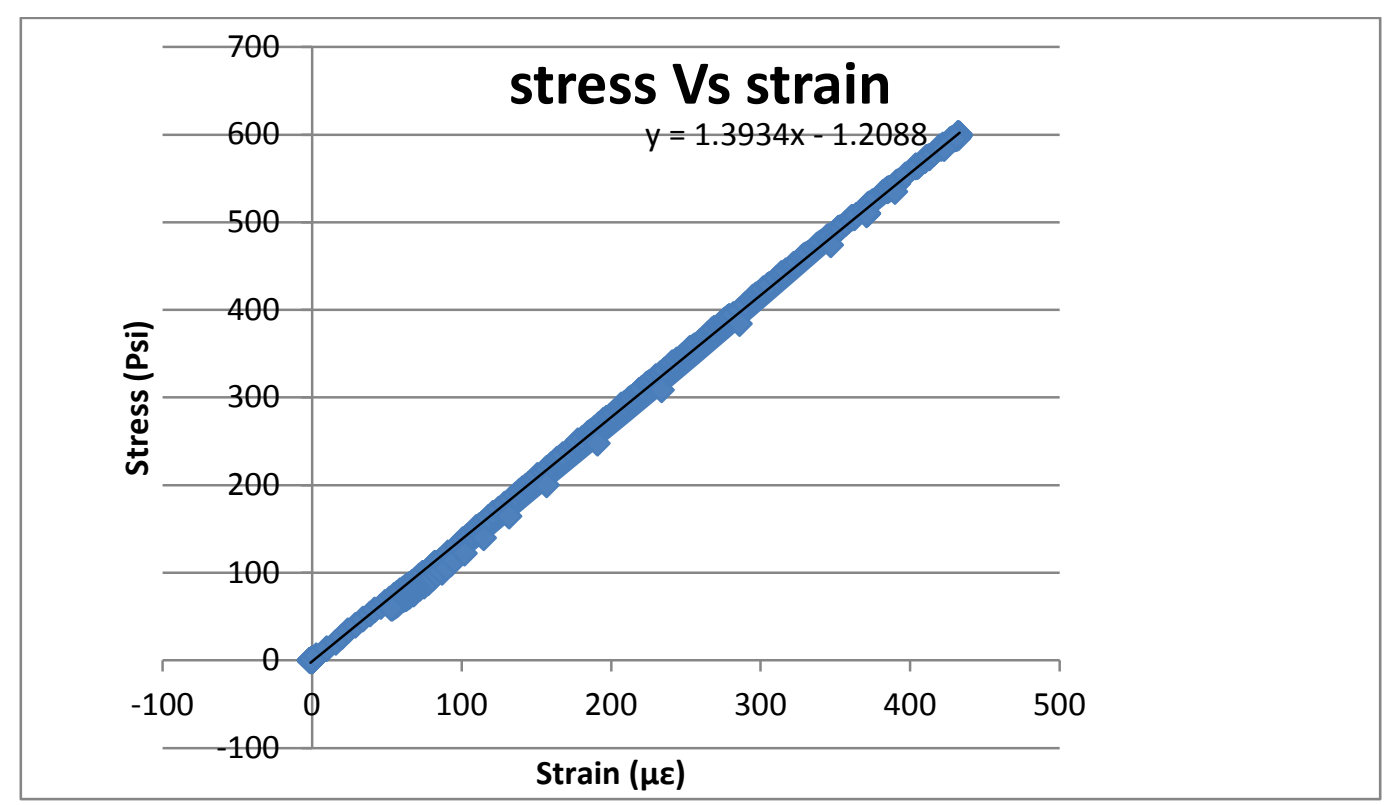

Figure A- 2: Stress Vs Strain for Tie \#3

Elastic modulus $=\mathrm{E}=1.3934 \times 10^{6} \mathrm{psi}$ (From the slope of the graph in Figure A-2)

Moment of Inertia $=\mathrm{I}_{\text {transformed }}=245 \mathrm{in}^{4}$

Flexural Rigidity $=\mathrm{EI}_{\text {transformed }}=1.3934 \times 10^{6}$ x $245=341 \times 10^{6} \mathrm{lbs}_{-1 \mathrm{in}^{2}}$ 


\section{E. Tie \#4}

Calculation of flexural rigidity using 3 point bending test

This specimen was done using first configuration.

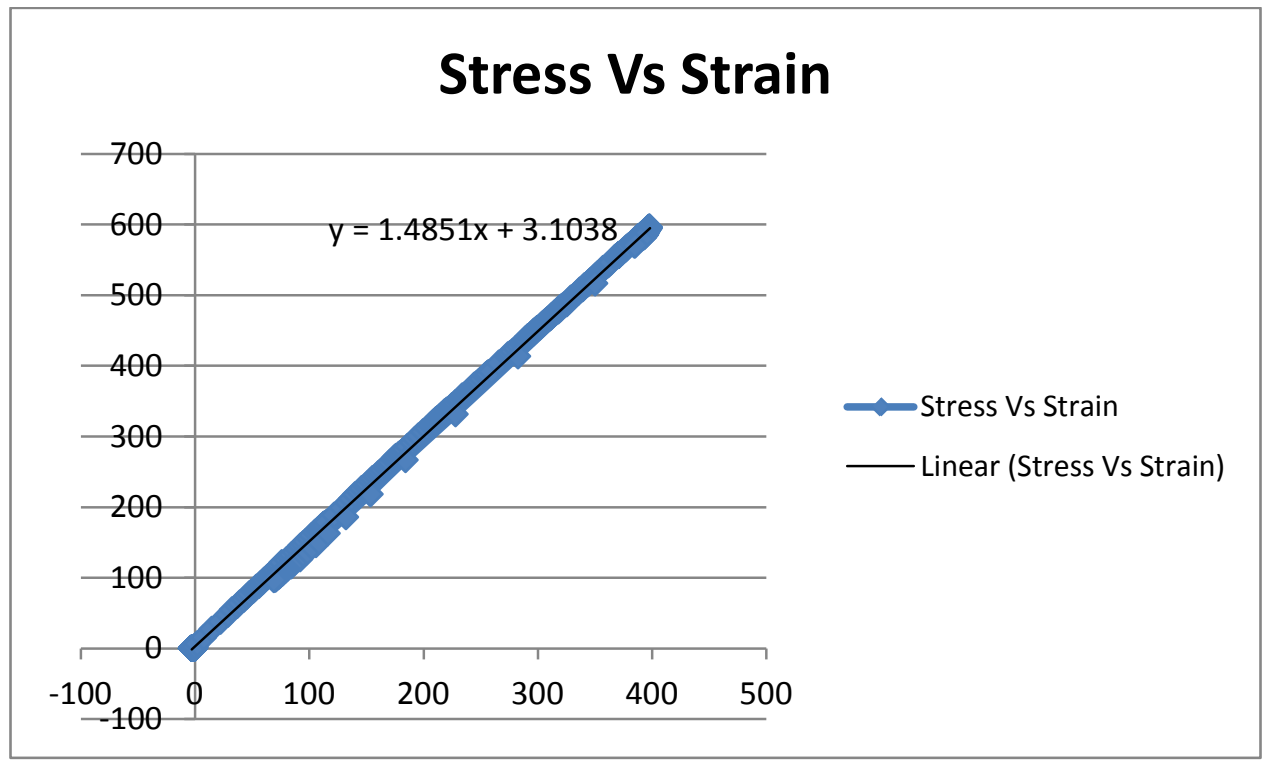

Figure A- 3: Stress Vs Strain for Tie \#4

Elastic modulus $=\mathrm{E}=1.485 \times 10^{6} \mathrm{psi}$ (From the slope of the graph in Figure A- 3)

Moment of Inertia $=\mathrm{I}_{\text {transformed }}=245 \mathrm{in}^{4}$

Flexural Rigidity $=$ EI $_{\text {transformed }}=1.485 \times 10^{6}$ x $245=363 \times 10^{6} \mathrm{lbs}_{-} \mathrm{in}^{2}$ 


\section{F. Tie \#5}

Calculation of flexural rigidity using 3 point bending test

This specimen was done using second configuration.

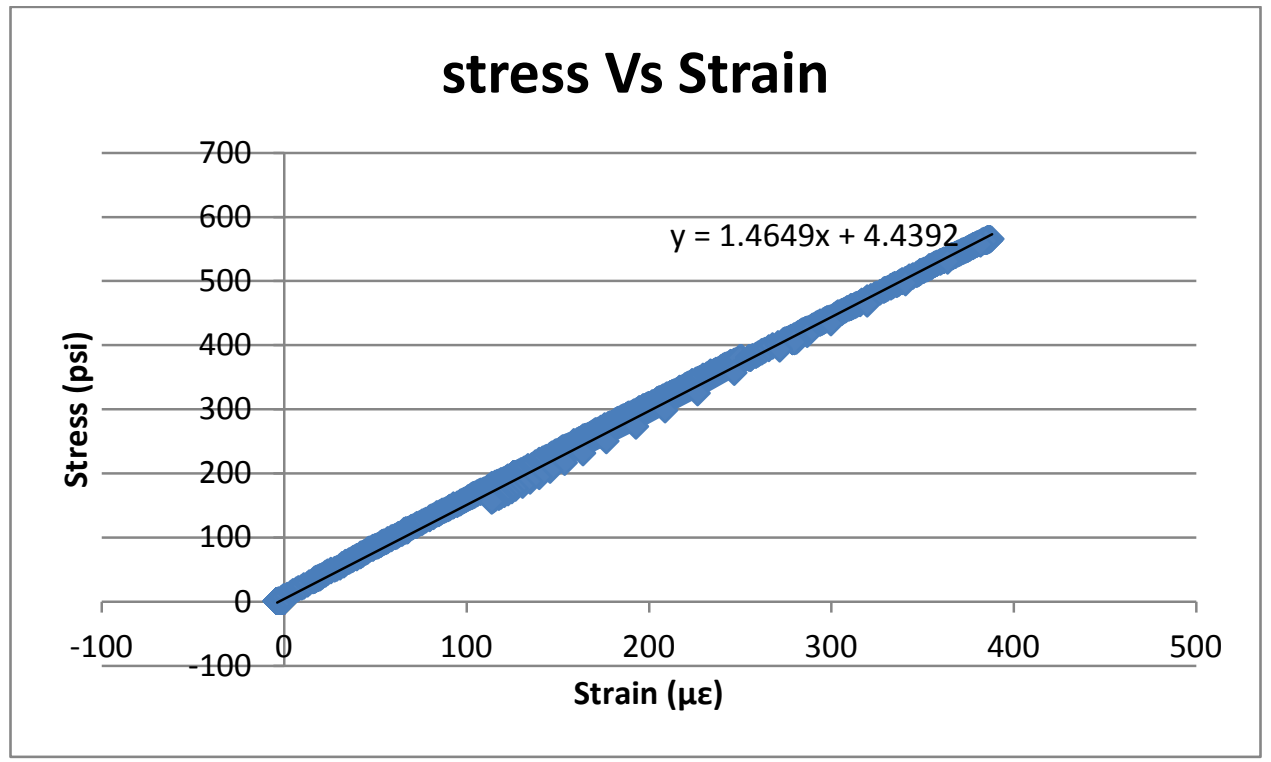

Figure A- 4: Stress vs Strain for Tie \#5

Elastic modulus $=\mathrm{E}=1.4649 \times 10^{6} \mathrm{psi}$ (From the slope of the graph in Figure A- 4)

Moment of Inertia $=\mathrm{I}_{\text {transformed }}=265.59 \mathrm{in}^{4}$

Flexural Rigidity $=$ EI $_{\text {transformed }}=1.4649 \times 10^{6}$ x $265.59=389 \times 10^{6} \mathrm{lbs}_{-i n^{2}}$ 


\section{G. Tie \#6}

Calculation of flexural rigidity using 3 point bending test

This specimen was done using second configuration.

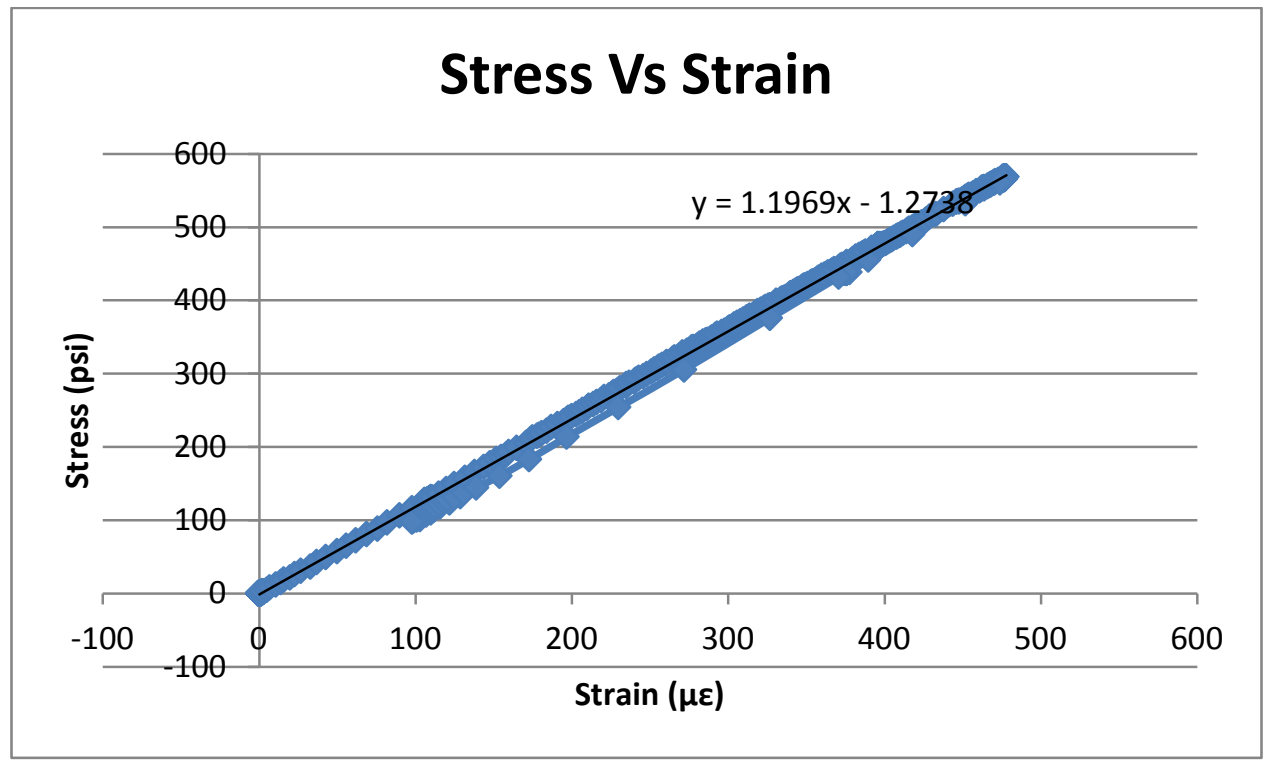

Figure A- 5: Stress vs Strain for Tie \#6

Elastic modulus $=\mathrm{E}=1.1969 \times 10^{6} \mathrm{psi}$ (From the slope of the graph in Figure A- 5)

Moment of Inertia $=\mathrm{I}_{\text {transformed }}=265.59 \mathrm{in}^{4}$

Flexural Rigidity $=\mathrm{EI}_{\text {transformed }}=1.1969 \times 10^{6} \times 265.59=317 \times 10^{6} \mathrm{lbs}_{\text {-in }}{ }^{2}$ 


\section{APPENDIX-B}

\section{A. Calculation of bending stress for first configuration}

Note:

1. Span length $(L)=60$ in.

2. $\mathrm{I}_{\text {transformed }}=268 \mathrm{in}^{4}$ (Table 5-2)

3. Neutral Axis

$$
\mathrm{C}=\frac{\sum A_{i} y_{i}}{\sum A_{i}}=3.75 \text { in }
$$

4. Calculation of bending stress ( For three points bending )

Bending Stress $=\frac{M C}{I_{\text {transformed }}}=0.20988 \mathrm{P}$

Bending Moment $=\mathrm{M}=\frac{P L}{4}=15 \mathrm{P}$

\section{B. Composite Tie}

Calculation of flexural rigidity using 3 point bending test

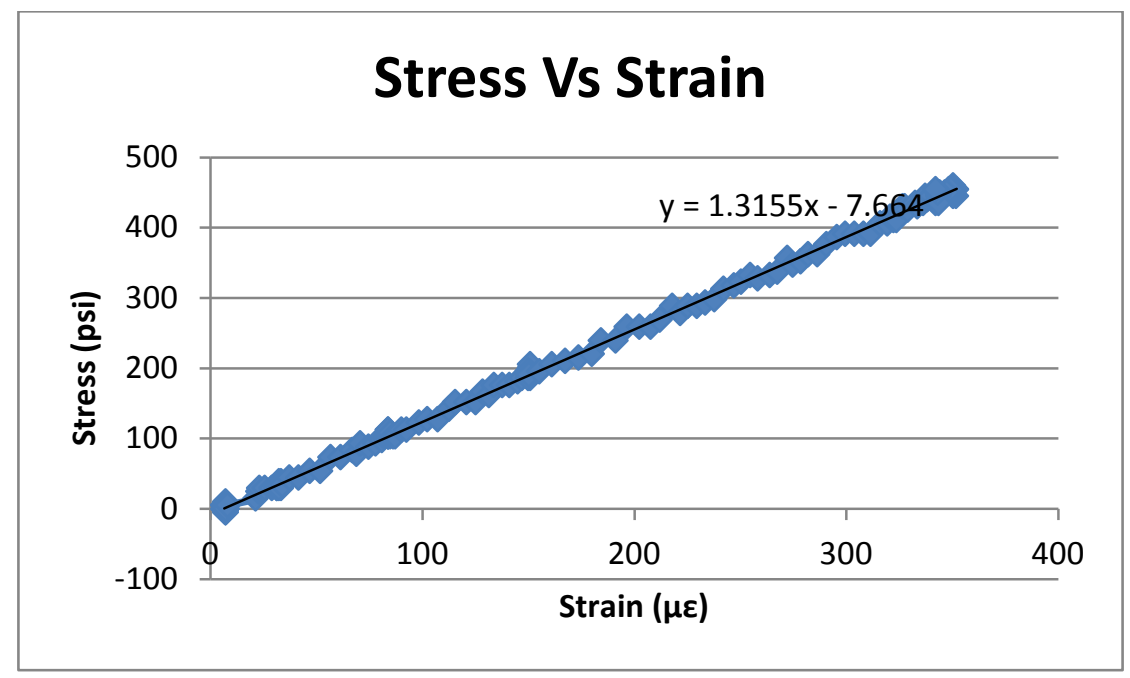

Figure B- 1: Stress vs Strain Graph for Recycled Composite Tie

Elastic modulus $=\mathrm{E}=1.3155 \times 10^{6} \mathrm{psi}$ (From the slope of the graph in Figure B-1) 
Moment of Inertia $=\mathbf{I}_{\text {transformed }}=268 \mathrm{in}^{4}$

Flexural Rigidity $=\mathrm{EI}=1.3155 \times 10^{6} \times 268=352 \times 10^{6} \mathrm{lbs}^{-\mathrm{in}^{2}}$

Modulus of Rupture

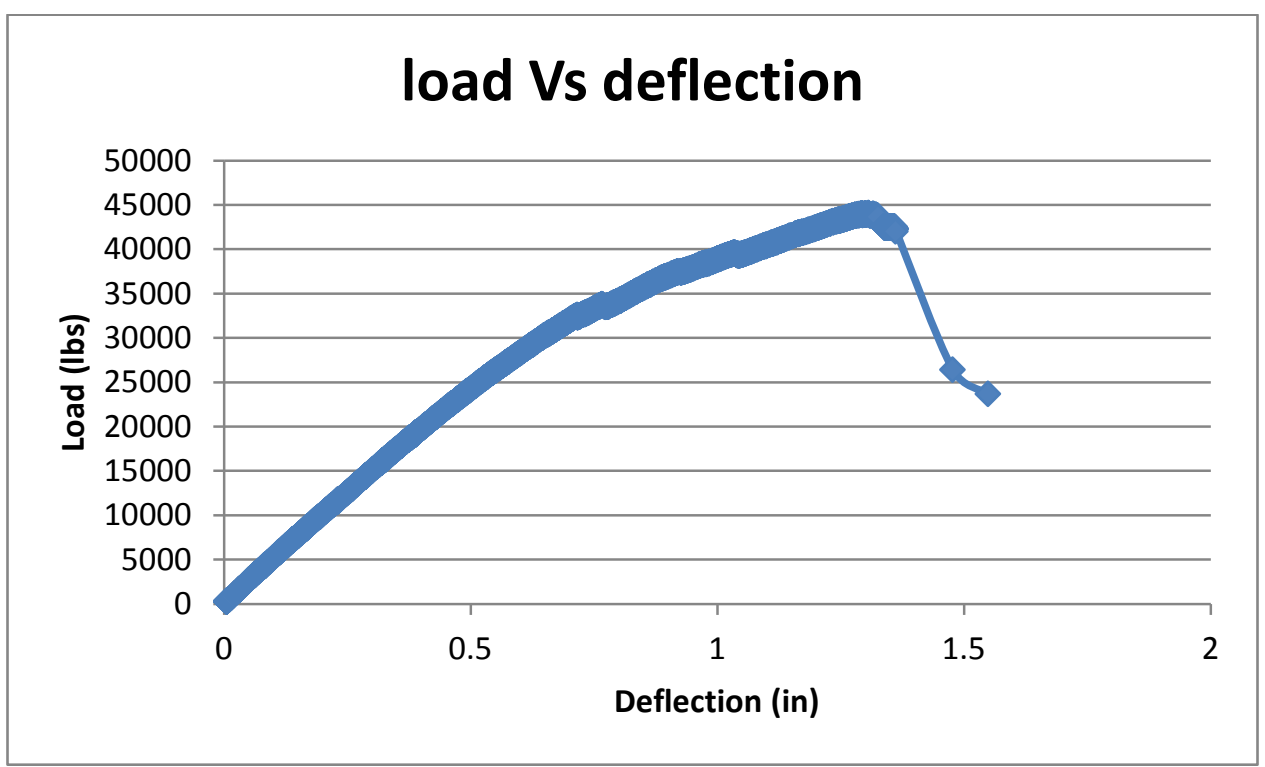

Figure B- 2: Load vs Deflection graph for composite tie

\section{$\underline{\text { Recycled Composite Tie }}$}

The maximum load to failure

$\mathrm{P}=45.66$ Kips

Static Bending Strength

$\mathrm{M}=\frac{P * L}{4}=\frac{45.66 * 60}{4}=660$ in-kips

Modulus of Rupture

$\sigma=\frac{M * C}{I}=\frac{660 * 3.75}{268}=9244$ Psi 


\section{Wood Tie}

Calculation of flexural rigidity using 3 point bending test

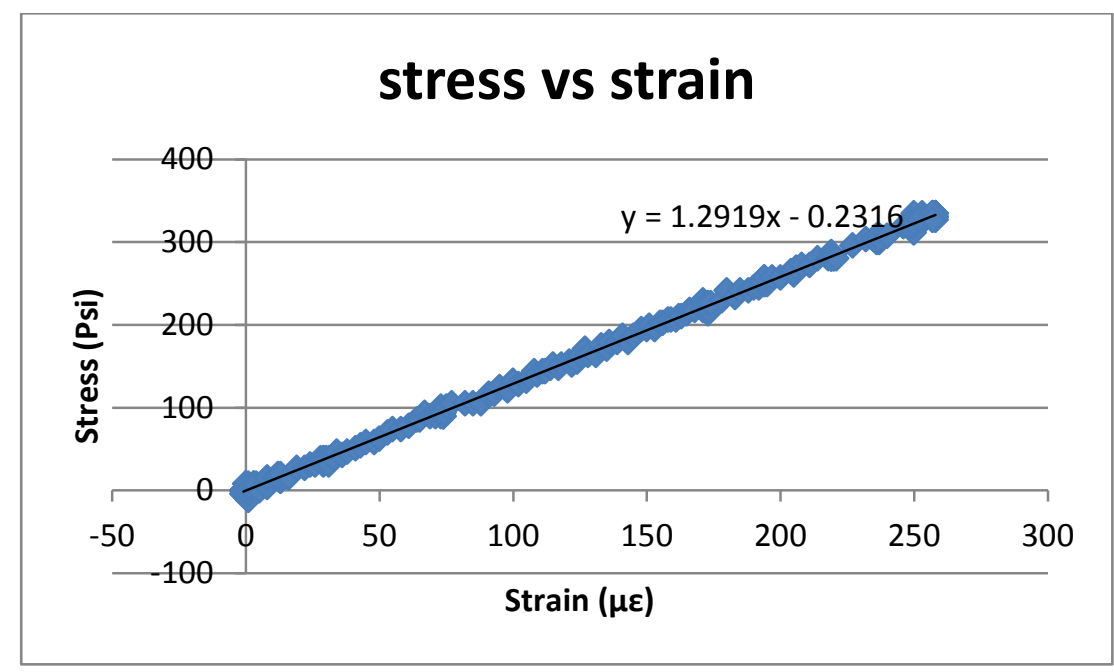

Figure B- 3: Stress vs Strain Graph for Wood Tie

Elastic modulus $=\mathrm{E}=1.29 \times 10^{6} \mathrm{psi}$ (From the slope of the graph in Figure B- 3 )

Moment of Inertia = I = 144 in $^{4}$

Flexural Rigidity $=\mathrm{EI}=1.29 \times 10^{6} \times 144=185 \times 10^{6} \mathrm{lbs}^{-i n^{2}}$ 
Modulus of Rupture

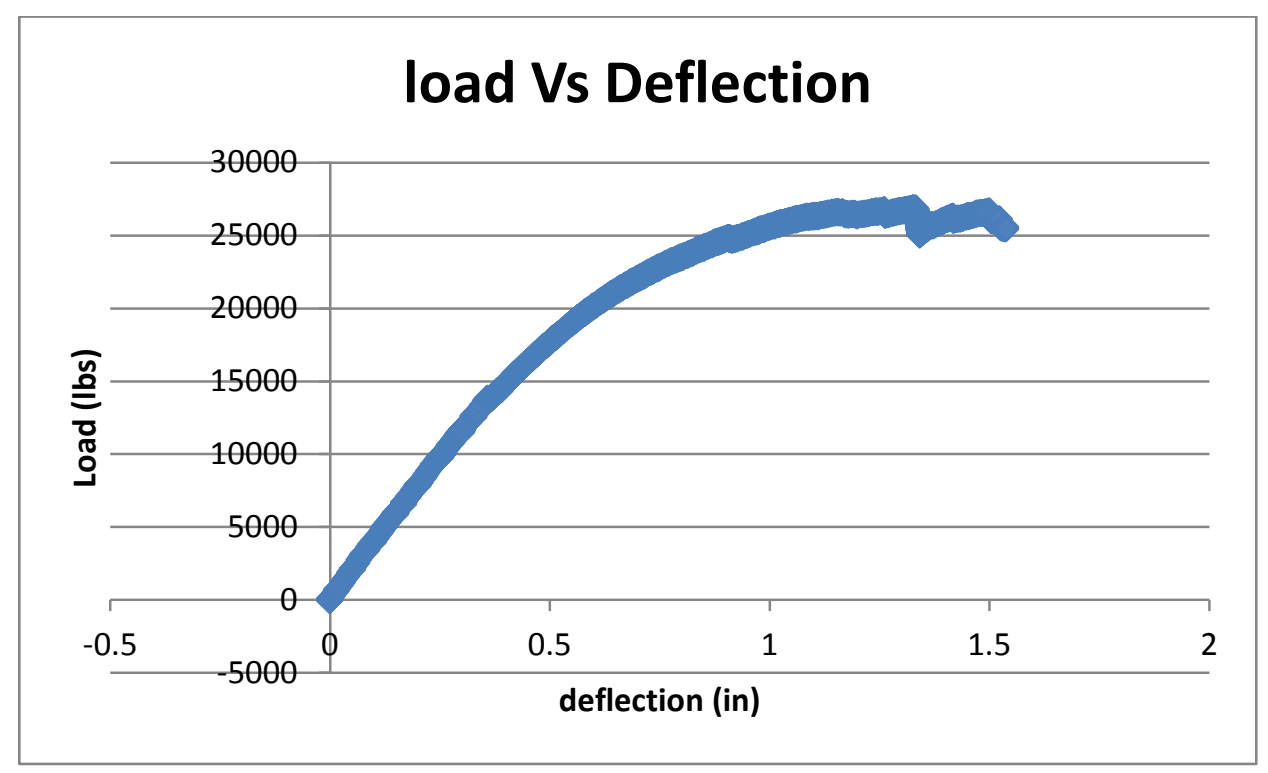

Figure B- 4: load vs deflection graph for wood tie

$\underline{\text { Wood Tie }}$

Maximum load to failure

$\mathrm{P}=26.86$ Kips

Static Bending Strength

$\mathrm{M}=\frac{P * L}{4}=\frac{26.86 * 60}{4}=403$ in-kips

Modulus of Rupture

$\sigma=\frac{M * C}{I}=\frac{403 * 3.1}{144}=8680 \mathrm{Psi}$ 


\section{APPENDIX-C}

\section{A. First configuration}

Table 0-1: Strains at tie center and tie rail seating $(\mu \varepsilon)$

\begin{tabular}{|c|c|c|c|c|c|c|c|c|}
\hline \multirow[b]{2}{*}{ Ties } & \multicolumn{2}{|c|}{ Static } & \multicolumn{2}{|c|}{ Crawl } & \multicolumn{2}{|c|}{$15 \mathrm{mph}$} & \multicolumn{2}{|c|}{ Full Train } \\
\hline & $\begin{array}{c}\text { Tie } \\
\text { center }\end{array}$ & $\begin{array}{c}\text { Tie } \\
\text { Seating }\end{array}$ & $\begin{array}{c}\text { Tie } \\
\text { center }\end{array}$ & $\begin{array}{c}\text { Tie } \\
\text { Seating }\end{array}$ & $\begin{array}{c}\text { Tie } \\
\text { center }\end{array}$ & $\begin{array}{c}\text { Tie } \\
\text { Seating }\end{array}$ & $\begin{array}{c}\text { Tie } \\
\text { center }\end{array}$ & $\begin{array}{c}\text { Tie } \\
\text { Seating }\end{array}$ \\
\hline Wood & 484 & & 534 & & 494 & & & \\
\hline $\begin{array}{c}\text { Tie\#1 } \\
\text { straight }\end{array}$ & 87 & -165 & 102 & -117 & 94 & 72 & & \\
\hline $\begin{array}{c}\text { Tie \#2 } \\
\text { Sharp curve }\end{array}$ & 1001 & -179 & 1103 & 609 & 984 & 320 & 999 & 350 \\
\hline $\begin{array}{l}\text { Tie \#3 } \\
\text { straight }\end{array}$ & 180 & 427 & 164 & -497 & 118 & 78 & & \\
\hline $\begin{array}{c}\text { Tie \#4 } \\
\text { Gentle curve }\end{array}$ & 181 & -826 & -202 & 934 & -228 & -794 & 190 & 312 \\
\hline
\end{tabular}




\section{B. Second Configuration}

Table 0-2: Strains at tie center and tie rail seating $(\mu \varepsilon)$

\begin{tabular}{|c|c|c|c|c|c|c|c|c|}
\hline \multirow{2}{*}{ Ties } & \multicolumn{2}{|c|}{ Static } & \multicolumn{2}{c|}{ Crawl } & \multicolumn{2}{c|}{15 mph } & \multicolumn{2}{c|}{ Full Train } \\
\cline { 2 - 8 } & Tie & Tie & Tie & Tie & Tie & Tie & Tie & Tie \\
\hline Tie \#5 & 396 & -170 & 402 & -293 & 429 & 80 & 395 & 135 \\
straight & center & Seating & center & Seating & center & Seating & center & Seating \\
\hline Tie \#6 & 324 & -178 & 324 & -178 & 311 & -285 & 386 & -196 \\
Gentle curve & & & & & & & & \\
\hline
\end{tabular}

Table 0-3: Deflections on recycled composite tie at different locations (inch)

\begin{tabular}{|c|c|c|c|c|}
\hline Ties & Static & Crawl & 15 mph & Full Train \\
\hline Tie \#4 & 0.009 & 0.006 & 0.015 & \\
Gentle curve & 0.014 & 0.045 & 0.041 & \\
\hline Tie \#5 & & & & \\
\hline Tie \#7 & 0.003 & 0.018 & 0.01 & 0.007 \\
Sharp curve & & & & \\
\hline
\end{tabular}


Table 0-4: Lateral movement of the tie at different locations (inch)

\begin{tabular}{|c|c|c|c|c|c|}
\hline $\begin{array}{c}\text { Location of } \\
\text { ties }\end{array}$ & $\begin{array}{c}\text { Location in } \\
\text { between }\end{array}$ & Static & Crawl & $15 \mathrm{mph}$ & Full Train \\
\hline Straight & Wood and \#1 & 0.016 & 0.022 & 0.012 & \\
\hline Gentle curve & Wood and \#4 & 0.005 & 0.003 & 0.002 & \\
\hline Sharp curve & Wood and \#7 & 0.001 & 0.001 & 0.001 & 0.001 \\
\hline
\end{tabular}

Table 0-5: Longitudinal movement of the tie at different locations (inch)

\begin{tabular}{|c|c|c|c|c|}
\hline $\begin{array}{c}\text { Location on } \\
\text { Tie }\end{array}$ & Static & Crawl & $\mathbf{1 5} \mathbf{~ m p h}$ & Full Train \\
\hline Tie \#1 & -0.001 & -0.004 & 0.006 & \\
\hline Tie \#2 & -0.009 & -0.01 & -0.01 & \\
Sharp curve & & & & \\
\hline Tie \#6 & -0.003 & -0.001 & -0.001 & 0.008 \\
Gentle curve & & & & \\
\hline
\end{tabular}

Table 0-6: Gage change at different locations (inch)

\begin{tabular}{|c|c|c|c|c|}
\hline $\begin{array}{c}\text { Location of } \\
\text { ties }\end{array}$ & Static & Crawl & $\mathbf{1 5} \mathbf{~ m p h}$ & Full Train \\
\hline Straight & 0.195 & 0.243 & 0.343 & \\
\hline Gentle curve & 0.078 & 0.085 & 0.033 & \\
\hline Sharp curve & 0.35 & 0.342 & 0.257 & 0.286 \\
\hline
\end{tabular}


